\title{
Youth and the Politics of the Present
}

Youth and the Politics of the Present presents a range of topical sociological investigations into various aspects of the everyday practices of young adults in different European contexts. Indeed, this volume provides an original and provocative investigation of various current central issues surrounding the effects of globalization and the directions in which Western societies are steering their future.

Containing a wide range of empirical and comparative examples from across Europe, this title highlights how young adults are trying to implement new forms of understanding, interpretation and action to cope with unprecedented situations; developing new forms of relationships, identifications and belonging while they experience new and unprecedented forms of inclusion and exclusion. Grounding this exploration is the suggestion that careful observations of the everyday practices of young adults can be an excellent vantage point to grasp how and in what direction the future of contemporary Western societies is heading.

Offering an original and provocative investigation, Youth and the Politics of the Present will appeal to students and researchers interested in fields such as Youth Studies, Globalization Studies, Migration Studies, Gender Studies and Social Policy.

Enzo Colombo is a Professor of Sociology and Culture at the Department of Social and Political Sciences, University of Milan, Italy.

Paola Rebughini is Professor of Sociology of Culture at the Department of Social and Political Sciences, University of Milan, Italy. 
Routledge Advances in Sociology

259 Comparative Sociology of Examinations

Edited by Fumiya Onaka

\section{The Human Rights City}

New York, San Francisco, Barcelona

Michele Grigolo

\section{I Horizontal Europeanisation}

The Transnationalisation of Daily Life and Social Fields in Europe Edited by Prof. Dr. Martin Heindenreich

\section{The Marginalized in Genocide Narratives}

Giorgia Donà

\section{The Social Structures of Global Academia}

Edited by Fabian Cannizzo and Nick Osbaldiston

\section{Citizenship in the Latin American Upper} and Middle Classes

Ethnographic Perspectives on Culture, Politics, and Consumption

Edited by Fabian Cannizzo and Nick Osbaldiston

\section{Youth and the Politics of the Present}

Coping with Complexity and Ambivalence

Edited by Enzo Colombo and Paola Rebughini

For more information about this series, please visit:

www.routledge.com/Routledge-Advances-in-Sociology/book-series/SE0511 


\section{Youth and the Politics of the Present}

Coping with Complexity and Ambivalence

\section{Edited by Enzo Colombo and Paola Rebughini}


First published 2019

by Routledge

2 Park Square, Milton Park, Abingdon, Oxon OXI4 4RN

and by Routledge

52 Vanderbilt Avenue, New York, NY 10017

Routledge is an imprint of the Taylor \& Francis Group, an informa business

(C) 2019 selection and editorial matter, Enzo Colombo and Paola

Rebughini; individual chapters, the contributors

The right of Enzo Colombo and Paola Rebughini to be identified as the authors of the editorial material, and of the authors for their individual chapters, has been asserted in accordance with sections 77 and 78 of the Copyright, Designs and Patents Act 1988.

The Open Access version of this book, available at www.taylorfrancis.com, has been made available under a Creative Commons Attribution-Non Commercial-No Derivatives 4.0 license.

Trademark notice: Product or corporate names may be trademarks or registered trademarks, and are used only for identification and explanation without intent to infringe.

British Library Cataloguing-in-Publication Data

A catalogue record for this book is available from the British Library

Library of Congress Cataloging-in-Publication Data

A catalog record for this book has been requested

ISBN: 978-0-367-I5099-0 (hbk)

ISBN: 978-0-429-19826-7 (ebk)

Typeset in Times New Roman

by Apex CoVantage, LLC 


\section{Contents}

List of figures vii

List of tables viii

List of contributors ix

A complex uncertainty: young people in the riddle of the present 1

ENZO COLOMBO AND PAOLA REBUGHINI

\section{PART I}

Complexity

1 Learning (not) to labour: how middle-class young adults look for creative jobs in a precarious time in Italy

LORENZO DOMANESCHI

2 Negotiating reality through the prosumption of the 'unreal' self: young people's identities in an age of economic precarity

KONSTANTINOS THEODORIDIS, STEVEN MILES AND KEVIN ALBERTSON

3 'Flexi-lives': facing the mobility imperative

VALENTINA CUZZOCREA

PART II

Uncertainty

4 Fragile transitions from education to employment: youth, gender and migrant status in the EU

ÇETIN ÇELIK, FATOŞ GÖKŞEN, ALPAY FILIZTEKIN, İBRAHIM ÖKER

AND MARK SMITH 
5 Precarious and creative: youth facing uncertainty in the labour market

SONIA BERTOLINI, VALENTINA MOISO AND MARGE UNT

6 Youth and precariousness in Spain: beyond a waiting time BENJAMÍN TEJERINA

7 The myth of flexibility: young adults' expectations of work in the digital economy in Milan

8 Uncertainty management strategies in the process of identity formation of Polish young adults

MONIKA BANAŚ

\section{PART III}

Involvement

9 Young women of Muslim background in France and Britain: personal and public projects DANIĖLE JOLY

10 Occupying the city: from social housing to the theatre ANTIMO LUIGI FARRO AND SIMONE MADDANU

11 'I would rather choose a mixed school': young people's secondary school choice in a low-income, multi-ethnic neighbourhood

KIRSTEN VISSER

12 Our Nation's Future: youth visions of a post-Brexit Britain MARCO ANTONSICH, PANAGIOTA SOTIROPOULOU, LEILA WILMERS, CUOMU ZHAXI AND SOPHIE-LOUISE HYDE 


\section{Figures}

4.1 Predicted relative wage differences across vulnerable groups relative to adult males (students excluded)

5.1 Conceptual map

7.1 What work do you aspire to do?

7.2 How would you describe work today?

12.1 Bloodshot

12.2 As we leave the EU

12.3 Bus stop

171

12.4 Please hold the door

173

12.5 May's force is against you

174

12.6 Conversation expectation

176 


\section{Tables}

4.1 Estimation of employment status, relative risk rates (excludes students)

4.2 Determinants of occupation status across vulnerabilities (students excluded)

6.1 List of individual interviews and focus group

10.1 Essentials of occupations 


\section{Contributors}

Kevin Albertson is Professor at The Business School at Manchester Metropolitan University. His research interests range from business and social forecasting to: the frontiers-zone crisis; social innovation; crime; and the application of classical and behavioural economics to socio-political issues.

Marco Antonsich is a Senior Lecturer in Human Geography at Loughborough University. His research interests revolve around nation and migration, focusing particularly on Italy. Among his publications are Everyday Nationhood (Palgrave, 2017) and Governing through Diversity (Palgrave, 2015)

Monika Banaś is Associated Professor at the Institute of Intercultural Studies, Faculty of International and Political Studies, Jagiellonian University, Cracow. Her research interests focus on theory of culture, mutual dependences of economy and culture, migration trends in contemporary societies, welfare state and crisis. She holds a PhD in American studies and a post-doctoral degree (doctor habilitus) in political science with a specialisation on social cohesion and cultural integration of multi-ethnic societies. Currently she is involved in an individual project dedicated to political culture in Poland and Scandinavia in comparative perspective.

Sonia Bertolini is Associate Professor at the University of Turin, where she teaches sociology of work. Her research interests concern labour market flexibilisation; youth labour market entry; female labour market participation, labour market flexibilisation and transition to adult life; and sociology of professions. Among her publications are Youth on Globalised Labour Market. Rising Uncertainty and its Effects on Early Employment and Family Lives in Europe (Barbara Budrich Publishers, Opladen, Germany, and Farmington Hills, United States, 2011; edited with H.P. Blossfeld and D. Hofäcker), and Flessibilmente giovani: percorsi di lavoro e transizioni alla vita adulta nel nuovo mercato del lavoro (Il Mulino, Bologna, 2012).

Çetin Çelik is Associate Professor at Koç University, Istanbul. His research interests deal with different forms of educational inequalities within the context of migration. He is author of The Process of Leaving School and Meaning 
of Schooling: The Case of Turkish School Leavers in Germany (University of Bremen, 2012). His recent research explores links between identity formation and educational achievement of the second-generation migrant youth and broader social policies and institutional regulations in Turkey and Germany.

Enzo Colombo is Professor of Sociology of Culture and Intercultural Relations at the Department of Social and Political Sciences, University of Milan, Italy. His research interests lie in everyday multiculturalism, active citizenship, cultural aspects of the globalisation process, young adults' identification and civic participation. He has published in top peer-reviewed journals. He is author of Children of Immigrants in a Globalized World: A Generational Experience (Palgrave, 2012; with P. Rebughini).

Valentina Cuzzocrea (MA and $\mathrm{PhD}$, Essex) is Senior Assistant Professor in Sociology at the University of Cagliari, Italy, where she teaches (advanced) theory and methods of social research, and visiting Senior Research Fellow at the Department of Sociology, University of Vienna. She previously held research positions in Germany (Max Weber Kolleg, Erfurt) and the University of Kent. She is interested in various aspects of research on young people, and more recently on how this intersects with issues of time and space, publishing on this latter front in Current Sociology, Time \& Society and Sociological Research online. Her last books are Mobility, Education and Employability in the European Union. Inside Erasmus (Palgrave, 2018; with D. Cairns, E. Krzaklewska and A.A. Allaste); and The Consequences of Mobility: Skilled Migration, Scientific Development and the Reproduction of Inequality (Palgrave, 2017; with D. Cairns, D. Briggs and L. Veloso).

Lorenzo Domaneschi is Research Assistant at the Department of Social and Political Sciences, University of Milan, Italy. His main research interests are cultural identity and consumption practices among youth cultures.

Antimo Luigi Farro is Professor at Sapienza University of Rome, Department of Social Sciences and Economics, and coordinator of the $\mathrm{PhD}$ Program. Former President of RC47, International Sociological Association, he is Member of CADIS, Center of Analysis and Sociological Intervention (EHESS/CNRS) Paris, France. His research interests include social movement studies, sociology of labor, migration and urban sociology. He wrote the 'Spin Time: From the right to housing to a new left' and 'Conclusions' sections in Chapter 10 of this book.

Alpay Filiztekin is Professor, Dean of Faculty of Businnes at Özyeğin University of Istanbul. His research topics include economic growth, regional development, urban economics, applied econometrics and economic history. He is particularly interested in agglomeration economies, education, labour markets and inequality.

Alessandro Gandini is a sociologist and a senior researcher at the Department of Social and Political Sciences, University of Milan. Previously, he was a lecturer in the department of Digital Humanities, King's College, London. 
His research interests include the transformation of work, social relations and research methods in the digital society. He is the author of The Reputation Economy (Palgrave, 2016), the co-author of Qualitative Research in Digital Environments (Routledge, 2017) and a co-editor of Unboxing the Sharing Economy, part of The Sociological Review Monograph Series (2018).

Fatoş Gökşen is a Professor in the Department of Sociology at Koç University Istanbul. Her main research interests are in the field of social policy, gender and educational inequalities, and media studies.

Sophie-Louise Hyde is a poet, researcher and entrepreneur based at Loughborough University. She was awarded her PhD in 2017 for her part-creative thesis: "We Should Be United": Deploying Verbatim Methods in Poetry to (Re)present Expressions of Identity and Ideas of Imagined Community in the 2011 Birmingham Riots'.

Danièle Joly is Professor Emeritus in the Department of Sociology at the University of Warwick, Associate Researcher at the College d'études mondiales (MSH-Paris) and at the IFRI (Paris). She has completed a European Commission Marie Curie Fellowship at the Ecole des Hautes Etudes en Sciences Sociales (CADIS), conducting research on Muslim women's political participation in Europe. In 2011-2012, she was Resident Researcher at the Institut d'Etudes Avancées-Paris. Prior to that and from 1998, she was director of the Centre for Research in Ethnic Relations at the University of Warwick. She obtained a Licence es Lettres from the University of Nanterre and a master's degree in industrial relations from the University of La Sorbonne. She has directed a number of European Commission and other international collaborative research projects. Her areas of expertise include Muslims in Europe, refugees and asylum policy in Europe, ethnic relations and integration. Her publications include L'Emeute (2007), Muslims in Prison (2005), Blacks and Britannity (2001), Haven or Hell: Asylum Policy and Refugees in Europe (1996), Britannia's Crescent: Making a Place for Muslims in British Society (1995), Refugees: Asylum in Europe (1992), The French Communist Party and the Algerian War (1991) and, with Khursheed Wadia, Muslim Women and Power: Civic and Political Engagement in West European Societies (Palgrave MacMillan). She is editor of International Migration in the New Millennium (2004) and Global Changes in Asylum Regimes (2002).

Luisa Leonini is Professor of Sociology of Consumption at the Department of Social and Political Sciences, University of Milan, where she convenes the MA in public and corporate communication. Her research interests in recent years have focused on the study of youth and the impact of economic crisis, its implications for everyday life and consumption lifestyles.

Simone Maddanu received his $\mathrm{PhD}$ at the School for Advanced Studies in Social Sciences (EHESS) of Paris, France. His research focuses on social movements, common goods, migrations, ethnic relations, and Islam in Europe. He has been 
Research Fellow in Paris (2009-2010), Cagliari University (2010-2013), and Sapienza University of Rome (2014-2015), he is currently teaching sociology at the Seminole State College of Florida, in the United States. He wrote the 'Introduction', 'Common social spaces', 'Metropoliz: Contemporary arts and global citizens' and 'Teatro Valle: Cultural and urban common goods' sections in Chapter 10 of this book.

Steven Miles is Professor of Sociology and head of the Research Centre in Applied Social Sciences at Manchester Metropolitan University. His particular interest is in the role of consumption in impacting on the question of identity, at both the individual level and that of the city. His key publications include Consumerism as a Way of Life (Sage, 1998), Youth Lifestyles in a Changing World (Open University Press, 2000) and Spaces for Consumption: Pleasure and Placelessness in the Post-Industrial City (Sage, 2010). He is currently Editor-in-Chief of the Journal of Consumer Culture.

Valentina Moiso is a postdoctoral researcher in sociology at the University of Turin, Department of Cultures, Politics and Society, Italy. Her research interests include household finance and social vulnerability, innovation in money circuits, Islamic finance, mafia expansion and collusive relations. She has published in Stato e Mercato and Critique Internationale, among several other journals. Recently she has contributed to the volume The Making of Finance: Conventions, Devices and Regulation (Routledge, 2018; edited by I. Chambost, M. Lenglet and Y. Tadjeddine).

İbrahim Öker is a PhD candidate in the Department of Political Science, University of Minnesota, Twin Cities, United States.

Paola Rebughini is Professor of Sociology of Culture and Intercultural Communication at the Department of Social and Political Sciences, University of Milan, Italy. Her research interests lie in social theory, agency in everyday life, social movements, cultural aspects of globalisation processes, young adults identification and civic participation. She has published in top peer-reviewed journals. She is author of Children of Immigrants in a Globalized World: A Generational Experience (Palgrave, 2012; with E. Colombo) and of other books in Italian and French.

Mark Smith is Professor Human Resource Management and Dean of Faculty at the Grenoble Ecole de Management, France. He has carried out research work for a number of European and National institutions and previously worked at Manchester Business School, UK. His interests focus on labour market policy and outcomes for women and men including working conditions, workingtime, equality and work-life integration. He has authored or co-authored over fifty books, book chapters and journal articles. His most recent books include Youth Employment (with J. O’Reilly, C. Moyart and T. Nazio published by 
Policy Press in 2018), Gender and the European Labour Market (with F. Bettio and J. Plantenga, also published by Routledge in 2013) and Business Ethics - A critical approach: integrating ethics across the business world (with P. O’Sullivan and M. Esposito, published by Routledge in 2012).

Panagiota Sotiropoulou is a Lecturer in Human Geography at Loughborough University. She has recently finished her PhD entitled 'Pre-Service Teachers' Multicultural Competence and the Factors Influencing Its Development: The Case of Greek Pre-Service Teachers'. Her research interests lie in the intersection between geography and education.

Benjamín Tejerina is Professor of Sociology and Director of the Collective Identity Research Center at the University of the Basque Country. His research interests include collective action and social movements, living conditions, precariousness and transformations in the work's culture and civic transitions.

Kostantinos Theodoridis is a PhD candidate in the Department of Sociology at Manchester Metropolitan University, United Kingdom. His research interests developed to a more critical examination of consumption during the economic crisis in Greece, and his doctoral research explores young people's identities and the changing nature of consumption as a social and cultural phenomenon through the lens of digital space and social media.

Marge Unt is Professor of Comparative Sociology and Head of the Institute of International Social Studies (IISS) at SOGOLOS at Tallinn University. Her research interests are in life-course studies in comparative perspective, namely youth transitions from school to work, early career, gender inequalities, late career transitions and active ageing in general. She coordinated a Horizon 2020 project, 'Social Exclusion of Youth in Europe: Cumulative Disadvantage, Coping Strategies, Effective Policies and Transfer (EXCEPT)' (2015-2018).

Kirsten Visser is an Assistant Professor in Urban Geography in the Faculty of Geosciences at Utrecht University, the Netherlands. Her research activities focus on geographies of children and youth, neighbourhood effects, urban inequality and diversity.

Leila Wilmers is a doctoral researcher in the School of Social Sciences, Loughborough University currently working towards a $\mathrm{PhD}$ on constructions of the nation's continuity in Russia. Her research interests include nationalism, identity and memory, with a particular focus on the post-Soviet region.

Cuomu Zhaxi is a $\mathrm{PhD}$ student at the Centre for Research in Communication and Culture, Loughborough University. Her current project on the media representation of Tibetans and Chinese nationalism is sponsored by a Loughborough University studentship and a Universities' China Committee in London research grant. 



\title{
A complex uncertainty Young people in the riddle of the present
}

\author{
Enzo Colombo and Paola Rebughini
}

\section{Introducing the book}

It is widely perceived that contemporary society is changing fast and that the interpretative categories, practices and words that we have inherited from the past are now inadequate to account for everyday experience. This perception is likely not new, and since modernity, all Western societies and all generations have felt a sense of lack and crisis. Crisis, instability and uncertainty have often been described as typical 'modern' conditions related to the rapidity of social and material changes (Mannheim, 1928; Polanyi, 1944; Koselleck, 2004) and to the difficulty of understanding and assimilating the heritage of previous social experiences (Arendt, 1961). From a historical point of view, the sensation of being unable to understand the current 'metamorphosis of the world' (Beck, 2016) cannot be considered a new experience, although it is new from a subjective point of view.

Yet, even if we can discuss the originality of the current situation, it is undeniable that a series of transformations - concerning work opportunities, intercultural encounters, gender relationships, migration processes, awareness of environmental threats, and ICT technology, to name some of the most important ones - are subjecting taken-for-granted routines and habits to great stress. Such changes are inducing a search for new ideas, concepts and activities that fit the new and fastchanging contexts better.

Young people - especially those among them with high social and cultural capital, more in tune with practices of mobility and interconnectivity - are in a very specific position in relation to these changes. As they grew up, they internalised and took for granted the main transformations that characterised the transition from 'classical', 'industrial' society to a different social organisation, usually called with differentiated and sometimes contradictory names: 'radical modernity', 'post-industrial', 'postmodern', 'risk' or 'network' society. Although the different terms foreground different aspects of the changes that have characterised Western societies, they all share the standpoint that the old set of concepts, ideas, words, routines and habits inherited from modern thought need a radical adjustment to the new situation. 
The current cohort of young adults have grown up as 'natives' of the new social organisation. They have learned to live in new spatial and temporal dimensions, characterised by the mediation of new technologies, the possibility - real or virtual - of travelling easily and coming into everyday contact with different cultures and points of view. They have learned to take into account the uncertainty related to the persistence of economic instability, the rapid changes in labour markets, the risks of environmental disasters, the fragility of democracies and the threat of violence and terrorism of a constant 'war at home'. So as not to succumb to subalternity and marginality, they have needed to learn new languages, new codes and new rules to adapt to the different contexts in which they must act.

In this book we consider observation of the practices and experiences of young people facing the challenges of a globalised society, the uncertainty of the future, the continuous transformations of the job market and the growing presence of cultural diversity as yielding important insights into how the overall society is transforming. It is from the specific standpoint of a 'generational gaze' that this book analyses, in situated European contexts, the locations of agency as 'politics of the present'.

\section{Generation as an analytical tool}

The concept of 'social generation' can be a useful analytical framework for reading and analysing social changes (Woodman and Wyn, 2015). While we recognise the current fragmented nature of the field of youth studies (Côté, 2014; Woodman and Bennet, 2015; France and Threadgold, 2016), and the criticism concerning the risk of transforming the social generational paradigm emerging in youth studies into a new orthodoxy devoid of analytical precision (Morgan and Idriss, 2012; France and Roberts, 2015), we suggest that the use of social generation as a heuristic tool can help overcome a too-simplistic opposition between the 'structural' and 'cultural' perspectives (Furlong, Woodman and Wyn, 2011). To achieve this goal, it seems necessary to avoid reifying generations and considering them as homogeneous. A careful analysis of how generational experiences intertwine with different social positions is necessary to understand how agency and structural constraints mutually define each other and how the action of the subjects is concretely defined within this mutual definition. This can highlight some ways in which agency and inequalities among young people are intertwined and affect each other (Colombo, Leonini and Rebughini, 2018).

In recent years, social generation has emerged in youth studies as a conceptual framework that helps overcome the pitfalls of a functionalist approach that risks reducing youth experience to a series of mechanical transition events: completion of schooling, labour market entry, leaving the parental home, forming first union, entry into parenthood (Buchmann and Kriesi, 2011). Research focusing on transition often ends up by presenting an excessively pessimistic image of young contemporaries highlighting their faulty, messy, irregular and failed transitions, measured against the standard of the previous cohorts (Wyn and Woodman, 2006; 
Blatterer, 2007). The concept of social generation was originally introduced into the sociological debate by Karl Mannheim (1928/1952) to refer to a particular cohort of individuals united in a self-conscious age stratum by their specific collective response to a traumatic historical event or catastrophe, and constituting a concrete group with the necessary political awareness to become drivers of social change (Edmunds and Turner, 2002). While Mannheim emphasised political and intellectual self-awareness as the characteristic of a generation (Aboim and Vasconcelos, 2014), we consider generation as primarily defined by the subjective experience of the inadequacy of what is at hand to manage the complexity and novelty of mundane situations, with the impossibility of following consolidated and shared routines. Such impossibility is marked by the perceived necessity to acquire new languages, routines and practices. We consider social generation to be a useful analytical reference whenever we try to make sense of the experience of individuals and groups that have to cope with situations in which the words, concepts, routines and patterns of behaviour that they have inherited from previous cohorts are no longer satisfying. Rather than defining a group of people sharing a precise political project or utopia, the concept of social generation can be useful to refer to the shared experience of knowing 'what doesn't work anymore without knowing [or without agreeing on] what does work, how it might work and where it leads' (Beck, 2016, p. 189). As Lizardo and Strand observe (2010, p. 223):

all periods of dissolution of external support for action and the reconstitution of new ones separate actors into institutional generations, at the level of practical consciousness, even if some sort of homogeneity at the level of discursive consciousness (explicit institutionalization) is achieved. This separates the (institutionally) 'old' who have less of a capacity to retool and relearn new habits from the (institutionally) 'young' who are able to reconvert (through skill transfer) not yet crystallized practical investments into new patterns of habitualized expertise to generate and organize action under currently developing external supports.

Thus, generation can be a useful analytical notion to define the shared experience of living a 'crisis of presence' (De Martino, 1975), a momentary failure of the possibility of synthesis according to past references, and in the absence of new and clear references for orienting oneself in the future. Social generation can be a useful analytical tool with which to explore how people construct new meanings and new practices to cope with historical situations in which personal becoming cannot refer to given and well-established categories and vocabularies. Young people perceive themselves 'as falling out of history', in a sort of presentism, where they are forced to exercise creative solutions in response to the unpredictability of everyday life (De Certeau, 1984).

However, once this epistemological posture has been taken, it is necessary not to reify or crystallise it. It is important to analyse how 'meaningful actions' 
are constituted and deconstructed within their historical-social framework, to focus on the different situated and contextualised positions, and on the relationships between capability/possibility and structural dimensions/systems of categorisation.

Assuming a generational perspective centred on changes does not mean focusing attention only on the subjective dimensions of the action, ignoring the importance of the 'political economy' (Côté, 2014, 2016), and the structural dimensions that define the possibilities for action. On the contrary, it means recognising that every generation location consists of a multiplicity of possible generation units that constitute what Beck (2016, p. 194) calls 'generational constellations': a diagnostic concept in which demographic dimensions and material inequalities, diversity in education and labour market position, gender, ethnicity and other forms of social categorisation overlap and interpenetrate.

The variability of 'social locations' (Anthias, 2013, 2016) precludes the possibility of considering a generation as a unitary and homogeneous group and asserts the need to look carefully at the material and cultural differences that differently characterise how individuals and groups react to similar historical-social experiences (Côté, 2014; France and Threadgold, 2016). The notion of 'social location' aims to represent a more complex and cultural informed idea of social class. It suggests that class, gender, education, ethnicity, age and other forms of social categorisations all contribute, with their specific form of intersection, in shaping different conditions of existence and different dispositions and opportunities. In our view, the notion of social location stresses the intertwining of material, cultural and symbolic dimensions in shaping the resources and the constraints that inform people's definition of the situation and their agency. From a methodological point of view, the notion of social location invites consideration of the specific social context in which and from which social actors give meaning to their social experience and find room for their actions. It suggests avoiding too abstract generalisations ('the youth') and taking seriously the interweaving of social categorisations that define the space of subjectivity and action.

Overall, the aim of this book is to show that the capability, and the need, to manage complexity, plurality, uncertainty and variability - what we call the politics of the present - has become a mark of the experience of contemporary youth and may constitute a basic component in creating innovative forms of social relationships. Moreover, it shows how this capability is affected by different social locations.

While the book explores different local and specific situations in which such capacity can be analysed, in this introductory chapter we start by focusing on two main transformations that are promoting deep changes in how young people make sense of their everyday experience: complexity and uncertainty. These are considered the two main analytical elements that call for a politics of the present. The transformations of the perception and experience of space and time contribute to making complexity and uncertainty the constituent elements of the contexts within which young people find themselves living and acting. This means that 
new skills and competencies are needed to cope with constantly new situations, and that possessing or not possessing these new skills can make the difference between being included and being excluded. This can give us some indications about the possible directions in which the everyday actions of young people will develop in order to cope with complexity and uncertainty.

\section{Facing complexity}

One of the most important changes introduced by the processes of globalisation can be summarised in the term 'complex connectivity' (Tomlinson, 1999, p. 2). The term is used to denote the intensification of global interconnectedness (Held et al., 1999) and the complex and dense network of linkages that it implies. It highlights the fact that people's experiences are 'more connected' because what happens in people's lives is closely related to the actions and decisions of others, and that the specific characteristics of everyday situations in which people have to act - acquaintances and friends with whom they are in contact; news and information to which they have access; the goods and the commodities they can buy; the music, movies or novels they love; behaviour models and rules to which they decide to comply - often originate in places far from their physical location. The radical and deep penetration of complex connectivity in everyday experience transforms the idea of proximity, familiarity and belonging.

In a context of complex interconnectedness, what is perceived as part of people's sphere of interest, as part of their domestic, daily world, is no longer delimited by the immediacy of the geometric space. It is rather the synthesis of the interconnections that can and are to be activated, as well as those that impose themselves from the outside and that cannot be avoided. In this way, the idea of proximity is transformed. It does not refer primarily to the spatial dimension of everyday experiences, but to their relational characteristics. What is near is not necessarily what is spatially close, but what is in relation with people, what they feel to be close, because it touches them, involves them, becomes part of their routines and their world of meaning.

The changes in the way in which individuals perceive proximity and the world of everyday life have important consequences. A first consequence is that, especially for young people who have grown up by internalising this different experience of proximity, interconnectedness is perceived as unavoidable. It is taken for granted and conceived as a constitutive part of normality that individual lives are affected by facts, decisions and rules generated and circulating on a global scale. Consequently, proximity makes sense for its connections with real, perceived or imagined global localities that are 'in touch' with the lived space of everyday experience rather than being defined by physical proximity. The world of everyday life is mainly defined by its relational rather than spatial characteristics, by topology rather than by topography (Lash, 1999; Lury, Parisi and Terranova, 2012; Shields, 2013). As Kallio, Häkli and Bäcklund (2015) observe, topology is a useful way to describe dynamic relations that cannot be 
(entirely) contained by scaled spatial entities, such as the geographical concepts of territory, country or city.

By paying attention to connections, relations and changes, young people are driven to find the raw materials for the construction of their points of view, lifestyles, routines, allegiances, sympathies, engagements and identifications in global flows and in the networks of global interconnection to which they can gain access, rather than simply using what is available in their immediate spatial context. What constitutes their more familiar, personal, and authentic world is no longer derived from the automatism of being located in a specific geographic locality. It rather derives from their location in the networks of global interconnection and from their capacity to activate and keep active connections. This does not mean that locality has become inconsequential; it simply signals that locality, and any sense of attachment and belonging, has to be actively constructed out of a particular constellation of social relations in order to be meaningful, to be able to produce identity, to become a marker of identification and distinction (Massey, 1991; Hugh-Jones and Madill, 2009). In this way, the ideas of community, belonging, continuity, identity and difference are problematised and must be revised to fit the new experiences better. Variability, eclecticism, bricolages and adaptability become the standard. Being able to build an original, effective and rewarding proximity by coming into contact with global networks that are considered closer to one's personal characteristics is more important than being similar and loyal to the people living in the immediate geographical context. The necessity to build personal localities from the multiplicity of options available promotes a growing sensitivity to diversity. Super-diversity (Vertovec, 2007) becomes the main feature of everyday experience, and young people (must) learn to recognise, assess, value or hide differences. This does not mean that geographical location becomes irrelevant (see Visser in Chapter 11 of this book), but rather that it assumes a relational character (see Antonsich et al. in Chapter 12). The resources available and the spatial and social collocation condition the type, the strength and the extension of the relations that define the sense of the place.

A second important consequence is that, by promoting an emphasis on meaningful connections (topology) rather than on geometric links (topography) (Castells, 1996; Lash, 1999; Lury, Parisi \& Terranova, 2012), the current globalisation processes bring to the fore practices of attributing meanings to social reality. They foreground the processes of the social production of reality and encourage reflexivity (see Chapter 1 by Domaneschi and Chapter 9 by Joly in this book). Producing a personal and original proximity means being able to manage global interconnected localities; it means recognising the diversity of contexts and understanding the rules that apply to them. In order for this task to be accomplished, young people must learn to move from one environment to another. They must use different languages, understand and apply different rules, take into account the expectations of the different people inhabiting the different networks that they visit, and avoid being excluded. Constructing and preserving topological proximities of this kind requires the capacity to adjust, translate and transform. 
The experience of constantly moving from one context to another and of linking together elements from disparate global flows makes evident that what is valid in a specific context cannot be exported successfully to others. It becomes evident that rules, codes and languages do not derive from universal principles or laws; they cannot be taken for granted or regarded as unchangeable. Instead, they depend on the contexts in which people are to act, the goals they aim to achieve and the hierarchies of power that apply in the specific situation. In this way, a relativistic attitude is promoted: rather than adhere to a defined set of norms, young people learn that it is important to understand what is valid in the specific contexts in which they must act.

The injunction to be flexible assumes an ambivalent value. On the one hand, it presses young people to be independent, to make their own choices, to express their preferences amid the great possibilities offered by the global networks. On the other hand, it becomes evident that the individual possibility of choice is restricted to the options already present in the global flows, while the possibility to have a voice in defining new options is problematic. In this way, the capacity/necessity to understand the relativity of the different contexts foregrounds the importance of agency. At the same time, however, it shows the strength of structural constraints; constraints that cannot be easily ignored, avoided or bypassed because they arise from conditions, decisions and processes that are placed on indefinite dimensions, more and more distant from the possibility of subjective intervention, modification and resistance (Beck, 1992). As Alberto Melucci (1996, p. 43) so effectively remarked:

we have become migrant animals in the labyrinths of the metropolis, travellers of the planet, nomads of the present. In reality or in the imagination, we participate in an infinity of worlds. Each of these worlds, moreover, has a culture, a language, and a set of roles and rules to which we must adapt whenever we migrate from one of them to another. Thus we are subjected to mounting pressure to change, to transfer, to translate what we were just a moment ago into new codes and new forms of relation.

However, the capacity to be a nomad of the present depends on specific skills that are unequally distributed. Having the resources needed to be mobile, knowing different languages, understanding the different codes and applying them correctly to different situations, and tolerating ambivalence and uncertainty make the difference between being included or excluded, being able to take full advantage of the situation or being considered extraneous or unfit.

\section{Living uncertainty}

Besides interconnections and the necessity of continuous translations, being nomads of the present means being able to deal with contingency and uncertainty, to cope with a given space-time situation made by a complex overlapping of 
identities, references, opportunities and constraints. Like complexity, uncertainty also has become a fundamental aspect of post-industrial society, characterised by globalisation and digital economies. Although, contrary to complexity and connectivity, uncertainty is certainly not a new historical phenomenon and has always characterised social life, it is its current perception to represent a new issue. The perception of uncertainty is related to unprecedented levels of personal security, at least in Western countries, but also to growing levels of unpredictability of the future. It is the certainty of uncertainty, without promises of a final goal, the realisation that uncertainty is here to stay and that we need an art of living permanently with it (Bauman, 1999). Uncertainty, as the lack of ontological references in everyday life (Giddens, 1984), as structural insecurity to which every individual has to find situated and impermanent solutions, can be considered typical of current post-industrial societies (Beck, 2006). Everyone is constantly looking for a personal stability with strongly individualised characteristics, while maintaining relationships with the recognition, the representations and the choices of others (Martuccelli, 2017). Uncertainty encourages the focus on the contingent situation, while the references of the past are vanishing, history becomes a history of the present (Spivak, 1999) and contingent and singularised solutions are related more to the given of the context that to past experiences.

In terms of space and time relations, this historical transition has enhanced a process of presentification that has also changed the perception of one's agency and vulnerability, especially among the younger generation. While in philosophical terms (such as in Husserl) presentification concerns the reproduction of an impression, recalling an absent object to mind, and is related to the notions of 'presence' and 'absence', in sociological terms 'presentification' means a subjective relation with time. Presentification can be considered a lifestyle focused on the present, on immanence, accompanied by a difficulty in imagining the future, typically observed among youth in Western countries (Alteri, Leccardi and Raffini, 2016; Colomb, Leonini and Rebughini, 2018). Presentification is characterised by the paradoxical oscillation between fatalism and hyper-realism. On the one hand, the difficulty in selecting among and interpreting the complexity of the data in front of oneself generates a fatalistic attitude, a new avatar of what Bourdieu (1984) called the amor fati; on the other hand, it leads to a realistic approach, free from illusions and utopias and based on a sort of life-long learning. The difficulties in making long-term plans, or foreseeing the effects of current choices, enhance tactical attitudes and require the ability to surf on the instability of the present, instead of openly confronting oneself with structural constraints. Moreover, the necessity to choose among multiple strategies and unforeseeable perspectives requires an agency based on an oxymoron of 'obligation/opportunity' connected with the need to face the complexity and variability of situations (see Bertolini et al. in Chapter 5 and Banaś in Chapter 8 of this book).

It is in the practices and choices of young people that we can observe a normalisation of uncertainty, sometimes translated into a sort of 'active resignation', whereby action must be taken anyway, because remaining still would 
mean succumbing. In this case, agency is based on the capacity to understand the options available, avoiding immobility and failure to recognise opportunities or to promote and create them.

Because time has been accelerated by technological change (Eriksen, 2001; Rosa and Scheurman, 2009), the presentification of action, whose coordinates are only those of the contingent situation, requires a rapid reaction. Again, although current acceleration can be considered only an 'acceleration of acceleration' typical of the modern framework (Koselleck, 2004), this is another evident generational turn. The acceleration of social and technological transformations fosters a rapid erosion of personal and collective experiences, a decreasing time period during which expectations based on past experience reliably match the future. The time required to make decisions, to orient one's action or to evaluate ideas and experiences is more and more brief. Choices and decisions, as well as values, have an increasingly short period of validity, and it becomes impossible to follow consolidated and shared routines. Because opportunities cannot be missed, cumulating multiple and short experiences - albeit unsatisfactory - is necessary to avoid social exclusion and isolation. This management of the present means being able to situate oneself where the flows of chances and information are thicker and more intense.

In this new scenario, precariousness does not concern work experiences alone; it also involves the possible effects of choices and decisions concerning everyday life (Cingolani, 2014; Bröckling, 2016). Young people today are constantly called upon to shape their biographies and make choices, not because of the weakening of structural constraints - such as family and gender patterns - but because of their proliferation (Beck, 2016). A life plan can no longer be the organising principle of a biography, while on a systemic level we witness the fading of the myth of progress and the end of the teleological orientations of history, with a sensation of continuous metamorphosis of everyday life references. Multitasking capacities become paramount.

Indeed, this new experience of time and agency is in tune with the immaterial and digital economies of knowledge, where most new professions are despatialized and can be performed in different spaces and at different times with the help of technological devices. Presentification is extended to different forms of spatiality and the same 'present' can follow us in different contexts, of personal and professional life.

\section{New skills, new exclusions}

The capacity to deal with the growing complexity and uncertainty of everyday experience promotes new skills but also marks new lines of exclusion. Being able to navigate super-diverse, fast-changing and uncertain environments requires the development of a specific set of personal capacities (Melucci, 1996), which depend on the material and cultural resources on which an individual can draw to think and act in order to be recognised as a person by others, and to invest energy 
in personal fulfilment. Personal capacity refers to 'a formal and processual capacity which enables the individual to assume a situational identity without a loss of a deeper sense of continuity of her/his personal existence' (Melucci, 1996, p. 52).

Such material and cultural resources for personal capacity can be analysed as both historical and conjunctural, and not only as related to the social position from a structural point of view. This means that we can analyse them from a generational perspective and investigate their consequences at the intersection among different categories such as gender, education and family economic background. Indeed, the consequences of presentification, for example as in the precarisation of jobs and opportunities in the labour market, are generational characteristics, but they can vary according to specific situations, to personal and family resources, and they involve different forms of social inequality (Lorey, 2015; Kelly, 2017; Colombo, Leonini and Rebughini, 2018).

Besides personal capacities to seize the right opportunity, agency starts from different chances and resources, and thus from different contingent social positions, for example from the different intersecting of gender, education and family context in terms of economic resources, social relations and educational background. This means a different mix of opportunities and constraints, a different starting point in evaluating one's vulnerability and points of strength. It means relying on skills of adaptation and improvisation, but also facing unexpected risks of exclusion. Yet, it is evident that young people from families with good economic, social and educational capital not only can rely on much broader and more composite resources, but they can also accept longer periods of uncertainty and precariousness, or jobs below their expectations, as temporary transition phases towards their goals. Conversely, young people with less economic and educational capital, who usually live in or come from families that also have low economic, relational and educational resources, are obliged to invest only in their personal capabilities, with a higher form of individual responsibilisation.

Indeed, uncertainty and complexity require new skills and foster new forms of social stratification, whose combination of 'capitals' - in Bourdieu's (1984) sense - only partially correspond to previous forms of social inclusion and exclusion. While the reference to social structures becomes increasingly blurred, the over-investment in personal capacities becomes evident. The challenge of finding a job and constructing a professional career tends to be declined as a personal challenge, while agency is widely perceived as the capacity to seize the moment, to manage ambivalence, to translate from one code to another, to orient expectations in accordance with the expectations of the context. The capacity of improvisation and adaptation becomes a new form of agency, free from the pride and self-confidence typical of the 'modern subject', whose limits were recognised in external natural and social constraints to be overcome. Young people seem aware that economic, social or environmental limits have to be taken seriously into account, trying to bend or manipulate them, at least in the contingency of the situation. Their agency continues to be a practical capability of doing, related to the crafting capacities of the human as homo faber, whose characteristics are 
no longer exclusively related to the material interaction with the environment, but continue to be oriented by the search for the sense of what is made (Sennett, 2008). Adaptation and improvisation are not simple reactions to the growing unpredictability but include the sense of the practices of such improvisation (see Farro and Maddanu in Chapter 10 of this book).

\section{The politics of the present}

The necessity to govern, invent and reconfigure everyday life becomes a new form of 'politics of the present'. This specific 'politics', as the art of governing what is going on - to find the 'desirable effects', as in the Aristotelian Politics - is a technique of everyday life that young people learn to apply to cope with unpredictability, more than to predispose the future. At the same time, such politics is a generative production of new practices 'from below'. Politics means trusting one's capacity to grasp and modify the situation, to avoid abandoning oneself to events and the processes of alienation. When amor fati and cynical hyper-realism collapse in the concreteness of a specific situation, the politics of the present arises as the necessity to manage the given.

Here, the present is a reference to the specific frame of the action, to the spatial and temporal situation where young people must act, a situation characterised by contingency and continuous becoming. The frame of the action is dominated by unpredictable circumstances that evade the capacity of the subjects to foresee them, and by the elaboration of solutions, choices and practices that start from the current configuration of social relations. Obstacles, or unexpected chances, can appear without notice, and they have to be treated with solicitude. Thus, the politics of the present has a deep immanent character: practices and choices, personal capacities and tactics, have to be processed here and now.

Navigating the present, with its multiplicity, its instability and the uncertainty of seizing the right moment, means being able to translate experiences and competences from one situation to another. Experiences are not cumulated in a temporal way, in a vertical stratified form, but connected in a horizontal, presentified way, to be rapidly converted. The present is no longer a fleeting moment, but the only horizon where relations and strategies can be organised. The politics of the present is a way to be able to seize connections, and contradictions among them, beyond mere adaptive utilitarianism.

This tendency towards a 'politics of the present' as a form of agency, of critical and creative capability, and not only as form of adaptation, can be considered a historical phenomenon, but it can be more easily observed - with different intensities and characteristics - among the current generation of young people. To some extent, this recalls de Certeau's (1984) definition of agency as the 'art of doing', a way to cope with the constraints of the situation developing a sort of problem-solving creativity, for which lives assume the form of a continuous self-management of contingent resources. This also recalls Foucault's 'art of not being governed like that and at that cost' (1997, p. 27), as attempts to escape the 
constraints of the situation, acknowledging the necessity to work with and within the current situation, navigating among constraints that cannot be definitively overcome.

The politics of the present is a government of contingency, the art of those who are accustomed to improvisation here and now; it is different from the Foucauldian 'ontology of the present' (Foucault, 1997), or from Butler's (2005) reference to vulnerability as incompleteness of personal autonomy. More than an analytical definition of the capabilities of the subject, based on an idealistic representation of the subject and her/his agency, the politics of the present assumes the characteristics of a historical and generational stage, a cultural attitude embodied in the everyday practices of young people. It outlines a transition in which technological, material and social changes, intertwined with cultural diversity, fosters a new idea of agency, more related to negotiations and connections than to radical oppositions and coherent ideas of the future.

Inevitably, the relative absence of the state, of welfare resources and of political and institutional references from the discourses of young people is the complementary side of the strong injunction to self-government. In a neoliberal landscape, young people are accustomed to the idea that social inequalities will not be overcome with the help of institutional interventions. Distrust in institutional solutions to inequalities of chances is the complementary side of the politics of the present and its emphasis on situated solutions.

\section{Politics of the present and challenges of the future}

Besides its capacity to refer to individual experiences of managing and surfing uncertainty and to highlight forms of agency firmly placed in the here and now of the contingent situation, the idea of politics of the present directs attention to the collective and social implications of young people's efforts to govern what is going on. Politics, in this case, refers both to a form of discipline that regulates individual and collective action and to the ways in which the action confirms or transforms existing institutions by redefining the conditions of collective action.

In the former case, politics of the present can highlight how the pressure imposed by the necessity to cope with complexity and uncertainty constitutes new forms of constraints and opportunities. Young people are constantly called upon to expand their personal abilities and to invest resources in self-realisation as autonomous and active subjects (see also Tejerina in Chapter 6 of this book). In order not to be isolated or excluded, young people have to be reflexive; they have to learn to remain up to date, on the move (for the relevance of the 'mobility imperative', see Cuzzocrea in Chapter 3 of this book). On the one hand, they are under constant pressure to develop useful resources to face complexity and uncertainty, and to promote creativity, innovation, detachment from the taken-for-granted and exploration (as shown by various chapters in this book: see particularly Chapters 5, 9 and 10). On the other hand, the injunction to be active and creative constitutes a new form of self-discipline. As Theodoridis et al. show in Chapter 2, in situations 
of resource restriction or in the impossibility of acting effectively for the loosening of structural constraints, action can be oriented towards forms of masking difficulties and can be reduced to the maintenance of a self-image, often virtual and disconnected from real experience, which conforms to social expectations. The capacity for action and innovation is then reduced to maintaining a self-image in tune with the social demands, encouraging young people to be in harmony with the contexts rather than acting to modify them for their own benefit. The binding force of the context is further accentuated by the observation that possessing a strong endowment of personal capacity is not always sufficient if the context does not allow it to be fully exploited (see Chapter 1 in this book).

New forms of potential exclusion emerge. Producing the necessary personal capacity, the indispensable set of skills and resources, can be problematic when young people start from a disadvantaged social location. The fatigue and the difficulty of investing constantly in personal capacity can also foster forms of closure and adaptation to one's condition, especially among those with the most limited material and cultural resources. In this case, the effort to control the uncertainty and variability of the contexts can be resolved in an attempt to limit mobility between one context and another, exposing as little as possible to unknown situations and new relational circles or placing trust in forms of stability that the present contexts do not seem able to offer (see Chapter 7 by Visser and Chapter 11 by Gandini and Leonini in this book). This can foster also feelings of 'lagging behind', new forms of closure and attachment to presumed past certainties, restoring vigour to forms of authoritarianism, populism and racism.

A politics based on contingency and oriented to managing complexity and uncertainty, rather than assuming the task of overcoming them - which appears objectively problematic and beyond the individual's capacity for action - brings to the fore the importance of social location, and the different distribution of social, material and cultural resources. The affirmation of the politics of the present induces us to reconsider both the forms of political mediation and the policies to support participation and prevent marginalisation. Civic and political participation become more fractured and episodic, while they can assume forms of strong intensity and involvement.

The politics of the present requires a specific form of illusio (Bourdieu, 2000): the belief that the game in which we are involved is worth playing but, at the same time, the ability to maintain a certain distance, to look at the game with 'irony' (Rorty, 1989). Rather than being taken for granted, the politics of the present requires that the rules have to be scrutinised and understood, so that they can be fully exploited, allowing the actors to seize the favourable moment. The forms of involvement do not exempt from maintaining a reflexive distance from the game; a distance that can appear both as a form of distrust towards the fairness of the game, and as an ability of the actors to consider themselves agents and not to lose sight of the structural dimensions that delimit the game, supporting the awareness that the definition of its rules goes beyond the possibility of action of individual players. Participation and support for political and institutional action is no longer 
guaranteed 'in the long run', but subjected to verification and rejection when the action or policy fails to achieve the desired results. This stresses how contingency and presentification affect the political action, eroding the guarantee that political support or political involvement can be maintained without immediate concrete results (Alteri, Leccardi and Raffini, 2016; Broom, 2017).

To conclude, this book shows how the politics of the present in which young people live today outlines new forms of opportunities and constraints, new privileges and new processes of exclusion. Young people who do not have the skills appropriate to the circumstance, or cannot be 'reflexive, active and flexible' enough because of the lack of appropriate resources, risk new forms of marginality. Taking seriously the idea of living in a politics of the present implies also the effort to imagine active policies of support for an adequate development of personal capacity. This means policies focusing on the development of material, relational and cognitive resources that allow young people to maintain a space of agency, despite the constraints of a society increasingly characterised by economic instability, growing social inequalities, environmental alarms, fears for the future and other forms of uncertainty, but also by complex interconnections that can open unexpected pathways.

\section{References}

Aboim, S. and Vasconcelos, P. (2014). From political to social generations: A critical reappraisal of Mannheim's classical approach. European Journal of Social Theory, 17(2), pp. $165-183$.

Alteri, L., Leccardi, C. and Raffini, L. (2016). Youth and the reinvention of politics: New forms of participation in the age of individualization and presentification. PaCo Partecipazione e conflitto, 9(3), pp. 717-747.

Anthias, F. (2013). Hierarchies of social location, class and intersectionality: Towards a translocation frame. International Sociology, 28, pp. 121-138. doi: 10.1177/02685 80912463155.

Anthias, F. (2016). Interconnecting boundaries of identity and belonging and hierarchymaking within transnational mobility studies: Framing inequalities. Current Sociology, 64(2), pp. 172-190. doi: 10.1177/0011392115614780.

Arendt, H. (1961). Between past and future: Six exercises in political thought. New York: Viking Press.

Bauman, Z. (1999). In search of politics. Cambridge: Polity Press.

Beck, U. (1992). Risk society. London: Sage.

Beck, U. (2006). The cosmopolitan vision. Cambridge: Polity Press.

Beck, U. (2016). The metamorphosis of the world. Cambridge: Polity Press.

Blatterer, H. (2007). Contemporary adulthood: Reconceptualizing an uncontested category. Current Sociology, 55(6), pp. 771-792. doi: 10.1177/0011392107081985.

Bourdieu, P. (1984). Questions de sociologie. Paris: Minuit.

Bourdieu, P. (2000). Pascalian meditations. Cambridge: Polity Press.

Bröckling, U. (2016). The entrepreneurial self: Fabricating a new type of subject. London: Sage. 
Broom, C. (2017). Youth civic engagement in a globalized world. New York: Palgrave Macmillan.

Buchmann, M.C. and Kriesi, I. (2011). Transition to adulthood in Europe. Annual Review of Sociology, 37, pp. 481-503.

Butler, J. (2005). Giving an account of oneself. New York: Fordham University Press.

Castells, M. (1996). The rise of the network society. Oxford: Blackwell.

Cingolani, P. (2014). Révolutions précaires: Essais sur l'avenir de l'émancipation. Paris: La Découverte.

Colombo, E., Leonini, L. and Rebughini, P. (2018). A generational attitude: Young adults facing the economic crisis in Milan. Journal of Modern Italian Studies, 23(1), pp. 61-74. doi: 10.1080/1354571X.207.1409532.

Côté, J.E. (2014). Towards a new political economy of youth. Journal of Youth Studies, 17, pp. 527-543. doi: 10.1080/13676261.2013.836592.

Côté, J.E. (2016). A new political economy of youth reprised: Rejoinder to France and threadgold.Journal of Youth Studies, 19(6), pp. 852-868. doi: 10.1080/13676261.2015.1136058.

De Certeau, M. (1984). L'invention du quotidien. I. Arts de faire. Paris: Gallimard.

De Martino, E. (1975). Morte e pianto rituale nel mondo antico. Torino: Bollati Boringhieri.

Edmunds, J. and Turner, B.S. (2002). Generations, culture and society. London: Open University Press.

Eriksen, T.H. (2001). Tyranny of the moment: Fast and slow time in the information age. London: Pluto Press.

Foucault, M. (1997). What is critique? In: S. Lotringer, ed., The politics of truth. New York: Semiotext(e), pp. 23-82.

France, A. and Roberts, S. (2015). The problem of social generations: A critique of the new emerging orthodoxy in youth studies. Journal of Youth Studies, 18(2), pp. 215-230. doi: 10.1080/13676261.2014.944122.

France, A. and Threadgold, S. (2016). Youth and political economy: Towards a Bourdieusian approach. Journal of Youth Studies, 19(5), pp. 612-628. doi: 10.1080/13676261. 2015.1098779 .

Furlong, A., Woodman, D. and Wyn, J. (2011). Changing times, changing perspectives: Reconciling 'transition' and 'cultural' perspectives on youth and young adulthood. Journal of Sociology, 47(4), pp. 355-370. doi: 10.1177/1440783311420787.

Giddens, A. (1984). The constitution of society: Outline of the theory of structuration. Cambridge: Polity Press.

Held, D., McGrew, A., Goldblatt, D. and Perraton, J. (1999). Global transformations: Politics, economics and culture. Cambridge: Polity Press.

Hugh-Jones, S. and Madill, A. (2009). 'The air's got to be far cleaner here': A discursive analysis of place-identity threat. British Journal of Social Psychology, 48, pp. 601-624.

Kallio, K.P., Häkli, J. and Bäcklund, P. (2015). Lived citizenship as the locus of political agency in participatory policy. Citizenship Studies, 19(1), pp. 101-119. doi: 10.1080/13621025.2014.982447.

Kelly, P. (2017). Young people's marginalisation: Unsettling what agency and structure mean after neo-liberalism. In: P. Kelly and J. Pike, eds., Neo-liberalism and austerity. The moral economies of young people's health and well-being. London: Palgrave Macmillan, pp. 35-51.

Koselleck, R. (2004). Future past: On the semantic of historical time. New York: Columbia University Press. 
Lash, S. (1999). Another modernity: A different rationality. Oxford: Blackwell.

Lizardo, O. and Strand, M. (2010). Skills, toolkits, contexts and institutions: Clarifying the relationship between different approaches to cognition in cultural sociology. Poetics, 38 , pp. 204-227. doi: 10.1016/j.poetic.2009.11.003.

Lorey, I. (2015). State of insecurity: Government of the precarious. London: Verso.

Lury, C., Parisi, L. and Terranova, T. (2012). Introduction: The becoming topological of culture. Theory, Culture \& Society, 29(4-5), pp. 3-35. doi: 10.1177/0263276412454552.

Mannheim, K. (1928/1952). The problem of generations. In: K. Mannheim, ed., Essays on the sociology of knowledge. London: Routledge \& Kegan Paul Ltd, pp. 157-185.

Martuccelli, D. (2017). La condition sociale moderne: L'avenir d'une inquietude. Paris: Gallimard.

Massey, D. (1991). A global sense of place. Marxism Today, June, pp. 24-29.

Melucci, A. (1996). The playing self. Cambridge: Cambridge University Press.

Morgan, G. and Idriss, S. (2012). 'Corsages on their parents': Employment and aspiration among Arabic-speaking youth in Western Sydney. Journal of Youth Studies, 15(7), pp. 929-943. doi: 10.1080/13676261.2012.683405.

Polanyi, K. (1944). The great transformation. New York: Farrar \& Rinehart.

Rorty, R. (1989). Contingency, irony, and solidarity. Cambridge: Cambridge University Press.

Rosa, H. and Scheurman, E. (eds.) (2009). High speed society. Social acceleration, power, and modernity. University Park, PA: The Pennsylvania University Press.

Sennett, R. (2008). The craftsman. New Haven: Yale University Press.

Shields, R. (2013). Spatial questions: Cultural topologies and social spatialisations. London: Sage.

Spivak, G.C. (1999). A critique of postcolonial reason: Towards a history of the vanishing present. Cambridge, MA: Harvard University Press.

Tomlinson, J. (1999). Globalization and culture. Chicago: University of Chicago Press.

Vertovec, S. (2007). Super-diversity and its implications. Ethnic and Racial Studies, 30(6), pp. 1024-1054. doi: 10.1080/01419870701599465.

Woodman, D. and Bennett, A. (eds.) (2015). Youth cultures, transitions, and generations: Bridging the gap in youth research. Basingstoke: Palgrave Macmillan.

Woodman, D. and Wyn, J. (2015). Youth and generation: Rethinking change and inequality in the lives of young people. London: Sage.

Wyn, J. and Woodman, D. (2006). Generation, youth and social change in Australia. Journal of Youth Studies, 9, pp. 495-514. doi: 10.1080/13676260600805713. 
Part I

Complexity 



\section{Learning (not) to labour \\ How middle-class young adults \\ look for creative jobs in a \\ precarious time in Italy}

\section{Lorenzo Domaneschi}

\section{Introduction}

The economic crisis that started in 2008 considerably affected young Italians, becoming part of their everyday life and a taken-for-granted frame of reference (Colombo and Rebughini, 2012). Compared with their peers in Europe, Italian young adults suffer from a higher unemployment rate and more persistent condition of precarious employment, which affects their everyday living conditions and their passage to adulthood (ISTAT, 2016). Such experience of job insecurity, the fragmentary nature of professional careers and the difficulty of achieving economic autonomy strongly contribute to setting a wider scenario of social changes that eventually creates 'a new generational location' (Colombo, Leonini and Rebughini, 2018, p. 62, emphasis in the original).

Hence, the starting hypothesis of the research presented here is that 'the crisis' is not just a temporary economic conjuncture; rather, it is a shared experience, the 'normal' context in which young people are about to accomplish their transition from school to work, from childhood to adult life (Cuzzocrea, 2011). Therefore, the crisis itself becomes a social phenomenon reshaping the social positions of individuals in both structural and subjective terms.

Nowadays, one relevant effect often highlighted by scholars and public opinion of such a 'new generational location' is an increasing distance between young people and public issues and the consequent uncertainty characterising youth's existential condition, with a weakening of their wider expectations and projects and a forced focalisation on private and present issues (Brannen and Nilsen, 2002). Nevertheless, volunteering and political activism outside institutional contexts are increasing among youth, and the economic crisis, instead of only pushing young people deeper into the realms of the 'private' sphere, also caused a proliferation in several of these forms of participation (Henn, Oldfield and Hart, 2017; Genova, 2018). Within such a frame, the chapter presents the case of a collective of students in Italy as an alternative small-scale form of political and cultural action and explores its dynamics and limits. While examining a particular form of youth activism in political squats, the chapter aims particularly to unpack the 'black box' of youth agency (Coffey and Farrugia, 2014) within the present structural context set by the economic crisis. 
Therefore, the main questions that guide this study concern how classical structural categories like gender and cultural capital work together in defining the structural gap between aspirations and actual potential, by a specific social group of middle-class millennials. Which sets of constraints and alternative opportunities are put back into play in the daily practices of middle-class young students? What is the experience and possibly reflexive re-interpretation according to different degrees of this structural gap?

In order to understand such issues, there is the need to look at the specific intersection of structural dimensions - gender, class and education - which generates different social locations (Anthias, 2013) that, in turn, create different constraints, opportunities and strategies. Accordingly, by intersecting gender and cultural capital, I aim to highlight the stratification internal to a generational location. Thus, I start by briefly introducing the question of youth agency and the role of intersectional studies in approaching such an issue. Then, I show how I drew on the seminal work by Willis as a sort of ante-litteram intersectional scholar in order to investigate middle-class young students in Italy. Finally, I present and discuss the main empirical findings coming from my field work, and I conclude by analysing how the precariousness produced by the incongruences between the school system and the labour market opens a surplus of space for reflexivity, hence a sort of sur-reflexivity ${ }^{1}$ which could become a specific resource in coping with the present frame of uncertainty.

\section{Youth agency, intersectionality and habitus fragmentation}

Agency is essential to one of the most considerable theoretical debates in contemporary youth sociology: 'the relationship between individualization . . . and contemporary youth inequalities' (Coffey and Farrugia, 2014, p. 464). Accordingly, a relevant issue in the way agency is frequently operationalised in the sociology of youth relates to issues on how the relationship between the subject and power is understood (Spencer and Doull, 2015). From this point of view, agency and structure are considered separate and opposed forces found in different portions of the social world and with different effects on the social organisation of everyday life. In this view, structure explains reproduction, whereas an autonomous creative agency explains social change, with Bourdieu (1990) and Beck (1992) being brought in to represent, respectively, the structural constraints and the creative agency of this dichotomy (Woodman, 2009). Eventually, the debate has led to the need to move outside simplistic distinctions between agency and structure and, following from this, to the call for increased dialogue between Beck's work and Bourdieu's positions (Farrugia, 2013).

In line with such a plea, it becomes particularly useful to adopt the intersectionality perspective (Crenshaw, 1989; Walby, Armstrong and Strid, 2012; Colombo and Rebughini, 2016) in order to cope with both the various structural dimensions and the individual agency. In fact, the possibility of analysing the articulation of 
structural categories such as class, gender and race/ethnicity - instead of considering them as independent and separate forms of power relations - is at the basis of the notion of intersectionality as 'an epistemological approach to domination' (Colombo and Rebughini, 2016, p. 439). This leads to expanding the theoretical and heuristic potential of intersectionality as an analytical tool, not exclusively related to the investigation of overlapping forms of oppression, but which also concerns the more general relationship between individual agency and structural determinants. In short, the aim is precisely to show how intersectionality can make a new contribution to the traditional agency/structure debate.

Despite differences and variations, the common theoretical claim of accounts of intersectionality is that different social categories mutually constitute each other as overall social structures as well as in creating composite identities. Structural categories such as gender, cultural capital and class are not parallel; they create each other and consequently cannot be examined separately. Converting this statement into the analysis of youth cultures allows us to think of the complexity of the shared social situation created by the frame of the 'crisis' as well as 'the complexity of their collective answers to their situation' (Jensen, 2018, p. 414). In a nutshell, it allows us to investigate the constraints and possibilities of a new generational location. Taken as an epistemological approach to domination, then, 'intersectionality may be useful for the analysis of not only the "matrix of domination" but also the "matrix of privilege" to show how any single categorisation only works in relation to other categorisations to produce a field of opportunities and constraints' (Colombo and Rebughini, 2016, p. 443).

In this broader - epistemological - sense, intersectionality may be usefully compatible with Bourdieu's sociology, in particular his view on the body and his idea of the habitus as socially conditioned embodiment (Jensen and Elg, 2010). Habitus is in fact both classed, gendered, ethnicitised and racialised. Thinking of the habitus as multidimensional and complex (that is, as simultaneously conditioned by different social structures) but also as the basis for practical agency (Bourdieu, 1990) seems fully compatible with this particular 'epistemological' approach to intersectionality.

A key register of the concept of habitus is, in fact, that it incorporates past experiences which are modified by present ones, as well as a sense of a probable future (Bourdieu, 1990). Yet, Bourdieu changed his presentations of the notion of habitus during his works: from earlier elaborations, where a unified habitus is prevalent, to later conceptions of habitus fragmentation (Silva, 2016). It then accounts for a plural interiority in tension with dissonances and fragmented belongings. This is a key theoretical connection with intersectionality: how the habitus incorporates differences and is transformed as the person relates to various fields both over time and simultaneously. The habitus 'helps to understand social change because it provides multiple locations to negotiate submission and defiance, adaptability and resistance' (Silva, 2016, p. 174). A challenge for the habitus in contemporary life is then integration, but integration is not solely made within a unit. It can happen from various units and present varied depth and texture in different cases and circumstances. 
In the case of young people of Generation Y (Strauss and Howe, 2006; Kelan, 2014), therefore, the research aims to investigate in what way this generation not necessarily in its most marginal positions - is positioned with respect to structural categories like gender and cultural capital: namely, how and how much they are more or less able to manipulate and reflexively managing such categorisation and how, at the same time, these intertwined categories contribute to define contexts in which these individuals are located. Hence, intersectionality is employed as an analytical approach to investigate how different 'structural categories' act not only by adding privileges or disadvantages but, above all, by defining the conditions for particular social locations (Anthias, 2013).

\section{Learning (not) to labour: the case of young middle-class activists in Italy}

The idea of generational locations (Mannheim, 1952; Woodman and Wyn, 2014), understood as a set of attempts at a solution, answer or response to a shared situation, did not necessarily imply an optimistic prognosis for such solutions. For example, resistance may be practiced in a way that actually strengthens the reproduction of class society. Such mechanisms, in fact, were the main theme of Paul Willis's seminal work, Learning to Labour (1978), that explicitly contains a sophisticated analysis of the relationship between youth agency and structural reproduction. He demonstrated that youth creative resistance against class dominance in school - a practice he termed counter school culture - in fact facilitated the reproduction of the overall class system and was part of what doomed working-class young students (the 'lads') to traditional, dreary sweatshop jobs. Willis argued that 'the lads' gained status from the construction of a tough and sexist masculinity in a situation where they were otherwise disadvantaged due to their class position (Willis, 1978). Thus, mixing and matching the effect of different social categorisations (class and gender), 'Willis' analysis may be considered an example of an intersectional analysis without the concept'. (Jensen, 2018, p. 415).

Hence, the inspiring work by Willis could be very useful in researching the present situation in Italy, especially the case of middle-class young millennials. In fact, if we look at the latest Istat report (2016), 62.5\% of young Italians between 18 and 34 years of age, the so-called Generation Y (Howe and Strauss, 2000; Kelan, 2014), still live with their parents, with a marked difference among women $(56.9 \%)$ and men $(68 \%)$, but above all a significant difference with the European average, which stands at $48.1 \%$. The most interesting aspect of this sociologically growing inequality, the effects of which seem to fall especially on the generation born between 1980 and 2000, concerns the impact from the initial structural conditions: according to Istat (2016), in fact, Italy is among the European countries where the advantage of individuals whose starting status is 'high' is greater; that is, at the age of 14 years they lived in a house owned and who had at least one parent graduated and occupied in a managerial profession. 
Therefore, the research aims to examine the particular generation of millennials (born between 1980 and 2000), as defined as a new shape of 'generation betrayed' (Bourdieu, 1979, p. 148) in which the gap between the aspirations produced by the school system and the actual possibilities it offers becomes a structural fact, that affects in a different way all members of a generation. This imbalance caused by such a structural gap between aspirations and possibilities nowadays assumes objectively and subjectively - different forms according to different social locations, particularly in the case of the middle-class young student.

If working-class kids, as shown by Willis, while showing capacity for innovation and agency, through opposition to the school they condemned themselves to a social destiny equal to their origin, we could ask what happens to middle-class young adults today within the frame of crisis. If school degrees do not guarantee the working and social position neither to the middle class, but rather produces more and more precariousness, how do the identities of the middle class reproduce themselves?

In order to analyse and map the different social locations of these youngsters positioned in the mismatch between the 'educational paradigm' and the prospects of precariousness in the labour market, the ethnographic tool, as again proved by Willis, is needed to grasp the daily living experience of these boys and girls. Accordingly, conclusions presented in this chapter arise from the author's longstanding ethnographic engagement with a group of 26 middle-class young students from 19 to 26 years of age (10 female and 16 male) in Milan, who squatted in an empty building in the city centre in order to create a brand new space of both political and artistic action, sharing skills and information with one another. In particular, for 11 months I engaged in participant observation (March 2017 to April 2018) and carried out in-depth interviews in order to uncover the rituals, practices and mentalities produced by the participants of this youth political and cultural space, and to understand how new subjectivities and collectivities might come into being.

Finally, in order to investigate the dynamics of their particular social location, I operationalised that into the dilemma about the possibilities and opportunities for planning their future: that is, to plan or not to plan (Devadason, 2008; Woodman, 2011). The search interest, in fact, is to investigate the dynamics of the particular kind of 'planning agency' at work in the moment of thinking about the future and imaging and projecting expectations and aspirations.

\section{Unpacking the black box of youth agency: six ideal typical profiles}

While the interviews and ethnographic transcripts were analysed using thematic analysis for commonalities, in this chapter I will not present the analysis, as is often the case, as a number of transcript excerpts from a selected part of the participants to illustrate each theme. Instead, as other scholars have already proved 
useful (Woodman, 2011; Franceschelli and Keating, 2018), I will present material from six participants in the form of a small case study on each using a number of extended quotations from the interview. Thus, I will illustrate the main themes using the narratives and cases of specific individuals who distilled the wider patterns apparent in the data. These case studies, along with contextual information about their everyday lives and practices collected through the ethnographic work, help us to shed light on the ways in which young people talk about their future and eventually make sense of the often-contradictory experiences of their lives.

The discussion of empirical findings through these six small cases brings to light the dual - and never dualistic - process of agency and structure; that is, the intersection of the categories of age, gender and cultural capital and the differentiation in the ability to manipulate more or less actively these social categorisations. To this aim, I will comparatively present two cases at a time, in order to highlight three different themes that clearly emerged from the whole narratives: (a) the dichotomy lying in their vision of future as a field of opportunity versus a general sensation of feeling stuck in the present; (b) the comparison with past generations; and (c) the feeling of an objective trade-off between achieving a 'structural security' and constructing a 'personal culture'.

\section{Marco and Filippo: on being young, male and educated}

When talking about their future expectations, all the participants started from their perspective on finding a job nowadays, in Italy, at the time of precariousness. Yet, particularly two of them, Marco and Filippo, ${ }^{2}$ described vividly the polarisation of such perspective. Both of them, in fact, were born in the same year (1996), they are both students in humanities and their parents are managers or professionals. Nevertheless, while Marco spent the first part of his childhood and his scholastic career in a suburb, Filippo lived all his life downtown and attended one of the better high schools in Milan.

When I asked Marco to explain something more about his hopes and expectations about the future, he offered a very nuanced way of thinking about the potentiality of what he called 'his generation' and the multiple institutional impediments on the way. According to him, in fact, only if you are given some 'personal resources', mostly from family and education, is there a chance to not 'remain stuck' where you are.

Many of my peers with which I shared schools when we were young . . . they didn't have the same possibilities . . . but I'm not talking about money or stuff . . . I mean ... it's not about economic resources . . it's more a sort of . . personal resources . . . being open minded ... my mother used to give me books to read since I was 3 ... and not everyone got such possibilities ... and when you live in some places with some dynamics ... I mean ... in the suburbs where I lived . . . well . . . from there you can't really go anywhere ... such neighbourhoods create a deep split between the ones that 
actually seek for a chance and maybe they could eventually work it out . . . and the ones that give up to their reality . . . and finally they start some random job and they will remain stuck forever in this loop ... you know ...

While Marco saw his view of the future as a possibility to escape from institutional weights and constraints that work to lock 'his generation' in the place of uncertainty and precariousness, Filippo proposed a quite different narrative about the future of his generation.

we are 20 years old now . . in a society in which it seems that if you're 20-something you're not of value . . . but we know we have skills . . especially in arts, music . . . and politics too ... and in this little lab we try to understand what we can do with such talents ... the fact is that ever since I was a child I've always been told that here in Italy . . . well . . . there is not work for us ... and you grow up thinking that as long as you're only a young man, you are not of value . . . then you start university, but you're still too young to be of value . . . and then maybe you get a degree, but you're still too young to make any difference ... well ... in such a place ... it's hard to think that the world is your oyster . . . you know what I mean? ... Yet, I'm 20 years old and I have in fact my life in front of me and it's now the time to really affect my life ... we must continue to do so even if we do not make a lot of money with this . . this does not matter to me.

Clearly, Filippo reflexively deconstructed the hegemonic discourse about his generation that is reported to be not yet ready to properly participate in the world. Eventually, he is able to manipulate the dominant categorisation about 'age' and to convert his actual location in a sort of reservoir of agency and creativity, where future becomes more and more a field of opportunities to catch than a cage of constraints to battle.

\section{Chiara and Loredana: on being part of a generation}

The strong feeling of being stuck in the present and the possibility of eventually overcoming such a constraint is often considered by young millennials to be a legacy of the past generation. In fact, Chiara and Loredana deal explicitly with such an issue. They are both born respectively in 1996 and 1995, and both their parents are professionals. While Chiara was attending a design school, Loredana was just concluding her first degree in philosophy and was about to start a master's degree program in performing arts.

Chiara highlighted how the fear and anxiety about the future are linked to the conversion of the labour market within a frame of precariousness and uncertainty. As she explained during the interview, while her parents could benefit from a guaranteed path from education to work, she and her peers suffer from a generalised anxiety because of the break of such a path. Chiara also finds herself 'split' in 
a sort of dilemma, between her confidence in her personal agency and her ability to work out everything she wants; and, on the other side, the structural and objective limitations she kept encountering in the real world.

when I compare mine with other generations . . well . . my parents simply got graduation at university and everything was easy ... Take philosophy for example ... my uncle got a degree in philosophy ... and then he worked all his life at Corriere della Sera [national newspaper] . . . I mean . . . he never suffer of any kind of anxiety . . . now . . . a lot of my friends studying philosophy ... they share the fear of the future... I can see a lot of people around me who are lost and anxious about their future ... and such a panic eventually locked them to the present ... so that they are not able to dream big. . . . To me ... I have conflicting opinions . . . on one side ... when I think about my future I feel like I'm doing well and sooner or later . . . I'll find a job or something ... I'm pretty sure I'll figure it out. . . Yet, when it comes to actually doing stuff . . . another part of me tells me exactly the opposite ... and eventually I find myself split in such a dilemma.

While Chiara experienced such a 'split' as an everyday condition of ambivalence, Loredana elaborated even more on the question of comparison between generations. In fact, she is able to handle the social categorisation about 'generation' and she separates the condition of anxiety and uncertainty from the definition of her generation, that is, of what it means to be young in this moment in Italy.

the thing with attending a humanistic course is that after a while . . . it's natural to feel stuck . . . but that's only because we, as a generation, are used to live in the family longer and longer . . . and this gives us a point of view which is not ours ... It's still the one of our parents . . so we often look at our future with those eyes ... that are not the eyes of the contemporaneity ... and this thing ... I mean ... looking at my future through my mother's anxiety . . . it drives me crazy . . . in fact . . . if I consider what today actually represents to me ... it doesn't look so terrifying . . . we often carry on what are in fact the fears of the past generation . . like ... 'have you already find a full time job?' but what if I don't want that? . . there is a generalized anxiety which is inherited from our parents that influences too much our choices ... and it has to be overcome . . I I don't know how but I really think we're in a middle of a fight between us and the anxiety of those who came before us.

Through her reflexivity on her actual generational location, Loredana actively rearranged the meaning of precariousness and future uncertainty, attributing such perspective to the vision of the past generation more than to hers. Yet, as she states at the end of the extract, this does not mean that the ambivalence ('the fight') between feeling stuck in the present and viewing opportunities is solved; rather, 
it moves the issue of fragmentation from the structural gap between school and the labour market, towards the reflexive redefinition of her generational location.

\section{Serena and Nadia: on being young, female and educated}

A very similar perception of ambivalence can be found also in the case of gender, as the two cases of Serena and Nadia, both born in 1994, help to illustrate. While Serena's parents have working-class jobs, Nadia's parents work as artists in the film industry. While Serena is studying law at the university, Nadia works at a big multinational fashion company.

During the interviews, both of them told me about the feeling of a trade-off between what they could find after school in the labour market and what they are interested in doing in their personal life. Yet, such a trade-off is experienced quite differently from the two girls, exactly in the way they experience their gender. In fact, Serena explicitly questions the dominant gendered categorisation of females in the labour market and highlights how she feels the need of 'something else' outside the labour market, in order to become what she aspires.

It scares me a lot . . I mean really . . . it scares me thinking that if I want to work in something near to what I'm studying I will need to go away ... from Italy ... I mean . . . I worked since before starting university . . but when the only job you can find is to be a hostess ... I mean . . . take my word . . a as a girl, sure there is few things worse than doing that job ... even if you're doing it for a serious company and you're not dressed up like a sort of doll ... I mean . . . the job would be to stay still, to shut up and that's it . . I mean . . . what is it? ... we're ending up building a generation of waitress, hostess and fashion lovers . . . right now, relying only on institutional supports like university or high schools, it's simply not enough anymore, it can't make you a person out of yourself... that's why we need something else ... that's why we start this lab.

In Nadia's case, the question of gender is not so explicit. Nevertheless, the tradeoff between her personal agency and contradictory structures is even more deep. What is at stake is something more than a structural gap between her subjective aspirations and the objective solutions offered by the institutions.

Right now ... I'm taking a road . . I mean . . . I now work in the fashion system . . . they hired me . . . so . . . well . . I don't know . . it's not that I don't like it ... it's just that Ifeel the contradiction between my personal life project in the fashion system . . . and what I'm doing here . . . at Lume . . . in fact ... since recently ... I never told the guys that I was studying fashion ... . and I always thought I needed to choose between working in the fashion system and political participation ... but now that the fashion people hired 
me for a full time job ... I think at a personal level I would keep working there since I love it and it let me to pay the rent, but at the same time I would save my moral integrity keeping working here ... and maybe eventually even combining the two worlds ... that would be what I really want to learn.

All in all, 'the contradiction' she feels 'at a personal level' concerns the possibility to keep working in the fashion field, as it fulfils her personal desires as a girl; and, at the same time, being an activist in the artistic laboratory, as it fulfils different ambitions of her being a girl. In the end, as she neatly states, her main aspiration is to be able to 'combine' the 'two worlds', which means to be able to live what she feels as an ambivalence, without solving it anyway.

\section{Conclusion}

In his landmark study of working-class youth in England, Willis (1978) offered keen insight into the process through which working-class students, the 'lads', creatively set up an experimental counter-school culture, penetrated the dominant ideology and eventually disqualified themselves from anything but working-class jobs. Willis's study is in fact a benchmark for understanding the processes of social reproduction for the working class. Less understood, however, is the process through which middle-class youth engages with the same 'educational paradigm' from which the 'lads' tried to escape.

As the previous extracts have shown, the internal divisions and contradictions that Willis was keen to highlight in the practices of working-class youth can be found also in middle-class processes of identity formation (Kaufman 2003). Thus, while social categorisation like gender, generation and cultural capital certainly act as constraints and contribute to defining the specific social location of middleclass young students, at the same time, such categorisations could be actively manipulated and handled by this particular group of young people, contributing to redefine the boundaries of the same social location.

In particular, three main themes could be underscored. First, social identity of these middle-class young students is constructed against the 'educational paradigm' very much like in the case of working-class youth; yet, in this case, the frame of reference for their social identity is searched and found outside the labour market. The research findings show, in fact, that middle-class young adults opposed to the neoliberal aesthetics and discourse of hard work and discipline (Franceschelli and Keating, 2018) find in the scholastic institution a discourse of creativity and talent, and a mechanism of conversion from the constraints of precariousness into opportunities for creativity and cultural innovation.

Second, as the discussion of interviews has proved, there is a strong situational management of generational, educational and gender contradictions. Uncertainty is a structural factor in the contingency which millennials have to deal with. Despite cultural capital and gender structurally affecting the possibilities in planning about the future and creating aspirations, however, the research indicates 
that more relevant than possessing such resources is the practical possibility of activating them. Hence, the active management of contradictory structures (like family, school and work) can be driven by a different particular intersection of dispositions (like age, gender and cultural capital) which in turn leads to engagement with practical strategies towards complexity and uncertainty.

Third, the particular change of perspective at work in this specific case of middle-class young activists who look outside the labour market in order to find the resources to construct their social identity is in fact made possible thanks to the exceeding space of sur-reflexivity, so to speak, opened by the same fragmentation of the habitus generated by the precariousness produced by the incongruences between the school system and the labour market. This creates the possibility of reflexive strategies for habitus integration (Silva, 2016), which guarantee to keep the ambivalence without going back to any unity.

In conclusion, returning to the more general and core sociological issue of the power balance between agency and social structure, two specific spaces for research could be identified: to develop the potential of applying an intersectional approach to the field of youth cultures, and to identify new areas of empirical research in this sub-field; to call in question the category of millennials as a generation itself, to show how this category is in fact unable to grasp the different situations socially experienced by different components of the current young generation.

\section{Notes}

1 I rephrase such a term from the well-known definition of 'sur-modernitè' by Augè (1992) in order not to highlight the supremacy of such a reflexivity over others, instead aiming to show the 'exceeding' part of the such an agency.

2 All student names are pseudonyms.

\section{References}

Anthias, F. (2013). Hierarchies of social location, class and intersectionality: Towards a translocation frame. International Sociology, 28(1), pp. 121-138.

Augè, M. (1992). Non-Lieux: Introduction à une anthropologie de la surmodernité. Paris: Seuil.

Beck, U. (1992). Risk society: Towards a new modernity. London: Sage.

Bourdieu, P. (1979). La distinction, critique sociale du jugement. Paris: Les Editions de Minuit.

Bourdieu, P. (1990). The logic of practice. Cambridge: Polity Press.

Brannen, J. and Nilsen, A. (2002). Young people's time perspectives: From youth to adulthood. Sociology, 36(3), pp. 513-536.

Coffey, J. and Farrugia, D. (2014). Unpacking the black box: The problem of agency in the sociology of youth. Journal of Youth Studies, 17(4), pp. 461-474.

Colombo, E. and Rebughini, P. (2012). Children of immigrants in a globalised world: A generational experience. Basingstoke: Palgrave Macmillan.

Colombo, E. and Rebughini, P. (2016). Intersectionality and beyond. Rassegna Italiana di Sociologia, 3, pp. 439-469. 
Colombo, E., Leonini, L. and Rebughini, R. (2018). A generational attitude: Young adults facing the economic crisis in Milan. Journal of Modern Italian Studies, 23(1).

Crenshaw, K. (1989). Demarginalizing the intersection of race and sex: A black feminist critique of antidiscrimination doctrine, feminist theory, and antiracist politics. University of Chicago Legal Forum, 140, pp. 139-167.

Cuzzocrea, V. (2011). Squeezing or blurring? Young adulthood in the career strategies of professionals based in Italy and England. Journal of Youth Studies, 14(6), pp. 657-674.

Devadason, R. (2008). To plan or not to plan? Young adult future orientations in two European cities. Sociology, 42, pp. 1127-1145.

Farrugia, D. (2013). Young people and structural inequality: Beyond the middle ground. Journal of Youth Studies, 16(5), pp. 679-693.

Franceschelli, M.F. and Keating, A. (2018). Imagining the future in the neoliberal era: Young people's optimism and their faith in hard work. Young, 26(4S), pp. 1-17.

Genova, C. (2018). Youth activism in political squats between centri sociali and case occupate. Societies, 8(3), p. 77. Available at: www.mdpi.com/2075-4698/8/3/77/htm.

Henn, M., Oldfield, B. and Hart, J. (2017). Postmaterialism and young people's political participation in a time of austerity. The British Journal of Sociology. Available at: https:// onlinelibrary.wiley.com/doi/abs/10.1111/1468-4446.12309.

Howe, N. and Strauss, W. (2000). Millennial's rising: The next great generation. New York: Vintage Books.

ISTAT. (2016). Rapporto annuale 2016. La situazione del Paese. Rome: Istituto nazionale di statistica.

Jensen, S.Q. and Elg, C. (2010). Intersectionality as embodiment. Kvinder, Køn \& Forskning, (2-3), pp. 30-39.

Jensen, S.Q. (2018). Towards a neo-birminghamian conception of subculture? History, challenges, and future potentials. Journal of Youth Studies, 21(4), pp. 405-421.

Kaufman, L. (2003). Learning to not labor: How working-class individuals construct middle-class identities. The Sociological Quarterly, 44(3), pp. 481-504.

Kelan, E. (2014). Organising generations - what can sociology offer to the understanding of generations at work? Sociology Compass, 8(1), pp. 20-30.

Mannheim, K. (1952). The problem of generation. In: K. Mannheim, ed., Essays on the sociology of knowledge. London: Routledge \& Kegan Paul Ltd, pp. 276-322.

Silva, E.B. (2016). Unity and fragmentation of the habitus. The Sociological Review, 64(1), pp. 166-183.

Spencer, G. and Doull, M. (2015). Examining concepts of power and agency in research with young people. Journal of Youth Studies, 18(7), pp. 900-913.

Strauss, W. and Howe, N. (2006). Millennials and the pop culture. Strategies for a new generation of consumers in music, music television the internet and video games. Great Falls, VA: Life Course Associates.

Walby, S., Armstrong, J. and Strid, S. (2012). Intersectionality: Multiple inequalities in social theory. Sociology, 46(2), pp. 224-240.

Willis, P. (1978). Learning to labor: How working-class kids get working-class jobs. New York: Columbia University Press.

Woodman, D. (2009). The mysterious case of the pervasive choice biography: Ulrich Beck, structure/agency, and the middling state of theory in the sociology of youth. Journal of Youth Studies, 12(3), pp. 243-256. 
Woodman, D. (2011). Young people and the future: Multiple temporal orientations shaped in interaction with significant others young. Nordic Journal of Youth Research, 19(2), pp. 111-128.

Woodman, D. and Wyn, J. (2014). Youth and generation. Rethinking change and inequality in the lives of young people. London: Sage. 


\title{
Negotiating reality through the prosumption of the 'unreal' self Young people's identities in an age of economic precarity
}

\author{
Konstantinos Theodoridis, Steven Miles \\ and Kevin Albertson
}

\section{Introduction}

In what follows, we address the relative effect of the economic crisis on the changing nature of consumption. In particular, we emphasise the need to recognise the ways that young people adjust when a primary source of their identity construction has been negatively affected by the economic hardships caused by prolonged austerity. Since the onset of the global financial crisis, young people's everyday lives have been characterised by extreme levels of uncertainty across countries and regions (Cairns, 2014). Such uncontrollable situations and 'manufactured risks', which undermine the certainty of everyday life, according to Ulrich Beck (1992), sit at the very heart of our everyday experience of a so-called risk society. For young people, the implications of a risk society are expressed by a state of affairs in which the complexities and uncertainties of the world increasingly threaten their personal sense of well-being. This is perhaps best expressed as a breakdown of 'normal biographies' (Furlong and Cartmel, 1997).

The impact of the economic crisis upon young people in Greece, and specifically the capital city of Athens, has been profound. Young people's lives have been affected in unprecedented ways during the social, economic and political crisis of the last years (Triliva, Varvantakis and Dafermos, 2015). The conditions have resulted in the creation of a newly emerged social stratum consisting of underpaid youth apparently living in a state of precariousness (Kretsos, 2014). In this chapter we consider qualitative data emerging from a series of focus groups that were designed to consider the relationship between young people's consumption in Greece and their efforts to construct identities in an age of precarity.

Given that most young people have grown up in a digital world, it is likely that most are active Internet and social media users, keeping pace with the practices of their generations as digital citizens (Buckingham and Willett, 2013). Indeed, young people are the early adopters of such technology (Lenhart et al., 2015). Thus, over the past decade, social networking sites (SNS), or alternatively, social media (Papacharissi, 2015), have become a space for negotiating various aspects 
of young people's identities. As social media use has expanded, young people have come, in response, to rely on it for the presentation of the self and for the active, contemporaneous performance of self (Hogan, 2010). This raises questions about how young people use their social media profiles under precarious economic and social circumstances. In particular we are concerned with the purpose of shared videos and photos which might be used, for example, to highlight the impact of risk, or rather more instrumentally, to create an impression of continued affluence during a period of economic downturn.

\section{From consuming goods to consuming social media: constructing coherent biographies}

For many years, sociologists have considered the role of consumption as a context for the creation of meaning and strategies for the construction of the self (Friedman, 1994). This meaning-making process is implied in the work of Campbell (1987), who argues that individuals emerge without having an already ascribed identity. In this way, in his analysis of the consumer revolution, Campbell suggests that it is important to shed light upon the complexity of how the nature of demand is shaped by individual actions. In the context of social media, for example, the audience to 'the show' is effectively absent, and applause is delivered in the number of 'likes' one is paid for one's consumption choice. Thus, we can begin to think of consumption as, what is in effect, a presentation of lifestyle, although one that is not the only form of enacted self-improving optimism. Photoand video- sharing social media platforms can thus be argued to be the "minicathedrals of consumption' of our age.

If we accept that consumption constitutes a vehicle for the construction of potentially meaningful identities and that consumption provides a key resource that helps the individual construct a stable sense of self, it remains unclear how such a vehicle can be maintained in a risk society (Beck, 1992) where consumption resources are limited. Online forms of self-representation clearly tell us something profound about the changing nature of consumption (Marwick, 2015), but the most potentially beneficial line of enquiry is best focused on the way in which online representations of self, composed of 'moments of being', can substitute, to some extent, for the reality of consumption. Such moments may perhaps be less about the reality of someone's life and may rather reflect their aspirations in this regard.

Under the gaze of their peers on social media, young people may be motivated to compete in how it is they present themselves from one moment to the next. Such moments may simultaneously buttress close relationships and increase feelings of trust and belonging (Bayer et al., 2016). In this sense, the virtual arena in which young people consume, and thus young people's consumption in general, is more liable to be about impression management than it has ever been before: the power to empathise some aspect of consumption, to neglect to mention others; the power, to an unprecedented degree, to control one's own brand. 


\section{Young people and social media platforms}

Young people can be said to be engaged in a continuous effort to represent the self (Livingstone, 2008), and visual representations of self and the comments and appreciation they attract play a perpetual role in shoring up an individual's sense of who and what it is they are. Meanwhile, as van Zoonen (2013) suggests, there is not a singular representation of the self, but many different and fragmented aspects of it. Social network sites provide an environment in which such diversity can, in theory, thrive, as Lincoln and Robards (2014) point out in their discussion of Facebook, a social network site which has already achieved 10 years of operation. Yet, it may be that the competition for 'likes' will rather drive the user towards a uniform and non-challenging presentation of the self.

The new digital tools that are broadly used in content-sharing platforms provide the flexibility and control that individuals utilise to modify both their public and private identities (van Dijck, 2008). Moreover, Tiidenberg and Baym (2017) demonstrate that, in the discourse of buying, and of commenting on the images demonstrating appropriate consumption choices, social media provides a platform upon which the appearance of excess can be effectively celebrated. Instagram is potentially especially effective in this regard, not least given the fact that $50 \%$ of young people use it (Duggan et al., 2015). But the key to an understanding of the role of social media in a so-called Network Society (Castells, 2010) and its impact on young people's identity construction lies in the question of why elements of the fragmented self are played out through the spaces that social media provides.

Papacharissi, Mendelson and Papathanassopoulos (2011) specifically consider photo galleries as a tool of self-representation and as a way to maintain biographies online. They focus on the Facebook profiles of college students in order to understand why young people use the photo 'tagging' via a collage of personal images as a practice of self-reflection and identity construction. It is by no means unusual today, for example, for young adults to incorporate multiple hashtags and to 'tag' others as a key part of their online social media activities. The multiplicity and the plurality of hashtags signifies feelings, emotions, situations and identifies relations among peers. In addition, boyd (2014) points out that it is through social media platforms that young people have been able to construct their own 'networked publics'. In this way, teens have established a space within which they are able to gather and socialise in a way which does not conform to specific elements of formality and conformity.

\section{Choice profile as an expression of 'choice biographies'}

In modern times, one of the main assumptions about our experience of everyday reality is that it is transforming at a rapid rate. What used to be static in terms of the rhythms of life experience has now apparently been superseded by a 
fragmented temporality. This increases the ephemerality of phases of the 'project' and moments of the life course. For instance, 'InstaStories', a feature which enables the user to share photos or videos which disappear after 24 hours, provides impermanent moments of desirable biography, a biography which may or may not accurately represent the reality of everyday life. Due to their fragmented nature, such stories have to be constantly reinvented in favour of new ones which take on significant meaning in the context of the individual's lived reality. Here, it is equally important to focus on the experiences of young people as 'creators' and 'curators' when it comes to their social media usage. The active creation and management of their profile represent constant work for the citizen consumer (Soper, 2007). It follows that young people are being reconstructed as 'prosumers' (Ritzer and Jurgenson, 2010) insofar as they are producing and consuming in building their online profiles and biographies. In so doing, they not only consume social media, they reproduce it; social media thus becomes the stage on which one's life is played out.

It is difficult to try to analyse new periods of life and transformations which are realised by today's young people without using the term 'choice biography' (Furlong and Cartmel, 1997). For du Bois-Reymond (1998), 'choice biographies' are a product of the friction between the freedom of choice and the coerced selection of the most socially suitable. Today's young people face changes in their life course which have affected their transitions moving from linear to non-linear and reversible. A similar mode of transition has affected the process of consumption. The structure and content of consumption has changed from 'normal consumption' - that is, where the act and its conspicuous representation occur sequentially or simultaneously - to 'choice consumption'. Moments of consumption and their representations are no longer linear. Not every moment of consumption becomes simultaneously a moment of self-representation; a moment of consumption might be more valuable to the profile of a user after some time. The representation of conspicuous consumption can be, effectively, 'banked' for later use. Reflection, not on consumption itself but on how the portrayal of it is received, is, rather, an ongoing part of the experience. Consumption itself is commodified; it is presentation that counts. The uploading of a photograph, for example, is as identity-supporting as a new purchase or the night out that the photograph depicts.

Against this increased use of social media, we must also consider that young people today, and not least in Greece, are facing many changes arising from the 2008 economic crisis. These may adversely affect their ability to consume in the traditional sense. For example, they are less likely to be in a position to follow their career aims due to structural problems associated with the labour market. Such pressures leave young people in a precarious position. On the one hand, they are culturally compelled to reproduce the lifestyles of previous generations; on the other, they are forced to adapt to the new economic reality of precarity (Standing, 2014), instability, badly paid jobs and uncertainty. The reality is that, even as consumption plays a progressively more significant role in how young people see themselves, its realisation is threatened by the impact of social and 
economic change in their everyday lives. Its representation might not, however, be so threatened.

\section{Young people in an empirical context}

We choose to undertake focus groups as a means of addressing the changing ways in which young people in Greece are consuming at a time of technological freedom and yet of economic constraint. Given that social media operates in such a thoroughly cultural context in which personal and social meanings are negotiated, focus groups were considered to be the most appropriate tool. The sample we interviewed were effectively post-adolescent: none of them were married or had children. The key priorities for the young people we interviewed included having a job, seeking opportunities abroad, achieving aspirations online, family, flexibility and success. The role of social media is to provide a space in which young people can assert their sense of identity through consumption in such a way that the uncertainties and frustrations they experience in these other elements of their lives can be at least partially offset by the admiration that representations of conspicuous consumption provide.

A number of our interviewees expressed difficulty in recognising the symptoms of the economic crisis. Evidence of crisis is, of course, statistically clear. For example, in 2015 youth unemployment rates reached around 50\% (ELSTAT, 2016). However, some of the participants spoke explicitly about the way, on the one hand, that everybody talks about the economic crisis, and yet at the same time they can see that many 'places of consumption', such as bars, cafeterias and restaurants, remain full to the brim. Following this, a participant questioned how it is so many people can afford iPhones and keep going to shops. Many of them queried whether any such crisis actually exists. Vicky (21) questioned whether she is the only one who cannot see the crisis:

I might not see the crisis. It might be the case that the neighbourhood where I live isn't the appropriate area but I think that consumption hasn't been reduced but it is increasing.

Many participants recognised that their generation's economic prospects will not change for the better, either during the crisis or after, and that, as a result, realising similar consumption patterns as parents is, in general, less likely. The discussion around the variation in representations of excess in consumption between generations continues to be a central concern. Iole had the impression that when it comes to consumerism, young people about her age engage rather more than older generations. Antigone explained this as a form of inconsistency:

I believe that the crisis has hit more older people and at the same time, young people behave as they can't see it, as. ... And their choices are specific and related to their image. 
Many authors have discussed the performative nature of image in the construction of young people's identities. For Marwick and boyd (2011), for example, young people are the group most likely to exercise and interact with multiple audiences in order to 'improve' their personal brand. From this point of view, self-branding and micro-celebrity can be identified as prevailing types of youth 'attitude' (Marwick, 2015). In order to belong, young people must pay close attention to how they are perceived, not least by their peers. Antigone claimed that there is a new mentality among youth, but not to the extent that they take responsibility for the crisis. In short, young people's relationship to consumption, far from being reduced as part of the material conditions associated with the economic crisis, are actually playing a more prominent role in how they see themselves. Thus, Antigone describes a young man's consumption of an iPhone as a way that he can prove himself. The fact he is able to do so despite the crisis makes what the iPhone signifies more powerful than ever.

The consumption of mobile phones was a recurring theme in our data collection, and respondents referred to the compulsion for young people to buy the latest mobile phone just so that they are seen to buy it. So Chris, for example, makes a comparison between himself and 'irrational' consumers, who apparently buy technological devices without a reasonable logic for doing so. Yet, Chris also spoke about how he planned to save money for a year in order to get his new mobile phone when it entered the market. Clearly, competitive portrayals of consumption play a key role in how young people assert their status, and ideally as soon as new technology comes onto the market. While buying an expensive car or getting on the housing ladder is something of an impossible dream for young people, the constant quest for innovation and other technological devices signifies their intention to display relative affluence during times when people more generally are prioritising their essential needs while making more considered economic choices. Consumption plays a similar role for young people today, but it does so in more of a reactive than a proactive fashion. In this respect, young people are what Bauman (2007) calls 'flawed consumers'. They are defined through consumption, but their relationship with it is about survival. Where 'belonging' is beyond their financial means, to avoid not belonging becomes the goal.

\section{Social media representations and consumption: the shaping of the consumer self}

Antigone, a 21-year-old Greek student who works as a dance teacher, spoke about her friends and how they have to keep buying new clothes for going to nightclubs in order to take pictures, upload them to their profiles and finally succeed in their ultimate goal, that is, to get more likes on their social media platforms. This reflects the fact that for young people, it is the online representation of the event, rather than the event itself, in which the significance lies. The purchase of new clothes provides a rationale for posting pictures and thus provides a vehicle for attracting more viewers, followers and 'likes'. In this sense, consumption 
provides a means to an end; to feel one belongs to the group through the status that such 'likes' engender. Yet such 'likes' are social media history tomorrow. This motivates the ongoing quest for the innovative:

INTERVIEWER: Are there any examples of people like your friend who buys something new just for the sake of uploading a photo and get more likes?

ANTIGONE: Yes, of course!

GEORGE: Everybody!

CHRIS: Too many people!

VICKY: Yes!

ANTIGONE: Yes, because she will upload the photo and then she is not going to wear it again, just after one year. [. . . She will wear it and then won't use it for a long time, she will buy new stuff.

Despite a level of exaggeration in the last statement as regards the length of time until the item will be used again, there is a consensus that this is a common practice amongst young people's peers. Moreover, young participants' increasing emphasis on the way that they experience their entertainment has changed what it means to go on a night out. For example, Chris mentioned how young people would previously have gone but without the focus on taking selfies for the sake of their public profile (Tiidenberg, 2016). On this point, Chris was absolutely clear and made a kind of self-criticism after a moment of reflection:

I might sound a bit like a grandfather now, but in the past, there wasn't a 'selfie time' or that this photo goes so well on Instagram and it will get 200 million likes.

In discussing going out, the young adults we interviewed said that from the total number of hours that they spend in a club, five as they estimated, they were likely to spend at least two of those hours on their mobile phones. Our respondents also talked about friends who 'lived for likes' and for social media appraisal. When they speak about it, they have in their minds specific friends who are dependent on the 'performance' of their online profiles. So, for example, a friend of Chris's puts so much emphasis on how he represents himself online that he actually feels depressed when a photo doesn't 'perform' very well and he can spend days reflecting on how he can best improve his self-production in this regard.

There are several interesting aspects about the use of social media representations in the context of the choices young people make as regards their individual biographies. Iole speaks about how social media structures and improves one's social position. It provides 'evidence' that young people can apparently afford a specific lifestyle and are relatively comfortable financially. Our respondents talked about how some of their friends go to specific bars and cafes and that these reflect a particular lifestyle. They characterise these fellow consumers as 'normal' people, like them, but who try to communicate their choices through what is a 
more glamorous lifestyle. As we have noted, conspicuous consumption, in this case through its ostentatious online representation by young people in Greece, plays a role even at times of genuine economic crisis.

\section{Following the rules: ephemerality and the 'unreal'}

The process which young people follow in order to upload videos and photos and to share their experiences on social media platforms is complicated and abides by specific rules. This process effectively constitutes a freely available form of consumption designed for the promotion of self. What is important here is that this self does not exist in reality; it serves only to imply the reality a young person wishes to present. This brings us to the question of what can be defined as 'real' and 'unreal' in this context.

Take for example Chris (21), who talked about staying at home and playing online games with his friend. His friend is a person who we could characterise as being addicted to the 'logic of likes'. This friend constantly interacts with an 'unreal' world through $24 / 7$ access to someone else's private life through multiple devices and platforms. For example, Chris's friend's passion and addiction to social media engagement led him to upload a picture of himself near the beach, supposedly taken at a time shortly after they had stopped playing e-sports and talking on Skype. Chris knew that his friend was, in fact, at home at the time. In fact, his friend had taken this picture two days previously and simply saved it up to post later, thus effectively digitally time-managing the self. It was apparently not just the beach trip, but the timing of it which was important in this case. The notion of 'unreality' or 'semi-reality' sits at the core of our analysis in the above respect. The performances that young people engage in is, in part, a form of 'impression management' (Goffman, 1959), and the degree of effective management that is possible, in turn, is dependent upon how 'of the moment' the particular social medium may be; our respondents commenting, for example, on the decline of Snapchat.

Another interesting example of how young people's constructing a parallel reality in their 'consumer persona' plays a key role is through personal relationships. For example, one respondent described how a couple went on holiday abroad and uploaded many pictures in which they apparently expressed their love for each other. Yet on her return, the friend telephoned in tears to explain that everything was not good between them. With unintended irony, Antigone put it, 'the reality on Facebook is totally different'.

Despite the knowledge that they themselves manipulate the presentation of their consumption experiences, many young people seemed unaware that others would do the same. For example, many of those we interviewed discussed the pressures that young people were under to go out and to be seen to be going out. One of our participants discussed her experience of staying home on a Saturday night. She describes how she made a conscious decision not to go out. But when she saw her friends' shared videos and 'InstaStories', a wave of disappointment 
came over her. Similarly, a male participant talked about his decision not to go out to a club. He expressed his disappointment to his friends about not going out with them. However, he was surprised when they claimed that they had not had a good time after all despite what appeared online to be a great night. He joined them the next time they went out but ended sitting alone near the beach checking his phone for the whole evening. For him, the night was an 'absolute disaster', and yet the posted videos suggested something altogether different. There is evidence here of social conformity. As a young person, it appears that you are simply obliged to upload momentary expressions of good time and happiness. You cannot admit that a night out was a failure, as to do so would reflect entirely negatively on how you will be perceived by others and, indeed, how you perceive yourself.

This misrepresentation/falsification of reality also happens in the case of shopping. Several of the participants offered examples of their friends going to a clothing store to try new clothes and taking pictures in the fitting rooms. These pictures were subsequently uploaded, thereby creating the impression that the items concerned were purchased, which, in fact, they were not. A similar example is the case of a group of friends going out to shop. One participant described how some of her friends took pictures with many bags, implying that she had spent a lot of money. The reality was that she had bought just one item, and all the other items actually belonged to her friends. In this way, young people manipulate social media as a means of presenting a fake reality to propagate the values with which young people wish to be associated. The question here, though, is really, who is manipulating whom? Of course, young people may experience happiness and excess during moments of consumption. In such cases, social media is used as a means by which young people confirm, validate and magnify these moments of consumption. Consumption choices are no longer validated and justified through word of mouth. The validation of successful 'consumption-choices' which fit in with an individual's overall biography must happen online if the person is to succeed in the social media market-place, where success is evidenced by 'likes'.

We must bear in mind these conversations took place in a country and a city, namely Athens, which has been tremendously affected by the disastrous effects of an economic crisis the like of which has not been seen in Europe since the end of World War II. In this context, our participants admitted that the excess they present via social media is a necessity insofar as consumption can continue to be signalled, even when its costs are being reduced. It is in this sense that they argue that evidence of the crisis simply does not exist on Instagram.

INTERVIEWER: Can you see elements of the economic crisis on Instagram? IOLE: It isn't there.

VICKY: Instagram doesn't show the crisis.

CHRIS: On Instagram I do not want to show my problems, I want to show that I don't have any!

VICKY: That's it.

IOLE: Everything is perfect. I don't know what you do, but I'm perfect. 
The reality of these young people's lives is that the sense of choice that they have feels broad in its scope. Consumption gives them a sense of ownership of their self-branding. But ultimately, the fact that they are obliged to define themselves in this way means that they will always be disappointed: they will never reach the point of satisfaction.

\section{Conclusion}

This chapter has begun to interrogate the interconnection between a consumerist and a social media logic, or, put another way, the complementary narratives of consumption and social media representations and the critical idea of ephemerality in the conceptualisation of the prosumer self. It is clear young people may exercise agency and reap the benefit of choice through the online management of the self. However, while social media simply makes more choices available regarding the avenues of self-representation that are available for them to prosume, in doing so, it limits that choice. It ties young people even more closely to the orthodoxy of consumption and specifically to the notion that the authenticity of the self can be established through the means by which that self is represented. The financial crisis accentuates the role of social media as a financially viable option in a world that otherwise limits the choices young people have as 'flawed consumers' (Bauman, 2007). Thus, young people have little choice but to represent themselves through their online 'consumer persona'. Such a persona provides them with some semblance of stability; but by buying into the appearance of stability, they defer the need to deal with the very instability from which they seek to escape.

\section{Acknowledgements}

Konstantinos Theodoridis's contribution was supported by a scholarship from the Alexander S. Onassis Foundation, Greece.

\section{References}

Bauman, Z. (2007). Collateral casualties of consumerism. Journal of Consumer Culture, 7(1), pp. 25-56.

Bayer, J.B., Ellison, N.B., Schoenebeck, S.Y. and Falk, E.B. (2016). Sharing the small moments: Ephemeral social interaction on snapchat. Information, Communication \& Society, 19(7), pp. 956-977.

Beck, U. (1992). Risk society: Towards a new modernity. London: Sage.

boyd, d. (2014). It's complicated: The social lives of networked teens. New Haven: Yale University Press.

Buckingham, D. and Willett, R. (eds.) (2013). Digital generations: Children, young people, and the new media. London: Routledge.

Cairns, D. (2014). 'I wouldn't stay here': Economic crisis and youth mobility in Ireland. International Migration, 52(3), pp. 236-249. 
Campbell, C. (1987). The romantic ethic and the spirit of modern capitalism. New York: Basil Blackwell.

Castells, M. (2010). The rise of the network society. Vol. 1. Oxford: Wiley-Blackwell.

Du Bois-Reymond, M. (1998). 'I don't want to commit myself yet': Young people's life concepts. Journal of Youth Studies, 1(1), pp. 63-79.

Duggan, M., Ellison, N.B., Lampe, C., Lenhart, A. and Madden, M. (2015). Social media update 2014. Pew Research Center, 19.

ELSTAT (Hellenic Statistical Authority). (2016). Labour force survey: 1981-2015. Available at: www.statistics.gr/el/statistics/-/publication/SJO03/-.

Friedman, J. (1994). Consumption and identity. Vol. 15. Chur: Harwood Academic.

Furlong, A. and Cartmel, F. (1997). Young people and social change: Individualization and risk in late modernity. Buckingham: Open University Press.

Goffman, E. (1959). The presentation of self in everyday life. New York: Penguin.

Hogan, B. (2010). The presentation of self in the age of social media: Distinguishing performances and exhibitions online. Bulletin of Science, Technology \& Society, 30(6), pp. 377-386.

Kretsos, L. (2014). Youth policy in Austerity Europe: The case of Greece. International Journal of Adolescence and Youth, 19(supp. 1), pp. 35-47.

Lenhart, A., Duggan, M., Perrin, A., Stepler, R., Rainie, H. and Parker, K. (2015). Teens, social media \& technology overview 2015. Washington, DC: Pew Research Center (Internet \& American Life Project).

Lincoln, S. and Robards, B. (2014). 10 years of Facebook. New Media \& Society, 16(7), pp. 1047-1050.

Livingstone, S. (2008). Taking risky opportunities in youthful content creation: Teenagers' use of social networking sites for intimacy, privacy and self-expression. New Media \& Society, 10(3), pp. 393-411.

Marwick, A.E. and boyd, d. (2011). I tweet honestly, I tweet passionately: Twitter users, context collapse, and the imagined audience. New Media \& Society, 13(1), pp. 114-133.

Marwick, A.E. (2015). Instafame: Luxury selfies in the attention economy. Public Culture, 27, pp. 137-160.

Papacharissi, Z., Mendelson, A. and Papathanassopoulos, S. (2011). Media perspectives for the 21st century. New York : Routledge.

Papacharissi, Z. (2015). We have always been social (Editorial). Social media + Society. Available at: http://journals.sagepub.com/doi/full/10.1177/2056305115581185.

Ritzer, G. and Jurgenson, N. (2010). Production, consumption, prosumption: The nature of capitalism in the age of the digital prosumer. Journal of Consumer Culture, 10(1), pp. 13-36.

Soper, K. (2007). Re-thinking the 'good life': The citizenship dimension of consumer disaffection with consumerism. Journal of Consumer Culture, 7(2), pp. 205-229.

Standing, G. (2014). The precariat-the new dangerous class. Amalgam, 6(6-7), pp. 115-119.

Tiidenberg, K. (2016). Boundaries and conflict in a NSFW community on Tumblr: The meanings and uses of selfies. New Media \& Society, 18(8), pp. 1563-1578.

Tiidenberg, K. and Baym, N.K. (2017). Learn it, buy it, work it: Intensive pregnancy on Instagram. Social media + Society, 3, p. 1. Available at: http://journals.sagepub.com/ doi/abs/10.1177/2056305116685108.

Triliva, S., Varvantakis, C. and Dafermos, M. (2015). YouTube, young people, and the socioeconomic crises in Greece. Information, Communication \& Society, 18(4), pp. 407-423. 
van Dijck, J. (2008). Digital photography: Communication, identity, memory. Visual Communication, 7(1), pp. 57-76.

van Zoonen, L. (2013). From identity to identification: Fixating the fragmented self. Media, Culture \& Society, 35(1), pp. 44-51. 


\title{
Chapter 3
}

\section{'Flexi-lives'}

\section{Facing the mobility imperative}

\author{
Valentina Cuzzocrea
}

\section{Introduction}

My starting point in this chapter is the acknowledgement that, in order to understand the implications of precarity in young people's lives, it is necessary to go beyond the experience of employment. However, it is also necessary to go beyond a dichotomy which considers life and work as two separate spheres in potential need of harmonisation - commonly framed through the idea of work-life balance. In my doctoral research, which is mainly brought together in Cuzzocrea (2011a), I attempted to see this through an elaboration of the concept of 'flexi-lives' (as opposed to 'flexi-jobs'), which I used in relation to different contexts such as Italy and the United Kingdom, focusing on the specific roles which individualism and individualisation play within coping strategies. A somewhat similar proposition was made more recently by Farrugia, Threadgold and Coffey (2018, p. 273), who argue that in youth studies:

an ongoing focus on employment conditions such as relative security and financial remuneration has obscured another equally critical dimension of the relationship between youth and work - that is, the significance of the practice of labour itself in the formation of contemporary youth.

In a context in which structural insecurity is widespread for young people, a 'flexilives' approach promises to capture the sense of work and the sense of youth.

The chapter is structured as follows: (a) I will illustrate briefly the conceptual basis which has sustained my elaboration of the concept of flexi-lives; (b) even more briefly, I will examine the characteristics that it has taken in the case of Italy; and (c) I will illustrate my proposal for an enhanced version of this concept in light of recent progress which has been made on the importance of space and mobility in young people's lives. While the specific case of Italy is a strong, albeit extreme, one (Bello and Cuzzocrea, 2018), given the particularly unfavourable position that early career individuals occupy in the labour market and in the life course (Cuzzocrea, 2011b), it is my hope that scholars reflecting on different case studies may also find the enhanced, dynamic version of a flexi-lives approach 
tantalising in relation to other contexts. However, my discussion here is mostly based on conceptualisation rather than on empirical data. I will start by illustrating what I mean by 'flexi-lives'.

\section{Flexi-lives as coping strategies}

A wealth of empirical studies have been dedicated to understanding how young people cope with constructing their path into adulthood in difficult socio-economic circumstances (for some recent Italy-based studies, see for instance Bertolini and Torrioni, 2015; Leccardi, Alteri and Raffini, 2016; Leccardi, 2017; Rebughini, Colombo and Leonini, 2017; Spanò, 2017; Colombo, Leonini and Rebughini, 2018). In a similar vein, a 'flexi-lives' perspective has been elaborated as a mean to avoid reductionism to the employment sphere and, instead, to build up a broader picture, taking in contextual- and cultural-specific dimensions of individualism and individualisation, and leave space to indicate in what ways these strategies may differ in relation to scope, ambition, expectation and focus. ${ }^{1}$ In other words, building a professional path is seen here not only in relation to its work component but as part of a wide-ranging life perspective. Individualism and individualisation are at times used interchangeably in what can be almost-overwhelmingly rich debates; I have argued that they can be enacted in diverging directions across the course of a life path. To start my discussion, I will provide here a basic definition of the two.

Individualism usually refers to the primacy of an individual's interests (Marshall, 1998) based on a 'cult' of agency and self-control, according to which individuals are owners of themselves and responsible for that which is theirs. This is connected to 'a particular type of culture associated with private property rights, personal consumption and individual autonomy' (Turner, 2006, p. 282), and, from a political standpoint, to a 'doctrine associated with liberalism that emphasises the autonomy, importance, and freedom of the individual in relation to the state' (Turner, 2006). Individualism is often said to be a salient aspect both of eastern culture and of modernity, and many early sociologists became very worried by what they saw as the increase of individualism. Yet, as Martuccelli (2017) stresses, for a figure such as Tocqueville, individualism did not mean egoism, or a retreat back into the self, but instead functioned as a democratic glue. Leccardi argues that 'in contemporary individualism, not only does the private dimension emerge, but there is an interrelation, within this dimension, of aspects tied to the redefinition of public and private, new forms of political participation, even ethical aspects' (p. 136; my translation). Bellah et al. (1985, p. 143) insisted on the value of 'think[ing] for [oneself], judg[ing] for [oneself]s, mak[ing] [one's own] decisions, liv[ing one's] lives as we see fit'. Today, the relevance of individualism for looking at how young people construct their paths is the way in which it allows a perspective centred on the individual's self in the planning of a life and career, and a focus on the ways in which young people, as agents, are able to play with the structures of opportunity (in the sense of Roberts, 2009). It presupposes 
a reflexivity which is self-confident and self-assuring through a belief in meritocracy. This trait has been found in several works in youth studies, for instance by Wyn and Dwyer (1999). But subcultural youth studies may use this concept, too, for example to discuss certain kinds of contemporary selfhood such as the socalled 'Me-me-me generation'.

For Elliott and Lemert (2009), individualism and individualisation are two different analytical directions in relation to contemporary individualism. Here, I propose that individualisation be understood within its specific context of second or reflexive modernity (Giddens, 1991; Beck, 1992; Beck and Beck-Gernsheim, 2002). The individualisation thesis stresses that, under current conditions, identity is transformed into a task (Stevenson, 2006) in which everything has to be negotiated, and everything has to be actively chosen. The 'individualised individual' is made free from belongings such as class and family, a phenomenon known as 'disembeddedness'. While this can offer a certain amount of relief and freedom, individuals do not find themselves completely unburdened in their self-propelled search for their own sense of continuity. Biographies cease to follow standard patterns and self-actualisation, and the expression of one's personality becomes a requirement (Giddens, 1991). The debate around individualisation has often revolved around the so-called 'choice biography', a concept according to Woodman (2009) that resulted from a misread of Beck and that was put together in order to criticise an overemphasis on agency.

In my own reading, reflection on individualisation is relevant to exploration of young people's processes of path-construction through the glimpses it can offer into the extent to which young adults are willing and able to elaborate new strategies outside of established routes. Depending on the context that they occupy, young people will perceive different levels of risk in pursuing such paths, and particular class, gender or family backgrounds, for example, will affect the sort of flexi-life which is created. There is a link, here, to Furlong and Cartmel's (2007 [1997]) famous reading of the struggles of young people in contemporary society, which has become widely known in youth transition literature through the idea of 'epistemological fallacy'. This is a 'disjuncture between objective and subjective dimensions [. . .]' which 'obscures underlying class relationships'. More precisely:

although social structures, such as class, continue to shape life chances, these structures tend to become increasingly obscure as collectivist traditions weaken and individualist values intensify. As a consequence of these changes, people come to regard the social world as unpredictable and filled with risks that can only be negotiated on an individual level, even though chains of human interdependence remain intact.

(Furlong and Cartmel, 2007 [1997], pp. 2-3)

Epistemological fallacy leads to a subjective exaggeration of the capacities of individual agency. The interpretation that young people are 'blind to the existence 
of powerful chains of interdependency' (Furlong and Cartmel, 2007 [1997], p. 114) determined by structural issues has had wide success; however, it is not empirically found everywhere. For instance, this aspect has been contested by France and Haddon (2014) and Farthing (2016). In order to explore some nuances of flexi-lives in context, I will now turn to offer an initial elaboration, focused on individualism and individualisation which, as yet, lacks a spatial element. I will then proceed with reflection on the role that spatial reflexivity can play in this understanding.

\section{Flexi-lives in Italy: poor individualism, strong individualisation}

Based on interviews conducted in 2003-2004, my first elaboration of flexi-lives (see Cuzzocrea, 2011a) established a perspective on early career professionals based in Italy which sees them acting and reacting in ways that reflect a typical mix of individualism and individualisation. This mixture, I argued, was entrenched in specific cultural dispositions. The professionals described demonstrated poorly individualistic, but strongly individualised tendencies in their strategies. I made this argument on the basis that the individuals involved tended to perceive the professional organisations within their chosen sectors as formal entities in which they had no space to make a difference and, moreover, as bodies which failed to provide them with any substantial provision for making a career. Therefore, they formally joined professional associations when it was necessary, but with the awareness that this formal requirement would not help them in any substantial way and that further strategies were needed. In order to create a name as professionals, such activities as working over weekends as a sailing instructor were mentioned as more effective than displaying professional expertise. 'Social closure' was portrayed as daunting in professional circles in a way which could be particularly averse to newcomers. Likewise, when it came to discussing how they fit into the organisational structures around them, individual paths were described as lacking in purpose, as if external conditions could affect them at any time, in any way. As new entrants, young professionals reported that they felt they were assumed to commit to the organisation with total trust, which was not, however, based on professional aspects. This involved for instance difficulty in negotiating salaries, or even in expressing the wish to receive a salary at all.

The feeling of belonging to a certain place was very important in the eyes of these young professionals, even though it clearly limited the opportunities available, given that it established a set of boundaries within which their strategies were confined. An opposition between those who remained and those who left seemed to help make sense of the material collected for this piece of research. Informants spoke extensively about how their opportunities were bounded within the territories in which they lived. In addition, this sense of belonging seemed (broadly speaking) to guide every other strategy: for instance, when they felt in need of money, they approached their parents, rather than taking out a loan from 
a bank, which would have not been granted to them in most cases. This obviously made them depict themselves as in a state of dependency rather than as able to enact choices.

They did not tend to conceive themselves as free-floating individuals in the graduate labour market, as if it was difficult for them to have a sight of something in front of them. They were usually aware of implications for their actions, being reflexive, and inclined to ponder and speculate rather than to act. Their approach to opportunity could be seen in negative terms, given that they tended to identify what was not working, rather than taking opportunities. From there, their narratives evolved around describing and justifying the strategies that they put into action in order to avoid those very problems. This is the meaning of a decisive individualised approach which is nevertheless not experienced in individualistic terms. The assumption is that the structural conditions in which they found themselves could not easily be manipulated on their own. They felt they had to overcome them in some other way, but within the constraint of remaining in a particular place. In that specific location, they mostly acted by avoiding what they identified as difficulties in reaching their professional aim. This often led to a great deal of creativity, but in a way that, as I have discussed elsewhere (Cuzzocrea, 2012), was eminently precarious and therefore cannot be taken as a celebration of individuals' capacities.

For instance, the lack of an organisational structure, with specific goals to be achieved and duties to be performed, was not perceived as offering the possibility for free action, but the situation was instead understood as if the only remaining alternative was the placing of oneself in someone else's hands. With personal connections prevailing over other considerations, the recognition of talent and skills was constantly perceived as at-threat. Individualistic strategies seemed to be impeded by a sense of the impossibility of making a difference, or of making one's own way, in the workplace. Structural conditions, therefore, would not allow the flourishing of individualistic strategies, but the overall conditions nevertheless forced them to elaborate individualised solutions. They ended up relying largely on family and informal resources. While professional horizons were still somehow possible to identify, the paths described to reach them were troubled and tortuous (Cuzzocrea, 2011a, p. 134). I concluded that it was necessary to adopt a broad approach in order to capture the salience of their strategies. In this sense, mobility becomes a part of a general attitude, and it is to this aspect that I now turn.

\section{Flexi-lives facing mobility}

While the concept of flexi-lives was originally elaborated in order to make sense of differences in the ways in which young people in specific contexts constructed a life path, adding the spatial element to a flexi-life perspective helps to put this into a global scenario, encompassing issues of location for young adults caught up 
in a periphery-core dynamic (King, 2015). In other words, the flexi-lives of young people are increasingly mobile flexi-lives.

Since my previous research was conducted, individuals' disembeddedness from place - a derivate from 'choice biographies' - has been placed into question by an increasing reference to the importance of 'place' in studies emphasising the meaning of position within the life course (Cook and Cuervo, 2018; Cuzzocrea, 2018). It is now recognised that 'physical environments are not inert backdrops against which social life unfolds' (Prince, 2014, p. 698), and that this 'new spatialization of the social' (Shields, 2017, p. 533) is an important element of this. In turn, studies of youth are increasingly considering issues of place, space and mobility, partly coming out of mobility studies (Sheller and Urry, 2006). Concurrently, the interest in mobility has attracted growing interest. Sheller (2017) states:

like the spatial turn, the new mobilities paradigm challenged the idea of space as a container for social processes, and thus brought the dynamic, ongoing production of space into social theory across many different domains of research.

(Sheller, 2017, p. 628)

The scope of this is huge for the study of young people: while the 'mobility dream' was never unproblematic (Glick Schiller and Salazar, 2013; Yoon, 2014; Cairns et al., 2017), not even the earliest scholars of mobility in the social sciences argued for monolithic representations of it (Urry, 2000, 2007). It is in the dynamism mentioned by Mimi Sheller that we can find a useful revisitation of the flexi-lives perspective. For young adults, defining where their strategies will take place means the solving of what Cairns (2014) calls 'spatial dilemmas' in a transition phase. It is also apparent that for some young people, we cannot talk about wanting to be mobile but more cynically about having to be such. In case of countries where not only is youth unemployment dramatic, but where wider cultural aspects which impede the construction of a career path and, more generally, the attainment of independence also exist, thinking about mobility as a possibility for solving one's problem is far from extraordinary. Young people who have grown up in peripheral locations, in particular, 'naturally' look at mobility as a particularly crucial resource (Van Mol 2016; Cuzzocrea, forthcoming 2019): mobility and migration are an immediate response for young Italians, especially if they are highly qualified (Caneva, 2016; Assirelli et al., 2018).

Using a 'mobile' lens for the study of young adult lives can have several purposes, which recent literature has investigated in some depth (Thomson and Taylor, 2005; Crivello, 2011; Baas, 2012; Marcu, 2012; Cairns, 2014; Van Mol and Timmerman, 2014). Within this, the mere imagination of mobility has been deemed to be central for the construction of the future (Connolly and Healy, 2004; Aynsley and Crossouard, 2010; Cuzzocrea and Mandich, 2016). In a recent study on the Erasmus + program, I have argued that being 'free to dream about what is 
possible' 'should be regarded as a significant development, and the imaginative power [of Erasmus] should not be dismissed or under-estimated' (Cairns et al., 2018 , p. 15). I maintain this as a proposition in this chapter; one that may be most efficient when studying strategies for mobility enacted through particular mobility programmes. Urry (2007) has identified five different modes of mobilities, each of which is located within specific social institutions and spatial practices: corporeal, physical movement of objects, imaginative travel, virtual travel and communicative travel. Cresswell (2010) talks about 'constellations of mobility', made by movements, representations and practice. Baas (2012) talks about a way of life which may be characterised by being 'neither here nor there' (p. 10) and which can be seen as a process through which personal development and the transition to adulthood happen. It is apparent that mobility, when considered in conjunction with the elaboration of life strategies, is a further element of fluidity, but also a disruption in young people's lives. Moreover, mobile transitions are not alien from injustices, marginalisation and exclusion; in fact, the willingness and readiness to be mobile has been termed 'mobility capital' (Murphy-Lejeune, 2002), with all the structural inequalities that this term evokes. We now turn to consider how this issue is linked to individualisation and reflexivity.

\section{Mobile individualism, mobile individualisation: when reflexivity becomes 'spatial'}

In an enhanced version of the flexi-lives approach, individualisation should be understood in such a way that young people can be capable of including a 'geographical dimension' (Cairns, 2014, p. 6) within their plans, aspirations, hopes and strategies. This would constitute an element of self-improvement; in Cairns's words, 'becoming mobile and being reflexive about mobility is of particular importance to young people who aspire to better themselves through pursuing higher education trajectories and professional career paths' (2014, p. 28). Others use the term 'reflexivity' to discuss the possibility of being mobile, for example, for youth in rural contexts (Farrugia et al., 2014). Discourses about mobility have long been seen as inextricably linked with success, as if it cannot happen without mobility (Looker and Naylor, 2009). Yet the idea of permeability and flux which has been theorised by such authors as Massey (1999) has modified this landscape. For instance, in a study on how young Sardinians see their future, we argued that in conditions of insularity, mobility may become a turning point, allowing young people to take opportunities which are not evident or apparent in the local context, and to see these as opportunities for self-experimentation (Cuzzocrea and Mandich, 2016).

This discussion brings us to question if the complexity which characterises individualised paths increases when an element of mobility enters the lives of these young people. Not only do they have to tackle poor structural conditions (in terms of organisational structure, unfavourable labour markets, poor institutional support); mobility makes planning more complicated as it implies the potential of 
tackling unknown realities and unknown modes of work. Additional issues then emerge: is a now-established individualised approach facilitated by moving? Or it is perhaps from the openness that it derives another layer of burden?

Obviously, additional empirical data are needed to address this. However, spatial reflexivity can be seen precisely an as element of a 'politics of the present'. It is a way to see strategies enacted in the interconnection between different discourses: 'choice biographies' and individualisation theses, as well as spatial/ mobilities dilemmas. It offers potential for re-elaborating the role of structural factors alongside subjective orientations. In fact, while individualisation remains a wide umbrella under which choice biographies are enacted, spatial reflexivity is more precisely able to make us reflect on how young people 'manage' themselves through engaging in exchanges as a practical capacity, and most of all to capture the fluidity that these passages entail. Rarely do young people think that they are moving on a permanent basis in the contemporary world. At the same time, they do reflect on the possibilities that a variety of locations offers as possible destinations in which to realise their ambitions, plans, dreams. I want to quote here from an interview conducted for the original study (Cuzzocrea, 2011a, p. 91). The informant here is an HR professional who, when asked to talk about his view of his professional path, replied:

Everything is . . cloudy, complex, because what I have seen in these years is that your future depends a lot on those who run you. At this point, I could be filling a managerial role, had I continued with the first managing director I worked with, while for the current one the role I have now is more than enough. ... But someone else may arrive tomorrow morning and fall in love with me!

This informant was firm in his decision, due to family reasons, to live and work in a peripheral area of Naples. In this sense we can say that he enacted some kind of spatial reflexivity, given that he was conscious of the limitation that this could place on him compared to relocating to Milan - a city which he knew from previous experiences and which he used for comparison in his interview. We may ask how his view would be different had he engaged more with mobility, or had he decided to leave what he describes as a very difficult work environment for good. But the unpredictability that characterises his experience in such a destructured environment also makes him potentially less ready to enter into more structured working environments, and to speak up about his goals and ambitions. As Dana Prince (2014, p. 705) has noted, 'hoped-for or aspired-to possible selves may be supported, encouraged, and strengthened through positive interactions with people and place. Or, they may be ridiculed, silenced, denied, or belittled'. The set of expectations built up in Italian environments, and described in the interviews conducted for this original work, do not make it easy for people to move from one working environment to the other, impeding individualistic dispositions. This may be a peculiarity that perhaps is not shared with contexts outside of Italy. 
However, on the basis of this discussion, other equilibriums can be imagined for other contexts, playing out on the basis of dynamics of individualism and individualisation, and the resulting notions of mobile flexi-lives.

\section{Conclusions}

In thinking about possibilities for updating the flexi-lives approach, this chapter draws on suggestions from several bodies of work, encompassing studies on individualism, individualisation and the recent spatial/mobility turn. There has been a plethora of studies praising youth creativity in solving the node of young people's uncertainty inside and outside the labour market - and there are several focused on the Italian case. However, an important aspect for young people to become aware of is that life can be 'imagined in other terms'. Alongside this is the importance of putting this into practice, temporarily and in unknown contexts. For 'politics of the present' based on flexi-lives to be incisive, too, a further complication of strategies of construction of one's path through the mobile element can be useful to grasp a more elaborated version of the picture.

If individualism and individualisation are both centred on ways to make agency interact with structure in a way which makes it more proficient, then mobility can come into play to disrupt existing mechanisms and render evident the efforts of young people in finding a route which is suitable for them. Whether this is simply good news should not be taken for granted: for instance, in a previous study of young people involved in international internships in Europe (Cuzzocrea and Cairns, under review), the material collected through an online survey revealed that mobility seemed to contribute to personal development. However, the same young people who praised this possibility did not perceive, as a result of this development, any clear improvement in their chances in the labour market. It is interesting to note that increasing opportunities for mobility, whether through structured mobile opportunities or through more improvised routes, are on their way to becoming mainstream.

Through engagement with these arguments, this chapter has sought to provide insights into how a 'flexi-life' approach can adapt to the presence of a strong mobility discourse, and the new challenges which are likely to be imposed on young adults as a consequence. This chapter has also reflected about the ways in which individualism and individualisation can be transformed when young people engage in mobile routes. It mainly discusses the possibility of generating research questions around which a future research agenda can be built, considering contextually the challenges of the mobility discourse alongside the challenge of precarity in the lives of young adults.

\section{Note}

1 In the original conceptualisation of 'flexi-lives', I had also considered the element of 'self-entrepreneurship' alongside individualism and individualisation, as a means to further locate this disposition within the characteristics of local situations. 
However, I will not go into that discussion here, as I aim to place 'flexi-lives' within a wider discussion of the experience of precarity under current socio-historical conditions.

\section{References}

Assirelli, G., Barone, C. and Recchi, E. (2019). 'You better move on': Determinants and labor market outcomes of graduate migration from Italy. International Migration Review, 53(1), pp. 4-25.

Aynsley, S. and Crossouard, B. (2010). Imagined futures: Why are vocational learners choosing not to progress to HE? Journal of Education and Work, 23(2), pp. 129-143.

Baas, M. (2012). Imagined mobility: Migration and transnationalism among Indian students in Australia. London: Anthem Press.

Beck, U. (1992; orig. ed. 1986). Risk society: Towards a new modernity. London: Sage.

Beck, U. and Beck-Gernsheim, E. (2002). Individualization. London: Sage.

Bellah, N., Madsen, R., Sullivan, W.H., Swider, A. and Tipton, S.M. (1985). Habits of the heart: Individualism and commitment in American life. Berkeley/Los Angeles/London: University of California Press.

Bello, B.G. and Cuzzocrea, V. (2018). Editorial: Introducing the need to study young people in Italy. Journal of Modern Italian Studies, 23(1), pp. 677-683.

Bertolini, S. and Torrioni, A.M. (eds.) (2015). La flessibilità come opportunità e come vincolo: Un approccio multidisciplinare. Torino: Celid.

Cairns, D. (2014). Youth transitions, international student mobility and spatial reflexivity: Being mobile? Basingstoke: Palgrave Macmillan.

Cairns, D., Cuzzocrea, V., Briggs, D. and Veloso, L. (2017). The consequences of mobility: Skilled migration, scientific development and the reproduction of inequality. Basingstoke: Palgrave Macmillan.

Cairns, D., Krzaklewska, E., Cuzzocrea, V. and Allaste, A.A. (2018). Mobility, education and employability in the European union: Inside erasmus. Basingstoke: Palgrave Macmillan.

Caneva, E. (2016). Giovani Italiani che Emigrano: Percorsi di Vita Inediti All'epoca Della Crisi Economica Globale. Mondi Migranti, 10(3), pp. 79-93.

Colombo, E., Leonini, L. and Rebughini, P. (2018). A generational attitude: Young adults facing the economic crisis in Milan. Journal of Modern Italian Studies, 23(1), pp. 61-74.

Connolly, P. and Healy, J. (2004). Symbolic violence and the neighbourhood: The educational aspirations of 7-8 year old working-class girls. The British Journal of Sociology, 55, pp. 511-529.

Cook, J. and Cuervo, H. (2018). Staying, leaving and returning: Rurality and the development of reflexivity and motility. Current sociology, ifirst February 23, 2018.

Cresswell, T. (2010). Towards a politics of mobility. Environment and planning D: Society and space, 28, pp. 17-31.

Crivello, G. (2011). Becoming somebody: Youth transitions through education and migration in Peru. Journal of Youth Studies, 14(4), pp. 395-411.

Cuzzocrea, V. (2011a). Flexi-jobs or flexi-lives? Starting a professional career in Italy and England. Preface by M. Glucksmann. Bologna: Odoya.

Cuzzocrea, V. (2011b). Squeezing or blurring? Young adulthood in the career strategies of professionals based in Italy and England. Journal of Youth Studies, 14(6), pp. 657-674. 
Cuzzocrea, V. (2012). Creativity and the 'art to get by': Or, what is old in new practices of work. In: V. Cuzzocrea, P. Sahu and P. James, eds., Valuing work: Challenges and opportunities. Oxford: Inter-Disciplinary Press, pp. 113-130.

Cuzzocrea, V. (2018). Rooted mobilities in youth's narratives of the future. Current Sociology, 66(6), pp. 1106-1123.

Cuzzocrea, V. (forthcoming 2019). Youth, peripherality and the mobility discourse in Europe. In: S. Duggan, K. Finn, J. Gagnon, E. Gray and P. Kelly, eds., Social justice in times of crisis and hope. New York: Peter Lang.

Cuzzocrea, V. and Cairns, D. (under review). Pinball youth? Deferement of Labor Market Entry and International Internships.

Cuzzocrea, V. and Mandich, G. (2016). Students narratives of the future: Imagined mobilities as forms of youth agency? Journal of Youth Studies, 19(4), pp. 552-567.

Elliott, A. and Lemert, C. (2009). The global new individualist debate: Three theories of individualism and beyond. In: A. Elliott and P. du Gay, eds., Identity in question. London: Sage, pp. 37-64.

Farrugia, D. (2016). The mobility imperative for rural youth: The structural, symbolic and non-representational dimensions rural youth mobilities. Journal of Youth Studies, 19(6), pp. 836-851.

Farrugia, D., Smith, J. and Harrison, T. (2014). Emplacing young people in an Australian rural community: An extraverted sense of place in times of change. Journal of Youth Studies, 17(9), pp. 1152-1167.

Farrugia, D., Threadgold, S. and Coffey, J. (2018). Young subjectivities and affective labour in the service economy. Journal of Youth Studies, 21(3), pp. 272-287.

Farthing, R. (2016). Writing in a role for structure: Low-income young people's dual understanding of agency, choice and the welfare state. Journal of Youth Studies, 19(6), pp. 760-775.

France, A. and Haddon, E. (2014). Exploring the epistemological fallacy: Subjectivity and class in the lives of young people. Young, 22(4), pp. 305-321.

Furlong, A. and Cartmel, F. (2007 [1997]). Young people and social change. Maidenhead: Open University Press.

Giddens, A. (1991). Modernity and self-identity: Self and society in the late modern age. Cambridge: Polity Press.

Glick Schiller, N. and Salazar, N.B. (2013). Regimes of mobility across the globe. Journal of Ethnic and Migration Studies, 39(2), pp. 183-200.

King, R. (2015). Migration and Southern Europe: A center-periphery dynamic? In: M. Baumeister and R. Sala, eds., Southern Europe? Italy, Spain, Portugal, and Greece from the 1950s until the present day. Frankfurt am Main, Germany: Campus, pp. 139-169.

Leccardi, C., Alteri, L. and Raffini, L. (2016). Youth and the reinvention of politics: New forms of participation in the age of individualisation and presentification. Partecipazione e conflitto, 9(3), pp. 717-747.

Leccardi, C. (2017a). Le ambivalenze del nuovo individualismo. Ripensare il legame sociale nell'epoca dell'accelerazione. In: C. Leccardi and P. Volontè, eds., Un nuovo individualismo? Individualizzazione, soggettività e legame sociale. Milano: EGEA, pp.131-154.

Leccardi, C. (2017a). The recession, young people, and their relationship with the future. In: I. Schoon and J. Bynner, eds., Young people's development and the great recession: Uncertain transitions and precarious futures. Cambridge: Cambridge University Press, pp. 348-371. 
Looker, D.E. and Naylor, T.D. (2009). At risk of being rural? The experience of rural youth in a risk society. Journal of Rural and Community Development, 4(2), pp. 39-64.

Marcu, S. (2012). Emotions on the move: Belonging, sense of place and feelings identities among young Romanian immigrants in Spain. Journal of Youth Studies, 15(2), pp. 207-223.

Marshall, G. (ed.) (1998). Individualism. In: Oxford dictionary of sociology. Oxford: Oxford University Press.

Martuccelli, D. (2017). Il singolarismo, nuovo avatar dell'individualismo. In: C. Leccardi and P. Volontè, eds., Un nuovo individualismo? Individualizzazione, soggettività e legame sociale. Milano: EGEA, pp. 115-130.

Massey, D. (1999). For space. London: Sage.

Murphy-Lejeune, E. (2002). Student mobility and narrative in Europe: The new strangers. London: Routledge.

Prince, D. (2014). What about place? Considering the role of physical environment on youth imagining of future possible selves. Journal of Youth Studies, 17(6), pp. 697-716.

Rebughini, P., Colombo, E. and Leonini, L. (eds.) (2017). Giovani dentro la crisi. Milano: Guerini.

Roberts, K. (2009). Opportunity structures then and now. Journal of Education and Work, 22(5), pp. 355-368.

Sheller, M. and Urry, J. (2006). The new mobilities paradigm. Environment and planning A, 38(2), pp. 207-226.

Sheller, M. (2017). From spatial turn to mobilities turn. Current sociology monograph, 65(4), pp. 623-639.

Shields, R. (2017). Expanding the borders of the sociological imagination: Spatial difference and social inequality. Current sociology, 65(4), pp. 533-552.

Spanò, A. (ed.) (2017). I giovani del Sud di fronte alla crisi: Strategie di sopravvivenza e capacità di innovazione. Milano: Franco Angeli.

Stevenson, N. (2006). Individualization theory. In: B. S. Turner (eds.), The Cambridge dictionary of sociology. Cambridge: Cambridge University Press, p. 184.

Thomson, R. and Taylor, R. (2005). Between cosmopolitanism and the locals: Mobility as a resource in the transition to adulthood. Young, 13(4), pp. 327-342.

Turner, B.S. (2006). Individualism. In: B.S. Turner, ed., The Cambridge dictionary of sociology. Cambridge: Cambridge University Press.

Urry, J. (2000). Sociology beyond societies. London: Routledge.

Urry, J. (2007). Mobilities. Cambridge: Polity Press.

Van Mol, C. and Timmerman, C. (2014). Should I stay or should I go? An analysis of the determinants of intra-European student mobility. Population, space and place, 20, pp. 465-479.

Van Mol, C. (2016). Migration aspirations of European youth in times of crisis. Journal of Youth Studies, 19, pp. 1303-1320.

Woodman, D. (2009). The mysterious case of the pervasive choice biography: Ulrich Beck, structure/agency, and the middling state of theory in the sociology of youth. Journal of Youth Studies, 12(3), pp. 243-256.

Wyn, J. and Dwyer, P. (1999). New directions in research on youth in transition. Journal of Youth Studies, 2(1), pp. 5-21.

Yoon, K. (2014). Transnational youth mobility in the neoliberal economy of experience. Journal of Youth Studies, 17(8), pp. 1014-1028. 

Part II

Uncertainty 



\section{Fragile transitions from education to employment \\ Youth, gender and migrant status in the EU}

\section{Çetin Çelik, Fatoș Gökșen, Alpay Filiztekin, Ibrahim Öker and Mark Smith}

\section{Introduction}

The current financial crisis has persistently affected youth across Europe by making higher unemployment rates, precarious working conditions and uncertainty 'normal context' for them (Colombo, Leonini and Rebughini, 2018). Beck suggests in his 'second modernity' thesis that the standardisation of life course by major institutions that ensure riskless transitions for individuals between different stages throughout their lives - such as education, work, marriage and retirement started to weaken decades earlier (Beck, 2016). The present economic crisis, however, gave this destandardisation process an important twist; the capacity of the state institutions in distribution of various goods and services concerning health, education and equitable forms of social welfare have incredibly shrunk (Colombo and Rebughini, 2015).

Welfare states in Europe have responded to destandardisation, precarity, ambiguity and risks in different ways. In this chapter, we map vulnerability in schoolto-work (STW) transitions across the EU by the intersectionality of gender and migrant status. By following Anthias (2013), we consider intersectionality as social location such as gender, class, race, sexuality, faith, disability and so on, not an identity, that create constrains, opportunities and strategies. The following section discusses the conceptualisation of vulnerabilities and the intersectionality of gender and migrant status for risks of vulnerability, and the third section relates these discussions to the variations across institutional frameworks. The fourth section outlines our conceptual methodological approach to the cross-national analysis of vulnerabilities. The fifth section unpacks the variations and pathways of school-to-work transitions of young women and men born inside and outside the EU. The final section draws conclusions while highlighting the limits of current policy making to address the vulnerabilities of young people.

\section{Vulnerability, gender and migrant status}

In the broadest sense, vulnerability refers to the situation of individuals, households or communities that are exposed to potential risks and their inability to 
anticipate, withstand and recover from adverse shocks (Morrone et al., 2011). Individual risks such as low income and dropping out of school are strongly associated with 'vulnerability to poverty' (Dercon, 2006). However, 'social vulnerability', as opposed to 'economic vulnerability', identifies vulnerable groups such as children at risk, females, the disabled, migrants and the elderly, and it underlines broad structural characteristics that define these vulnerable groups (Loughhead and Mittal, 2000; Eurostat, 2016). This conceptualisation of vulnerability allows us to consider the range of diverse factors affecting vulnerability of young people, such as gender and migrant status.

The labour markets across the European Union (EU) remain clearly divided along gender lines (Bettio et al., 2012). Female labour force participation remains lower than male participation; women still account for most unpaid work in the household, and when women are employed in paid work, they are overrepresented in the informal sector and are among the poorest and lowest paid (Smith, 2012). These gender differences on and off the labour market create risks of vulnerability that interact with other dimensions - for example, poor education, and ethnicity - leading to potentially greater exposure to vulnerability over the life cycle. One such significant dimension is migrant status (Meeuwisse, Severiens and Born, 2010); young migrants generally face non-recognition of training credentials resulting in 'de-skilling', where they can only obtain jobs beneath their qualifications (Cortina et al., 2014). Rubin et al. (2008) show that migrant women fare worse on the labour market than both EU-born women and migrant men. Previous research has identified a range of factors that influence the success of migrant women in European labour markets such as educational attainment and skills, recognition of vocational qualifications, children and family structure, type of migration and length of stay, language skills, social-cultural environment and legal status (Peraccio and Depalo, 2006). When we disaggregate migrant women into those born within the EU and those from third countries outside the EU, it becomes apparent that third-country women migrants face even greater levels of disadvantage in the EU labour force than EU nationals and EU-born migrant women and third-country migrant men (Peracchi and Depalo, 2006).

\section{Vulnerability in institutional contexts}

Such risks of vulnerability by gender and migrant status do not occur in a vacuum but are influenced by the institutional environment in which young people find themselves (Whelan and Maitre, 2010). Drawing upon the work of authors such as Esping-Andersen's (1990, 1997), Gallie and Paugam (2000), Korpi (2000) and Walther (2006, pp. 124-129), we can categorise the regime types for the schoolto-work transitions to contextualise the risks of vulnerabilities for young people: universalistic, liberal, employment-centred and sub-protective and post-socialist regime. Universalistic regimes are characterised by a comprehensive educational 
system with minimal streaming and flexible training possibilities (EspingAndersen, 1997). While it is typically associated with Nordic countries, such as Denmark and Sweden, the Netherlands can also be considered in the universalistic cluster, provided that the 'hybrid' nature of this country should be recognised (see Walther, 2006, p. 129). In this regime, individual rights and responsibilities are considered part of collective social responsibility. Counselling is highly institutionalised at all stages of education, training and employment and serves to facilitate school-to-work transitions (Walther, 2006). The vocational education and training (VET) system, based on a dual training principle in school and work with employers actively involved in the training, turns into a collectivist skill formation in this regime (Crowley et al., 2013). Hence, the absence of early tracking, availability of second-chance schools and continuing training provided by market institutions prepares the ground for flexible and reversible school-to-work transitions (ETUC, 2012).

Unlike a universalistic regime, a liberal regime emphasises individual rights and responsibilities over collective provisions, and youth is a transition that should end quickly with economic independence (Gallie and Paugam, 2000). Typical examples would include the United Kingdom. The educational system provides little vocational provision and the VET policy is highly focused on relatively low-level qualifications (Hadjivassiliou et al., 2015). Employer engagement with vocational education is also low and internship conditions are generally poor. Young people, therefore, tend to stay in education if possible rather than entering the vocational schemes or labour market at an early age. Entrance to the labour market is structured rather flexibly with multiple and flexible entry points, and this can make the school-to-work transition fragile, uncertain and insecure (ETUC, 2012). Moreover, the educational system equips young people with inappropriate or insufficient skills, causing a mismatch in the labour market (Hadjivassiliou et al., 2015).

In an employment-centred regime, the state, as the key stakeholder, shapes the school-to-work transition (Walther, 2006). Typical examples include France and Belgium. Schools are organised more selectively to channel young people into occupational careers and different segments of the labour market. This selectivity can result in an accumulation of disadvantaged youth from migrant backgrounds in weaker segments of the labour market (Alba, 2011). The limited involvement of employers in the school-to-work system and the 'institutional stasis' that stems from the central role of the state are barriers to smoother and more equal transitions for youth (Smith, Toraldo and Pasquier, 2015). In addition, strict employment protection legislation provides protection for 'insiders' on the labour market at the expense of new entrants and those with temporary contracts (Mills and Prag, 2014).

The sub-protective transition regime is characterised by a relatively low percentage of standard contracts and a high share of young people in unprotected living conditions (Walther, 2006). The family and the informal economy play 
significant roles in this regime. Countries from the south of Europe are often used as examples, including Spain and Greece. Typically, vocational training is not well developed and, as is the case in employment-centred regimes, the involvement of companies in vocational training is weak. Against this background, school-to-work transitions are quite heterogeneous, non-linear and unpredictable (Bradley and Devadason, 2008). In addition, transitions are significantly influenced by social class, gender and ethnicity.

Post-socialist regimes might be regarded as a mix of liberal and employmentcentred approaches. Comprehensive education programmes are more widespread than vocational education due to the latter's poor reputation and rigidity. Therefore, post-socialist regimes are characterised by a predominance of general education, high levels of educational attainment and weak linkages between the education system and the labour market, often resulting in a mismatch between skills and market needs. In line with Wallace (2002), we include the Slovak Republic in this category (see also Hadjivassiliou et al., 2015).

These five country groupings provide a framework with which to analyse school-to-work transitions and the particular risk to vulnerabilities created for young people. In the next section, we discuss the operationalisation of these concepts in relation to young migrant women and men.

\section{Methods, data and definitions}

To explore the vulnerabilities of young women and men in Europe and the impact of their migrant status, we use the EU-SILC (cross-sectional) waves from 2005 to 2013 (Eurostat, 2015), with a particular focus on the economic crisis of 20082010. To capture cross-national differences in the duration of school-to-work transitions and the diffusion of precariousness into older cohorts, a broad definition of youth is used to include individuals aged 16 to 29 .

Using EU-SILC, we estimated a series of multinomial logit models and calculated the relative risk rates for labour market status of youth who are not in education. Our dependent variable in these models depicts four different states: being employed full-time (base state/category), being employed part-time, unemployed and inactive. The independent variables of interest are gender, migrant status, and education level and year dummies. We also control for age and years after finishing school, as an approximation of potential experience. To assess the quality of transition, we estimated simple linear regression models. In these models, the International Socio-Economic Index (ISEI) ${ }^{1}$ developed by Ganzeboom, De Graaf and Treiman (1992) is the dependent variable, and our variables of interest are age groups, gender and migrant status. The ISEI scores occupations according to their average educational and income levels, reflecting how occupational location influences the ability to convert educational levels into income. It would have been useful to integrate the social class of parents into our analyses; but unfortunately, these data were available only for those young people who were living 
with their parents - a weakness where migrants are concerned. Hence, we focused on the occupational positions of young individuals as a dependent variable in our econometric analyses to capture the quality of youth transitions varying across vulnerable groups.

To show how school-to-work transitions vary across different institutional settings, we picked countries that represent each regime type discussed in the previous section. We chose Denmark and the Netherlands to represent the universalistic regime; France and Belgium to account for the employmentcentred regime; Slovakia as the case country of post-socialist regime; the United Kingdom as the pioneering example for the liberal regime; and Spain and Greece to understand the STW experiences of young people under subprotective regimes.

Any analysis of ethnicity and migration is limited by the available data, and one important limitation of European data is that we are unable to identify second-generation migrants. The current EU-SILC survey includes a question on country of birth, so it is only possible to consider the stock rather than the flow of migrants, with no information on duration of residence. Thus, in our cross-national analysis, we focus only on migrant youth born outside the EU. Although we could not account for the heterogeneity of this group because of data limitation, this choice is valid in an analysis of vulnerability since existing research has confirmed that 'third country migrants' tend to be among the most-disadvantaged groups among migrant populations and within wider society (Kogan and Müller, 2003)

A final methodological issue is the sample size of non-EU-born youth in the EU-SILC data. Migrants constitute $5-11 \%$ of the population (pooled average between the years 2005 and 2013) in the countries represented in this study, except for Slovakia, where there are very few. The share of migrants is higher in the United Kingdom and Spain, approaching 11\%, as opposed to Denmark, where they constitute only $5 \%$. In all these countries, the share of migrants is higher among the adult population.

\section{Results}

\section{Vulnerable groups and labour market outcomes}

Our multinomial logit estimates show that in all of the countries, higher educational attainment is associated with lower risk of unemployment (see Table 4.1). Similarly, age and potential experience of an individual decrease the risk of unemployment. When the results are examined to account for vulnerability, it is observed that the most disadvantaged group in terms of unemployment is migrant females in all countries (Table 4.1, Panel a). Skilled and unskilled female migrants face intersecting gender and ethnic discrimination combined with risks of low-paid employment and a greater share of unpaid domestic work. Research 


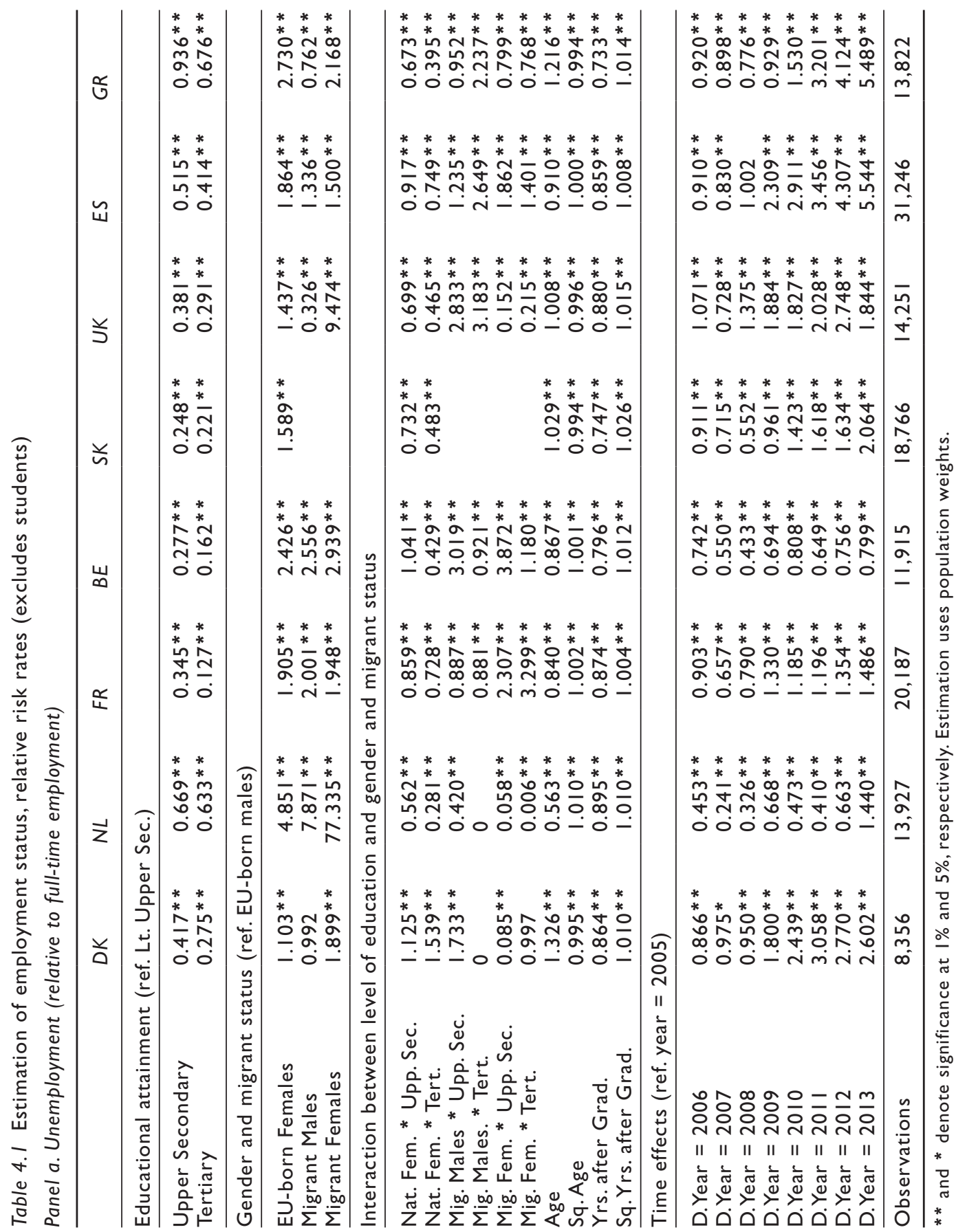




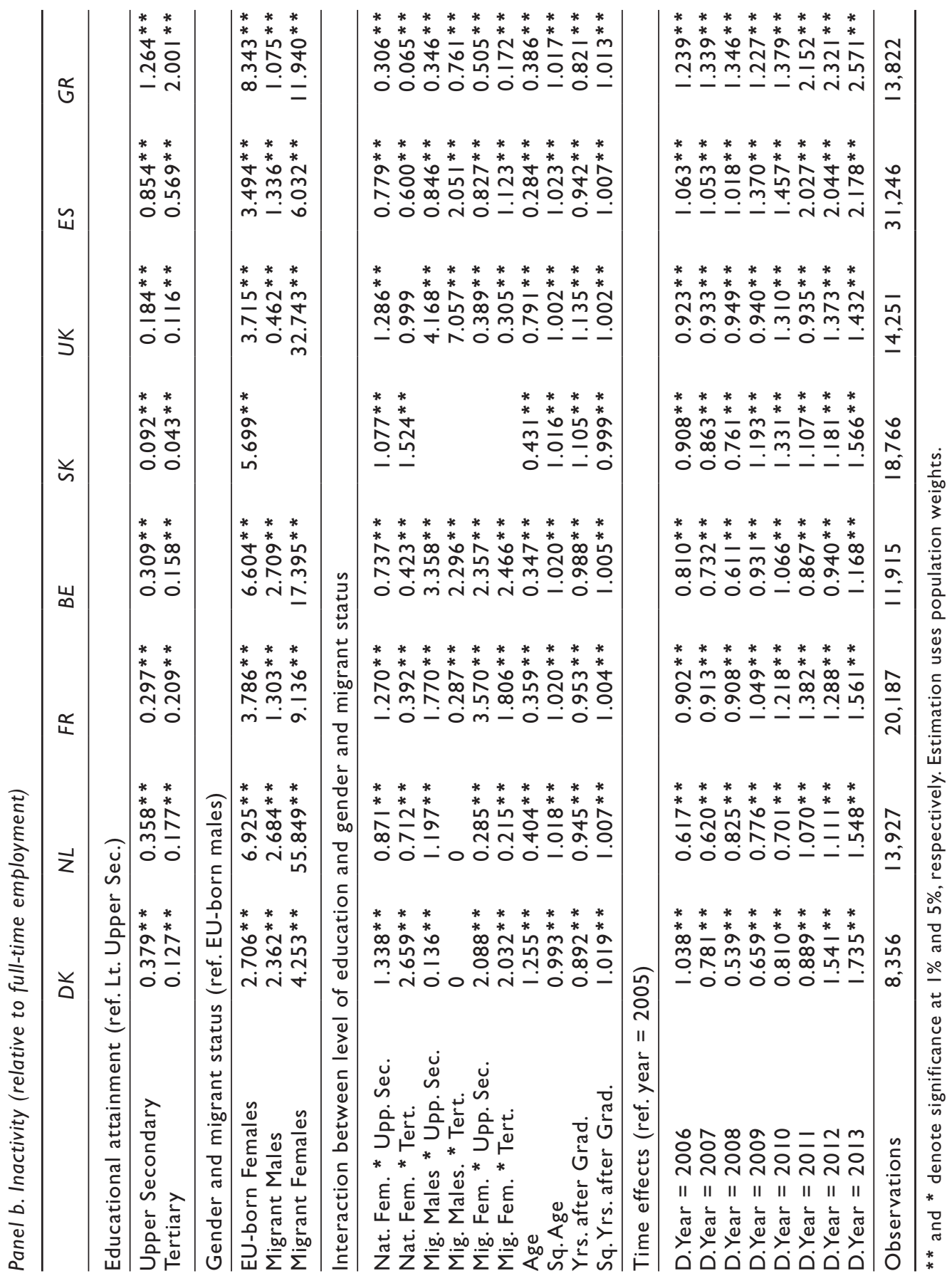




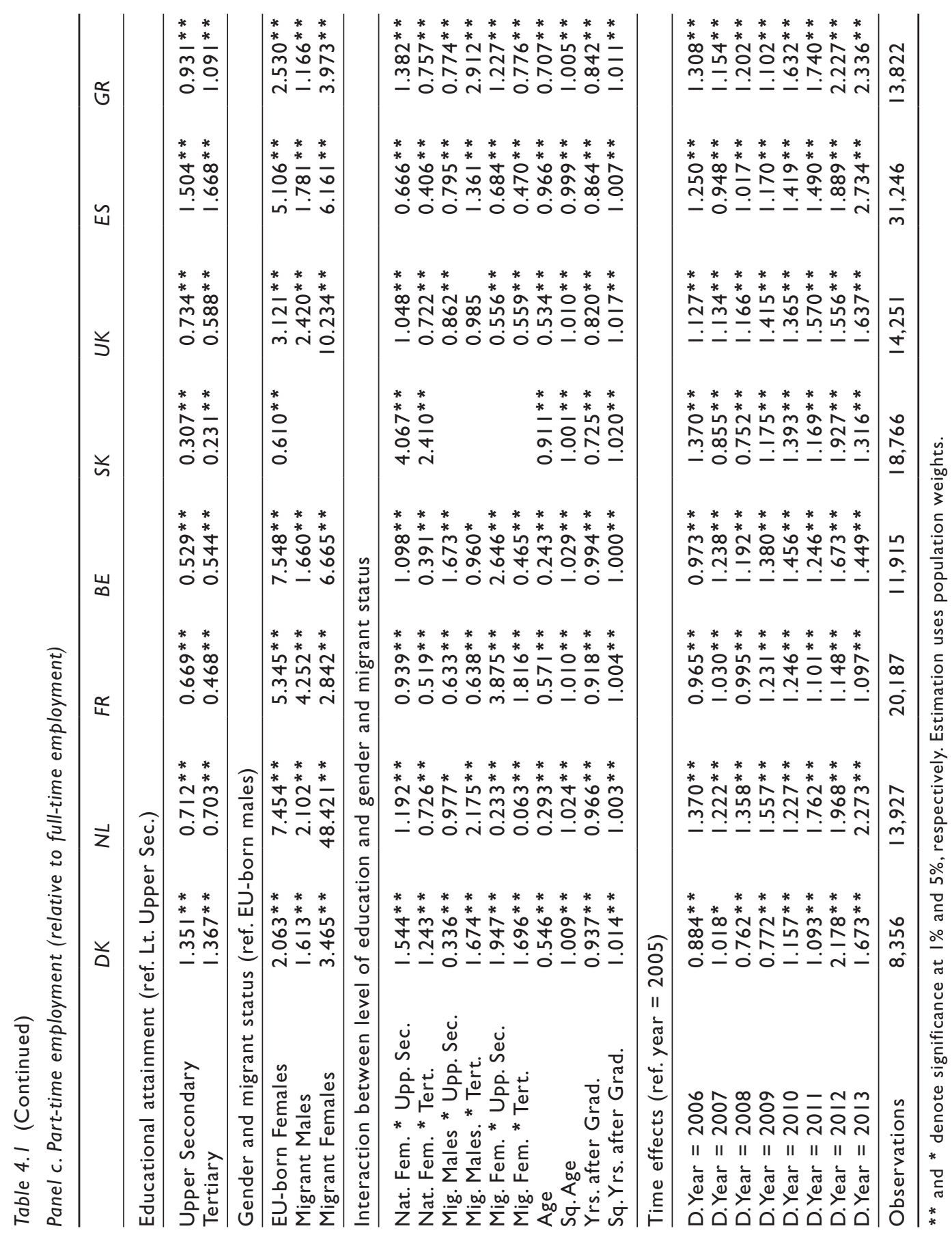


shows that female migrants are concentrated in unskilled, undervalued and lowpaid sectors, often employed as domestic workers in hard-to-regulate sectors of the labour market (Evans, 2016). Female migrants may also be less able to advance their own interests, they have less decision-making power within the home and they are less likely to have the capabilities to engage with the political decision-making and policy processes (O’Neill and Domingo, 2016). Furthermore, women, whether migrant or not, are more likely than males to be unemployed. The lowest risk of unemployment, on the other hand, is observed among the EU-born male population, in all countries other than the United Kingdom and Greece.

Education provides some protection. Analysis of interaction terms between education level and dimensions of vulnerability underline that more educated EU-born females are less likely to be unemployed in all countries except Denmark. The risk of unemployment among the more educated migrant females; however, is considerably higher in employment-centred countries and Spain. The proportion of female migrants who hold a university degree is, in most countries, almost on a par with that of immigrant men. Nevertheless, educated migrant women have lower rates of employment relative to their EU-born counterparts. Holders of foreign degrees may face problems of recognition as well as factors such as country of origin language barriers and access to certain sectors of the labour market, for example public sector jobs. The latter may particularly affect women more than men, because the professions in which women tend to be concentrated are those which are predominantly regulated by the public sector.

Similar patterns are observed for the risk of inactivity, and higher educational attainment reduces the risk in all countries. The only exception is Greece, where labour market conditions have been very poor and young people have been affected by a lack of job creation capacity of the market. Table 4.1 (Panel b) also reveals that migrant females have the highest risk of inactivity. For example, in the Netherlands, this group is 55 times more likely to be inactive compared to EUborn males. Here, the interaction terms show that inactive migrant females consist mostly of less-educated individuals. In Denmark, France and Belgium, however, the reverse is true.

The school-to-work transition process may involve several intermediate statuses between learning and work, such as temporary jobs, or dual statuses, i.e. combining learning and work, such as part-time jobs (Walther and Pohl, 2005). Part-time work, however, might also be an important indicator of vulnerability. Part-time work, particularly with short hours over an extended period, does not ensure sufficient income security in terms of wages and pension incomes. Hence, in our analysis of STW, we do not treat the part-timers as the ones who have successfully transitioned to employment.

The results in Table 4.1 (Panel c) indicate that education in employmentcentred countries is associated with greater opportunities for full-time employment, 
unlike in universalistic regimes. Yet in France and Belgium, females and migrants are less likely to be in full-time employment than EU-born males. Yet migrant females in the employment-centred countries are also less likely to be in employment, more like universalistic regimes, regardless of their educational attainment. Even educated female migrants face difficulties while transitioning from school to work. This finding is consistent with the literature that argues that disadvantaged youth are worse off in countries that can be characterised as having less tightly structured education. When education is weakly linked to the workplace and vocational education is obtained on the job, disadvantaged groups can be more adversely affected (Gangl, 2001)

In the United Kingdom, higher levels of education are associated with better chances of full-time employment. Again, as is the case in all other countries, UK males are more likely than other groups to be unemployed or inactive. However, the interaction between gender and education shows interesting results: educated migrant males are more likely to be unemployed or inactive than educated migrant women. To fully understand this finding, one needs to look at the labour market outcomes of diverse ethnic groups whose level of educational and economic resources vary significantly. Unemployment risks for highly educated immigrants vary by gender. Employability and a period of unemployment might be more stigmatising for immigrant males from poorer countries such as Bangladesh and Pakistan, whereas unemployed women from the same countries may be perceived less negatively thanks to gendered notions of nurturing and obedience (Mooi-Reci and Ganzeboom, 2015).

The results for sub-protective regimes show that unemployment and inactivity are more common among women, and this is a more critical issue for young migrant females. As in the case of the liberal cluster, young educated migrant males are found to be least likely to make a successful transition from school to work. Low vocational specificity in the educational system coupled with moderate degrees of labour protection in sub-protective regime countries may explain these findings.

\section{The quality of school-to-work transitions for vulnerable groups}

Table 4.2 provides estimation results of our OLS models to assess the quality of transitions for each country. The base line group in the estimation is EUborn male adults with less than upper secondary education. As expected, education plays a crucial role in access to a high-status job for all groups. Similarly, potential experience on the labour market increases the chances of having highstatus jobs. In line with the gendered risks noted earlier, having controlled for (potential) experience, females are more likely to have low-status occupations compared to men. 


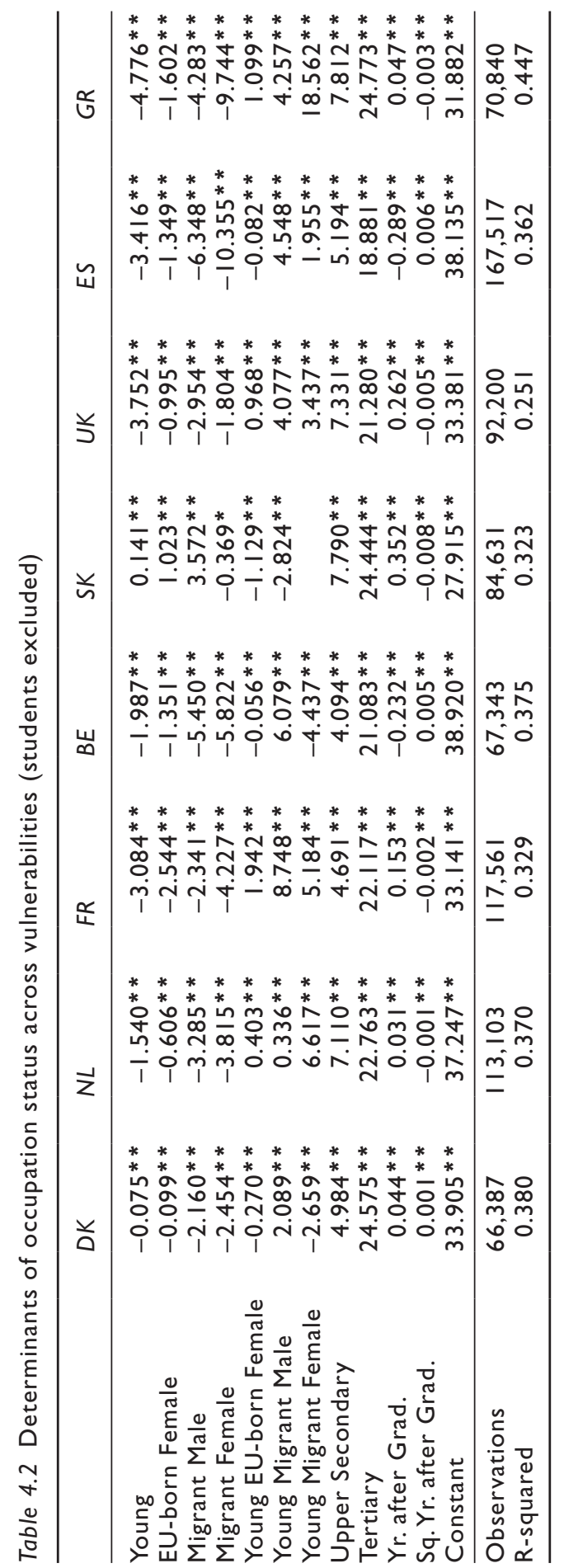


In all countries, access to higher status jobs - higher occupational scores - for adult migrants are lower than for adult EU-born, more so for migrant females than migrant males. This finding is consistent with the findings of the previous research (Rubin et al., 2008) indicating that migrant women are not only concentrated in a few sectors of the economy, but these sectors are in the lowest-skilled segments, which usually involves low status, low pay, and limited rights within the labour market. Some of these sectors, like sales and services and care services, typically demand unskilled, interchangeable and substitutable labour (Massey and Constant, 2005). It is likely that the lower occupational scores of migrant women are a result of human capital factors - lack of language proficiency, qualifications, unfamiliarity with the receiving country - combined discriminatory processes that lead to disadvantage (Rubin et al., 2008).

Contrary to the disadvantaged positions of the older migrants, we observed that young migrant males are more likely to have high-status jobs in all countries, particularly in France (Table 4.2). This might stem from the fact that, in this analysis, we considered only a small subset of migrants, employed individuals. Furthermore, less-educated migrants are less likely to be employed; hence, in this analysis we observe mostly the more educated subset of migrants whose human capital might provide them with opportunities to have higher-status occupations.

In addition to the quality of jobs, we provide another estimation of quality outcomes by estimating a standard Mincerian hourly wage equation based on salary income, the number of months in full-time employment, and usual weekly working hours during the reference period. ${ }^{2}$ Independent variables are as previously indicated, that is, gender, migrant status, age group, education level and (potential) experience. The model also includes the IESE occupation score and time dummies. The results are reported in Figure 4.1.

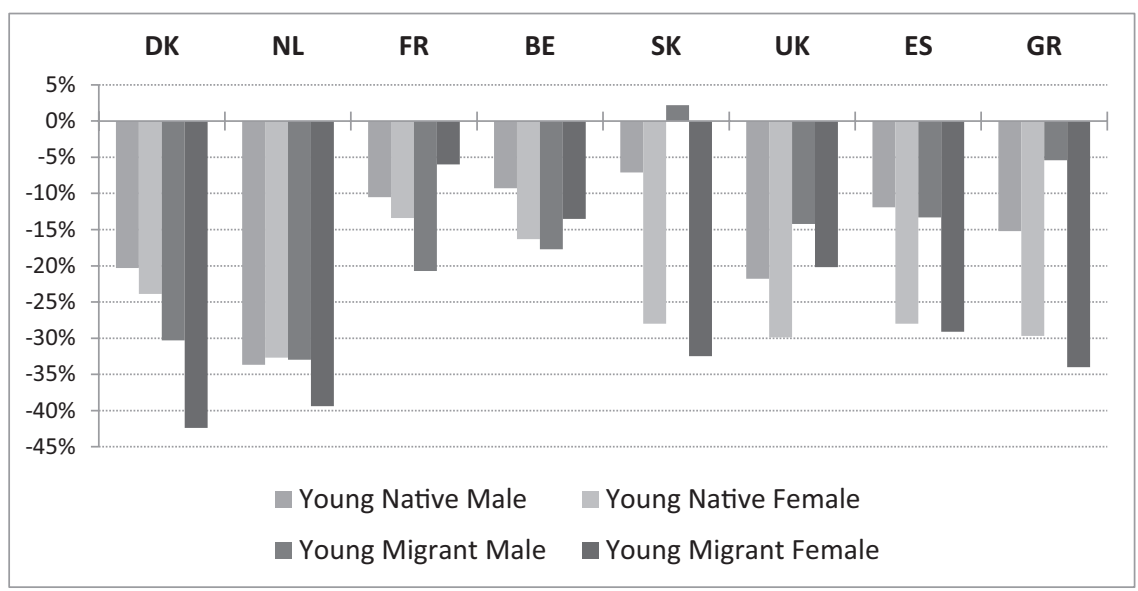

Figure 4.I Predicted relative wage differences across vulnerable groups relative to adult males (students excluded)

Source: Own calculations on EU-SILC using cross-sectional population weights of those over age 16. 
The wage gap between young males and females is widest in the Slovak Republic. Controlling for education and (potential) experience, we found that the wages for migrants are also lower in most countries than for the EU-born population, although young migrants earn more than adult migrants, except in Denmark. This finding might again be a consequence of the problem noted earlier; that is, we considered only a relatively small subset of migrants who have a comparative advantage in human capital. In the United Kingdom and Greece, young migrants in work earn significantly more than any other group in these countries. Note that migrants in the United Kingdom had a higher education than anywhere else, a result that is likely driven by the very few observations on young migrants with lower education in that country. From our analysis of job quality outcomes, we again find that females and migrants are more likely to be disadvantaged. Furthermore, even if these groups have the 'privilege to be employed', the status of jobs they are hired for is lower, as are their wages.

\section{Summary and conclusions}

The dynamics of vulnerabilities result in heterogeneous and fragmented transitions between school and the labour market, with women and migrants often suffering the most. Nevertheless, despite these common pressures, this chapter also shows that school-to-work regimes, embedded in the specific structural, cultural, historical and institutional contexts of various welfare states, reproduce different inequalities to varying degrees.

Overall, our results suggest that low-educated migrant women may have fewer options than EU-born women on the labour market and so take up the more limited range of jobs that are available to them given their qualifications, skills and migrant status. The findings also indicate that less-educated EU-born women have higher rates of employment compared to migrant women. As argued by Rubin et al. (2008), this could be due to a variety of supply, demand and institutional factors affecting the willingness or ability of migrant women to participate in the labour force; unfamiliarity with employment opportunities available; lack of language skills (supply factors); discrimination along gender and/or ethnic/racial lines in the labour market (factors that may be influencing demand); lack of recognition of qualifications; or visa restrictions on employment (institutional factors which affect both supply and demand).

Based on our findings, we argue that regimes characterised by an institutionalised VET system and strong counselling support for training and employment such as that found in Denmark tend to perform relatively well in facilitating school-to-work transitions of different vulnerable groups. One of the major strengths of the universal regime seems to lie in its minimal streaming and flexible education, supported by broad second-chance options at local levels, both in education and training. These polices play a major role in integrating vulnerable groups such as low-skilled and minority youth into education and the labour market. 
By contrast, France's employment-centred regime, characterised by fewer second-chance options, creates early disconnection of immigrant youth from education and the labour market. The UK liberal regime is an interesting case in terms of the effect of youth unemployment on vulnerable groups. Unlike in other countries, vulnerability is not directly correlated with immigration or minority status. However, this finding should not hide the fact that low-skilled immigrant and minority youth are particularly disadvantaged in a regime characterised by a relatively weak VET system and a low level of employer engagement with training. In the sub-protective regimes of Spain and Greece, transitions are more heterogeneous, non-linear and unpredictable. Limited standard workplaces, unprotected living conditions, and a large informal economy combine with an undeveloped VET system to make socio-economic status, gender and ethnicity strong determinants of youth unemployment. Additionally, compared to other regimes, in sub-protective regimes such as Greece, gender vulnerability is a highly distinct characteristic.

In the countries considered in this chapter, there is some evidence of policies aimed at narrowing the gaps, but only for the most disadvantaged and in a limited range of areas, namely, improving the level of educational attainment. The gender gaps documented in this chapter actually reflect segregation of educational and training choices as well as a range of other processes both in and out of the labour market that serve to reinforce gender roles and stereotypes. The evidence suggests that gender differences open up early in the life course (Plantenga and Manuela, 2013). and therefore, that a more comprehensive approach is required.

\section{Notes}

1 Earlier versions of SILC data use the ISCO-88 classification at a more aggregate level. Starting from 2011, the classification was switched to ISCO-08, with a larger set of 52 occupations that provides a better match with ISEI.

2 The dependent variable is a log of hourly wages for those who are employed full-time, who have reported a positive salary income and whose usual working hours are fewer than 85 per week.

\section{References}

Alba, R. (2011). Schools and the diversity transition in the wealthy societies of the West. American behavioral scientist, 55(12), pp. 1616-1634.

Anthias, F. (2013). Hierarchies of social location, class and intersectionality: Towards a translocational frame. International sociology, 28(1), pp. 121-138.

Beck, U. (2016). Varieties of second modernity and the cosmopolitan vision. Theory, culture \& society, 33(7-8), pp. 257-270.

Bettio, F., Corsi, M., D’Ippoliti, C., Lyberaki, A., Lodovici, M.S. and Verashchagina, A. (2012). The impact of the economic crisis on the situation of women and men and on gender equality policies. Luxembourg: European Commission. 
Bradley, H. and Devadason, R. (2008). Fractured transitions: Young adults' pathways into contemporary labour markets. Sociology, 42(1), pp. 119-136.

Colombo, E. and Rebughini, P. (2015). Italian young people coping with the consequences of economic crisis: An intersectional analysis. Oñati socio-legal series, 5(4).

Colombo, E., Leonini, L. and Rebughini, P. (2018). A generational attitude: Young adults facing the economic crisis in Milan. Journal of Modern Italian Studies, 23(1), pp. 61-74.

Cortina, J., Taran, P., Elie, J. and Raphael, A. (2014). Migration and youth: Challenges and opportunities. Global Migration Group. UNICEF.

Crowley, L., Jones, K., Cominetti, N. and Gulliford, J. (2013). International lessons: Youth unemployment in the global context. Lancashire: The Work Foundation, Lancaster University.

Dercon, S. (2006). Vulnerability: A micro perspective. 149 QEH Working Paper Series.

Esping-Andersen, G. (1990). The three worlds of welfare capitalism. Princeton, NJ: Princeton University Press.

Esping-Andersen, G. (1997). Welfare states without work: The impasse of labor shedding and familialism. In: G. Esping-Andersen, ed., Continental European social policy. Welfare states in transition. National adaptations in global economies. London: Sage, pp. $66-87$.

ETUC. (2012). ETUC action programme on gender equality. Available at: www.etuc.org/ en/document/etuc-action-programme-gender-equality.

Eurostat. (2015). EU statistics on income and living conditions (EU-SILC) methodology private households. Eurostat. Available at: http://ec.europa.eu/eurostat/statistics-explained/ index.php/EU_statistics_on_income_and_living_conditions_(EU-SILC)_methodo logy_-_private_households [Accessed 26 February 2016].

Eurostat. (2016). People at risk of poverty or social exclusion. Eurostat. Available at: http://ec.europa.eu/eurostat/statisticsxplained/index.php/People_at_risk_of_poverty_ or_social_exclusion [Accessed 26 February 2016].

Evans, A. (2016). The decline of the male breadwinner and the persistence of the female carer: Exposure, interests and micro-macro interactions. Annals of the American association of geographers, 106(5), pp. 1135-1150.

Gallie, D. and Paugam, S. (eds.) (2000). Welfare regimes and the experience of unemployment in Europe. Oxford: Oxford University Press.

Gangl, M. (2001). European patterns of labor market entry: A dichotomy of occupationalized vs. non-occupationalized systems? European societies, 3(4), pp. 471-494.

Ganzeboom, H.B., De Graaf, P.M. and Treiman, D.J. (1992). A standard international socio-economic index of occupational status. Social science research, 21(1), pp. 1-56.

Hadjivassiliou, K., Tassinari, A., Speckesser, S., Swift, S. and Bertram, C. (2015). Policy performance and evaluation: United Kingdom. WP3.3/UK. STYLE Working Papers. Brighton: University of Brighton. Available at: www.style-research.eu/publications/ working-papers.

Hadjivassiliou, K., Tassinari, A. and Swift, S. (2015). Barriers to and triggers of policy innovation and knowledge transfer in the UK. STYLE Working Papers, 4.1/UK. CROME, University of Brighton. Available at: www.employment-studies.co.uk/ resource/barriers-and-triggers-policy-innovation-and-knowledge-transfer-uk.

Kogan, I. and Müller, W. (ed.) (2003). School-to-work transitions in Europe: Analyses of the EU LFS 2000 Ad Hoc module. Mannheim: Mannheimer Zentrum für Europäische Sozialforschung. 
Korpi, W. (2000). Faces of inequality. Gender, class, and patterns of inequalities in different types of welfare states. Social politics, 7(2), pp. 127-191.

Loughhead, S. and Mittal, O. (2000). Urban poverty and vulnerability in India: A social perspective. Social change, 30(1-2), pp. 33-54.

Massey, D. and Constant, A. (2005). Labour segmentation and the earnings of German guestworkers. Population research and policy review, 24(5), pp. 489-512.

Meeuwisse, M., Severiens, S. and Born, M. (2010). Reasons for withdrawal from higher vocational education. A comparison of ethnic minority and majority non-completers. Studies in higher education, 35(1), pp. 93-111.

Mooi-Reci, I. and Ganzeboom, H. (2015). Unemployment scarring by gender: Human capital depreciation or stigmatization? Longitudinal evidence from the Netherlands, 1980-2000. Social science research, 52, pp. 642-658.

Morrone, A., Scrivens, K., Smith, C. and Balestra, C. (2011). Measuring vulnerability and resilience in OECD countries. Presented at the IARIW-OECD Conference on Economic Insecurity, Paris, France, November 22. Available at: www.iariw.org/papers/2011/mor ronepaper.pdf.

Mills, M. and Prag, P. (2014). Gender inequalities in the school-to-work transition in Europe. Short Statistical Report No. 4. Rand Europe.

O'Neill, T. and Domingo, P. (2016). Women and power: Overcoming hurdles to women's leadership and decision making. London: Overseas Development Institute.

Peracchi, F. and Depalo, D. (2006). Labor market outcomes of natives and immigrants: Evidence from the ECHP. SP Discussion Paper No. 0615 Social Protection, World Bank.

Plantenga, J. and Manuela, S.L. (2013). Starting fragile: Gender differences in the youth labor market. Luxembourg: Publications Office of the European Union.

Rubin, J., Rendall, M.S., Rabinovich, L., Tsang, F., Oranje-Nassau, C. and Janta, B. (2008). Migrant women in the European labour force current situation and future prospects. Santa Monica, CA: RAND Corporation.

Smith, M. (2012). Social regulation of the gender pay gap. European Journal of Industrial Relations, 18(4), pp. 365-380.

Smith, M., Toraldo, M.L. and Pasquier, V. (2015). Barriers to and triggers of policy innovation and knowledge transfer in France. STYLE Working Papers. WP4.1/FR. Brighton: CROME, University of Brighton.

Wallace, C. (2002). Opening and closing borders: Migration and mobility in East-Central Europe. Journal of Ethnic and Migration Studies, 28(4), pp. 603-625.

Walther, A. and Pohl, A. (2005). Thematic study on policy measures concerning disadvantaged youth. Study commissioned by the European Commission. Tübingen: IRIS.

Walther, A. (2006). Regimes of youth transitions: Choice, flexibility and security in young people's experiences across different European contexts. Young, 14(2), pp. 119-139.

Whelan, C.T. and Maitre, B. (2010). Welfare regime and social class variation in poverty and economic vulnerability in Europe: An analysis of EU-SILC. Journal of European Social Policy, 20(4), pp. 316-332. 


\section{Precarious and creative \\ Youth facing uncertainty in \\ the labour market}

\section{Sonia Bertolini, Valentina Moiso and Marge Unt}

\section{Introduction and theoretical background}

Today, young people grow up in a context of extensive transformations in work opportunities, which encourages innovative practices in the way they organise their everyday lives. Most of these innovative practices are still individual efforts, attempts to manage ambivalence and uncertainty. Nevertheless, they may anticipate the capacity to act and to speak in a pioneering way, to set up an original and exemplary action that could become a model for the action of a wider part of the population. In particular, those among them with high social and cultural capital, more in tune with practices of mobility and interconnectivity, recognise it and put it into viable schemes for interpretation and evaluation. The chance to take disparate elements from these current models in order to put together one's life in a specific way depends on their economic and technological opportunities, on their network of accessible relationships and on the individual's own personal abilities to choose. It requires the development of specific skills based mainly on access to and management of the symbolic codes used and valued in various contexts, and on the capacity to move from one context to another (Rebughini et al., 2017).

Difficulties in entering the labour market complicate the situation of young people, who are already being sorely tested from the point of view of the transition into adult life. Literature (Blossfeld et al., 2005) stressed that job uncertainty is not the same for everyone and in every context, because it is filtered by the institutions (employment system, educational system, welfare state system and family system). On the side of the employment system, the spread of flexibility could take place without a substantial reform of the welfare state system and without the implementation of adequate active employment policies, as in Italy, increasing the perception that if you lose your job, you are exposed to high income uncertainty and a low probability of re-employment. Therefore, in changing jobs, a risk arises not only for those going from atypical work to typical jobs, but also from the atypical towards situations of unemployment or even inactivity, because in the absence of a contract renewal, in times of economic crisis, many people stop looking for work. The guidance provided by the educational system and proposals for vocational training, with rare exceptions, does not yet seem able to help young 
people overcome work uncertainty by defining career paths that are consistent with their skills.

The presence of policies inspired by the logic of de-commodification and defamilisation is another relevant point in structuring the context of opportunities for young people. At the meso level, the economic capital of the family of origin, which protects them in the periods when they await work, as well as the cultural capital that provides metacognitive resources (Berloffa, Modena and Villa, 2015) and social capital, affect the ways and the times when one finds work and the transition to a stable, good-quality job.

Therefore, the institutional, social and cultural contexts radically change the perspective within which individuals make decisions and help reconcile the different transitions (Mayer, 1997; Heinz, 2001). Starting at this point, this chapter focuses on the decisional mechanism and strategies at the individual level. The focus is on investigating the link between uncertainty in the labour market and autonomy, that is, leaving the parental home and being able to financially provide for their own needs, highlighting the coping strategies youth put in place in different institutional contexts.

The results come from a comparative qualitative analysis lasting three years in the frame of the EXCEPT project - Horizon 2020 programme: 386 interviews with young people aged 18-30 in nine European countries (Bertolini et al., 2018). Evidence from recent research has shown that job insecurity leads to putting off decisions regarding the transition to adult life (Blossfeld et al., 2005; Nazio, 2008; Barbieri and Scherer, 2009; Bertolini, 2011; Jansen, 2011; Reyneri, 2011; Blossfeld et al., 2012; Bertolini, Hofacker and Torrioni, 2014; Rebughini et al., 2017). The problem is that long-term planning for your career, and consequently private life, becomes difficult, if not impossible, when working with short-term contracts. However, having to halt planning because you do not know what will happen next, once your contract has ended, may induce an attitude - that is, playing for time - which then spreads to other dimensions of life.

\section{Research design: highlighting creativity facing precariousness}

To take into account the context in analysing individual decisional mechanisms means to take into account the influence the social fabric that surrounds them has on the actor, without losing the reference to action with its own sense of a Weberian paradigm. Deviations from standard rationality thus are not immediately defined as irrational behaviours but are traced back to the good reasons that guide actions or to the practical sense that guides individuals.

We are referring to a model of rationality that is more complex than the standard one, so in our perspective, some distorting elements of the latter are no more than alternative kinds of rationality. Individuals, first of all, encounter limitations in resorting to explicit knowledge, i.e. when they implement 'rational' processes of research, hypothesis verification and learning, thus arriving at simplified 
representations of the situation. Therefore, we have sought traces of the intentional meaning of their action, which does not coincide with the instrumental rationality of the neoclassical economic paradigm. Such a level of analysis, however, also highlights the use by individuals of tacit or paradigmatic knowledge that is part of their experience and emotional baggage. The actors have a particular practical sense, which they activate when encoding information and making decisions. The baggage that allows individual action to be practiced (agency) is also composed of a series of cognitive maps of reality definition, cognitive schemes to understand and interpret the real, which constitute the link between the ways of doing and those of feeling proper to the emotional sphere (De Leonardis, 2001).

In order to trace these cognitive patterns in our particular research object, a good way may be to enter into the concept of heuristics developed in cognitive psychology (compare Gigerenzer and Todd, 1999; Goldstein and Gigerenzer, 2002; Monti et al., 2009), that is to say, those simple rules systems that people follow to face problems and make decisions in the face of complex systems and incomplete information. Giving attention to the practical sense of individual actors, and to the simple rules that inform their actions, allows us to discover many mechanisms that would not have emerged otherwise. In particular, we are referring to creative solutions that youth put in place in order to face uncertainty in the labour market.

Literature has highlighted the role of creativity for the young generation, given the changes in institutional setting - labour market and welfare state, but also the production system (Armano and Murgia, 2012; Morgan, Wood and Nelligan, 2013; Rebughini et al., 2017). Particularly in more recent years, the literature about creativity has moved ever closer to the studies on social innovation, which is to search innovative solutions to social problems that affect contemporary society, such as youth unemployment in Europe.

In this frame, the institutional actor - the state and therefore social policies becomes increasingly absent in providing opportunities for young people, who are alone in facing the risk of uncertainty (Beck, 1986; Sennett, 1998). In particular, we look at decision mechanisms and strategies of young people facing the transition of leaving the parental home and then looking for housing and economic autonomy in an uncertain labour market.

The framework of the chapter is based on the following links (Figure 5.1). The focus on subjectivity is important in order to allow the simple rules and the practical sense to emerge: in this way, it is possible to complete the information on the impact of job insecurity on youth life that emerged from previous quantitative studies. Job insecurity is accompanied by postponement of transitions to adult life, non-default transitions order and reversible transitions (Rindfuss et al., 1988; Buchmann and Kriesi, 2011). The first consequence of job insecurity, which is having an inadequate income, goes hand in hand with loss of sustainability of household expenses, non-payment of fines and other expenses and over-indebtedness (Fourcade and Healy, 2013; Perrin-Heredia, 2013). In the literature, there is a lack of studies moving from qualitative approaches that at the same time take into account the reconstruction of institutional contexts (see Moiso, 2018). 


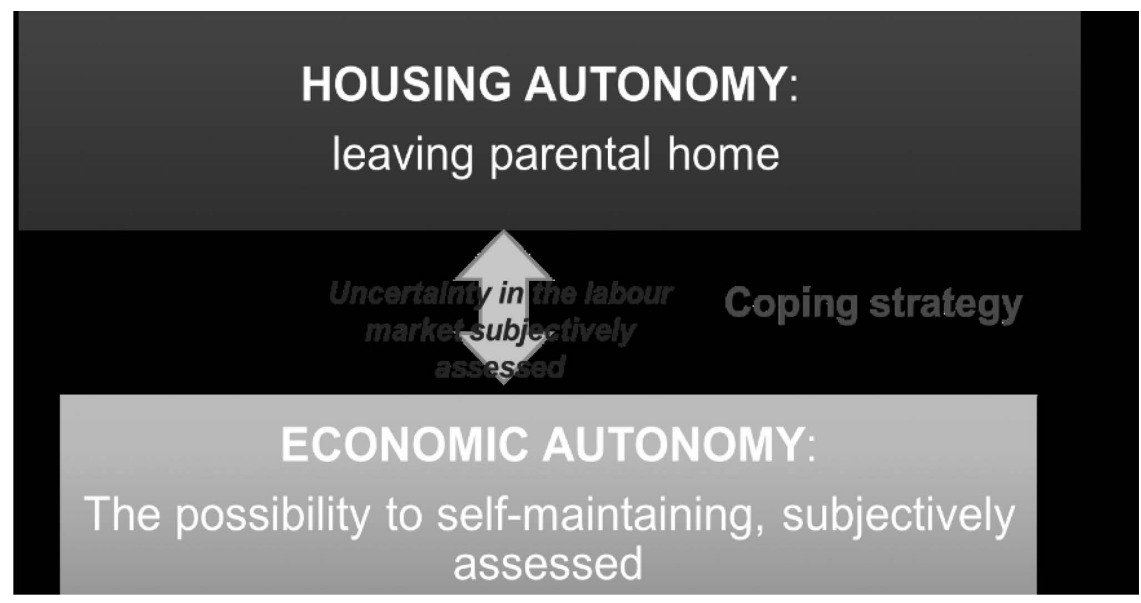

Figure 5.I Conceptual map

\section{Institutional context}

In Italy, youth employment status shows a high level of unemployment compared to the EU average: $35 \%$ in the $15-24$ age group and $16 \%$ in the $25-34$ age group (Reyneri, 2011; Eurostat, 2017; see Bertolini, 2018). In the frame of flexibility, several labour market reforms have introduced temporary contracts in the last years, but adequate forms of social protection are not yet available (Bertolini, 2011). The risk of being trapped in a secondary and sub-protected labour market is higher for young people with respect to older workers (Barbieri, 2011). The crisis in 2008 has worsened this situation. The data show an increase in fixed-term and atypical contracts especially for young people. At the same time, a higher number of NEET among youth (Eurostat, 2017) and an increased risk of poverty in comparison with other age groups are due to the uncertainty and the low level of salaries linked to the atypical contracts (Eurostat, 2016). In the absence of a minimum income scheme, in Italy, the family is still the main provider of welfare and the first form of support young people turn to in case of unemployment or low labour market attachment (Saraceno, 2014; Meo and Moiso, 2018).

In Estonia, the status of youth employment shows a lower level of unemployment than the EU average: $12.1 \%$ in the $15-24$ age group and $5.2 \%$ in the $25-49$ age group (Eurostat, 2018). However, the youth employment situation has been volatile, as Estonia was severely hit by the last crisis when youth unemployment was skyrocketing. However, Estonia recovered more quickly than many other EU countries from the last recession, and its unemployment rate has been decreasing since 2011. Since the employment protection legislation is relatively low for everyone, the temporary contracts are not widespread. It is also important to mention 
the overall level of public funding available for activation and social protection. In Estonia, the public spending on social protection and active labour market measures are well below the EU average. Although investments in active labour market measures have risen since its accession to the European Union in 2004, they are still less than half of the EU average in 2016 (0.18\% of GDP in Estonia vs $0.42 \%$ in the EU-28) (Unt, 2018). Thus, also in Estonia, the family is still the main safety net in case of unemployment or low labour market attachment.

\section{Data and method}

We will compare the youth strategies of young people in Estonia and Italy. The sample is composed of 103 interviews conducted during the period December 2015-November 2016 with young people aged 18-30, temporary workers, unemployed or working 'under the table', balanced by gender and educational qualifications.

The Italian sample consisted of 50 young people, balanced for gender and age: there were 25 young men and 25 young women; 25 were aged 18-24, while the other 25 were aged 25-30. Regarding their educational level, 26 out of 50 interviewees had a secondary level of education (ISCED 3, only one ISCED 4), 12 had a low educational level (ISCED 0-2) and 12 had a tertiary education (ISCED 5-6). With respect to the well-known Italian territorial divide, 31 of them were living in the city of Turin (in Piedmont, northern Italy) and 19 in Catania (in Sicily, southern Italy). In terms of involvement in targeted policies, 27 interviewees had been involved in policy measures, but only one with a form of economic support, and 23 participants had not participated in any such measures.

The Estonian sample consisted of 53 young people, balanced for gender and age: there were 25 young men and 28 young women; 24 were aged $18-24$, while the other 29 were aged 25-30. Regarding their educational level, 23 out of 50 interviewees had up to a lower secondary level of education (ISCED 0-2), 21 had completed upper secondary education (ISCED 3-4) and 9 had a tertiary education (ISCED 5-6). With respect to the territorial divide, 29 were from the two largest cities in Estonia, Tallinn and Tartu, and 24 were from counties located near the south-eastern border of Estonia and a county at the north-eastern border. In terms of involvement in targeted policies, 29 interviewees had been involved in policy measures, and 24 participants had not participated in any such measures.

The interviews were semi-structured: leaving a free narration, the person interviewed was given the opportunity to indicate the most important aspects for them in relation to the uncertainty. Through the comparison with 'control' questions that asked them to explain the moments, the problems and the most important concerns related to this, we wanted to trace the heuristics activated by the actors in the processes of information collection and maturation of choices.

With different variations between countries depending on the institutional structure in Estonia and Italy, we have found creative strategies in the following areas: housing choices, cost containment and savings. 


\section{Housing choices}

In the frame of autonomy, the first problem for young people working in an uncertain labour market is to face the income discontinuity. Regarding their housing choices, the results showed some creative solutions: sharing a house, returning to the parental house, having autonomy at intermittence or autonomy elsewhere or a partial autonomy.

\section{Sharing a house (for necessity) in both countries}

Cohabitation allowed for sharing expenses with other people and lowering their living costs. To share expenses and reduce living costs is widespread in countries where you do not leave your parents' home to live as a couple (Bertolini et al., 2018), such as in the United Kingdom, Sweden and Poland. In Italy, the interviewees living outside the parental house told a different story with respect to the past. In fact, the experience of living in a house shared with flat mates was quite common among them, and this result was something totally new for Italian youth, who in the past were not used to doing so. Even some of those living in the parental house at the moment of interviews had moved out for some periods in the past, mainly to enter University or to pursue other educational/working experiences in a town different from their own. However, the cohabitation seemed to work as a temporary strategy.

In Estonia, cohabitation is considered more normal, especially among young people leaving the parental home while they are studying. Still, seeing as the heating can be very expensive during winter, even cohabitation is not always enough for young people to cover their expenses, and they are forced to move back to their parental homes.

Sharing as a creative solution for young people facing uncertainty in the labour market is a well-known issue in the literature, especially in analysing new solutions to contain the costs of self-employed workers (D'Ovidio, 2016). Sharing practices are presented in the frame of reciprocity, solidarity and the creation of a virtuous circle of exchanges among people. In contrast, exploring motivations and feelings on the basis of this choice in our sample, young people would prefer to live alone and share their homes only for economic reasons.

\section{Returning to parental house (always out of necessity) against living with parents and redefining autonomy}

In the event of unemployment, many interviewees who were already living alone decided to return to the parental home. In Estonia, many interviewees had studied elsewhere and then returned to the parental household because they could not afford to live alone anymore. Thus, returning home in this case has been a way to cover the break between the end of an educational path and the start of their 
working path. Returning home is also a coping strategy in case of a breakup: when the couple splits, it is much harder to cover the costs of housing alone, or the apartment is left to the other partner.

Indeed, perhaps in connection with ever-decreasing job opportunities due to the economic crisis, it appears that job insecurity in Italy prompts youth to consider either the most immediate present or the foreseeable future. In this view, you have to focus entirely on the present; consequently, autonomy is limited both in time and space. That is exactly what prevents young people from deciding to leave their family of origin. For our sample, being autonomous mostly meant managing daily or short-term economic problems and decisions and paying for leisure-time expenses and little more.

\section{Autonomy intermittence, autonomy elsewhere and partial autonomy}

Asking for help from parents is the most common strategy, but with differences between countries. In Italy, parents are a normal source of support for young people before going to live alone.

I mean, I don't know, to me it seems quite normal that a family, if they can, would support their child during University. . . . I realize that to stay here in Turin, outside from my parents' house . . . I need the economic support of my parents, in this very moment, I mean, partially at least, not totally, but yes, partially. So . . . I mean I don't, I don't feel totally independent, that's for sure. . . . Now that I've worked a little bit ... I still have some money left (from my last job), so a little bit, I can make do by myself, but before (during University) it was totally on them

(Veronica, F, 26, U, IT)

In Estonia, young people stay at the parental home for financial reasons, being unable to rent their own flat. In order to leave the parental home, they often need parental backup and support, because costs of renting, especially in big cities, are perceived as very high. All the young people who had purchased their own home had received strong support from their parents or other close relatives. One way to reach housing autonomy is via inheritance. For instance, Mai lives in a oneroom apartment without a kitchen with her two children. She owns the apartment, which was bought for her with her grandmother's inheritance when she was 16 . She understands that at the moment she wouldn't manage financially if she didn't own her apartment, so this is a very important protective factor.

I would rather live in a 16 square-meter place, which is mine, than in a rented apartment ... it is small, but it's mine.

(Mai, F, 28, U, EE) 
In Estonia, home ownership is considered desirable among vulnerable youth even if they realise that without a stable job, it is not feasible to have a mortgage. Therefore, only those whose parents are able to guarantee the mortgage and support the payments can opt for the strategy of buying a place to live in. Therefore, young people dream about home ownership, but no one has managed to take concrete steps towards it without strong parental involvement. For instance, Kaidi (F, 22, $\mathrm{U})$ and her partner had saved enough money for the down payment of a flat in Tallinn, but they were unable to get a loan from a bank because only one of them is working. Kaidi's partner's mother was ready to take out the loan in her name for them. They will be paying the loan payments themselves.

\section{Cost containment and savings}

Regarding the cost containment and savings area, results shows these strategies: saving, containing, accounting and programming.

\section{Neither cicadas nor ants}

The youth interviewees were well aware of the inadequacy of their income and were really active in money management strategies. In particular, saving is represented as a necessity for young people. Saving is often related to the lack of income support to help atypical workers in facing periods of unemployment.

Saving was a common strategy across the two national samples. Youth interviewees appeared to be able to adapt their material living conditions to their context and its socio-economic features. However, their ability was strongly limited and conditioned by their job insecurity or low salary level. Despite these difficulties, there were differences among countries given the institutional contexts. In Italy, saving could be a strategy to cope with job insecurity only if losing housing autonomy:

the simple fact of being able to save something, to know that someone pays you to do something . . . this is something that makes you more responsible. ... Seeing as I live with my parents, my housing expenses are almost non-existent.

(Dario, M, 28, permanent employed, IT)

To sum up, for the young interviewees, saving is a short-term strategy to face uncertainty and income discontinuity, without establishing the conditions for a future stability. Therefore, this strategy is necessarily short-term, to buffer uncertainty and discontinuity of income. In other words, it can be seen as a strategy of 'maximization of minimum', according to which, individuals prepare for the worst situation and choose the best option among the worst. The advantage that it offers is that it is not necessary to evaluate all the possible alternatives, but only the worst and the usefulness associated with it. 


\section{Containment (if you are alone)}

In money management, the role of opportunities and constraints given the context in which the individual acts is particularly relevant. In our two samples, institutional differences matter in the following terms: first, income support levels, which are particularly low in Italy, and the legitimisation of family support, higher in Italy. Where income support is limited, the strategy is to consume without spending too much. Many strategies did not include accounting and were limited only to shopping: in these cases, interviewees bought goods only at a sale or else cheap items, avoided expensive shops and looked for free recreational activities. It is a sort of 'readjustment of preferences toward the down period' (Elster, 1999) and/or they construct a new rhetoric to justify their situation, as in the case of Andrea:

I act . . like this week, I'm not going out . . . or if I go out . . . I meet my friend, sometimes he comes to get me, sometimes I go to get him . . . we don't go very far . . . maybe to the nearby park . . . if the park, we take the Frisbee or football ... or we go to the centre, we walk around ... without spending money, without spending anything ... we get around by our own means so we spend even less, in hindsight ... we spend ONLY on Saturday evening

(Andrea, M, 19, temporary job, IT)

\section{Accounting and programming}

Using cash money, writing expenses and using technology are common strategies among the young people interviewed. Indeed, budget constraint emerged as the most widespread strategy and was enforced in its most literal and direct meaning: some young people used cash only and spread their salary across the entire month by limiting its availability in the house. Therefore, strategies based on accounting were an optimal solution for some young people in order to keep both expenditure and its planning in check:

I support myself financially . . . I created a file, in Excel (laughing), I put in income and expenditure, so that I can make a forecast.

(Emma, F, 20, temporary employed, IT)

Some interviewees described how they divided their income into days or weeks in order to manage until the end of the month, so they knew exactly how much they could spend:

It is like, normal . . . for me that . . I don't have an income all the time. . . . Well and, as I have like, in the previous years, been to America (several times) [to sell books] then it was also like that that I earned most of my income during the summer. . . . And during the rest of the year I didn't have 
much income ... so then you have to know how to distribute your finances for the whole year.

(Sergei, M, 26, permanently employed, EE)

\section{Reframing autonomy}

As for the mechanisms which link a weak attachment in the job market to postponing an exit from the parental home, the interviews showed that attitudes have changed compared to those highlighted in previous research. Indeed, job insecurity is likely to make it impossible for young people to make optimal decisions concerning their lives: halting decision-making appears to be the mechanism young people use to manage high insecurity and uncertainty. Moreover, it's not just that juveniles postpone decision-making about the transition into adulthood (because it requires time and money), since their decisions are also, and most importantly, affected by a range change: decision-making becomes short-term, and self-binding decisions become problematic.

It is possible to say that, rather than making their decisions under risk conditions (i.e. in situations where they can take into account and estimate the probability of each possible result), young people make their decisions under insecure conditions (i.e. some probabilities are unknown). Simply, the institutional context they are embedded in doesn't allow them to understand why and how to get a steady job and a secure income, which they nonetheless deem essential for even planning on leaving their family of origin, let alone starting their own.

Searching for a link among the previous strategies, it is possible to find a common thread among the interviewees from the two countries. Young Italians are in some sense forced to share housing with other people, and they prefer to return to the parental house. This preference is linked to a widespread and important strategy for the Italian interviewees: saving. For Italian young people, staying at home is a waiting strategy that can be analytically seen as a norm of sustainability. This situation leads to a redefinition of the concept of autonomy and one's own level of autonomy. For the Italian interviewees, 'Autonomy' is not living alone. The re-composition of resources requires the support of one's peers:

A person can be autonomous, not necessarily because they live on their own, in a small flat or house, but also continuing to live with others.

(Edoardo, M, 31, temporary job, IT)

Moreover, 'Autonomy' is not only supporting oneself, because wages are so low that to be economically autonomous, one would have to give up living.

For Estonians, autonomy is highly valued, seeing as it has been a general norm to move out of the parental home rather early. However, it is very challenging to obtain housing without a stable and sufficient income, and therefore, living with 
one's parents for longer is perceived as a new normality, especially by males, the unemployed and those living outside of the biggest towns.

It's just different nowadays. Before you left home, left school, got married and a job, got an apartment, stuff. Well, um things are different now. People just continue living at their parents' home, their parents work and they then live off their parents' income.

(Erki, 24, M, unemployed, EE)

To sum up, this implies important consequences in terms of representation of autonomy among young people with lower social and cultural capital.

Comparing states in which the value of the norm is very different - in Estonia it is very important, in Italy less so - has shown that at the moment young people in Europe are facing similar problems. In both countries young people's creativity has a function of resilience in dealing with the economic consequences of job insecurity: creativity lies in actively re-composing available resources. On the other hand, our analysis has shown the character of short-term strategies of these behaviours. In both countries, there is the lack of specific policies dedicated to young people both in terms of labour, housing, access to credit to sustain their transition to adult life and their short-term strategies for creating conditions for youth to plan their future.

\section{References}

Armano, E. and Murgia, A. (2012). Mappe della precarietà. Bologna: Odoya.

Barbieri, P. (2011). Italy: No country for young men (and women). In: H.P. Blossfeld, S. Buchholz, D. Hofacker and K. Kolb, eds., Globalized labour markets and social inequality in Europe. Basingstoke: Palgrave Macmillan, pp. 108-146.

Barbieri, P. and Scherer, S. (2009). Labour market flexibilization and its consequences in Italy. European sociological review, 80, pp. 1-16.

Beck, U. (1986). Risikogesellschaft: Auf dem Weg in eine andere Moderne. Frankfurt am Main, Germany: Suhrkamp.

Berloffa, G., Modena, F. and Villa, P. (2015). Changing labour market opportunities for young people in Italy and the role of the family of origin. Working Paper, n. 998. Banca d'Italia.

Bertolini, S. (2011). The heterogeneity of the impact of labour market flexibilization on the transition to adult life in Italy: When do young people leave the nest? In: H.P. Blossfeld, D. Hofäcker and S. Bertolini, eds., Globalized labour markets and social inequality in Europe. Basingstoke: Palgrave Macmillan, pp. 163-186.

Bertolini, S., Hofacker, D. and Torrioni, P. (2014). L'uscita dalla famiglia di origine in diversi sistemi di Welfare State: L'impatto della flessibilizzazione del mercato del lavoro e della crisi occupazionale in Italia, Francia e Germania. Sociologia del lavoro, 136(IV), pp. 125-144.

Bertolini, S. (ed.) (2018). Giovani senza futuro? Insicurezza lavorativa e autonomia nell'Italia di oggi. Roma: Carocci. 
Bertolini, S., Bolzoni, M., Moiso, V. and Musumeci, R. (a cura di) (2018). The comparative qualitative research methodology of the EXCEPT project. EXCEPT working paper no. 53. Tallinn: Tallinn University Press. Available at: www.except-project.eu/ working-papers.

Bertolini, S., Deliyanni-Kouimtzi, K., Bolzoni, M., Ghislieri, C., Goglio, V., Martino, S., Meo, A., Moiso, V., Musumeci, R., Ricucci, R., Torrioni, P.M., Athanasiades, C., Figgou, L., Flouli, A., Kostouli, M. and Sourvinou, M.N. (2018). Labour market insecurity and social exclusion: Qualitative comparative results in nine countries. EXCEPT working paper no. 53. Tallin: Tallinn University Press. Available at: www.except-project.eu/ working-papers/.

Bertolini, S., Moiso, V. and Musumeci, R. (2018). Young adults in insecure labour market positions in Italy, results from a qualitative study. EXCEPT working paper no. 18. Tallin: Tallinn University Press. Available at: www.except-project.eu/working-papers/.

Blossfeld, H.P., Klijzing, E., Mills, M. and Kurz, K. (eds.) (2005). Globalization, uncertainty and youth in society. London: Routledge.

Blossfeld, H.P., Buchholz, S., Hofäcker, D. and Bertolini, S. (2012). Selective flexibilization and deregulation of the labor market. The answer of continental and Southern Europe to increased needs for employment flexibility and its consequences for social inequalities. Stato e Mercato, 96, pp. 363-390.

Buchmann, M.C. and Kriesi, I. (2011). Transition to adulthood in Europe. Annual review of sociology, 37(1), pp. 481-503.

De Leonardis, O. (2001). Le Istituzioni: Come e perché parlarne. Roma: Carocci.

D'Ovidio, M. (2016). The creative city does not exist: Critical essays on the creative and cultural economy of cities. Milano: Ledizioni.

Elster, J. (1999). Alchemies of the mind: Rationality and the emotions. London: Cambridge University Press.

Eurostat. (2016). Europe 2020 indicators - employment. Available at: http://ec.europa.eu/ eurostat/statistics-explained/index.php/Europe_2020_indicators_-_employment.

Eurostat. (2017). Europe 2020 indicators - employment. Available at: http://ec.europa.eu/ eurostat/statistics-explained/index.php/Europe_2020_indicators_-_employment.

Eurostat. (2018). Europe 2020 indicators - employment. Available at: http://ec.europa.eu/ eurostat/statistics-explained/index.php/Europe_2020_indicators_-_employment.

Fourcade, M. and Healy, K. (2013). Classification situations: Life-chances in the neoliberal era. Accounting, Organizations and Society, 38(8), pp. 559-572.

Gigerenzer, G. and Todd, P.M. (1999). Fast and frugal heuristics: The adaptive toolbox. In: G. Gigerenzer and P.M. Todd, eds., Simple heuristics that make us smart. New York: Oxford University Press.

Goldstein, D.G. and Gigerenzer, G. (2002). Models of ecological rationality: The recognition heuristic. Psychological review, 109(1), pp. 75-90.

Heinz, W.R. (2001). Lavoro e corso di vita: prospettive di ricerca comparative. In: C. Saraceno, ed., Età e corso della vita. Bologna: il Mulino.

Jansen, M. (2011). Employment insecurity and its repercussion on family formation - a theoretical framework. In: H.P. Blossfeld, D. Hofäcker and S. Bertolini, eds., op. cit.

Mayer, K.U. (1997). Notes on a comparative political economy of life courses. In: L. Mjoset, F. Engelstad, G. Brochmann, R. Kalleberg and A. Leira, eds., Comparative social research. Greenwich, CT: JAI Press, pp. 203-226. 
Meo, A. and Moiso, V. (2018). Precari e autonomi: un binomio (im)possibile. In: S. Bertolini, ed., op. cit.

Moiso, V. (2018). Circuits of trust and money. The resilience of the Italian Credito Cooperativo. In: I. Chambost, M. Lenglet and Y. Tadjeddine Fourneyron, eds., The making of finance: Conventions, devices and regulation. London: Routledge.

Monti, M., Martignon, L. and Gigerenzer, G. (2009). Le decisioni nel marketing finanziario: Dall'homo oeconomicus all'homo heuristicus. In: M. Balconi and A. Antonietti, eds., Scegliere, comprare: Dinamiche di acquisto in psicologia e neuroscienze. Berlin: Springer, pp. 57-80.

Morgan, G., Wood, J. and Nelligan, P. (2013). Beyond the vocational fragments: Creative work, precarious labour and the idea of 'flexploitation'. The Economic and labour relations review, 24(3), pp. 397-415.

Nazio, T. (2008). Cohabitation, family and society. New York: Routledge.

Perrin-Heredia, A. (2013). Le 'choix' en économie. Le cas des consommateurs pauvres. Actes de la recherche en sciences sociales, 199(4), pp. 46-67.

Rebughini, P., Colombo, E. and Leonini, L. (eds.) (2017). Giovani dentro la crisi. Milano: Guerini e associati.

Reyneri, E. (2011). Sociologia del mercato del lavoro. Vol. 2, Le forme dell'occupazione. Bologna: il Mulino.

Rindfuss, R.R., Morgan, S.P. and Swicegood, G. (1988). First births in America: Changes in the timing of parenthood. Berkeley: University of California Press.

Saraceno, C. (2014). Simmetrie perverse. I paradossi delle politiche di contrasto alla povertà negli anni della crisi in Italia. Social policies, 1, pp. 27-40.

Sennett, R. (1998). The corrosion of character: The personal consequences of work in the new capitalism. New York/Londres: W.W. Norton \& Company.

Unt, M. (2018). Way to work - strengthening the links between active labour market policy measures and social support services. Estonian country report. DG EMPL. Available at: ec.europa.eu/social/BlobServlet?docId=19783\&langId=en. 


\title{
Chapter 6
}

\section{Youth and precariousness in Spain}

\section{Beyond a waiting time}

\author{
Benjamín Tejerina
}

\section{The analyses of precariousness in Spain}

The issue of precariousness has attracted the attention of numerous researchers in recent decades, to the point of turning the concept of precariat into a way of defining the living conditions in contemporary societies (Standing, 2011). Some research studies have focused on the loss of centrality of work and its repercussion on the identity of young people (Pérez-Agote, Santamaría and Tejerina, 2005; Santamaría, 2009). Other studies have contributed to institutionalising concepts such as weak employment (Alonso, 2000, 2008), flexible and precarious workers (Bilbao, 1998; Díaz-Salazar, 2003) and work crisis (Castel, 1998).

A research line on precariousness has focused on the construction of subjects whose most relevant characteristic is the lack of some social attribute, in terms of identity or in terms of material assets: single mothers (Tobío and Fernández Cordón, 1999; González, Jiménez and Morgado, 2004) or reconciliation of work and family life (Carrasquer and Torns, 2007; Prieto, Ramos and Callejo, 2008).

Another line of analysis has focused on youth understood as a rite of passage (Van Gennep, 1986; Turner, 1988) and as precarious identity: wage conditions and work flexibility (Santos, 2003; Sánchez Moreno, 2004) that make youth emancipation and the fulfilment of life projects difficult, reinforcing dependent family relationships. The situations described by these research studies are the result of a shortage of resources necessary to become independent (Casal, 1996; Jurado, 2007; Pérez-Agote and Santamaría, 2008). According to these studies, the main difficulties are related to the housing market, the wage situation, the temporary nature of work, and also the role of the Mediterranean family, which condition the strategies to reach adult life (Olivares, 2002; Rico, 2005; Trilla and López, 2005; Machado, 2007) and the process of construction of identity (Sánchez Moreno, 2004; Díaz Moreno, 2007; Sánchez Moreno and Barrón, 2007).

The problem of employment in certain circumstances leads to situations of social exclusion. Several authors have called attention to the effects of working conditions on new generations, in sharp contrast with those lived by their previous generations (Pérez-Agote et al., 2001a, 2001b; Cal Barredo, 2002; Casal et al., 2006; Jiménez et al., 2008). 
A fifth line of research has dealt with the political dimension of precariousness understood as the relationship between the labour market, processes of emancipation and political option, which, albeit having weakened in recent decades, still has an influence. Similarly, special attention has been given to political culture, from the approach of youth behaviours, especially the relationship established between voting orientation and work situation, as well as the repercussion that both ideology and the economic situation have on this relationship (Lago, 2007; Salido and Martín, 2007). There are also studies that focus on the historical process and the way young people socialise within the context of the culture of precariousness (Gálvez, 2005, 2007a, 2007b).

Along the same lines, the studies related with the topic of social capital, voluntary work, associationism and social movements are worth mentioning. These aspects are important if we take into consideration that from the onset of the crisis in 2007, there has been a considerable increase in mobilisation around social precariousness (Tejerina et al., 2006, 2008; Tejerina, 2010).

Special mention should be made of Montero, Font and Torcal's studies on political confidence, social capital and associationism (2006). Likewise, the issues of participation and associationism (Ariño, 2004) have been studied more in depth.

Within the context of political action, analysis has been made of the way in which mobilisation against precarisation is produced and the context of political structure and opportunity in several European countries (Mosca, 2006). Some of the most recent political mobilizations, like those taking place in Arab countries such as Tunis, Egypt and Morocco, and more recently, those of the 15-M movement in several places in Spain, have had great ownership among youth sectors. The anti-austerity mobilisation has had a remarkable response among young people in different geographical contexts (Jiménez, 2016).

\section{Definition and methodology}

The term precarious, ${ }^{1}$ formerly reserved to fields such as health, construction, government action and peace, is now often found in colloquial language referring to a particular type of juncture, situation or state of things characterised by a lack of strength and stability. It can be considered a condition when associated to something permanent or a situation experienced in a context of greater or lesser availability of means and resources. As pointed up by Le Blanc (2007), the anthropological sense of precariousness is associated to the uncertainty and contingency that characterise the human condition.

The discourse on precariousness has been present in social sciences in categories such as anomie, alienation, marginality and poverty. An element that appears regularly in the conceptual development of precariousness is that of insecurity, a concept that in the contemporary era we find associated with risk, uncertainty and complexity. Precariousness regularly appears linked to the welfare state and its integration and exclusion policies (Castel, 2004, p. 324). Within the French context, the expansion of the term takes place first in relation to poverty linked to 
vulnerable families (Pitrou, 1978), then with employment status (Schnapper and Villac, 1989) and, in the 1990s, in relation to work (Paugam, 2007). In the meantime, in the Anglo-Saxon context, from the 1990s on, precariousness is related to flexibility and corrosion (Sennett, 2000).

Precariousness experiences a semantic shift from marginal towards a progressive approach to the field of work and employment, and with authors like Bourdieu (1999), Beck, Giddens and Touraine, its meaning moves towards the social structure or structuring processes of contemporary societies.

Precariousness is a concept that encompasses many aspects of life, but its recent development has taken place through processes revolving around the labour market and its constraints on the life and social relationships of subjects (Beck, 2000; Sennet, 2000; Prieto, 2007).

Precariousness can be understood as a structural situation or a circumstantial context in which people find themselves forced to act. Precariousness coming from the labour context, which then extends to other areas of people's lives, has mainly been analysed from this approach. Life precariousness can be defined as a situation of a structural or circumstantial origin characterised by a restriction, impossibility or limitation of access to the conditions, requisites and resources considered necessary in order to plan, carry out and manage an autonomous life. The level of restriction or limitation can reach different degrees of intensity according to the average available resources in a given society. Thus, precariousness is a relational category in a double sense: (a) in relation to the average of the given society, group or social category; and (b) in relation to the different areas of life (Tejerina et al., 2012, p. 22).

Precariousness is a concept that brings together the personal condition and situation in the relationship between an individual and the environment. Precariousness is the state one reaches through processes of precarisation understood as de-institutionalised life spaces. Precarisation processes affect identity insofar as individuals lose the modalities of attachment of the 'I' to the 'us' and the 'you', or see them altered.

Precarisation as a process reaches different dimensions related to entries and exits into and from risk zones, which refer to the limitations of individuals' resources and capacities: work, remuneration, consumption, residence, educational qualification, environment, family and emotional life, social relationships, health and civic engagement. Institutions also participate in precarisation as a process, through the practices of public action or by its absence, and through the regulation of precariousness insofar as institutions teach individuals to move within it.

In most cases experiencing precariousness, managing a daily existence filled with constraints and the strategies developed by individuals and collectives encompass very negative social consequences. However, there is still the possibility of understanding and analysing such strategies under the principles of social creativity and innovation, from the imaginative search for solutions in a situation of restriction of resources. 
Considered from this perspective, precariousness is not only a restrictive or punctual shortage but also a structural and generalised factor that becomes inserted in social life. Precariousness appears, not just like a failure of the system that needs repaired (discourse of exclusion/integration); rather, precarious situations are a mechanism associated with society's way of functioning.

It is worth noting that this mechanism has at the present time been accelerated in what we could call late modernity, settling at the very core of social life. Ultimately, precariousness does not operate only as a generator of residual, marginal spaces for exclusion; it has rather become a definer of daily social situations. Also, in the same sense, it has become a concept that articulates sociological definitions that cannot be explained anymore using the classical vocabulary of the social sciences (Tejerina et al., 2012, p. 23).

The various processes of precarisation and their multiple formulations can be put in order around a distinction between two theoretical-methodological definitions: that of simple precariousness, and that of generalised precariousness or complex precariousness.

Simple precariousness is understood as a synonym of shortage, in the closest sense to the common use of this word. It is therefore a negative feature, something punctual that needs solved: shortage, lack, instability, insecurity and insufficiency. This way of understanding precariousness corresponds with situations of regulatory crisis that produces highly vulnerable, deficient and disintegrated social spaces.

The second type of precariousness is understood as tenure, as a positive feature. Precariousness is not seen as something to be solved; rather, it is defined as life world that, having instability as a factor, requires managing and forces the development of singular strategies. In this way, precariousness is not a temporary situation but becomes a generalised precariousness or complex precariousness.

The interest of complex precariousness resides in that it allows us to better analyse the presence of the different managing strategies that, from a creative point of view, develop those who find themselves facing life precariousness, giving room to new ways of being and thinking precariousness. Our hypothesis is that, youth being one of the worse-hit sectors by precarisation processes, the worlds of precariousness are present in a generalised manner, or become present in a more intense manner, in certain situations of young people's social life.

The methodology involves the interpretation of data obtained using qualitative techniques. For the analysis of the definitions and experiences of precariousness, the metaphors young people use to narrate their situation and their biographical strategies, we conducted 45 semi-structured interviews and 10 focus groups with young people, between the ages of 20 and 34 at the time of the interview. For this study we selected only verbatim from nine personal interviews and one focus group, whose characteristics are presented in Table 6.1. 


\section{Methodological annex}

Table 6.I List of individual interviews and focus group

EI Female, 29 years. Holds a degree in teaching. Working as shop assistant. Living as a couple in an apartment with a mortgage.

E2 Female, 29 years. Holds a degree in law. Preparing for a job selection test. Living with her parents.

E3 Male, 29 years. Holds a degree in business administration. Unemployed. Living with his parents.

E4 Male, 29 years. Vocational education. Environmental technician. Living in a rented, shared apartment.

E5 Male, 25 years. Student. Temporary jobs. Living with a partner in a rented apartment.

E6 Female, 32 years. Holds a degree in translation and interpreting. Freelance translator. Living with a partner in a rented apartment.

E7 Male, 29 years. Vocational education. Has a temporary contract as a docker. Living with a partner in an apartment with a mortgage.

E8 Male, 28 years. Civil engineer. Has a temporary contract in equipment building. Long working days. Living with a partner in a rented apartment.

E9 Female, 30 years. Holds a diploma in social education. Temporary jobs. Health problems. Living in a rented, shared apartment.

EIO Male, 33 years. Has a supervised job. Living with his mother.

EII Female, 30 years. Single mother. Receiving Income Support Benefit (Renta de Garantía de Ingresos, RGI). Living in rented social housing.

EI2 Colombian female, 30 years. Single mother. Jobs without a contract. Living in rented accommodation.

GI Group of five women, around 30 years, emancipated and nonemancipated.

The information used in this chapter comes from four investigations in which the author acted as director between 2009 and 2018: (1) CSO2008-00886, 'Vital precariousness. The processes of precarisation of social life and identity in contemporary Spanish society'; (2) 'Vital precariousness and Basque youth. Social conditions and biographical strategies to lead a normal life'; (3) CSO2011-23252, 'Social responses to the crisis and processes of precarisation of life in contemporary society: Belgium, Spain, France, Italy and Portugal'; and (4) CSO201678107-R, 'Sharing society. The impact of collaborative collective action'.

\section{Meanings, narratives and experiences of precariousness}

There is a rather general consensus among social scientists about the diagnosis of the importance of risk and uncertainty in contemporary societies (Giddens, 1984; Beck, 2000; Bauman, 2001, 2003, 2005). The core idea in this diagnosis is that we find ourselves in a society characterised not by the administration of risk, but rather by radical uncertainty. 
The question we seek to answer in this section is whether this general uncertainty is part of how young people define their situation today because it has become part of their everyday experience. With this purpose, we will use the verbatin from the interviews carried out with young people throughout more than a decade. Let us remember that the people interviewed do not suffer extreme situations of precariousness; they have a middle or high level of education and, in most cases, they can get family or public help.

The use of the term precariousness in colloquial language appears associated with or as a synonym of different elements. The most frequent is that of job instability. If we take into consideration the testimonies gathered in the interviews, people tend to position themselves in a scale ranging from stability to instability. Instability tends to be associated with the lack of continuity or duration in time: 'I get temporary things, but stable jobs don't come up' (E5), or 'I have always had jobs, but I have not had a stable job' (E2). The challenge significant groups of young people are facing is how to reach job stability, especially at a time of increasing job market flexibility. Thus, the aim of some young people is to find out how to construct a life based on unstable stability.

Secondly, precariousness is defined as an experience of not fitting: I am not in the right place, I have wasted my time and the capabilities I have acquired are being lost: 'I studied for seven years, and I feel like I've lost those years, if I had studied a module' (E3); and 'I have studied for tomorrow to have a job . . . not to be in a store. I want to have a job for what I have studied all my life!' (E1).

The experience of precariousness is becoming subjective in a process of internalisation of the situation and the responses to get out of it or avoid the lack of stability. According to the testimony of the young people interviewed, this is achieved in two ways. The first way is through the permanent updating of the knowledge and competences acquired during education, which extends throughout the whole of the productive life: 'Today, training is a trade . . . what you studied four years ago has already become obsolete. ... They ask you for more and more of everything' (E3). The second way is by resorting to entrepreneurial capacity, investing in one's own capacity: 'Everything comes to you if you are an entrepreneur' (E7); and 'more training, so I will be more competitive' (G1). Ulrich Beck has called these subjects 'proletarians of self-realization'; Michel Foucault used the term 'entrepreneur of the self', and Isabell Lorey (2009) referred to 'self-precarisation' to define the situation of cultural producers (Carbajo, 2016, p. 1).

The experience of insurmountable difficulty pushes many young people to seek help or cooperation from other actors, mainly relatives or the public sector. Most testimonies point out the difficulty in getting through, in living with sufficiency: 'I have to tighten the belt a little, because with the salary and the public subsidy (RGI) it is still not enough' (E12). This situation can lead to the person's deactivation, to feeling overwhelmed and impotent: 'I feel bad, impotent, I cannot do anything' (E11); 'work can consume you, you're cannon fodder' (E10).

In the narratives about young people's everyday life, we find continuous references to the cliché of misfortune 'I've been lucky that where I am I'm fine' (E10). 
This also applies when they refer to the possibility of getting residential autonomy through the purchase of a home, which can only happen if you're lucky or you get a home from social housing drawing lots: 'It is very difficult to buy a house if you are not lucky' (E4).

Resources to alleviate precariousness come from two main sources, the family and public subsidies. The first is widely accepted and is generalised among young people who do not live far from their relatives or visit them regularly: 'When we visit the family we return home with Tupperware' (E4), and 'I managed in that my family supported me financially' (E6). The second one is highly stigmatised, to the point that receiving these types of support is like living on 'crutches', becoming a prosthetised subject who cannot live without his prosthesis: 'I do not like having to make an appointment with the social worker, I do not like to receive this (social help)' (E12), and 'I do not like to receive this (help) ... I feel sorry, anguished and in the end this tires me' (E11).

The definitions of what is precariousness are subject to variations according to the social position of the young people interviewed; but at the same time, the experiences narrated tend to point to a common territory, known and visited frequently or permanently, and a present time defined by the uncertainty which makes it difficult to think about the future.

\section{Metaphors about precariousness}

Where the meaning of common words cannot reach, metaphors can, by occupying the place of that which is being represented and helping to render visible some elusive elements. Both individual interviews and focus groups are riddled with such secondary references, which bring closer the meanings and consequences of precariousness, and the situations it produces with great economy of language. I shall develop this through six metaphors and images of how they experience precariousness: 'living from hand to mouth', 'being on a tightrope', 'stressed like crazy', 'in stand-by', 'taking a step backwards' and 'I want to be normal'.

The absence of long-term income stability among young adults is a source of unrest that each person copes with in their own way. As we mentioned earlier, it is the main source of uncertainty. The expression used to refer to this situation is quite a graphic one, 'living from hand to mouth'. Let us look at two testimonies: 'I do not have money in the bank, but I can live daily' (E4), and 'Tight, there are months that I live better, months that I live worse' (E6). Living day by day, week by week or month by month, but without a blue sky on the horizon, is a considerable part of a stage of transition, redefinition, positioning and search, but also a stage with an absence of the need to plan for the future, of basically thinking about the present, a nowism (Muñoz, 2007).

We find a second way of referring to uncertainty in the expression 'being on a tightrope'. The metaphor of the tightrope walker, trapeze artist, or the slackline refers to situations of lack of safe anchoring, of swaying that makes one's way an existence full of oscillations. The testimony of this young person explains it very 
clearly: 'Being a bit out there, on the wire, like the tightrope walkers . . . something precarious is something that does not have much balance, I do not know how to define it, that it can come down' (E5). Being on a tightrope prefigures a present that can sink at any time. This dimension of 'being on a tightrope' has become more pronounced among young people as a result of the financial and social crisis of 2008, but its roots predate this. The difficulties are faced as they arise, and one of the first consequences is the impossibility or difficulty in elaborating mid or long-term projects.

This way of living configures a mentality and a series of patterns to psychologically confront its consequences. The experience of precariousness also has implications for the body that generates resilience in young people to get through difficult and stressful situations, but also fears and processes of medicalisation to live with it day by day. Anxiety is a characteristic syndrome in precarious situations. Let us stop briefly in both dimensions. The lack of achievement of life expectations, especially when they are not realistic, reinforces resistance and the capacity to cope with these situations: 'The tolerance to frustration is barbaric, the management of stress to the maximum' (E9); 'I lost my tendency to get fat, but I'm not happy with myself' (E11). On the other hand, when the situation becomes uncontrollable from a personal point of view, the individual feels overwhelmed by the situation, as E12 expresses, 'it's killing me, it's really killing me'; and if one seeks professional help, medicalisation of anxiety increases the uneasiness and lack of confidence towards the health system, 'when they ask me the question, what are you afraid of? Of the doctors . . . they have made me such tricks' (E9).

The most common situation among Spanish young people is the experience of playing a waiting game, a situation where the plot is about to end, but while the good times and the good news arrive, the subject is in 'stand-by' mode; connected but at a standstill. This situation means an extension, sometimes desired, but generally not wanted, of being at home with the family, not being able to emancipate and have an autonomous life alone or with a partner. The lack of a stable job and the impossibility of living independently extend the transition into adult life. E2 expresses it in the following statement: 'I am already 30 years old and I feel like it a lot, to be able to leave home I need a stable job'. Also, couple projects are affected by this waiting situation: 'We have been together 11 years as a couple and you have the urge to have your own home', as E8 says; and 'I have already a desire, I wanted to go and live with her', in the words of E3.

Our testimonies represent experiences, which are generalised among contemporary young people, not just affecting a minority, and hence concepts such as transition into adult life or what it is to be an adult are called into question and require, at least, a redefinition (Furlong and Cartmel, 2007). We find a clear example of the crisis in the concept of transition from training to work. Testimonies are abundant on the mismatch between training and jobs occupied. The mismatch is between capacities and opportunities. The most frequent response is that of 'taking a step backwards' in order to take a step forward, the only way of reassembling the mismatched pieces: 'I think I should have studied something different' 
(E2). On other occasions, people go back into education, especially when one is overqualified, to try to get some training more in tune with what one wants to do or to increase the opportunities of finding another job, entering a spiral of requalification, excess of education, excess of qualification (Budría and Moro-Egido, 2008; Nieto and Ramos, 2010).

If precariousness is present in contemporary society, we should ask ourselves: what does normality consist of? Normality is defined as the absence of uncertainty and is identified with the common and ordinary actions, practices and desires of everyday life: 'I would like to see myself as a parent, with two children, and taking my children to see Athletic [of Bilbao, local football team]' (E3), or simply, 'Leave home and live my life' (E2).

\section{Debate}

The relationship of Spanish youth with precariousness is not all that different from that experienced in other European countries or in other geographical areas by young people born from the mid-1980s onward. It is, however, possible to identify two differential aspects: first, higher unemployment rates and difficulties in finding stable jobs, if we compare these magnitudes with other countries in central and northern Europe; second, the greater impact of the financial and social crisis of 2008 in Spain, compared with that experienced in other countries.

Nevertheless, precariousness (in a wider sense), uncertainty and the absence of normality are present in the lives of contemporaries. It is possible that, if Inglehart is right, those who have been socialised at a specific time of scarcity or prosperity construct clearly differentiated visions of the world and social values.

Six axes allow us to analyse the biographical strategies of contemporary young people's biographical strategies faced with precariousness, and are presented here for debate.

One, although there are important differences between the different types of precariousness, as there are higher or lower degrees of precariousness, we find that, in all cases, young people experience a mismatch between their capacities and the practical realisation. This gap makes them take a step backwards in order to keep going forward: going back to education, training in something different, re-qualifying, changing their place of residence, reinventing themselves. The idea pursued with this is to reassemble two realities that are perceived as mismatched.

Two, individual precariousness is not perceived as coming from a structural origin, so that the management of such situations is oriented to individual changes and processes of personal transformation.

Three, the responsibility of the situation is almost always attributed to each individual and demands a resilient response. This leads to working on one's own identity, a non-stop activity of investing in oneself, what we have come to call entrepreneurship of the self and, in some cases, a hyperactivity that leads to doing things non-stop. 
Four, family solidarity is key in understanding how young people can get stability in situations of precariousness, as is the existence of social support through public aid and subsidies. As stated in other research studies, it is reasonable to think that in southern European countries, the welfare state is more dependent on family help; while in other geographical areas, the state has more solid and developed mechanisms to deal with misfortune. But while family help is accepted without any difficulties, the second can be accompanied with social and personal stigma.

Five, the temporality in which young people are nowadays installed make it practically impossible to plan for the mid term. Living day by day and conjugating existence in the present tense is the correlate of the trivialisation of uncertainty.

Six, the transition from dependence to independence that used to occupy a short period of time in the past has been extended in recent decades. Extending the years devoted to education, together with the current working conditions and the difficulties in finding job stability, expand the time used to carry out this transition. The result is that new youth figures appear and the category of adult itself becomes blurred, as in many cases it does not establish a clear break with previous stages. Far from just waiting in this prolonged youth, what we usually find is a non-stop activity to withstand or overcome the impact of precariousness.

\section{Note}

1 A detailed development of the relationships between crisis and vital precariousness, as well as the definitions used in this chapter, can be found in Tejerina et al. (2012).

\section{References}

Alonso, L.E. (2000). Trabajo y postmodernidad: el empleo débil. Madrid: Fundamentos.

Alonso, L.E. (2008). Jóvenes: Precariedad laboral, precariedad de vida. Gaceta sindical: Reflexión y debate, 10, pp. 67-84.

Ariño, A. (2004). Asociacionismo, ciudadanía y bienestar social. Papers: Revista de Sociología, 74, pp. 85-110.

Bauman, Z. (2001). The individualized society. Cambridge/Malden, MA: Polity Press.

Bauman, Z. (2003). Trabajo, consumismo y nuevos pobres. Barcelona: Gedisa.

Bauman, Z. (2005). Vidas desperdiciadas: La modernidad y sus parias. Barcelona: Paidós.

Beck, U. (2000). Un nuevo mundo feliz: La precarización del trabajo en la era de la globalización. Barcelona: Paidós.

Bilbao, A. (1998). El trabajador precario. Arxius de sociología, 2, pp. 39-56.

Bourdieu, P. (1999). Actualmente la precariedad está en todas partes. In: P. Bourdieu, ed., Contrafuegos. Reflexiones para servir a la resisteneia contra la invasión neoliberal. Barcelona: Anagrama.

Budría, S. and Moro-Egido, A. (2008). Education, educational mismatch and wage inequality: Evidence for Spain. Economics of education review, 27(3), pp. 332-341.

Cal Barredo, M.L. de la (2002). Precariedad laboral y precariedad vital en los jóvenes. Inguruak: Revista Vasca de Sociología, 32, pp. 67-87. 
Carbajo, D. (2016). Proletarios de la auto-realización: Un abordaje crítico del emprendimiento juvenil. Communication Presented at the XII Congress of the Spanish Federation of Sociology, Gijón.

Carrasquer, P. and Torns, T. (2007). Cultura de la precariedad: Conceptualización, pautas y dimensiones. Una aproximación desde la perspectiva de género. Sociedad y Utopia, 29, pp. 139-156.

Casal, J. (1996). Modos emergentes de transición a la vida adulta en el umbral del siglo XXI: Aproximación sucesiva, precariedad y desestructuración. Revista Española de Investigaciones Sociológicas, 75, pp. 296-316.

Casal, J., et al. (2006). Cambios en las modalidades de transición en los países de capitalismo informal. Papers: Revista de sociología, 79, pp. 195-233.

Castel, R. (1998). La fin du travail, un mythe démobilisateur. París: Le Monde diplomatique.

Castel, R. (2004). La metamorfosis de la cuestión social: Una crónica del salariado. Buenos Aires: Paidós.

Díaz Moreno, V. (2007). Los jóvenes y las nuevas formas de movilización social y política. Sistema. Revista de ciencias sociales, (197-198), pp. 283-295.

Díaz-Salazar, R. (ed.) (2003). Trabajadores precarious: El proletariado del siglo XXI. Madrid: Hoac, D. L.

Furlong, A. and Cartmel, F. (2007). Young people and social change. New York: McGraw Hill.

Gálvez, S. (2005). La 'cultura de la precariedad' o los 'usos y costumbres' de las empresas: Un balance histórico del impacto generacional de la reforma del Estado de los trabajadores de 1984. Sociedad y Utopía, 25, pp. 19-52.

Gálvez, S. (2007a). La generación de la cultura de la precariedad: Una aproximación desde la historia del movimiento obrero. Sociedad y Utopia, 29, pp. 333-366.

Gálvez, S. (2007b). Las relaciones capital-trabajo en España: La 'cultura de la precariedad' como pauta cultural. Sociedad y Utopía, 29, pp. 105-113.

Giddens, A. (1984). The constitution of society: Outline of the theory of structuration. Cambridge: Polity Press.

González, M., Jiménez, I. and Morgado, B. (2004). Parejas y formas de convivencia de la juventud. Revista de Estudios de Juventud, 67, pp. 145-163.

Jiménez, B., et al. (2008). La emancipación precaria: Transiciones juveniles a la vida adulta en España a comienzos del siglo XXI. Madrid: Centro de Investigaciones Sociológicas.

Jiménez, M.L. (ed.) (2016). Jóvenes en movimiento en el mundo globalizado. México: UNAM-Newton.

Jurado, T. (2007). La precariedad temporal-salarial y sus efectos sobre la formación familiar. Sociedad y Utopia, 29, pp. 367-404.

Lago, I. (2007). Precariedad laboral y participación electoral desigual. Sociedad y Utopía, 29, pp. 451-461.

Le Blanc, G. (2007). Vidas ordinarias, vidas precarias. Buenos Aires: Nueva Visión.

Lorey, I. (2009). Gubernamentalidad y precarización de sí. Available at: http://ayp.unia.es/ r08/IMG/pdf/Gubernamentalidad-y-precarizacio.pdf [Accessed 11 April 2018].

Machado Pais, J. (2007). Chollos, chapuzas, changas: Jóvenes, trabajo precario y futuro. Barcelona: Anthropos.

Montero, R., Font, J. and Torcal, M. (2006). Ciudadanos, asociaciones y participación política en España. Madrid: Centro de Investigaciones Sociológicas. 
Moreno, A. (2000). Las familias monoparentales. Revista internacional de sociología, 26, pp. 39-63.

Mosca, L. (2006). May Day parade: Movilizaciones juveniles contra la precariedad laboral. Revista de Estudios de Juventud, 75, pp. 75-97.

Muñoz, A. (2007). Tácticas de comunicación juvenil: intervenciones estéticas. Revista de Estudios de Juventud, 78, pp. 11-23.

Nieto, S. and Ramos, R. (2010). Sobreeducación, educación no formal y salarios: evidencia para España. Documento de Trabajo no. 577. Madrid:Fundación de las Cajas de Ahorros.

Olivares, M.A. (2002). El proyecto profesional: un instrumento relevante en la transición a la vida activa del Universitario. Pedagogía Social: Revista interuniversitaria, 9, pp. 277-285.

Paugam, S. (2007). Las formas elementales de la pobreza. Madrid: Alianza Editorial.

Pérez-Agote, A., et al. (2001a). El trabajo en la Comunidad autónoma vasca. Actividad, ocupación y paro. Bilbao: BBK Gazte Lanbidean Fundazioa.

Pérez-Agote, A., et al. (2001b). La inserción laboral de los jóvenes en Bizkaia. Bilbao: BBK Gazte Lanbidean Fundazioa.

Pérez-Agote, A., Santamaría, E. and Tejerina, B. (2005). Transformaciones y tendencias de la cultura del trabajo en Bizkaia: Enfoque cuantitativo. Bilbao: BBK Gazte Lanbidean Fundazioa.

Pérez-Agote, A. and Santamaría, E. (2008). Emancipación y precariedad en la juventud vasca: Entre la anomia funcional y el cambio cultural. Bilbao: Servicio Central de Publicaciones del Gobierno Vasco.

Pitrou, A. (1978). La vie précaire: Les familles face à leurs difficultés. París: Études CNAF.

Prieto, C. (ed.) (2007). Trabajo, género y tiempo social. Madrid: Hacer editorial/Universidad Complutense de Madrid.

Prieto, C., Ramos, R. and Callejo, M.J. (2008). Nuevos tiempos del trabajo: Entre la flexibilidad competitiva de las empresas y las relaciones de género. Madrid: CIS.

Rico, N. (2005). Jóvenes: Precariedad más allá de la temporalidad y respuestas sindicales para construir el futuro. Gaceta sindical. Reflexión y debate, 5, pp. 285-295.

Salido, O. and Martín, A. (2007). Las urnas de la precariedad: El anclaje sociolaboral del voto juvenil en el 14-M. Sociedad y Utopía, 29, pp. 463-487.

Sánchez Moreno, E. (2004). Jóvenes: La nueva precariedad laboral: La experiencia de la precariedad laboral en los jóvenes españoles. Madrid: Secretaría Confederal de Juventud de Comisiones Obreras.

Sánchez Moreno, E. and Barrón, A. (2007). Social risk factors in Spanish youth and their impact on self-concept construction. Spanish Journal of Psychology, 10(2), pp. 328-337.

Santamaría, E. (2009). Trayectorias laborales en los márgenes del empleo: Experiencias de precariedad en los procesos de construcción identitaria. PhD Dissertation. Available at: www.educacion.gob.es/teseo/mostrarRef.do?ref=844974 [Accessed 12 June 2018].

Santos, A. (2003). Jóvenes de larga duración: Biografías laborales de los jóvenes españoles en la era de la flexibilidad informal. Revista Española de Sociología, 3, pp. 87-98.

Schnapper, D. and Villac, M. (1989). Rapport à l'emploi, protection sociale et status sociaux. Revue française de sociologie, 30(1), pp. 3-29.

Sennett, R. (2000). La corrosión del carácter: Las consecuencias personales del trabajo en el nuevo capitalismo. Barcelona: Anagrama.

Standing, G. (2011). The precariat: The new dangerous class. London: Bloomsbury Academic. 
Tejerina, B. (2010). The logic of the alterglobal movement. In: D. Singharoy, ed., Dissenting voices and transformative actions: Social movements in a globalizing world. New Delhi: Manohar Publication, pp. 41-67.

Tejerina, B., et al. (2006). O movimento por justiça global na Espanha: Activistas, identidade e cartografia politica da alterglobalizaçao. Sociedade e estado, 21(1), pp. 29-66.

Tejerina, B., et al. (2008). Spagna: Identità e cartografia politica del movimento. In: A. Farro, ed., Europa alterglobal. Componenti e culture del 'movimento dei movimenti' in Europa. Milán: Franco Angeli, pp. 149-175.

Tejerina, B., et al. (2012). Precariedad vital y juventud vasca: Condiciones sociales y estrategias biográficas para llevar una vida normal. Vitoria-Gasteiz: Servicio Central de Publicaciones del Gobierno Vasco.

Tobío, C. and Fernández Cordón, J.A. (1999). Monoparentalidad, trabajo y familia. Revista internacional de sociología, 22, pp. 67-97.

Trilla, T.C. and López, J. (2005). El acceso de los jóvenes a la vivienda: Una cuestión todavía no resuelta. Documentación social, 38, pp. 191-206.

Turner, V. (1988). El proceso ritual. Estructura y antiestructura. Madrid: Taurus.

Van Gennep, A. (1986). Los ritos de paso. Madrid: Taurus. 


\section{The myth of flexibility \\ Young adults' expectations of \\ work in the digital economy \\ in Milan}

\section{Alessandro Gandini and Luisa Leonini}

This chapter aims to expand the existing knowledge about cultures, attitudes and opinions of work of young adults who aspire to pursue a career in the knowledgebased, digital economy. Often referred to in the popular press as 'millennials' - a term that is controversial in and of itself, due to the flexible demographic boundaries by which it is connoted (see Howe and Strauss, 2009) - this generational cohort is invested by a popular narrative that describes it as broadly characterised by a 'different' approach to work if compared to older generations, being largely uninterested in 'jobs for life' and instead aspiring to greater independence and flexibility (see Macky, Gardner and Forsyth, 2008). This, however, goes as an unchallenged assumption also in the existing research on the topic, that is connoted by sparse empirical analyses and a largely oversimplified approach to the issues at stake (Deal et al., 2010; Hershatter and Epstein, 2010; Myers and Sadaghiani, 2010).

To the aim of unpacking and questioning this assumption in greater detail, this chapter presents an empirical exploration of the cultures of work among young adults in Milan. Considered the 'economic capital' of Italy, a country that has among the highest youth unemployment figures in Europe (Eurostat, 2018), Milan is an important hub for what concerns the tech economy, digital innovation and creative work in southern Europe (Gandini, Bandinelli and Cossu, 2017). The main questions this chapter asks are: what are the attitudes towards work that young adults seeking to pursue a career in the knowledge-based, digital economy in Milan display? What are their values, beliefs and expectations of work and the work life? How do these reflect in their personal and professional choices, and the way they see their future careers? To answer these questions, we administered a questionnaire to a group of 19- to 25-year-old students enrolled at various universities in the urban area, who take academic courses in disciplines such as communication, digital culture, management, sociology, political science, advertising and public relations. The questionnaire remained open for four weeks, circulated in the form of an online link, and it received 397 complete responses.

Findings put under question the often-unchallenged assumption that so-called 'millennials' are more interested in the pursuit of independence and flexibility, as opposed to job stability, than previous generations. Young adults aspiring to work 
in the knowledge-based, digital economy in Milan see independence and flexibility as one important aspect in a broader trade-off they seek to strike between job security on one side, and professional aspirations, passions and interests on the other. Despite the popular narrative that proclaims their disinterest in 'jobs for life' and a 'native' predisposition to exploit the chances of mobility and flexibility offered by the digital economy, their ideals and expectations about work seem in fact to be more nuanced than how they are often portrayed. The young adults surveyed in this study value independence and flexibility but not at all costs, and are fully aware of the constraints posed by the pursuit of a career in a context they recognise as highly fragmented. They see themselves as part of a 'transitional generation', being the first cohort that fully experiments the work-life balance options offered by the digital economy, and thus take a realistic stance about their future prospects. These insights suggest that cultures of work in the digital economy among younger generations appear to be more complex than what existing accounts about millennials and work tend to promote, and henceforth deserve more rigorous investigation and analysis.

The chapter is structured as follows. In the next section, we present a review of the emergent issues about the cultures and meanings of work in the knowledgebased, digital economy, as these appear in the international scholarship on the topic. Subsequently, we illustrate the design and administration of the survey at the centre of this work, while at the same time providing greater justification of the context in which this research was undertaken. Then, we look at the main findings emerging from the survey, and finally, we reflect on future research on this issue.

\section{Millennials and work in the digital economy}

An interdisciplinary body of research has questioned the evolving meanings and cultures of work in the rise of the 'new economy' (Castells, 1996). Between the late 1990s and the early 2000s, the idea of a radical change in the way people work, following the diffusion of email communications and, later, of the World Wide Web, seen as harbingers of a new era of innovation and prosperity (Leadbeater, 1997) gained popularity together with an emphasis on entrepreneurialism and the necessity to develop a personal brand as key aspects to establish professionally in a dynamic context (Gandini, 2016).

Scholars in areas such as cultural sociology and critical theory soon raised a critique to the enthusiastic accounts portrayed by this narrative, noting how these implied the prominence of individualistic values applied to work, principled on an 'entrepreneurial ideology' that was deemed to bring cultural and artistic labour closer to business and management professions (McRobbie, 2002, 2004, 2016). This also entailed a critique to the loosening of the boundaries between leisure and work (Neilson and Rossiter, 2005) and to the increased instability, insecurity and precarity (Ross, 2009) of work that characterised this emergent context. 
Later, with the rise of social media, this further evolved in an interpretation that envisaged how work was undergoing a process of delocalisation, displacing and 'untethering' (Johns and Gratton, 2013). The mere fact that work could be executed anywhere, anytime as long as an Internet connection is available led some to proclaim an upcoming 'shift' in the cultures of work (e.g. Botsman and Rogers, 2011). As a consequence of this 'shift', workers were suggested to become a 'startup' of themselves and to make full use of digital media for professional promotion (Hoffman and Casnocha, 2012). Work in the 'new economy' of the Internet was deemed to be a case of 'venture labour' (Neff, 2012), with this notion intending the outsourcing of the economic risk on individual workers who engage in rampant entrepreneurial ventures. This coincided with the rise of co-working spaces and their popularisation as alternative, non-hierarchical workplaces that cater to the needs of a workforce that seeks to be independent and to escape established professional pathways to pursue their passions and interests and engage in collaboration and 'sharing' (Gandini, 2015; Gandini et al., 2017). Some imaginative categorisations of new categories of workers also emerged, such as 'nomad workers' (O'Brien, 2008) and, more recently, 'digital nomads' (Reichenberger, 2018), a term that identifies a group of young, highly educated international workers who exploit the mobility offered by the digital economy and work remotely, on a global scale, in sectors such as digital marketing or the tech industry.

In the midst of this debate, less attention was posed instead on whether this actually constituted a broader cultural shift about work and workers aspiring to pursue a career in the digital economy. This has resulted in the widespread assumption that, because of their digital savviness and their somewhat 'natural' disposition towards taking advantage of the opportunities offered by mobile digital media, the younger generations of workers would by definition be more interested than its predecessors in pursuing the available option of a flexible, independent, entrepreneurial and international career. The few empirical studies available on this matter are, however, contradictory at best. Deal et al. (2010) argue that '(m)ost of the research on employed adults that examines attitudes at work among generations at the same age over time finds a few small statistical differences' if compared to younger generations in terms of work centrality, and conclude that 'what you do not see in the literature is evidence of the types of sweeping differences in attitudes, orientations, and work ethic that populate the popular press'. Others have suggested the existence of a set of assumptions around the changing relationship with work across generations, with older generations being more engaged and committed to the workplace, and younger generations being described as more collaborative but also more impatient, disloyal and disengaged (Myers and Sadaghiani, 2010). Some (Cennamo and Gardner, 2008) instead have pointed at the paucity of empirical data to support the claim of a generational divide on the basis of work values. More recently, Pyöriä et al. (2017) have evidenced how young adults appear to be more flexible in terms of changes to their occupational field than older cohorts, but do not seem to be less work-oriented than previous generations. 
These, however, are still contested claims that require further empirical verification, as they seem to suffer from excessive generalisation and oversimplification. This chapter aims to contribute to this ongoing debate, providing a baseline of empirical data on cultures of work characterising young adults in a context of high youth unemployment that might shed further light on the criticalities behind the categorisation of workers and their attitudes, perceptions and aspirations on a generational basis.

\section{Case justification and methodological note}

In this section we detail findings emerging from a questionnaire distributed to young adults aged between 18 and 25, enrolled in various university courses in the areas of sociology, digital culture and media-related disciplines at the University of Milan, Milan Bicocca, and the Catholic University of Milan. The survey consisted of 22 questions written in Italian, was distributed between October 2017 and January 2018 via a web link through the platform 'eSurveysPro' and gathered 397 complete responses.

There are particular reasons as to why Milan was chosen as the context for this research. Milan is historically considered an important city for the 'new economy' as here framed, due to the presence of a notable creative and cultural sector (Arvidsson, Malossi and Naro, 2010; d'Ovidio, 2010) and has been a lively centre for communications work since the 1980s (Gandini, 2016). In recent years, the local municipality has dedicated attention to the digital economy and the processes of innovation around it (Bonomi and Masiero, 2014), as exemplified by a public co-working scheme that lists shared work spaces 'approved' by the local authority (see Mariotti, Di Vita and Limonta, 2015).

A lively conversation around the impact of atypical work and precarious forms of employment on the younger generations has also animated the Italian public debate for more than a decade (see Armano and Murgia, 2012). In the tradition of the Italian sociology of work, a number of researchers looked at the features and specificities of the Italian labour market (see for instance Biagioli, Reyneri and Seravalli, 2004; Barbieri and Scherer, 2005), also focusing specifically on the changing notions of work for young adults (Bertolini, 2012). This showed the decline of permanent employment opportunities in a context in which the ideal of 'jobs for life' is historically strong (Accornero, 2001) but where self-employment is also among the highest in Europe (Ranci, 2012).

Another interesting aspect that characterises the Italian context is the existence of a highly felt public discourse around the 'crisis' that emerged in the aftermath of the 2007-2008 economic recession, and particularly after the 2011 state debt crisis (see Sacchi, 2015). The aftermath of the recession has particularly impacted the Italian population, both in terms of the actual shrinking of employment opportunities as well as in the public perception as a permanent condition of economic downturn (see Gallino, 2013). As part of this project, therefore, we also wanted to 
explore the extent to which this popular narrative has penetrated in the cultures, expectations and attitudes towards work that characterise the younger segment of Italian working population.

\section{Findings}

\section{Sample and demographics}

The sample is composed of $61 \%$ females and 39\% males. In terms of age, the vast majority of respondents belong to the target cohort of young adults, with the youngest respondents being 19 and the oldest respondents being 28 (median values 19 and 20). While the study is based in Milan, and almost all respondents are Italian, many of them are actually not originally from Milan, having migrated from other parts of the country to study, especially from the so-called 'hinterland' (suburban areas surrounding Milan) and from the southern regions of Italy. This, therefore, reflects an ample picture in terms of geographic variation across the Italian context. The sample mainly consists of undergraduate students (79\%), with a smaller representation of postgraduate students (20\%). Only $1 \%$ of participants already have a postgraduate degree.

In terms of familial demographics, the majority of respondents declared that their parents have a high school diploma as the highest education title (28\% for both parents, $22 \%$ for one of them). Around $22 \%$ of the surveyed participants say at least one of their parents has a degree (22\% at least one, $11 \%$ both of them), but almost $14 \%$ of respondents declare their parents' education title is inferior to a high school diploma. In terms of occupations in the family, fathers of respondents work or have worked a clerical job ('impiegato', $31.5 \%$ ) or as self-employed $(28 \%)$, with an equal percentage of factory workers and managers (18\%). Regarding mothers, $51 \%$ work or have worked a white-collar job (mostly administrative or clerical occupations), while around 14\% were reported as 'teachers'.

\section{What kind of work?}

Concerning the respondents' existing work experience, a relative majority declare $(42.5 \%)$ to be a full-time student with some previous work experience. A $37.5 \%$ of participants both study and work at the moment of answering the survey. This fits the narrative of working students who either develop work experience during their studies or work to earn money and sustain their income while studying. A minority (19\%) of participants have never worked. Among those with work experience, a majority work or have worked part-time (66\%), while $34 \%$ have worked or are working full-time. Internships seem to be a common route to work in the sample $(25 \%)$.

In terms of employment relation, $46 \%$ of participants work or have worked as dependent employees while $37 \%$ are or were employed as external collaborators 
('lavoro parasubordinato'). A minority (9\%) of students surveyed declare to work or have worked as self-employed. Concerning the channels through which they accessed work in their existing experience, a vast majority of participants seem to have found their job via personal or family ties $(61.5 \%)$, while $32 \%$ responded to a job ad (either offline or online). Interestingly, online networking was also mentioned as a quite important channel to find work, albeit in relative terms (7\%).

\section{Perceptions, attitudes, values}

The vast majority of participants declare they have chosen their discipline of study according to their passions and interests (84\%). Only $7 \%$ of participants say they decided their academic path on the basis of career perspectives and irrespective of their personal interests. In many cases, however, the work experience they achieved seems to be related to a field in which they do not want to end up working.

The vast majority of the young adults surveyed in this study (66\%) actually aspire to work in a different sector from the one they have worked in already. Around $9 \%$ of participants want to work a different job in the same sector they already experienced, while only $15.5 \%$ of the students surveyed want to continue with the exact same job. A vast majority want to work in the corporate sector, that remains a considerably attractive option to many (57\%). Interestingly, the portion of students aiming to work in the Third Sector or for an NGO (30\%) also seems to be relevant in relative terms. Only $10 \%$ aspire to work for the public administration.

In terms of employment status, an equal number of the participants surveyed in this study declare they have a preference for dependent work as well as to work as self-employed (27\%). This is an interesting insight considering that this figure is higher than Italy's already higher-than-average figures for self-employment, which sit between 14\% and 17\%, (see EEOR, 2010; Ranci, 2012). This furthermore shows that interest in self-employment is actually high in the younger generations. However, it is also interesting to note that $43 \%$ in fact do not have a clear preference. This may indicate, on the one hand, that young adults in our sample aspire to work no matter what; nonetheless, it might also suggest a deeper disillusion towards the search for permanent employment (more on this later).

In terms of channels to get work, the internship route remains strongly perceived to be a key pathway to employment opportunities (37\%). Also, personal contacts remain strongly perceived as important $(22 \%)$. Job centres $(18.5 \%)$ and university career centres (12\%) seem to be perceived as less important or useful; however, it is interesting to note that online social networking stands at a high $10.5 \%$ as a channel that participants expect to use in order to find a job (this is consistent with Pais and Gandini, 2015).

In addition to closed, multiple-choice questions, the survey included two open-ended text questions aimed to gain a broader set of qualitative insights on the expectations, aspirations and perceptions of young adults towards work 
aspirations. The first of these questions, in order of appearance in the survey, asked participants to specify what kind of job they aspire to, and in which sector. The body of text containing all responses to this open-ended question has then been polished and processed to the aim of producing a mapping 'content cloud' (see Cidell, 2010) and thus devises an exploratory semantic content analysis. Figure 7.1 displays the outcome of this analysis. Word size identifies the recurrence of the tag (the bigger the word, the more times it recurred).

The elaboration presented suggests a widespread interest in our sample around two broad professional areas: socially related work and communications/marketing. While this does not come as a surprise considering the academic courses our respondents are attending, a few things are interesting to note. One is the relevance of the tag 'azienda' (corporation), which suggests that working a white-collar job remains a desirable option for young adults in their future career. A second aspect concerns the words 'internazionale' (international) and 'estero' (abroad), which grasp both the aspiration of working in a transnational, global environment and the perceived necessity to emigrate abroad to pursue a successful career.

On this same topic, the survey subsequently included two questions where participants were asked to determine the degree of agreement they had with the

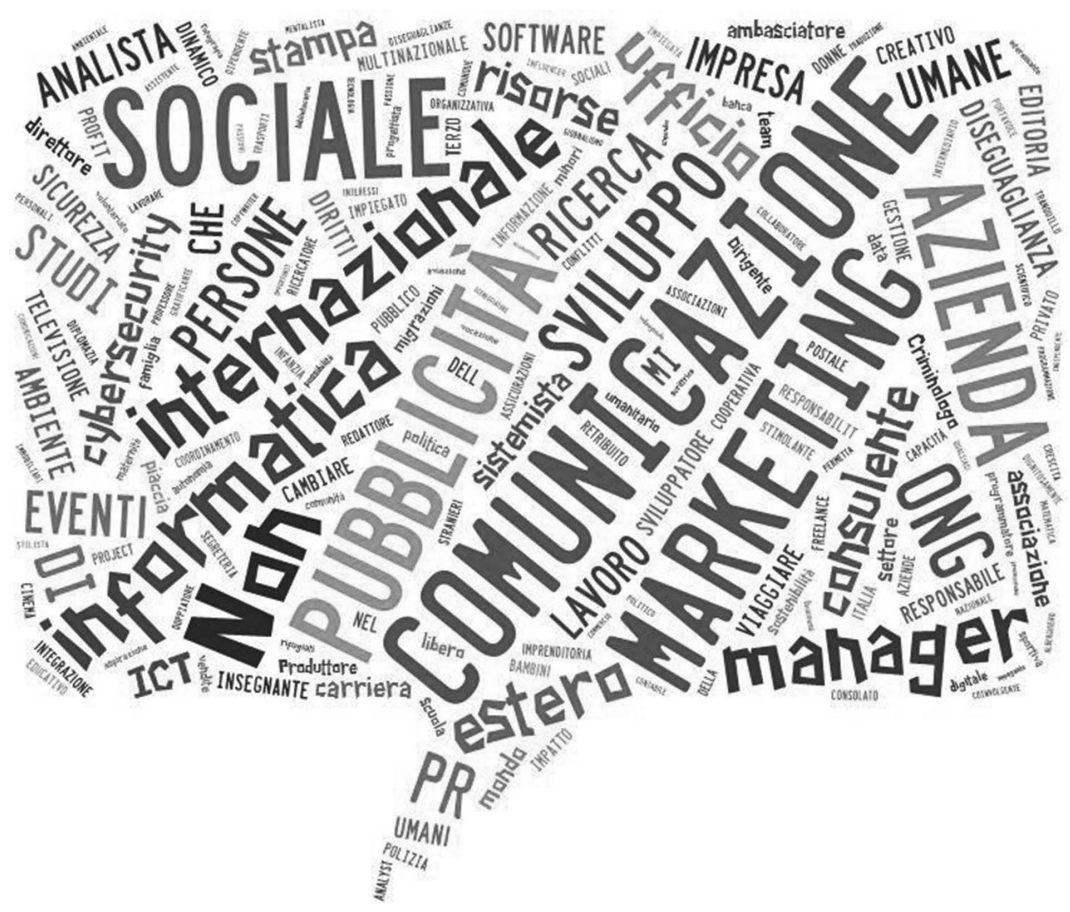

Figure 7.I What work do you aspire to do? 
statement proposed, in a range between 1 (I strongly disagree); 2 (I partially disagree); 3 (Indifferent); 4 (I agree); 5 (I strongly agree). Answers to these questions, taken together, unveil some important insights.

First, the vast majority continues to see a permanent, full-time job as something to aspire to, for a combined $76 \%$ (option $4=30 \%$; option $5=46 \%$ ). This, however, is counterbalanced by the overwhelming relevance of one's passions and interest, that score a combined $91.5 \%$ (option $4=24.5 \%$; option $5=67 \%$ ). At the same time, there seems to be a degree of scepticism among participants for what concerns whether they will be able to apply on the job the skills learned in their studies. Respondents seem to be confident about this, for a combined agreement of $64.5 \%$ (option $4=44.5$; option $5=28 \%$ ), yet we see also a relevant portion of responses indicating indifference to the topic (option $3=22 \%$ ). Economic safety is also perceived quite strongly as a very important element in the mix, thus partially disproving the flexible and entrepreneurial narrative described earlier (combined value of $84 \%$, option $4=28.5 \%$; option $5=55.5 \%$ ).

In line with the content cloud presented earlier, the portion of participants who aspire to do a job that has some kind of societal impact is relatively high (options 4 and 5 to this question account together for around 50\%). At the same time, there seems to be limited interest in developing a career only for the sake of social prestige (option 3, 'indifferent', was the most chosen one for this entry, at 32\%, followed by option 2, 'I partially disagree', at 26.5\%). While these results must be taken with caution due to a possible social desirability bias, they nevertheless suggest a more nuanced attitude towards individualism than what the literature on young adults and work actually suggests, particularly in regards to the debate on 'social innovation' and 'collaboration' (e.g. Bandinelli, 2015).

For what concerns the question of whether participants prefer full-time employment over a less stable but more fulfilling job in an area of interest, the answers are quite mixed, with options 2 ('I partially disagree', 32.5\%) and 3 ('indifferent', 35\%) being the most selected ones. Independence seems to be an important value for many participants - however, it is not a predominant or exclusive one. Participants seem to value autonomy in a permanent, full-time job (answer 4, 'I agree', the highest in relative terms at $34.5 \%$ ) but to slightly prefer the security of employment as opposed to the complete independence given by self-employment or entrepreneurship, with their related risks and insecurities (all middle values roughly equivalent). At the same time, the possibility to work a 9-to-5 job in order to have free time over the weekend is not perceived as highly attractive (option 3, 'indifferent', the highest value at 30\%). On the contrary, the innovative options of 'smart working' and coworking seem to be moderately attractive (option 4, 'I agree', at 38\%, and option 5 , 'I strongly agree', at $24.5 \%$, for a combined $62.5 \%$ ). All in all, results seem to suggest that independence and flexibility do not appear to be a straightforward preference for the sample of young adults here surveyed. Yet, the option to undertake a totally independent, entrepreneurial activity (e.g. managing one's own company) is connoted with nuances of insecurity, and remains a scattered aspiration.

It is also interesting to note that the prospect of emigrating to another country in order to pursue one's dream job is perceived as a favourable option for 
many of our participants (option 5, 'I strongly agree', the highest value at 35\%). This seems to be more preferable than looking for any job close to one's family or place of birth (option 3, 'indifferent', the highest value at 32\%). Finally, when asked about their perceptions of work in the present, if compared to the context of work in the past and particularly the career options available to their parents, results are also mixed. A significant 39\% of participants declare that in their views, the present context is more stimulating and engaging that that of their parents, but also underline that permanent employment is no longer an option to count on. An equally significant $32.5 \%$ believe that it was easier to find work in the past, but this often entailed contenting with 'any' job, a compromise that seems to be overall uninteresting for the vast majority of the sample. Yet, around $18 \%$ of participants believe the context of work was more favourable in the past, because it was easier to find jobs. Slightly less than $10 \%$ believe it is too difficult to find work at all in the present scenario.

A second open-ended question (the last question in the survey) asked participants to describe the work scenario from the perspective of a young adult. Similar to the other open-ended question, the body of text originating from this entry was processed to produce a 'content cloud' and an exploratory semantic analysis was performed. The word cloud in Figure 7.2 visually represents this analysis.

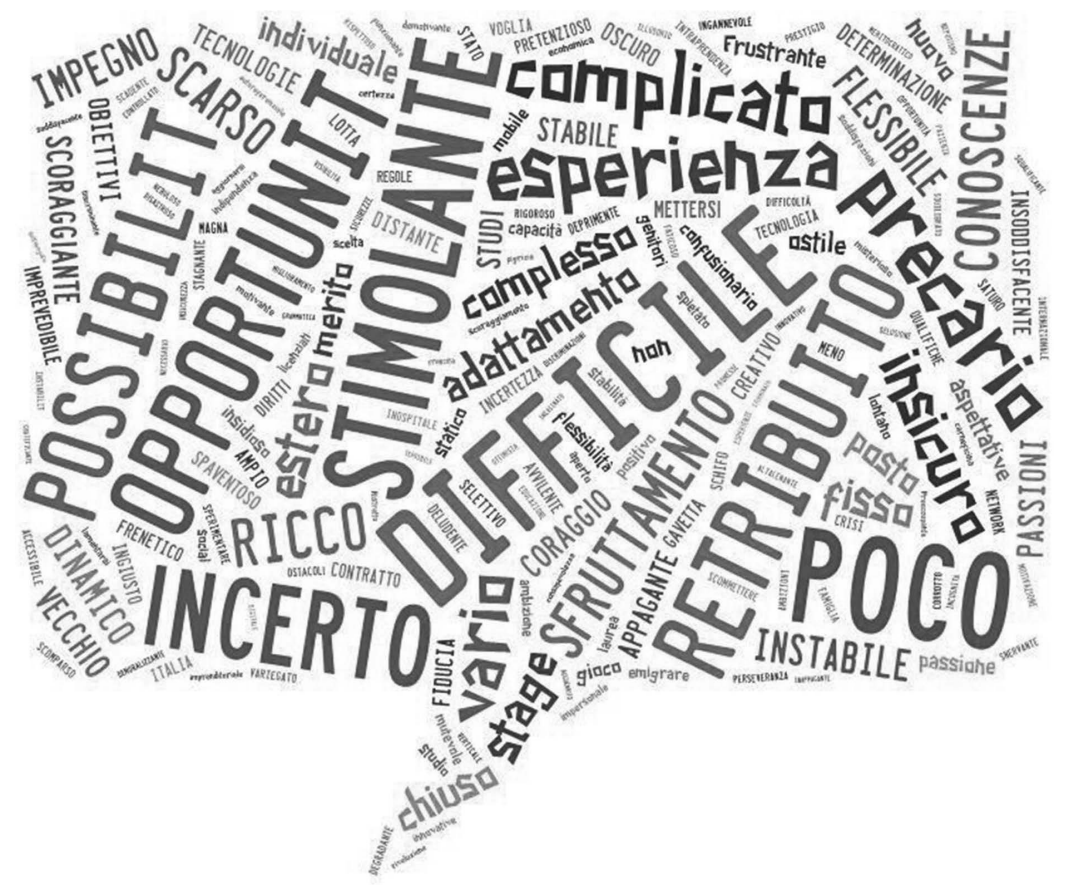

Figure 7.2 How would you describe work today? 
Likewise, word size identifies the recurrence of the tag (the bigger the word, the more it is recurrent).

The visualisation ostensibly displays the trade-off between independence and job security discussed in this chapter. The words 'difficile' (difficult), 'complicato' (complicated), 'precario' (precarious) and 'incerto' (uncertain) juxtapose to the tags 'stimolante' (stimulating), 'opportunità' (opportunity) and 'possibilità' (possibility), to render a scenario that evidences how young adults in Milan are largely aware of the difficulties and constraints they are likely to face in their professional life, but equally recognise the stimulating and engaging side of starting a career in spite of these constraints and, overall, seem to aim to strike a balance between these two broadly opposite poles.

\section{Conclusion}

This chapter has sought to expand the existing understanding of cultures, meanings, expectations and values about working in the knowledge-based digital economy displayed by young adults, commonly referred to also as Millennials and often advocated as a 'different' cohort, that aspires to independence and a flexible worklife. The observation of the Milanese case as an interesting example of a lively digital and tech context in a country that is marked by high youth unemployment and diffused precarity suggests that, contrary to the generalisations and oversimplifications connoted by the popular narrative (and sometimes by research), the notions of a generational difference between younger workers and older cohorts should not be taken as an uncontested assumption. Data offer, instead, a rather nuanced and complex spectrum of opinions by young adults about work that sometimes contradict one another. On the whole, young adults see themselves as in search for a trade-off between independence and flexibility on one side, and job security on the other, as they seek to start a career that gives them a stable future but equally fulfils their passions and interest. These attitudes blend with the continuing significance of the 'jobs for life' ideal, which remains strong in the Italian context, and seem not to have been replaced completely by a narrative of independence and digital mobility, despite the discursive framework of innovation and collaboration by which this generation is connoted and that is also, to some extent, present in this sample.

In an open-ended conclusion, this chapter suggests that wider, rigorous empirical examinations of the issue of a 'cultural difference' in approaches and expectations towards work on a generational divide are strongly needed. It seems interesting, for instance, to investigate further - perhaps in qualitative terms, through interviews or focus groups - why permanent employment remains so relevant in the Italian context (and perhaps beyond) despite at least two decades whereby the younger generations have been exposed to a 'cool' narrative of entrepreneurialism and flexibility that advocated the irreversible evolution towards an entirely mobile, flexible and 'nomad' workforce. Also, it may be interesting to question the extent to which, in the Italian case, the media 
discourse around the economic crisis - which has been strong and extensive for a decade and especially across the Italian state debt crisis of 2011 - may have had an influence in these perceptions, on a par with established familial expectations and class backgrounds.

\section{References}

Accornero, A. (2001). Pezzi di lavoro. il Mulino, 50(1), pp. 102-114.

Armano, E. and Murgia, A. (2012). Mappe della precarietà. Vol. 1 e 2. Bologna: Odoya.

Arvidsson, A., Malossi, G. and Naro, S. (2010). Passionate work? Labour conditions in the Milan fashion industry. Journal for cultural research, 14(3), pp. 295-309.

Bandinelli, C. (2015). Il miglior lavoro del mondo. Milano: Doppiozero-cheFare Books.

Barbieri, P. and Scherer, S. (2005). Le conseguenze sociali della flessibilizzazione del mercato del lavoro in Italia. Stato e mercato, 25(2), pp. 291-322.

Bertolini, S. (2012). Flessibilmente giovani: Percorsi lavorativi e transizione alla vita adulta nel nuovo mercato del lavoro. Bologna: Il Mulino.

Biagioli, M., Reyneri, E. and Seravalli, G. (2004). Flessibilità del mercato del lavoro e coesione sociale. Stato e mercato, 24(2), pp. 277-314.

Bonomi, A. and Masiero, R. (2014). Dalla smart city alla smart land. Venezia: Marsilio Editori.

Botsman, R. and Rogers, R. (2011). What's mine is yours: How collaborative consumption is changing the way we live (Vol. 5). London: Collins.

Castells, M. (1996). The rise of the network society. Cambridge: Blackwell.

Cennamo, L. and Gardner, D. (2008). Generational differences in work values, outcomes and person-organisation values. Journal of Managerial Psychology, 23(8), pp. 891-906.

Cidell, J. (2010). Content clouds as exploratory qualitative data analysis. Area, 42(4), pp. 514-523.

Deal, J.J., Altman, D.G. and Rogelberg, S.G. (2010). Millennials at work: What we know and what we need to do (if anything). Journal of Business and Psychology, 25(2), pp. 191-199.

d'Ovidio, M. (2010). Network locali nell'economia cognitiva-culturale: Il caso di Milano. Rassegna italiana di sociologia, 51(3), pp. 459-484.

EEOR European Employment Observatory Review. (2010). Self-employment in Europe. Available at: http://osha.europa.eu/en/publications/literature_reviews/self-employed [Accessed 28 February 2018].

Eurostat. (2018). Unemployment statistics. Available at: https:/ec.europa.eu/eurostat/ statistics-explained/index.php?title=Unemployment_statistics\#undefined [Accessed 26 September 2018].

Gallino, L. (2013). La lotta di classe dopo la lotta di classe. Bari: Laterza.

Gandini, A. (2015). The rise of coworking spaces: A literature review. Ephemera, theory \& politics in organization, 15(1), pp. 193-202.

Gandini, A. (2016). The reputation economy. Understanding knowledge work in digital society. Basingstoke: Palgrave Macmillan.

Gandini, A., Bandinelli, C. and Cossu, A. (2017). Collaborating, competing, coalescing, coworking: Artists, freelancers and social entrepreneurs as the new subjects of the creative class. In: J. Graham and A. Gandini, eds., Collaborative production in the creative industries. London: University of Westminster Press, pp. 15-32. 
Hershatter, A. and Epstein, M. (2010). Millennials and the world of work: An organization and management perspective. Journal of Business and Psychology, 25(2), pp. 211-223.

Hoffman, R. and Casnocha, B. (2012). The start-up of you: Adapt to the future, invest in yourself, and transform your career. New York: Random House Digital.

Howe, N. and Strauss, W. (2009). Millennials rising: The next great generation. New York: Vintage Books.

Johns, T. and Gratton, L. (2013). The third wave of virtual work. Harvard business review, 91(1), pp. 66-73.

Leadbeater, C. (1997). The rise of the social entrepreneur. London: Demos Publishing.

Macky, K., Gardner, D. and Forsyth, S. (2008). Generational differences at work: Introduction and overview. Journal of Managerial Psychology, 23(8), pp. 857-861.

Mariotti, I., Di Vita, S. and Limonta, G. (2015). Una geografia degli spazi di coworking a Milano. Imprese \& Città, 8, pp. 72-80.

McRobbie, A. (2002). Clubs to companies: Notes on the decline of political culture on speeded-up creative worlds. Cultural studies, 16(4), pp. 516-531.

McRobbie, A. (2004). Everyone is creative: Artists as pioneers of the new economy. In: E. Silva and T. Bennett, eds., Contemporary culture and everyday life. Durham, UK: Sociology Press, pp. 186-199.

McRobbie, A. (2016). Be creative: Making a living in the new culture industries. London: John Wiley \& Sons, Inc.

Myers, K.K. and Sadaghiani, K. (2010). Millennials in the workplace: A communication perspective on millennials' organizational relationships and performance. Journal of Business and Psychology, 25(2), pp. 225-238.

Neff, G. (2012). Venture labor: Work and the burden of risk in innovative industries. Cambridge, MA: MIT Press.

Neilson, B. and Rossiter, N. (2005). FCJ-022 from precarity to precariousness and back again: Labour, life and unstable networks. The Fibreculture Journal, 5.

Pais, I. and Gandini, A. (2015). Looking for a job online: An international survey on social recruiting. Sociologia del lavoro, 137, pp. 115-129.

Pyöriä, P., Ojala, S., Saari, T. and Järvinen, K.M. (2017). The millennial generation: A new breed of labour? SAGE Open, 7(1).

Ranci, C. (2012). Partite Iva: Il lavoro autonomo nella crisi italiana. Bologna: Il Mulino.

Reichenberger, I. (2018). Digital nomads - A quest for holistic freedom in work and leisure. Annals of Leisure Research, 21(3), pp. 364-380.

Ross, A. (2009). Nice work if you can get it: Life and labor in precarious times. New York: New York University Press.

Sacchi, S. (2015). Conditionality by other means: EU involvement in Italy's structural reforms in the sovereign debt crisis. Comparative european politics, 13(1), pp. 77-92. 


\title{
Uncertainty management strategies in the process of identity formation of Polish young adults
}

\author{
Monika Banaś
}

\section{Introduction}

The Polish politics and economy between 2007 and 2015 were shaped by political groups with centre- and socio-liberal tendencies as well as a Christian-democratic core. The party that held power at that time, the Civic Platform (PO, Platforma Obywatelska) was hardly interested in ideological activity (Kolczyński, 2008; Kowalczuk, 2011; Polska Times, 2011). The main issues emphasised in PO's political programme were the economy and the continuation of projects aimed at deepening the integration with the European Union (EU). The vast majority of the supporters of PO and the PO-PSL coalition (PSL, Polish People's Party) originated from large and medium-sized cities, less often from towns and villages, and they had considerable income and higher education (Kowalczuk, 2014; Newsweek Polska, 2015; parlament2015.pkw.gov.pl,). Eight years of PO-PSL's governance resulted in changes in the Polish economy (i.e. liberalising the market and reducing the supervisory role of the state towards economic processes), which on the one hand were expected by a part of the society - especially the wealthier one - but on the other hand, they also led to progressive deprivation of groups already economically disadvantaged. This was reflected, among other things, in growing migration of young people seeking employment in other EU countries. Interestingly, the Polish economy, loosely linked to Western economies, did not feel the shock caused by the economic and financial crisis of 2008 to such an extent. Relatively good ratings of the Polish economy on the international market and its positive evaluation by international rating agencies did not translate into the perceived financial and social security of all citizens (OECD Economic Surveys: Poland, 2014; Polish CSO - Central Statistical Office, 2015). The deepening social stratification seemed to remain unnoticed for the ruling coalition led by the PO. The above was in contrast to the views of the opposition party, Law and Justice (PiS, Prawo i Sprawiedliwość), which, in its programme and election campaigns in 2015, clearly stressed their intent to fight poverty and social inequality as well as direct greater attention towards young people and their better future on the domestic labour market. Stopping the outflow of the young labour force has become one of the priorities of the PiS, which in 2015, in the course of 
democratic elections, finally took over power in Poland. According to analysts, it was precisely the postulates addressed to young people, containing specific solutions regarding the labour market, which were an attractive argument for young voters.

\section{Young adults and the market}

In 2013, in the entire EU community, nearly $21 \%$ of young people aged 25-29 were outside the labour market, not continuing any form of education or apprenticeship. Moreover, young people were often exposed to lack of jobs or limited access to jobs, not only because of their lack of experience. This tendency became more pronounced after 2008 and was characteristic of the vast majority of EU member states (EUROSTAT, 2015, p. 11). It is also worrying that young people experiencing long-term unemployment, which is not a rare phenomenon in this cohort, lose the opportunity to actively participate in society, not only economically, but also culturally and socio-psychologically.

In the case of Poland, statistical data from 2013 regarding employment of young people, considered in the context of the total workforce ( 28 million people aged 15-74) and the total number of economically active people (16 million), are as follows: among people between the ages of 20 and $24,40 \%$ of them were learners only, $11 \%$ combined learning with work and $29 \%$ were only working. For the EU, these figures were respectively: $32 \%$ for learners only, $18 \%$ for those combining learning with work and 30\% for those only working (Eurostat, 2015, p. 140). This comparison shows that in Poland, young people aged 20-24 more often chose (in 2013) not to combine their educational and professional paths. Several factors may stand behind this; inter alia: the traditional way of upbringing, but also the market with its limited labour supply. Traces of this tendency can be found in the answers given by the respondents in the research that I have carried out.

The problem of young people being outside the labour market is not unique to the Polish economy. Unfortunately, this unfavourable phenomenon is also strongly present in other EU and European countries in general. European youth aged 15-24 are, on average, twice as often devoid of job opportunities in comparison to the so-called mature adults, as evidenced by statistical data for the EU area - if, for the total population of people able to work, $7.3 \%$ were unemployed, in the case of youth in 2016 it was as many as 18.7\%. For Poland, the total unemployment rate was then around $4.5 \%$ (the same as in the Netherlands), and in the cohort of young people $-17.7 \%$. For comparison, in the previously mentioned countries such as Greece, Spain, Italy and France, these numbers were much higher, reflecting a critical state of affairs: $21 \%$ and $47 \%, 16 \%$ and $44 \%, 11 \%$ and $38 \%, 9.2 \%$ and $25 \%$, respectively (EUROSTAT, 2017).

The high unemployment rate among young people, which is a result of inadequate supply of jobs, correlated with the highly competitive market, is a set of factors influencing the decisions of young adults on the issue of trying to get more and more education in the hope that this will increase their chances on the 
labour market. Besides, it is not uncommon that taking an additional field of study, another professional course or extending one's studies is seen as a way of deferring the moment of entering adulthood. This moment, as the experience of the last decade, may prove to be an unpleasant rite of passage, often fraught with disappointment and frustration as youthful dreams or ideals are lost in everyday reality (Beck, 1992; Giddens, 2002; Majerek, 2012; Hryniewicz, 2014).

\section{Junk contracts and precariat}

The economic crisis of 2008 resulted in the emergence of specific system solutions, among which there were forms of short-term (up to three months) employment, primarily allowing employers to significantly reduce labour costs. The so-called junk contracts have become a popular form of employment in the economies most affected by financial turbulence of the end of the first decade of the 21 st century. Less than a decade later, in 2016, the highest percentage of people employed in this way, forming the European precariat, was present in Croatia $(8.6 \%$ men and $8.2 \%$ women), France (5.2\% and $4.4 \%$, respectively), Spain (4.5\% and $4.8 \%$ ), Poland (4.8\% and 4.2\%), Finland (3.9\% and 4.8\%) and Slovenia (4.2\% and $4.9 \%$ ); and for the entire EU, 2.2\% for both sexes (EUROSTAT, 2017).

It is worth noting that for a country outside the EU structures, Iceland, characterised by a high HDI ratio, many people were employed under such contracts: $4.1 \%$ men and $4.2 \%$ women. In the case of economies that were the first to experience the effects of the 2008 crisis, the so-called PIIIGS (Portugal, Ireland, Iceland, Italy, Greece and Spain), only Iceland and Ireland managed to overcome financial difficulties relatively quickly. The other four are still struggling with problems that are a direct repercussion of the economic shock of the end of the first decade of the 21 st century (Comston, 2017). In this context, the Portuguese precariat is made up of $3.3 \%$ of the overall number of working men and $3.1 \%$ of working women; in Italy, the numbers are, respectively, $3.2 \%$ and $3.1 \%$; in Greece $-1.8 \%$ and $1.4 \%$; and Ireland, $0.6 \%$ and $0.8 \%$ (EUROSTAT, 2017).

Only a cursory look at the above numbers allows seeing a certain characteristic feature, correlated with the economic and cultural conditions of these countries. In five of them - Spain, Finland, Slovenia, Ireland and Iceland - women are more present in precariat; while in Croatia, France, Poland, Portugal, Italy and Greece, these are men. For the analysed case of Polish young adults, the masculine face of the precariat will be of significant importance (for more about junk contracts in Poland, see Mrozowicki, Krasowska and Karolak, 2015).

\section{Uncertainty, insecurity and ambivalence}

Uncertainty, as well as endangered economic, psychological and physical security (bearing in mind terrorist attacks happening since 2001), are the hallmarks of the post-modern and post-industrial era. The transition from industry-oriented production to service production was intended to bring to Western countries more 
favourable solutions in the economic and social spheres, resulting in rapid development and progress against their eastern rivals. This transformation, progressing in waves, resulted in accelerated information exchange, multiplication of communication channels and new forms of communication, using the achievements of modern technologies (Toffler, 1980; Castells, 2009; Lang and Lang, 2009; Vinge, 2013). Acceleration of the pace of development forced in turn the modification of forms of work, which resulted in the change of lifestyles both in their individual and collective dimensions. One of the characteristic features of the above was, as Toffler states in The Third Wave, the need for faster knowledge acquisition and the acquisition of competences that meet the requirements of highly competitive markets, including the global market. The acceleration of the pace of change has resulted in and continues to require ongoing replenishment - or even replacement - of the knowledge already acquired with new knowledge - hence, for instance, educational programmes marked with the acronym LLL (Life Long Learning). The necessity of constant learning, 'being up to date' with the latest tendencies and market trends, may be on one hand an inspiring challenge, maintaining the mental and physical fitness of the individual; but on the other, a source of stress, frustration, tension and even suffering - especially existential suffering (Bauman, 2000; Halcli, 2000; Giddens, 2002; Paul, Vastamäki and Moser, 2016). Keeping up with the high pace of life requires constant mobilisation and activity of both the individual and the community. To achieve and maintain this state, extraordinary measures are needed to ensure the adequate potential - i.e. natural, human/personal, infrastructural (including technological) and systemic resources (power and management). Accelerated use of these resources, frequently ignoring the consequences, often leads to destabilisation and loss of balance in many dimensions: economic (economic and financial crises), social (protests, unrest, riots, revolts), ecological (contamination of the natural environment: drinking water, air, soil) or health-related (diseases of civilisation, including obesity, diabetes, cancer, alcoholism, etc.) (Radandt, Rantanen and Renn, 2008; Wittchen et al., 2011; Hryniewicz, 2014). The risk of the appearance of these negative phenomena is high, and reality provides sufficient evidence that they have become an immanent element of modernity (Beck, 1992; Giddens, 2002; Hier, 2003; Bischoff, 2008).

\section{The world divided}

Highly developed societies of the beginning of the 21 st century have made their functioning dependent on high technologies, including the Internet. The digitisation of individual and community life has become so obvious that for young generations it is an immanent feature/disposition without which efficient functioning is impossible. This also applies to the majority of adults (source: Internet access in the $E U$ ). It should be noted, however, that access to high-speed Internet connections must be correlated with access to adequately functional devices that one must be able to use. And it's not just about a computer, a laptop or an iPad, but 
above all, mobile devices like smartphones, which are almost a 24-hour companion for a young person (often a child, definitely a teenager and young adult). In the European Union in 2014, 9 young people out of 10, aged 16-29, use network resources on a daily basis. For Polish teenagers aged between 12 and 15, the rate was 95.4\% (Statistics Poland, 2016). It is significant that the higher the formal education, the more frequent use of the so-called 'net'. (EUROSTAT, 2015, p. 12). The availability of devices and connections that allow the use of electronic resources, however, is not the same for everyone. The so-called phenomenon of digital exclusion, associated in the first place with older people, also affects children and young people living in less developed regions of Poland, mainly the areas along the eastern border. For them, the first barrier to overcome in personal and later professional development is the barrier of access to information, which is now increasingly taking the form of electronic information. The attributes of this state of affairs are partially reflected in the responses from the questionnaires.

\section{Self-identification and identity in crisis}

The opportunities provided by the Internet and the use of resources available in electronic form improve individual and collective life. Unfortunately, the Internet can also carry a whole set of threats, among others of a psychological nature, also affecting the processes of individual formation as well as community selfidentification. Identity or self-identification as phenomena which are in constant 'becoming' are subject to multiple factors having a source both in the individual (the actor) themselves and in the environment in which the individual (actor) acts or appears. An important role in this process is also played by the context of a specific moment of the subject's presence (Bauman, 2001; Brukaker, 2002; Castells, 2004; Szwed, 2007). The process of constructing identity is necessarily an activity divided over time, absorbing above all the psychological forces of the individual or community, often requiring also physical involvement (the case of, inter alia, migrants, displaced persons, refugees, people subject to gender reassignment, etc.). Becoming is a permanent element of this process, often occurring in a way which is imperceptible for the subject. It happens, however, that some phases, or stages of this process, may be felt by a subject - individual or collective particularly painfully as changing/destabilising the current state. The loss of balance or harmony, described in the scientific discourse of the last few decades very thoroughly (Erikson, 1970; Marcia, 1980; Giddens, 1991; Jawłowska, 2001; O'Brien, 2001; Vandenberghe, 2014), gave this phenomenon the name of the crisis, adding a negative value to the notion. This is to some extent right, if the state of destabilisation persists for a long time, but in the case of a short-term loss of stability, this condition does not necessarily mean something negative. According to Reinhart Koselleck, the widespread use of the term crisis separates it from its original meaning referring to 'disputing', 'facing something', 'testing one's strength' or 'fighting' (Koselleck, 2009, p. 22). Returning to this primary meaning, crisis in the case of an individual or collective identity would mean negotiating 
one's own image or own place in social reality, both with oneself and others. This particular 'dispute' or 'confrontation' has its perceptible costs of psychological nature, often physical, economic and, above all, cultural, designing the shape of future societies in an individual and collective dimension.

\section{Empirical study of Polish young adults}

The research which is the subject of this chapter was aimed at providing approximate preliminary data regarding the way of feeling and identifying the level of uncertainty that may accompany young adults on a daily basis (students studying at the Jagiellonian University in Kraków - one of the three universities located in the city). ${ }^{1}$ In addition, it was important to obtain feedback on how students deal with uncertainty, whether they have some uncertainty management strategies such as reducing the level of the phenomenon, and whether the experienced degree of uncertainty affects their self-identification and the perception (categorization) of these individuals by external observers.

Two hundred and thirty students of the Institute of Intercultural Studies at the Faculty of International and Political Studies took part in the research carried out in November and December 2017. Students were asked to complete an anonymous questionnaire consisting of 19 extensive questions (during classes, most often at the end of a class). From among the paper-based questionnaires, the feedback information suitable for scientific analysis was returned in 198 cases. The remaining answers did not meet the requirements of high-reliability information - the reason was the failure to complete a significant part of the survey, leaving questions unanswered, giving a contradictory answer, or providing answers indicating that the questionnaire was completed in an automatic way. For these reasons, 32 questionnaires were excluded from the analysis.

The answers obtained from the properly filled questionnaires allow construction of the following assumptions, leading to the formulation of several basic hypotheses:

H1. It is doubtful that the individuals, subject to the study, had strategies to deal with uncertainty or strategies to reduce uncertainty level; rather, these are spontaneous actions, reacting to the 'here and now', not involving a longer time perspective.

H2. Sources of obtaining information aimed at reducing the degree of uncertainty remain traditional: it is the immediate environment of the respondent in the sense of importance (a person for some reason important to the respondent); very rarely the source in this case is an institution, an administrative body, more often it is an environmental interview and gathering information to analyse further.

H3. There is a moderate correlation between the perceived degree of uncertainty and self-identification, and to a lesser extent, the identification of the individual by their external environment. 
The hypotheses result from interpretation of the responses characterised as follows.

Among 198 completed questionnaires, 26 were filled by men. This is a reflection of the sex proportions of students studying at the Institute of Intercultural Studies. ${ }^{2}$ Both fields of study, 'intercultural relations' and 'cultural studies in international perspective', are highly feminised.

Among the male respondents, the reason for taking up studies was primarily the desire to expand their competences, develop further and also to gain (literally) a well-paid job. In two cases, it was added that taking up studies was an alternative choice - without elaborating on the issue. Male respondents came mostly from southern Poland, from medium and large cities, in contrast to female respondents coming from small or large towns, with smaller towns under 25,000 residents dominating.

Twelve men presented themselves as a self-confident person who has a clear vision of what he wants to do. Ten, in turn, indicated a moderate degree of selfconfidence - they placed themselves at three on the scale, that is, half way between 'strong self-confidence' and 'self-confidence' and 'lack' self-confidence and 'a strong lack of self-confidence'.

Four respondents saw the everyday element of uncertainty as destabilising their normal acting, that is, de facto strongly hindering their harmonious (societal) functioning. In a group of 26 people, this is not a high number, but it should be noted. The vast majority of men do not feel that uncertainty about the future disturbs their functioning, or feel that it does only to a certain moderate degree (20 responses). Two respondents did not answer this question.

In the case of a question about discomfort in the face of uncertainty as to their immediate future, the answers were evenly distributed: eight for each category: strongly, moderately, not very much. Two people did not answer this question.

Regarding the strategies of dealing with uncertainty about the future, the answers indicating the choice of one option dominated, i.e. consulting the issue with the closest surroundings (people considered important by the respondents). Interestingly, despite the possibility of choosing several answers in this question, the majority chose one answer only.

The next largest group were men who based their strategy on the issue in question in an attempt to recognise the situation and consult with other people (important for them). Two people pointed to the replication of proven solutions as a way to reduce uncertainty; the same number considered giving up the decision to the so-called fate, and four admitted that they do not apply any strategy.

Regarding the impact of uncertainty of the future on self-identification, the majority of male respondents (12 people) answered that this happens only to a small extent. Slightly fewer people (8) stated that uncertainty affects the construction of their self-identification to a significant or definitely significant degree. The smallest group (4 people) did not state that uncertainty affected their self-identification. 
The issue of the impact of uncertainty on how the external environment perceives the respondent is slightly different. It turns out that 6 people described this relationship as very strong, 12 as weak but still occurring, and for 6 it did not occur at all. One respondent did not answer this question.

In cases requiring consultation or advice, the respondents first indicated the closest friends, then colleagues, followed by the parents or parent, then those whom they casually met. Interestingly, it was not uncommon to share doubts and concerns about the future with casual people online -14 respondents chose such an answer.

These were the answers given by male students, young men studying in the field of humanities and social sciences, as both 'cultural studies in international perspective' and 'intercultural relations' have such a character.

As far as female respondents are concerned, the information received from them, in several respects, slightly differs from the aforementioned cohort.

The reason for taking up studies in the case of female students was similar to the answers obtained from males, that is, the desire to broaden their knowledge, to acquire higher education, to satisfy their own ambitions and those of the immediate environment (family). It should be noted, however, that no respondent indicated the financial reason for taking up studies - a well-paid future job. Perhaps this argument is also important for young women, but it has not been explicitly articulated.

The vast majority of the respondents defined themselves as a self-confident person with clearly defined goals ( 88 people). A moderate degree of self-confidence and clarity of plans was demonstrated by 64 female students. Twenty women saw themselves as insecure and devoid of clearly defined goals for the future. The distribution of these answers correlated with another criterion - a place of origin (small, medium, large city/town) of individual respondents allows to put forward a hypothesis (which may be possible to verify by in-depth individual interviews, IDIs) that people originating from small towns or rural areas show a greater degree of determination in constructing their own broadly understood (not only in the professional sense) career.

The uncertainty of tomorrow as an element which is destabilising and strongly or very strongly hindering their normal functioning was indicated by 40 female students, almost two times fewer than respondents who do not seem to mind uncertainty ( 98 responses). The least numerous group were people perceiving the uncertainty of tomorrow as an element affecting their functioning to an average degree (32 responses). Perhaps 'taming' uncertainty is one of the methods (strategies?) of functioning in the modern world. Young adults, probably, have become accustomed to this permanent state and treat uncertainty as a permanent element of their world. This assumption can be verified by in-depth interviews. ${ }^{3}$

Uncertainty as causing discomfort to normal functioning was declared by 36 respondents; 54 women indicated a moderate state of discomfort due to the uncertainty of tomorrow, while the majority, 81 students, answered that they felt only a slight degree of discomfort or hardly any. 
The strategy of dealing with uncertainty in the vast majority of responses indicates the combination of ways of reducing the element of lack of proper information. The most frequently mentioned were, at the same time, consulting with people important to the respondents, and coming to grips with the situation by collecting data. There were also answers indicating the use of solutions previously tested by other people. No strategy was applied by 28 students, while the next six stated that the issue was not important to them and they left things to fate. It can therefore be concluded that for a relatively large group of young female students at this stage of life, planning, anticipating and undertaking the effort to develop solutions that reduce the risk of failure, are absent. It is difficult to determine to what degree these youthful attitudes will take the form of behavioural habits in the mature life of an individual.

As regards the issue - subjectively perceived - of the influence of uncertainty on their self-identification in the face of tomorrow, most respondents saw only a small degree of such influence. The vast majority indicated that uncertainty affects their self-identification to a small degree; for 28 people, it did not do so at all; for 44 female students, this relationship was significant (a significant degree of dependence) and for 6 respondents, it determined their self-identification (the uncertainty about tomorrow strongly affected their self-identification).

According to 74 young students, uncertainty of the future, to at least a small extent, affected their identification by the external environment. For 32 respondents, this happened to a significant or strong degree, while for 64 this dependency did not exist.

When it came to consulting someone or seeking advice in the case of anxiety and/or doubts about the future, female students most often indicated the parent or parents and a friend, and in the next sequence colleagues or acquaintances. People who were met in real life were not a very popular choice, and online connections were even less popular. Only 16 answers mentioned consulting a psychologist as the first instance.

\section{Conclusion and further research}

The results presented in this chapter lead to the conclusion that young adults, fulltime students of humanities and social sciences, seem to have no special strategy of dealing with the uncertainty of the future. Research carried out on a relatively small group of respondents, 198 individuals, may provide only an illustrative picture of the state of affairs - whether or not the uncertainty management strategy is in place. It follows in this case that the majority of young adults do not have such a strategy at all. However, another interpretation is possible that the strategy is the lack of one, since the late modernity is undergoing transformations that are ever faster and sometimes even difficult to keep up with. Developing a strategy that quickly turns out to be out of date in the context of Bauman's 'liquid modernity' or Vingean 'singularity' may therefore seem like a pointless activity. This strategy could be defined by the Polish saying 'things will go somehow'. 
Three hypotheses proposed in the paper and verified in the light of the data obtained through the questionnaire allow to conclude the following:

a Hypothesis 1 (H1) proposes that young adults, subject to the study, have neither strategies to cope with uncertainty nor strategies to reduce uncertainty level. Rather, the students prefer to produce spontaneous solutions by reacting to the 'here and now', which excludes a long-time perspective applied to management of their future lives and future careers.

b In the light of hypothesis $2(\mathrm{H} 2)$, sources of information to reduce the degree of uncertainty remain traditional. Information is obtained from the immediate environment of the respondent, in most cases a person or persons most immediate, i.e. parent or parents, friends, colleagues, peers. This source is further complemented by environmental interviews and information obtained from other non-institutional sources. Very seldom would the information to reduce the degree of uncertainty be looked for in an institution or an administrative body. This suggests very limited trust to official entities or even lack of trust which in itself may require separate research and more thorough investigation.

c Hypothesis $3(\mathrm{H} 3)$ claims there is a moderate correlation between uncertainty and self-identification of the respondents. The majority of young adults indicated that subjectively perceived uncertainty did influence their lives, although to a small but still noticeable degree. For 44 female students this relationship was significant and for six individuals uncertainty determined strongly their self-identification. As regards external environment and its identification of the individuals in question, uncertainty played a much smaller role.

The outcomes of the research raise a set of further, more detailed questions concerning inter alia the profound reasons of such a state of affairs. Advanced examination should therefore be based on the qualitative element; in other words, the research carried out in November and December 2017 should be continued and complemented by qualitative study, taking the form of in-depth interviews with individual students. The number of interviews to obtain the most reliable data should correspond to at least half of the number of collected surveys, and certainly should equal the number of the so-called saturation of the sample, i.e. the moment when subsequent answers do not bring anything new but merely repeat previously obtained information. This is the next stage of the project in progress, as it sheds more light on the real cause of the problem of uncertainty and its correlation with identity formation and identity cohesion of young adults or, while applying Jeffrey J. Arnett's terminology, emerging adults (Arnett, 2004, 2000).

\section{Notes}

1 The Jagiellonian University (www.uj.edu.pl) is the oldest university in Poland, founded in 1364. Nowadays around 40,000 students study here in 16 faculties. 
2 The Institute offers two fields of study: intercultural relations (BA and MA programmes) and cultural studies in international perspective (BA).

3 The in-depth interviews were still in progress at the time of preparation of this text for publication.

\section{Bibliography}

Arnett, J.J. (2000). Emerging adulthood. A theory of development of late teens trough the twenties. American Psychologist, 55(5), pp. 469-480.

Arnett, J.J. (2004). Emerging adulthood: The winding road from the late teens through the twenties. Oxford: Oxford University Press.

Bauman, Z. (2000). Ponowoczesność jako źródto cierpień (Postmodernity as a source of pain). Warszawa: Wydawnictwo Sic!.

Bauman, Z. (2001). Tożsamość - jaka była, jest, i po co? (Identity - how it was, is, and what for?). In: A. Jawłowska, ed., Wokół problemów tożsamości (On Identity Issues). Warszawa: Wydawnictwo LTW, pp. 8-25.

Beck, U. (1992). Risk society, towards a new modernity. London: Sage.

Bischoff, H.-J. (2008). Introduction. In: H.-J. Bischoff, ed., Risks in modern society. Mannheim: Springer, pp. 1-16.

Breakwell, G.K. (1986). Coping with threatened identities. London: Methuen.

Brukaker, R. (2002). Ethnicity without groups. Archives Européenes de Sociologie, XLIII(2), pp. 163-189.

Castells, M. (2004). The power of identity. London: Blackwell Publishing Ltd.

Castells, M. (2009). Communication power. Oxford: Oxford University Press.

Central Statistical Office, SCO. (2015). Macroeconomic studies and finance department of CSO. Macroeconomic Situation in Poland in the Context of the World Economic Processes, Warsaw, 2015.

Comston, B. (2017). When PIIGS fly. Available at: www.economicswire.net/when-piigsfly.html [Accessed 13 December 2017].

Erikson, E. (1970). Autobiographical notes on the identity crisis. Daedalus, 99, pp. 730-759.

EUROSTAT. (2015). Available at: http://ec.europa.eu/eurostat/statistics-explained/index. php/Being_young_in_Europe_today___executive_summary [Accessed 4 January 2018].

EUROSTAT. (2017). Available at: http://ec.europa.eu/eurostat/statistics-explained/index.php/ File:Youth_unemployment_figures,_2007-2016_(\%25)_T1.png [Accessed 4 January 2018].

Giddens, A. (1991). Modernity and self-identity: Self and society in the late modern age. Stanford: Stanford Uviversity Press.

Giddens, A. (2002). Runaway world: How globalization is reshaping our lives. London: Profile Books Ltd.

Halcli, A. (2000). Social movements. In: G. Browning, A. Halcli and F. Webster, eds., Understanding contemporary society: Theories of the present. London: SAGE Publications Ltd, pp. 463-475.

Hier, S. (2003). Risk and panic in late modernity: Implications of the converging sites of social anxiety. The British Journal of Sociology, 54(1), pp. 3-20.

Hryniewicz, J. (2014). Społeczeństwo ryzyka. Teoria, model, analiza krytyczna. Przegląd Socjologiczny, 63(2), pp. 9-33.

Internet access in the EU. Household internet access in the European Union (EU28) 20072017. (2018). Available at: https://www.statista.com/statistics/377585/household-inter net-access-in-eu28/ [Accessed 8 January 2018]. 
Jawłowska, A. (2001). Tożsamość na sprzedaż’(Identity for sale). In: A. Jawłowska, ed., Wokót problemów tożsamości (On identity issues). Warszawa: Wydawnictwo LTW, pp. 51-78.

Kolczyński, M. (2008). Strategie komunikowania politycznego (Communication strategies in politics). Katowice: Wydawnictwo Uniwersytetu Śląskiego.

Koselleck, R. (2009). Dzieje pojęć. Studia z semantyki i pragmatyki języka społecznopolitycznego (Begriffsgeschichten. Studien zur Semantik und Pragmatik der politischen und sozialen Sprache). Warszawa: Oficyna Naukowa.

Kowalczuk, K. (2011). Notowania Platformy Obywatelskiej - dziesięć lat działalności (Civic Platform's popularity - a decade of activity). CBOS (Public Opinion Research Center). Available at: www.cbos.pl/SPISKOM.POL/2011/K_115_11.PDF [Accessed 11 January 2018].

Kowalczuk, K. (2014). Pozycjonowanie oferty Platformy Obywatelskiej wobec Prawa i Sprawiedliwości w wyborach parlamentarnych w 2011 roku, (Positioning of the civic platform's offer versus the law and justice's programme in 2011. In: M. Cichosz and D. Skrzypiński, eds., Segmentacja, targeting, pozycjonowanie na rynku politycznym (Segmentation, targeting, positioning on the political market). Wrocław: Uniwersytet Wrocławski, p. 146.

Lang, K. and Engel Lang, G. (2009). Mass society, mass culture, and mass communication: The meaning of mass. International Journal of Communication, 3, pp. 998-1024.

Majerek, B. (2012). Oczekiwania i orientacje życiowe młodzieży polskiej i niemieckiej w sytuacji niepewności i nieprzewidywalności (Expectations and life orientations of polish and German youth in a situation of uncertainty and unpredictability). Ruch Pedagogiczny, 2, pp. 55-69.

Marcia, J.E. (1980). Identity in adolescence. In: J. Adelson, ed., Handbook of adolescent psychology. New York: Wiley.

Mrozowicki, A., Krasowska, A. and Karolak, M. (2015). 'Stop the junk contracts!' Young workers and trade union mobilization against precarious employment in Poland. In: A. Hodder and L. Kretsos, eds., Young workers and trade unions. London: Palgrave Macmillan.

O’Brien, M. (2001). Esej o płynnej tożsamości (An essay on the liquid identity). In: A. Jawłowska, ed., Wokót problemów tożsamości (About identity issues). Warszawa: Wydawnictwo LTW.

OECD Economic Surveys. (2014). Available at: www.keepeek.com/Digital-Asset-Man agement/oecd/economics/oecd-economic-surveys-poland-2014_eco_surveys-pol2014-en\#.WZ6mEelpw2w\#page2 [Accessed 22 January 2018].

Państwowa Komisja Wyborcza (nd). Wybory do Sejmu i Senatu Rzeczypospolitej Polskiej (Elections to the Seim and the Senate of the Republic of Poland). Available at: http:// parlament2015.pkw.gov.pl/349_wyniki_sejm [Accessed 17 February 2018].

Paul, I., Vastamäki, J. and Moser, K. (2016). Frustration of life goals mediates the negative effect of unemployment on subjective well-being. Happiness Studies, 17(2), pp. 447-462.

Polska Times. (2011). PO bezideowa. Available at: https://polskatimes.pl/olechowski-plat forma-to-bezideowa-korporacja-jak-pzpr-moze-sie-latwo-rozpasc/ar/382383 [Accessed 24 January 2018].

Radandt, S., Rantanen, J. and Renn, O. (2008). Governance of occupational safety and health and environmental risks. In: H.-J. Bischoff, ed., Risks in Modern Society. Mannheim: Springer. 
Statistics Poland. (2016). Spoleczeństwo informacyjne w Polsce w 2016 r. Available at: https://stat.gov.pl/obszary-tematyczne/nauka-i-technika-spoleczenstwo-informacyjne/ spoleczenstwo-informacyjne/spoleczenstwo-informacyjne-w-polsce-w-2016-roku,2,6. html [Accessed 2 February 2018].

Szwed, R. (2007). Modele tożsamości europejskiej a identyfikacje zbiorowe w Europie (Models of European identification and collective identifications in Europe). In: I. Borowik and K. Leszczyńska, eds., Wokót tożsamości: teorie, wymiary, ekspresje (On Identity: Theories, Dimensions, Expressions. Kraków: Zakład Wydawniczy NOMOS, pp. $163-178$.

Toffler, A. (1980). The Third Wave. New York: Morrow.

Vandenberghe, F. (2014). Globalisation and individualisation in late modernity: A theoretical introduction to the sociology of youth. Idéias, 8, pp. 115-172.

Vinge, V. (2013). Technological singularity. In: M. More and N. Vita-More, eds., The Transhumanist Reader: Classical and Contemporary Essays on the Science, Technology, and Philosophy of the Human Future. West Sussex: John Wiley \& Sons, Inc., pp. 365-375.

Wittchen, H.U., et al. (2011). The size and burden of mental disorder and other disorders of the brain in Europe 2010. European Neuropsychopharmacology, 21, pp. 655-679.

Wojtalik, M. (2015). Wyniki wyborów: PiS przejmuje Polskę, a prawica młodzież. Newsweek Polska, 26 October. Available at: www.newsweek.pl/polska/szczegolowe-wynikiwyborow-parlamentarnych-2015-jak-glosowaly-wojewodztwa/wz4sehs [Accessed 15 February 2018]. 

Part III

Involvement 



\title{
Young women of Muslim background in France and Britain
}

\section{Personal and public projects}

\author{
Danièle Joly
}

This chapter examines women of Muslim background in France and Britain with a focus on young women ${ }^{1}$ and investigates the parameters framing their action towards the realisation of their aspirations. ${ }^{2}$ The data feeding my comments derive from a long study about the civic and political participation of women from Muslim communities. ${ }^{3}$ In Britain, they mostly find their origins in the Indian Subcontinent, although a smaller number comes from other regions of the world, such as Iran, Iraq, Afghanistan and East Africa. Their French counterparts largely belong to families coming from North Africa and Sub-Saharan Africa, to which must be added more recent settlements from Turkey and the Middle-East. The vast majority of the women considered in this chapter grew up in their family's society of settlement and enjoyed a medium-to-good level of education. The chapter explores the women's capacity of action to pursue both personal and social projects and pays particular attention to the women's voice in the light of a feminist approach. My analysis rests on a combination of premises with respects to the ontology and the epistemology adopted, based on Archer's social realism (1995) and Touraine's sociological intervention $(1973,1978)$ which are summarised as follows. In the first instance, the women are situated within an objective structural and cultural environment which is not of their making and creates a set of constraints and enablements wherein they develop their action. However, the influence of this environment is not deterministic because they are subjects and actors of their own life. This research challenges common stereotypes and prejudices regarding Muslim women's passivity and home orientation. On the contrary, those women display a capacity of action which rests on two attributes: first, they are capable of critically assessing the environment surrounding them, whether it be within the ethnic group, majority society and/or Muslim circles; second, they are sensitive to and concerned with a number of issues which motivate their commitment in the public arena through civic and political initiatives.

\section{Structural and cultural framework}

The environment presiding over these women's life is articulated as two large interconnecting sets. The immediate circle within which they have been socialised 
consists of the family and the community while they also evolve within wider society in Britain and France. One good reason for separating the two does not only reflect the habitual discrepancy existing between family and society-wide modes of socialisation; it proves more salient in this case, since the subjects of our study belong to immigrant communities, and since they are faced with specific features of the society of origin which may contrast as well as overlap with the characteristics of the society of settlement.

The modes of social relations pre-dating migration were imparted through the family and community which for many women of Muslim background involved the extended family. Meanwhile, those women also worked out a life within wider society and in interaction with it. This complex concatenation of parameters must be taken into account in a study of Muslim women's action to develop their projects. In addition, one central element and a sine qua non for the development of autonomous action is to be found in the women's self-reflexivity (Archer, 2007) that underpins the meaning of action and lies at the heart of the analysis, rendering possible what Alain Touraine calls subjectivation (Touraine, 2013). The women nurture projects, hopes and aspirations which come up against constraints and enablements. Notwithstanding, those are not cast in stone, as freedom of interpretation is available to groups and individuals (Archer, 1995, p. 208), thanks to 'one of the most important differentiating powers proper to people [. . .], their intentionality' (p. 198) and their capacity of subjectivation (Touraine, 2013). Values, affects and subjective weighting intervene in the equation of choice, on the basis of discretionary judgements.

In the first instance, the women faced restrictions within their immediate social circle, which was still often structured along a patriarchal model pertaining to the country of origin. Indeed, the extended family model brought over from the homeland tended to subordinate the individual, and in particular the women to the collective; the latter comprising the extended family and the ethnic community dominated by traditional elder men. Moreover, women came under scrutiny as holders of the family honour (Van Bergen et al., 2009). In wider society, the women were confronted with yet another package of constraints related to their origin. These populations were at the receiving end of racial and religious discrimination concomitant with various prejudices. Moreover, at least in the early stages of migration, most of them were slotted in socially disadvantaged strata, and many did not master the English language, especially if they came from poor rural backgrounds. The women partook of all those disadvantages but also suffered from a further set of prejudices pertaining to an orientalist vision of Muslim women which portrayed them as passive, subdued, confined to home making and child bearing (Guénif-Souilamas, 2000). Furthermore, general gender inequality subsists in majority society. It could be argued that the double bundle of constraints emanating from two societies of reference multiplied the difficulties encountered by the women. In reality, the situation was more complex. The two respective social entities, the ethnic group and majority society, could palliate relative disadvantages insofar as they also awarded benefits. On the one hand, 
the ethnic group provided a comfort zone of familiarity and support in both countries of settlement. Thanks to its associations and mobilisation, it had secured a recognition of its cultural and social needs and contributed to the promulgation and implementation of laws and policies against racism and racial discrimination (Rex and Tomlinson, 1979), Muslims also subsequently gained a place for Islam in British society (Joly, 2007), although this scenario was not quite matched in France where issues related to laicité ${ }^{4}$ and the non-recognition of communities thwarted this process. With respect to majority society, the women found some advantages in laws against sexual discrimination and in the welfare state which awarded opportunities for education, health and social services. Albeit, this presentation of objective social settings comes short of accounting fully for the process of Muslim women's autonomisation wherein they exercise their subjectivity, and to which we now turn.

\section{Awareness and self-reflexivity}

What was evidenced throughout our investigation was the women's ability to submit their frequently adverse circumstances to a sharp scrutiny. The key of selfreflexivity opened up avenues of emancipation and active participation which rested on the women's capacity to analyse their position within their environment. Consequently, the package of constraints and enabling factors stemming from family and wider society also operated as an eye opener which equipped them to gain an understanding of their circumstances. In the first instance, they were recurrently confronted with contrasting views deriving from, one the one hand, the regions of origin and, on the other hand, the society wherein they lived: in addition, their situation as ethnic minorities enhanced the consciousness of differentiated visions. Furthermore, they belonged to communities of Muslim background on account of their country of origin, a feature which could not be ignored whether or not they identified with that religion. Indeed, events involving inter alia wars and terrorist attacks had projected Islam into the limelight both worldwide and in national settings, feeding considerable debates within and outside Muslim communities' circles. The women could thus position themselves from the vantage point of the minority and/or religious group to analyse majority society, from the viewpoint of majority society to submit minority and religious references to scrutiny; and they could carry out the same exercise between the latter two, thus being placed in a position 'inside' and 'outside', akin to that described by Simmel about the 'stranger' (1964). All those factors led many of the young women to decrypt their social environment and its discourse cogently, over and above the smokescreen of culture and ideology.

\section{The ethnic group}

With respect to the ethnic group, it was clear to the women that the order in place derived from a specific form of patriarchy brought over from the country 
of origin. They denounced the relations of power which subordinated women to men in general and to elder males in particular through a complex hierarchy ranking people according to their place in the immediate and extended family; they unpacked the control mechanisms and obligations which varied in keeping with one's position as daughter, wife, daughter-in-law, mother, sister, etc., complete with differentiated constraints. They wrote the persistence of this model within the prevalent role played by the wider group, the community. Altogether, young women brought up and educated in France and Britain were not submitting to this model and challenged it vehemently whenever it interfered with their aspiration to pursue personal life project or civic and political initiatives. In contrast with their readiness to accept accommodation with their close family, the women's attitude to the extended family and community testified to their determination to challenge the latter's influence. They perceived that one significant obstacle to their aspirations was embodied in the wider group comprising the extended family. Indeed, although our informants did not indiscriminately discard ethnic cultural characteristics and much valued the immediate family, they rejected the legitimacy of the wider group's authority. Many of the women commented on the critical domination attempted by the extended family if they happened to live in the community; they remarked that the denser the community networks in the district where they lived, the greater were the impediments to an extension of their autonomy. The interference of the extended family and community tended to remain more noticeable in Britain, where communities were more tightly structured. In France, the norm seemed to be established that those young women's decisions on their projects were debated within the nuclear family and largely supported; in Britain, mutatis mutandi, the women were also increasingly attaining this goal. One ardently pursued project was education with the aim of achieving a good position in employment, and this was predominantly well supported by the nuclear family in both countries. The question of marriage also figured prominently, especially in Britain where the tradition of arranged marriages was prevalent amongst groups from the Indian Subcontinent, and this was mostly resolved through a compromise with respects to our informants who, as mentioned earlier, benefitted from a certain level of education. Another issue related to castes, in Britain among people from the Indian Subcontinent and in France among Sub-Saharan Africans, a custom which could affect the choice of a spouse and which the young women vigorously challenged on both sides of the Channel.

A variety of strategies were embraced by the women in order to realise their projects: they were partial to compromise but confrontation could also be selected, such as Husniya who had divorced despite her parents' strong disapproval (Coventry), or Safa (Paris) whose sister had totally broken links with her family. In addition, a variety of other methods were adopted. Several women pursued what I have called a reversal strategy which inferred turning the very arguments of their opponents against the latter. For instance, several women called upon sacred texts which family or community would not venture to reject, namely the Quran, to defend their rights to education, the choice of a spouse, engagement in 
associations awarding social care, etc. Others used an avoidance approach, sidestepping obstacles rather than standing up to them. This is illustrated by Tahani, who, in a context where marrying one's daughter is an utmost concern, humorously relates her sister's manoeuvres:

My sister is now 24, my mum is having kittens, saying 'she's not married yet', because all the good guys have gone and people have stopped asking her. She, my sister was 18, 19, and people knocking on the door, and my sister said, 'no, I'm not ready, I'm studying, I'm not ready yet'. At the moment she's busy having her fingers in every single charitable pie possible [volunteering in charities], and she always argues 'why is it we have to wait before we can do anything, to wait until we get married before we can travel, or before we can do this, we can do that, it's a cultural thing'. She says 'why should I not be able to go and help out the people who have been affected by the Tsunami'.

Although most of the young women enjoyed much flexibility in their choices, a few of them had experienced dire control and violence. For instance, one young women had grown up in a family where her father beat her mother and exercised on both mother and daughter utmost control on any activities outside home, barring working for a salary (Andala, Coventry). Another young woman had been raped and beaten repeatedly by her husband 30 years older than her, in a marriage which had been forced upon her by her parents (Ezina, Paris). On a different question, clarity on the obstacles to their autonomy caused by their cultural environment did not hide to the women the role of politicians who collaborated with traditional males, leaders of communities, and who had reinforced patriarchal modes for the sake of securing ethnic communities' votes.

\section{Majority society}

The women were well aware of the many facetted discrimination and prejudices which pervaded society. In the first instance, they pointed to the persistence of racial and ethnic-based discrimination which raised obstacles in the path of their projects. However, they noted that this kind of discrimination had been superseded by a novel type based on religious criteria, namely Islam. It did not detract from the fact that, in Britain, the vast majority of them felt comfortable in being both Muslim and British; they valued the fact that British society permitted the display of religious signs in all public arenas (schools, politics, courts of law and in all the professions) and they clearly identified as British Muslims. Notwithstanding, they pointed to the upsurge of anti-Muslim prejudice which soared after the 9/11 events in New York. Undoubtedly, the twin tower terrorist attacks had constituted a salient watershed in Britain which had thrown its full military support in the US military intervention in Iraq and Afghanistan. Women in Britain also noted that military action abroad was matched by laws building up a securitisation of Islam 
inside the country, which was thereafter further stoked in the wake of the London terrorist attacks on 7 July 2005. France had not joined in the intervention in Iraq and the women pointed to a different landmark, namely the 2004 law banning 'ostensible' religious signs in schools, a law which had been designed to outlaw the wearing of the hijab in state schools In 2007, it was confirmed that this was also forbidden in all public service employment (30\% of total employment in France). A 2010 law thereafter banned face concealment (namely the full-face veil) in all public spaces including streets, shops, etc. These measures were much quoted by the women as levers of hostility against Islam, conveying negative messages about that religion and pinpointing them as prime targets of discrimination. Although the women in both countries were aware that young men suffered more severely from the security-led public discourse and measures directed at Muslims, they also took note of their own greater visibility when they adopted a dress code linked to their religion and, in France, signalled the gender discrimination which was attached to it, the law singling out women alone. Meanwhile, they were not taken in by what they called the 'hypocrisy' of politicians who did not hesitate to manipulate racial and religious issues to further their own interests, and they proved particularly perspicacious when it came to dissecting politicians' discourse and manipulations. They identified without hesitation that Muslims and Islam constituted useful scapegoats in the race for electoral gains. Moreover, the women were well-informed about and particularly attentive to economic and geopolitical interests world-wide. Politicians' discourses on human rights, women's rights and opposition to dictators as a justification for military intervention did not carry much weight for most of our informants who categorically attributed Western military intervention and involvement in the Middle-East to the competition for resources. Several also refuted the religious basis often advanced to explain the situation of Palestinians in Israel, affirming instead that it was a question of territorial possession.

Although some of the women stated that they had not experienced discrimination, almost all of them pointed to disadvantages linked to discrimination based on racial, ethnic, religious and gender criteria in French and British societies. They also spent a good deal of time attempting to explain the increased salience of Islam in Western societies, a theme that we feel is worth developing here. They took note of the widening adherence to forms of Islam that adopted a literal interpretation whose source they located originally outside Europe. In the main, the women attributed such a type of re-islamisation to widespread feelings of rejection, humiliation and exclusion among young Muslims. According to Fatouma (Paris), Muslims had been led to what she called 'the most extreme practices' as a result of 'rejection' by French society. Aman (Paris) advanced that young people responded to organisations like the Muslim Brotherhood because they could not turn either to France or their region of origin to feel that they belonged; this was compounded by 'ignorance and poverty' so that Islamists offered an alternative identification in the shape of the umma. Aman felt that it gave a 'meaning' to young Muslims' life while also fostering 'hatred against everyone'. Tahira 
(Coventry) similarly reckoned that Islam was reclaimed because it offered a sense of belonging. Wahida (Fontenay sous Bois) argued that Islamists capitalised on both the sentiment of failure among young people and on their quest for identity. On the whole, those comments mostly focused on young men, but it was noted that these explanations could also apply to young women. Souhila (London) concluded that social disenchantment had led to Islamic radicalisation and that the appearance of the niqab was associated to aggressive foreign policy against Muslim countries. In Wahida's opinion (Fontenay sous Bois), the greater number of women wearing a hijab was related to political manipulation by certain groups while she argued that this derived both from a search for identity and a quest for dignity in the aftermath of events like 9/11 whereby Islam was further disparaged and demonised.

\section{Islam and the Muslim group}

Although overlapping largely with the ethnic group, Islam and the Muslim group elicited separate consideration by most of the women. The prominence of Islam in the public arena led Muslim women to examine religious practice within the community and to apprehend the closely enmeshed cultural versus religious dimensions involved. Whether transmitted by the family or emanating from other sources, Islam was not taken for granted but had become the object of a close enquiry exploring innumerable features of it, either from an atheist or religious standpoint. The women who were believers commented at length on the multiple branches and schools of Islam, the spirit and the letter of Islam. Many women exposed how it had been turned into an ideological instrument to better control women, whether through the prism of ethnic tradition or that of Islamist political reformism. The young women easily discerned that these developments had not taken place in a vacuum. They realised that international events had had an impact on their own awareness as Muslims since the emergence of Islam had thrown them into the limelight, particularly when they wore a dress code which displayed their religion. Finally, several of them posited that living in a nonMuslim-majority country awarded a greater capacity to interrogate their own religion. In France a polarised spectrum of views opposed two broad categories of women: those who refuted any affinity with Islam on ontological grounds (for instance, if they were atheist) and/or protested against what they perceived to be an instrument of gender oppression; and those who claimed some identification with Islam either on religious, cultural and/or political grounds. In Britain, most of the women were believers, although not all practiced their religion and many challenged the ascribed subordination of women following widespread contemporary interpretations of the Quran. Several common features were shared by believers in both countries: they rejected what they called 'cultural Islam' steeped in traditional customs and called upon sacred texts to defy traditional practices. They also disregarded categorically the series of injunctions imposed by reformist political organisation which they deemed aimed inter alia to control women. 
Altogether, they mostly claimed an individualised form of Islam whereby they developed their own choice of practice and vestimentary code, independently of Muslims and non-Muslims alike. Many thus strove towards an application of their religion divested of cultural traditions and removed from the grip of Islamist interpretation. They turned Islam into a tool of autonomisation and into a lever of action. More remarkably, for all the believers in both countries, Islam represented an ethical guide for action, towards engagement in civic activities of a social, humanist and often universal character. Where Um is concerned, 'it's Islam that has sown the belief that life is either about justice or injustice and that justice must be increased and injustice done away with' (telephone interview).

Several of our informants had engaged in some form of civic and political initiatives which were underpinned by a strong sensitivity to all manner of injustice, within the ethnic group and in majority society with respect to national and international scenes. This was based upon their own experience and observation of disadvantage on gender, social, racial ethnic and religious criteria, either personally or indirectly. This interest extended beyond their country of residence so that they denounced the poverty engineered by imperialist domination and corrupt politicians in developing countries; they were concerned with issues of deprivation as much as situations of repression. While they were outraged by the international offensive against Muslims in connection with geopolitical and economic interests, they also condemned extremist Islam, advocates of terrorism and dictatorial Muslim regimes such as in Saudi Arabia. Many of the women declared their motivation to take part in civic and political action, putting forward their strong ethical sense, holding up values above norms, solidarity against individualistic interests, and humanitarianism in the face of material greed. This constituted a catalyser of action and a powerful instigator of emancipation.

\section{Social actors in the public arena}

While the subjects of our study had increasingly been able to deploy their autonomy in the sphere of education and employment through negotiating with the family, it was a taller order to participate in civic and political activities, for women in general and in particular for Muslim women. It is customarily also the mark of the highest level of emancipation to be able to take part in the shaping of one's society. Our research showed that our informants displayed clear aspirations to engage with the public domain in diverse ways (Joly and Wadia, 2017). Although we had sought out and found a number of women who had scaled the echelons of 'classical' politics, namely in political parties, in parliamentary or municipal government, we found that only a few had acceded to such level of politics. Nonetheless, the women's engagement spanned a great diversity of activities which can be categorised as follows. Several have joined the rank and file of political parties, many of which were minority parties mostly, although not only, on the left of the spectrum. Many women had taken part in campaigns and demonstrations either on foreign or national questions: against the war in Iraq, in support 
of Palestine, in marches against education reforms, against racism, etc. They had joined organisations that could be called transversal, like SOS Racisme, Réseau éducation sans frontières (in support of undocumented migrants), charities in aid of victims of natural disasters in developing countries; and they animated intercultural or interfaith fora. Several women were members of trade unions, more particularly students' unions. A few were involved in action concerning countries of origin: an organisation against fundamentalism in Algeria, an association aiming to combat excision in Guinea, a project supporting education in Pakistan. The bulk of the activities most attractive to the women related to social issues, either within institutions or in associations and charities: health, social care, Resto du Coeur, education, handicap, etc. In addition, some women had become active in what broadly covers culture and media, including social media. The question of Islam elicited various forms of activism. Some became active in initiatives combatting discrimination against Muslims, others in projects to support Muslim women against ethnic or religious constraints. Finally, a few had founded their own study group to examine sacred texts and interpret them from a women's viewpoint so that they could challenge ethnic or 'fundamentalist' interpretations. Finally, the question of women's well-being mobilised much interest, as seen in the following.

In Britain, the most critical catalyser of action was Britain's military intervention in Afghanistan and Iraq which, in its wake, had projected Islam centre stage in the media and in political debates. Several of the women we interviewed took part in Stop the War demonstration and local committees, sometimes taking on leadership positions. This involvement had worked as a launching pad for action as explained by the women who had thereafter expanded their arena of civic and political activities. Um provides a telling example of such a process.

The news that the USA and its allies had invaded Afghanistan provoked absolute fury [in her]. Following the events of 9/11 and the Afghan invasion, there were lots of stories of Muslims in the community being attacked verbally and physically - taxi drivers, friends of friends. It's the pursuit of justice that has made [her] want to make changes for the better in society and to help those who are disadvantaged.

Um explains how her political engagement thereafter rocketed in a few months. She described how she worked 40 hours a week as personal assistant to a Respect party MP (a party arising from the mobilisation against British military intervention and in opposition to the Labour government), plus another 15-20 hours a week working in the community, mainly helping women who needed help with form-filling (applications for various school matters for their kids, for driver's licence, benefits, etc.). She also volunteered with an association, talking to mothers and daughters about the importance of education, civic engagement, etc. Rana (London), who had started with student politics as education officer in the NUS, had initially focused on issues of racism; she was then prompted to join Stop the 
War because '9/11 was a life changing event for everyone in Bradford' where she came from. None of the women in France quoted the war in Iraq as of particular significance in their engagement, although several took note of the deleterious effect of the New York 9/11 events on the situation of Muslims. In France, one significant area of mobilisation was related to the prohibition of wearing a hijab at school and other public institutions. As a consequence, several of our French informants had been active in campaigning with the Collectif Une école pour tous-toutes (to protest against the banning of the hijab at school).

One important theme mustered the concern of young women on both sides of the Channel, namely gender domination and violence and any kind of gendered inequalities to be found in majority society which were often enhanced where Muslim women were concerned. Although only a few of our informants had encountered such episodes themselves, most were acutely aware that it took place commonly, and several joined or founded associations that addressed issues such as unequal treatment, domestic violence, forced marriages and excision. They imparted advice to victims of violence and worked with refuges for women: for instance in Britain, Shadia, who subsequently ran as a candidate for Respect in Birmingham, had started with volunteering in an Asian women refuge centre for women who faced domestic abuse; Walad (London), Parliamentary manager for an MP, had raised $£ 126,500$ from the Home Office to tackle the question of forced marriages. In France, Ezina (Paris) had founded an association especially to combat forced marriages and domestic violence, Aman had created the 'pole welcome to women victims' in Ni Pute Ni Soumise (NPNS, an association founded in 2003 to respond to violence against women). Wahida (Fontenay-sousBois) had set up the project 'logement relais' for young women victims of domestic violence and forced marriages; in addition, she collaborated with African local associations in Montreuil to mediate on these questions. In addition to questions of violence, several women dedicated their effort to counteract other kinds of inequalities. They took part in a number of initiatives destined to make available activities which young Muslim women found difficult to access. In Birmingham, Nadeema founded a theatre/music troupe addressed to Muslim women. Naima (Paris) had joined an association imparting educational support to girls excluded from school on account of their hijab. Asala (Mantes la Jolie) took part in and then led a project developing sports activities for young Muslim women. Other triggers of motivation were specifically related to the country of origin: women who had run away from Algeria such as Asala, whose brother had been killed by the Front islamique du salut (FIS), and Hayat (Paris), whose father had barely escaped an assassination attempt also by the FIS. Finally, matters of faith gained the interest of several women. However, it is worth signalling that they tended to keep away from invariably male-run mosque associations or political reformist branches. On the contrary, they generally opted to avoid established male-dominated entities and preferred to form their own groups to deepen their knowledge of Islam. 


\section{Conclusion}

The young Muslim women in our study demonstrated their versatility in their endeavours to gain ground towards the realisation of their personal and social projects. The women navigated within a changing hierarchy of priorities according to the conjuncture in the relations of power surrounding them, whether within the ethnic group or majority society. Our study evidences their capacity to analyse their environment critically and their concerns for a variety of public issues. Their self-reflexivity equips them to devise modes and strategies of actions which enable them to pursue their personal life projects and their participation in civic and political initiatives.

\section{Notes}

1 This includes women from 18 to 35 years of age, in keeping with the agreed age bracket for the whole book.

2 The criterion for inclusion in the sample was that the women were part of communities whose backgrounds lie in Muslim-majority countries independently of their degree of practise or belief; Muslim communities in Britain and France being considered as a sociological category in this piece of research (Bowen et al., 2014, p. 4). The women from Muslim communities who are the subjects of this study are thereafter called Muslim women in this chapter.

3 This chapter is based on an ESRC-funded research project led by Danièle Joly and Khursheed Wadia: Women from Muslim Communities and Politics in Britain and France (Award Ref: RES-062-23-0380. My thanks go to the MSH, the IEA and the CADIS. Because of constraints linked to funding, most of our informants were women with a certain degree of education, either attained in Britain or prior to migration. However, our research is in keeping with most studies on women's emancipation which reveal that this category of women are those who pioneer the development of autonomy and emancipation in the private and more particularly in the public domain (Githens, Norris and Lovenduski, 1994).

4 The separation between the church and the state, as per the 1905 law.

\section{References}

Archer, M. (1995). Realist social theory: The morphogenetic approach. Cambridge: Cambridge University Press.

Archer, M. (2007). Making our way through the world. Cambridge: Cambridge University Press.

Bowen John, et al. (eds.) (2014). European states and their Muslim citizens. Cambridge: Cambridge University Press.

Githens, M., Norris, P. and Lovenduski, J. (eds.) (1994). Different roles, different voices: Women and politics in the United States and Europe. New York: Harper Collins/ Longmans.

Guénif-Souilamas, N. (2000). Des 'beurettes'aux descendants d'immigrants nord-africains. Paris: Grasset.

Joly, D. (2007). L'émeute. Paris: Denoël. 
Joly, D. and Wadia, K. (2017). Muslim women and power. Basingstoke: Palgrave MacMillan.

Rex, J. and Tomlinson, S. (1979). Colonial immigrants in a British city. London: Routledge. Simmel, G. (1964). The sociology of Georg Simmel. New York: The Free Press.

Touraine, A. (1973). Production de la société. Paris: Seuil.

Touraine, A. (1978). La voix et le regard. Paris: Seuil.

Touraine, A. (2013). La fin des sociétés. Paris: Seuil.

Van Bergen, D., Saharso, S., Smit, J.H. and Van Balkom, A. (2009). Suicidal behavior of young immigrants in the Netherlands: Can we use Durkheim's concept of 'fatalistic' suicide to explain their high incidence of attempted suicide? Ethnic and racial studies, $32(2)$. 


\title{
Occupying the city \\ From social housing to the theatre
}

\author{
Antimo Luigi Farro and Simone Maddanu
}

\section{Introduction}

This chapter retraces the experiences of three different collective mobilizations carried out in Rome by young adults, activists and artists. Based on interviews and participant observations, the research ${ }^{1}$ came across occupying groups in Rome, like Blocchi Precari Metropolitani, Action, and Teatro Valle collective group. In some observed cases - in this chapter Metropoliz and Spin Time - they combine a 'deprivation based squatting' (Pruijt, 2013) - squatting as a way to face a housing crisis in the city, especially for migrants, precarious or disadvantaged people - with so-called 'entrepreneurial squatting', based on a counter-cultural perspective - a politically oriented practice that aims at producing alternative social relations and artistic performances (Mayer, 1993). Taking place during years characterised by un unmanaged presence of asylum seekers, refugees and undocumented migrants, these occupied spaces represent a sanctuary of salvation while sending a political message in favour of social housing, and against gentrification and private property. A multicultural community-based cohabitation remains at the core of these daily experiences.

As for Teatro Valle's experience, some activists and artists engaging in the theatre occupation are from similar squatting experiences in the city, Social Centres or occupied and autonomous spaces, and they keep a strong bond with those movements that claim the 'right to the house' (Martinez, 2013), and the 'right to the city' (Mayer, 2009; Harvey, 2012; Novy and Colomb, 2013). Nevertheless, Teatro Valle is not a squat. Artists and activists run new forms of management of the theatre schedule and laboratory while organising political meetups. As observed in other occupied theatres (Satta and Scandurra, 2014; Valli, 2015), at first they consider the occupation as a symbolic form of protest. Then, they create an organised artistic and political project that aims to rebuild or refund a cultural institution cognisant of the commons (Maddanu, 2018). As we will observe, the commonsbased practice introduces a new political narrative in the occupation experience. By relating the original theories of Elinor Ostrom (1990) with updated political analysis on urban commons (Harvey, 2001, 2012; Garnett, 2012) and cultural commons (Hess and Ostrom, 2006; Hardt and Negri, 2009; Negri, 2012; Dardot 
Laval, 2014), occupied Valle Theatre aims to refund a cultural institution through its self-managing experience. 'Valle Theatre as a common good' is an attempt to legitimize, and eventually institutionalise, an occupied common good (Bailey and Marcucci, 2013).

This chapter demonstrates how all these agencies, though through different everyday practices and forms of self-management - autogestion (Lefebvre, 1975; Brenner and Elden, 2009) - do not aim to integrate into the system or to get absorbed by the existing institutions, but to create alternative institutions and to assert a sense of justice (Sen, 2009), social rights, creativity and ethics (Touraine, 2015), in opposition to neoliberal system and gentrification dynamics.

\section{Common social spaces}

Occupying public and private buildings and facilities has been considered a political practice since 1960 in many Western countries (Castells et al., 1974; Daolio, 1974; Crouch and Pizzorno, 1978; Farro, 1986). On the one hand, the rise of the urbanisation process after World War II resulted in a new wave of domestic as well as foreign migrants in the city. The lack of housing and social housing is counterbalanced by a spontaneous creation of slums - in Italy, for instance, Ferrarotti (1979). On the other hand, a class conflict rose in order to cope with these issues and reclaim what at the time was called 'the right to the city' (Le droit à la ville, Lefebvre, 1968). These activities included traditional left-wing narratives, conducted by radical left-wing groups (Della Pergola, 1974). In the wake of these phenomena, the idea of autonomy and autonomous space, including prestigious historical examples such as La Commune of Paris, was backed by Henri Lefebvre (1970).

Following the rising of subjective, cultural and identity concerns, new waves of movements have introduced creative and, in different ways, artistic practices. Counter-cultures and alternative artistic productions infiltrate and animate new forms of occupation and squatting. In Italy, these experiences are well known as Social Centres. By self-financing artistic products, especially music and literature, they project a political message with a radical discourse (Famiglietti, 2006; Famiglietti and Rebughini, 2008) against capitalism and the state (Balestrini and Moroni, 1997). On the other hand, they have characterised the urban space by creating subcultures, defining cultural trends and leisure habits in the cities.

Self-produced alternatives proposed by the Social Centres have been successfully absorbed by the city amid different social classes. They have offered new political and cultural options, including relatively free-zones for drug consumption. The occupied spaces, especially public abandoned buildings, such as schools, administrative offices or former factories, exalt the logic of temporary liberated zones, which reflects Hakim Bey's idea (1985) of the Temporary Autonomous Zone (TAZ). By doing so, these practices set up practical alternatives in which a group of people (mostly young) can experience a cultural as well as political 
everyday life. All these experiences have been promoted and inhabited, practically and indirectly, on the one hand, by members and activists - young adults, politically or culturally inspired by Social Centres and the idea of an autonomous, alternative space; and, on the other hand, by the consumers or attendants students or young adults, from different social classes, who consider these places as culturally appealing and as trendy sources of entertainment.

Squatting becomes a political and cultural practice, also in response to housing needs and creative tendencies in the middle-sized or big cities. The approval and public recognition of some energised Social Centres in Italy (Membretti and Mudu, 2013) - for instance, Leoncavallo in Milan (Ibba, 1995) - have sometimes led to the legitimisation of these experiences, even on a local institutional level (Membretti, 2007). With the chance to become legalised, these occupied spaces have recently, in some cases, been won over by the idea, as observed in the Netherlands (Owens, 2009; Pruijt, 2017), and Germany (Mayer, 1993; Holm Kuhn, 2010; Vesudevan, 2015). The city, the local political institutions and the citizens acknowledge, in a sense, the role of some artistic squats that have 'earned' their spots as cultural and artistic attractions for a progressive/liberal audience in the city.

A Social Centre, an artistic squat - or just 'occupied space' - becomes part of the city, a landmark, in some cases a reference point for some precarious social categories: since 2014, some occupied spaces have hosted families or individuals from other countries, asylum seekers, undocumented migrants, and Roman people.

Different forms of occupation, claiming diverse rights, social justice or protesting for democracy, have risen from East to West, getting inspired by each other and echoing similar symbols in the public space. In the last decade, occupying the public space in the city has become a globalised and networked collective action. They nurture their hope for change and freedom by displaying their opposition to dictatorships, authoritarianism and regimes. From Tunisia and Egypt or other Arab countries - the so-called Arab Spring - to Turkey, and again more recently in Hong Kong (2014), millions of young and young adult people have occupied symbolic squares for weeks. In some cases, these collective actions have been considered for their uniqueness (Farro and Demirhisar, 2014), in terms of subjective as well as collective appropriation of highly controlled public spaces, exercising a role as citizens in a new civil sphere (Alexander, 2006), in order to claim personal rights and dignity, not just to defend the community (Khosrokhavar, 2012). Then, Western movements, from Occupy Wall Street and Occupy Montreal to M16 and the Indignados Movement in Spain, have criticised and protested against the financial capitalism, austerity measures, social injustice and lack of welfare policies within the current neoliberal system. All these experiences demonstrate that the city and the occupying practices still remain at the core of contemporary social movements. As an inseparable part of the production of space, globalised networks, such as new media and technology, contribute to redesign the geography of collective actions. 
As observed (Reed, 2005; Raunig, 2007), activists and artists create new forms of sociability and social, cultural and political projects by sharing occupied public spaces. Even during temporary occupations, activists engage with diverse categories of protesters in the attempt to produce alternative views and reclaim a right to public space (Mayer, 2009; Novy and Colomb, 2013) and social autonomy (Martinez, 2013). Updating Lefebvre's analysis, David Harvey's notion of the right to the city (2012) presents the idea of remaking citizens' social life by claiming common rights instead of individual ones, or rather, the private property. In this sense, the conceptualisation of the struggle for the common goods (Mattei, 2011; Negri, 2012; Weston and Bollier, 2013 Dardot and Laval, 2014), including the urban common goods (Garnett, 2012), addresses new narratives and goals against neoliberalism and the private property.

In the light of these new networked collective actions, from a square to the world, the diverse experiences of occupation that we consider in this chapter take on a different meaning. The role of the city as the fulcrum of the social movements and as a new global actor has been repeatedly highlighted (Sassen, 1991; Christopherson, 1994), especially within a European context (Bagnasco and Le Galès, 2000; King and Le Galès, 2017). The constantly growing urbanisation process in a global scale, while reshaping the cities into megalopolis and megacities, defines the urban context as the absolute producer of the social life. Nevertheless, we can observe a fragmentation of the social fabric that has led to new social experimentations in occupied spaces or reclaimed places, such as the public schools, gardens, squares, movie or Shakespeare theatres.

\section{Metropoliz: contemporary arts and global citizens}

In 2009 a group of activists occupied a former salami factory in the peripheral area of Rome, Prenestina 913. Until 2015, this facility hosted 60 families, including individuals from 10 different countries (South America, Asia, Africa and Eastern Europe), and Italians. The political group - Blocchi proletari metropolitani - that leads the occupation, emphasises the presence of Roma people, underlining the newest of this cohabitation with different, fragile, and precarious life paths.

Metropoliz hosts the Museum of the Other and the Elsewhere (MAAM), an alternative gallery for artistic exhibitions and contemporary arts. By contributing their pieces of art, artists keep the MAAM project alive and convey Metropoliz political messages. Particularly, they back social housing claims, the living together experience, and the multicultural and multi-ethnic community project. Moreover, artists' participation intertwines an artistic inspiration with the social and cultural meanings emerging from this cohabitation space. Paintings and sculptures decorate walls and other physical spaces of the facility, at the entrance as well as in the common living spaces.

The radical anti-institutional permanent mobilisation of young adult activists of Blocchi proletari metropolitani carries out, on the one hand, an anti-system management of an abandoned former factory in a peripheral area of Rome. This 
anti-capitalistic urban action claims for a 'right to the city' by conveying Marxist theories from social sciences, urban planning, architecture or sociological studies. In this way, Metropoliz finds a collaborative partner in the public university located nearby, elaborating critics against gentrification issues and real estate speculations. On the other hand, it stands for an alternative form of urban integration through a self-organised group of activists, artists and different communities of migrants. Within such a political agenda, families and individuals occupying Metropoliz are considered a resource against a possible coercive clearing up by law enforcement - MAAM is not open all the time, and a gate stays closed when no events are planned. At the same time, by becoming popular in the artistic landscape of Rome, Metropoliz enjoys a positive coverage that hypothetically prevents local and national authorities from attempting to evacuate the facilities.

Inside, Metropoliz organises meetings with the residents, in which the political collective conveys practical messages and strategies. Different needs, habits and perspectives come to light during these assemblies, in which conflicts and strategies of each ethnic group reappear (Broccia, 2012). The combination of the artistic production and installation with a community-based cohabitation is possible, thanks to the political collective. The success of MAAM guaranties the survival of the entire housing movement project.

\section{Spin Time: from the right to housing to a new left}

A seven-story building in Rome's historic downtown, formerly the headquarters of INPDAP (National Institution for Welfare of the Public Administration Employees), houses more than 150 families, the majority from foreign countries. Rooms on the ground floor and a basement with a huge amphitheatre are used to stage concerts, recreational events (theme nights with an entrance fee) and political events. Occupied in 2012, Spin Time gathers different political collective groups and left-wing activists in Rome.

Migrants are at the core of this occupation, not only in terms of numeric presence but also as a political radical message: in a context of conflicts and controversies around the recent waves of migration since 2011, Spin Time displays a strong support for the right to migrate and the hospitality duty. Plays, concerts and other events aim to stage - with and for them - migrants' condition, precariousness, sufferance and injustice. By unambiguously supporting migrants, Action (a movement that stands for the right to the house in the capital) and Spin Time unequivocally affirm a political position statement that follows a traditional struggle in support of the classes most at risk as potentially revolutionary actors (Frank, 1981).

This squatting space shows both a radical opposition to the political institutions and an attempt to create new bonds with different left-wing movements, as well as political parties and local institutions. Activists engaged in Action create a platform that strengthen a radical left-wing network in the city able to connect representatives and institutional actors. Spin Time offers a dynamic space 
for updated political debates and organised collective actions around a wide range of contemporary urban issues. Counting on an organised internal structure that relies on the important number of people hosted in the occupied facilities, Spin Time prevents any attempt to clear out the premises by law enforcement. Having become a solid, organised, 'deprivation based' (Pruijt, 2013) political squatting group, Spin Time represents a reference and a hosting space for other political collectives, Social Centre and occupied spaces militants in Rome. Furthermore, by opening to institutionalised political actors, Spin Time enhances grassroots urban movements and revitalises the left-wing.

\section{Teatro Valle: cultural and urban common goods}

In June 2011, a heterogeneous group of young and young adult artists and political activists occupied the oldest theatre in Rome, Teatro Valle - situated in the historic downtown, nearby the Senate of the Republic. The occupation occurred during the interruption of the theatre activities, officially due to a not-yet-scheduled upcoming restauration work of this historical site.

At first, the occupiers complained about the job insecurity of artists (Corsani, 2012; Giorgi, 2013; Langeard, 2013), the lack of cultural policies in the city and, last but not least, the possible acquisition of the national theatre by a private buyer. Contextualising this action, the occupiers displayed a more general criticism of local and national political and cultural institutions. Furthermore, in the light of the successful referendum repealing laws that would have, in fact, privatised the water in Italy, ${ }^{2}$ the appropriation of this 18th-century theatre is then theorised as a common good. During the occupation period (from June 2011 to August 2014), artists, activists and citizens experimented with artistic and political practices, in opposition to neoliberalism and the market of the artistic production.

Other well-known experimentations challenged the notion of art and politics (Smith, 2005; Raunig, 2007; Raunig and Ray, 2009), including the specific field of theatre (Case and Reinelt, 1991; Cima, 1991; Castañeda, 2006), by transforming, in some cases, the idea and role of actors and spectators (Boal, 1979, 1998; Babbage, 2004). In the Occupied Valle Theatre, the members supported creative and artistic production while hosting separated political debates and open meetings. In a first phase, characterised by a 'cooperative artistic practice', occupiers and sympathisers experiment with a form of shared theatre among other citizens and spectators. Although politics remains the fulcrum of the occupation, artists use this occupied space as a platform to perform new or old plays and invent new labour relations alternative to the liberal market. However, rather than contributing to a mere political theatre, artists engage in the occupation of elaborate collective dramaturgical projects ${ }^{3}$ and recitation programmes. ${ }^{4}$ Labour issues, social security and economic treatment for the artist are also discussed inside the occupied theatre and have led to the elaboration of alternative mutual aid for the artists, including different pay rates based on redistribution principles. In addition, by paying directly the $10 \%$ to the authors and registering them in the PATAMU 
platform, they skip the monopoly of the SIAE - Italian Society of Authors and Publishers, the Italian copyright collecting agency. Nevertheless, as none of their economic measures can solve the precariousness of artists, the problems related to the so-called intermittent art workers remain (Giorgi, 2013, pp. 110-135).

Managing the theatre seasonal schedule, the occupiers prove that selfmanagement of the public theatre is possible and must be encouraged. As soon as their artistic project receives international and national approval, ${ }^{6}$ the political project of the Occupied Valle Theatre can move forward. ${ }^{7}$ They promote a successful image of the occupied theatre as an open space that experiments an innovative sharing practice. Valle Theatre pursues a new political path by theorising their experience as a form of commons practice. By doing so, activists engage with a new political urban experiment that differentiates itself from other subsidiary practices (Arena and Cotturri, 2010), like the state school (Farro and Maddanu, 2015), by creating a radical collective action that aims to challenge and nurture the utopia of refunding the political institutions (Hardt and Negri, 2009; Mattei, 2011). This agency does not aim to be integrated into the system. Instead, it wants to create an alternative institution that could get rid of the existing - and perceived as ineffective - political institution in charge of the national theatre. Based on concrete practices, the movement of artists and activists, renamed artivists (Valli, 2015; Andò et al., 2017; Maddanu, 2018), after leaving the physical space of the theatre, are no longer able to continue the exceptional combination of artistic and political practice. As we observed during the plenary assemblies between 2014 and 2015, without a physical space to reproduce the management practices of a commons, the collective of ex-occupiers imagines an itinerant political and artistic project (Smith, 2005), but finally get stuck on an internal political impasse (Maddanu, 2018).

\section{Conclusions}

The three different occupation experiences we observed were carried out by young and young adult social actors that stand for a renewed right to the city. In the light of a constant urbanisation process, fragmentation of social life and its social fabric, different actors in the city try to connect traditional agencies with artistic practices. In order to cope the new challenges that emerge from the lack of social housing, and from the marginalisation of some social categories, especially migrants, political activists and artists are engaged in a radical collective action that defies public and private properties. Summarising the essentials of each occupation experience (see Table 10.1), these groups aim to operate in different parts of the city by asserting a sense of justice, social rights, creativity and ethics in opposition to the neoliberal system.

First, they put into practice the possibility of claiming the city and the housing right by occupying abandoned or empty facilities, mostly public places. In this way, they experiment new forms of socialisation and alternative cohabitations, which include ethnic minorities and migrants with different status. At the same 
Table 10.I Essentials of occupations

\begin{tabular}{cccc}
\hline & Metropoliz & Spin Time & Valle Theatre \\
\hline $\begin{array}{c}\text { Social programme } \\
\text { (keywords) }\end{array}$ & $\begin{array}{c}\text { Social housing, } \\
\text { multi-ethnic } \\
\text { cohabitation }\end{array}$ & $\begin{array}{c}\text { Social housing, } \\
\text { multi-ethnic } \\
\text { cohabitation }\end{array}$ & $\begin{array}{c}\text { Intermittent } \\
\text { art workers' } \\
\text { welfare; common } \\
\text { good-based } \\
\text { participation }\end{array}$ \\
Artistic activities & $\begin{array}{c}\text { Painting, } \\
\text { installations } \\
\text { and plastic arts }\end{array}$ & $\begin{array}{c}\text { Music (concerts) } \\
\text { and plays } \\
\text { (theatre) } \\
\text { (theatrical } \\
\text { schedule, plays } \\
\text { and dramaturgical }\end{array}$ & $\begin{array}{c}\text { writing) } \\
\text { Political goals } \\
\text { (keywords) }\end{array}$ \\
& $\begin{array}{c}\text { Autonomy and } \\
\text { autogestion in } \\
\text { a peripheral } \\
\text { area }\end{array}$ & $\begin{array}{c}\text { Autogestion and } \\
\text { networked } \\
\text { of left-wing } \\
\text { movement }\end{array}$ & $\begin{array}{c}\text { Self-management, } \\
\text { foundation } \\
\text { of institution, } \\
\text { cultural common } \\
\text { goods }\end{array}$ \\
\hline
\end{tabular}

time, they propose alternative economic and social relations, and mutual help. Second, they assert a political everyday practice that, in some cases, applies new political theories cognizant of the common good.

\section{Notes}

1 In this chapter we present part of the survey 'Sustainable practices of everyday life in the context of the crisis: Toward the integration of work, consumption and participation', funded by MIUR-PRIN 2010-2011 and coordinated by Laura Bovone (Università Cattolica di Milano), in collaboration with the Universities of Milano (coord. Luisa Leonini), Bologna (coord. Roberta Paltrinieri), Trieste (coord. Giorgio Osti), Molise (coord. Guido Gili), Roma, Sapienza (coord. Antimo L. Farro), Napoli Federico II (coord. Antonella Spanò).

2 National Referendum, 11-12 June 2011, abrogation of art. 154, DL, 3 April 2006, n. 152, clause 1 .

3 Like Crisi $($ tr. $=$ crises $)$ or Rabbia $($ tr. $=$ rage $)$. The latter promotes a so-called 'ecological circuit' based on an open participation in which attendants learn how to handle all the steps of a play (training, production, planning, distribution).

4 Nave Scuola (tr. = training ship) or Questo non è un Corso (tr. = this is not a course)

5 PATAMU is a copyright protect platform that offers free basic services and is based on donations.

6 In March 2014 the Valle Theater was awarded by the Princess Margriet Award of the European Cultural Foundation (ECF) in Brussels.

7 The collective group of occupiers, in collaboration with other participants, elaborate a common project that aimed to institutionalise the Valle Theater as a common good, directly managed by artists and engaged citizens. These discussions led to the Fondazione Teatro Valle Bene Commune (Foundation Valle Theater Common good), FTVBC, that counted approximately 5600 members: see a specific charter that explains the goals 
and meanings of this movement www.teatrovalleoccupato.it/wp-content/uploads/2013/ 10/STATUTO-FONDAZIONE-TEATRO-VALLE-BENE-COMUNE.pdf. [Accessed: 5 February 2015].

\section{Bibliography}

Alexander, J. (2006). The civil sphere. New York: Oxford University Press.

Andò, R., Farro, A.L., Maddanu, S. and Martinelli, A. (2017). Partecipazione e creatività: reinventare i beni comuni a Roma. In: L. Bovone and C. Lunghi, eds., Resistere: Innovazione e vita quotidiana. Roma: Donzelli, pp. 191-214.

Arena, G. and Cotturri, G. (eds.) (2010). Il valore aggiunto: Come la sussidiarietà può salvare l'Italia. Roma: Carocci.

Babbage, F. (2004). Augusto Boal. New York: Routledge.

Bagnasco, A. and Le Galès, P. (eds.) (2000). Cities in contemporary Europe. Cambridge: Cambridge University Press.

Bailey, S. and Marcucci, M.E. (2013). Legalizing the occupation: The teatro valle as a cultural commons. The South Atlantic Quarterly: Against the Day, Spring 112(2), pp. 396-405.

Balestrini, N. and Moroni, P. (1997). L'orda d'oro 1968-1977: La grande ondata rivoluzionaria e creativa, politica ed esistenziale. Milano: Feltrinelli.

Bey, H. (1985). T.A.Z.: The temporary autonomous zone, ontological anarchy, poetic terrorism. Weehawken, NJ: Grim Reaper Press.

Boal, A. (1979). Theater of the oppressed (C. \& M.-O. Leal McBride, Trans.). London: Pluto Press.

Boal, A. (1998). Legislative theater (A. Jackson, Trans.). London: Routledge.

Brenner, N. and Elden, S. (eds.) (2009). State, space, world: Selected essays: Henri Lefebvre. Minneapolis and London: University of Minnesota Press.

Broccia, F. (2012). Metropoliz: Strategie dell'abitare in un'ex fabbrica a Roma. Roma: Tesi di Laurea in Discipline Demoetnoantropologiche, Facoltà di Lettere e Filosofia, Università Sapienza.

Case, S. and Reinelt, J. (eds.) (1991). Conferring power in the theater: Theatrical discourse and politics. Iowa City: University of Iowa Press.

Castañeda, Q.E. (2006). The invisible theatre of ethnography: Performative principles of fieldwork. Anthropological Quarterly, 79(1), pp. 75-104.

Castells, M., Cherki, E., Godard, F. and Mehl, D. (1974). Sociologie des mouvements sociaux urbains: enquête sur la région parisienne. Vol. II, Crise du logement et mouvements sociaux. Paris: EHESS/CEMS.

Christopherson, S. (1994). The Fortress city: Privatized spaces, consumer citizenship. In: A. Amin, ed., Post-Fordism. Oxford: Blackwell, pp. 409-427.

Cima, G.G. (1991). Conferring power in the theater. In: Case and Reinelt, eds., op. cit., pp. 256-264.

Corsani, A. (2012). Dalla precarietà contrattuale alla precarizzazione esistenziale: L'esperienza dei lavoratori dello spettacolo in Francia. In: E. Armano and A. Murgia, eds., Mappe della precarietà, Vol. II. Bologna: Emil, pp. 19-36.

Crouch, C.D.P. and Pizzorno, A. (eds.) (1978). The resurgence of class conflict in Western Europe since 1968. Vol. I. National Studies.

Daolio, A. (ed.) (1974). Lotte per la casa in Italia: Milano, Torino, Roma, Napoli. Milano: Feltrinelli. 
Dardot, P. and Laval, C. (2014). Commun: Essai sur la révolution au XXIe siècle. Paris: La Découverte.

Della Pergola, G. (1974). Diritto alla città e lotte urbane. Milano: Feltrinelli.

Famiglietti, A. (2006). Radicalismo, cultura, violenza. In: A.L. Farro, ed., Italia alterglobal: movimento, culture e spazie di vita di altre globalizzazioni. Milano: Franco Angeli, pp. 33-76.

Famiglietti, A. and Rebughini, P. (2008). Un consumo diverso è possibile: la via dei centri sociali. In: L. Leonini and R. Sassatelli, eds., Il consumo critico. Pratiche, discorsi, reti. Roma-Bari: Laterza, pp. 85-112.

Farro, A.L. (1986). Conflitti sociali e città. Milano: Franco Angeli.

Farro, A.L. (2014). A new era for collective movements: The subjectivization of collective action. In: A.L. Farro and H. Lustiger-Thaler, eds., Reimagining social movements: From collective to individuals. London and New York: Routledge, pp. 15-34.

Farro, A.L. and Demirhisar, D.G. (2014). The Gezi park movement: A Turkish experience of the twenty-first-century collective movements. International Review of Sociology, 24(1), pp. 176-189.

Farro, A.L. and Maddanu, S. (2015). La scuola del mondo in un quartiere: Genitori ed esperienze di rigenerazione della vita sociale. Scuola Democratica, 1, pp. 211-230.

Ferrarotti, F. (1979). Roma da capitale a periferia. Roma-Bari: Laterza.

Frank, G.A. (1981). Reflections on the world economic crisis. New York: Monthly Review Press.

Garnett, N.S. (2012). Managing the urban commons. University of Pennsylvania Law Review, 160(7), pp. 1995-2027.

Giorgi, A. (2013). Le mobilitazioni dei lavoratori della cultura, dell'arte e dello spettacolo. In: L. Alteri and L. Raffini, eds., La nuova politica: Movimenti, mobilitazioni e conflitti in Italia. Napoli: EdiSeS, pp. 110-135.

Hardt, M. and Negri, T. (2009). Commonwealth. Cambridge: Harvard University Press.

Harvey, D. (2001). Spaces of capital: Towards a critical geography. London and New York: Routledge.

Harvey, D. (2012). Rebel cities: From the right to the city to the urban revolution. London and New York: Verso.

Hess, C. and Ostrom, E. (2006). Understanding knowledge as a commons: From theory to practice. Cambridge, MA: MIT Press.

Holm, A. and Kuhn, A. (2010). Squatting and urban renewal: The interaction of squatter movements and strategies of urban restructuring in Berlin. International Journal of Urban and Regional Research, 35(3), pp. 644-658.

Ibba, A. (1995). Leoncavallo 1975-1995: venti anni di storia autogestita. Genova: Costa \& Nolan.

Khosrokhavar, F. (2012). New Arab revolutions that shook the world. Boulder: Paradigm Publishers.

King, D. and Le Galès, P. (eds.) (2017). Reconfiguring European states in crisis. Oxford: Oxford University Press.

Langeard, C. (2013). Les intermittents en scènes: Travail, action collective et engagement individuel. Rennes: Presses Universitaires de Rennes.

Lefebvre, H. (1968). Le droit à la ville. Paris: Éditions Anthropos.

Lefebvre, H. (1970/2003). The urban revolution. Minneapolis: University of Minnesota Press.

Lefebvre, H. (1975). L'Etat dans le monde moderne. L'homme et la société, 37(1), pp. 3-23. 
Maddanu, S. (2018). The theatre as a common good: Artists, activists and artivists on stage. Interface: A Journal for and about Social Movements, 10(1).

Martinez, M.A. (2013). The squatters' movement in Europe: A durable struggle for social autonomy in urban politics. Antipode, 45(4), pp. 866-887.

Mattei, U. (2011). Beni comuni: Un manifesto. Roma-Bari: Editori Laterza.

Mayer, M. (1993). The role of urban social movement organizations in innovative urban policies and institutions. Topos Review of Urban and Regional Studies, Special Issue, pp. 209-226.

Mayer, M. (2009). The 'right to the city' in the context of shifting mottos of urban social movements. City, 13(2), pp. 262-274.

Membretti, A. (2007). Centro Sociale Leoncavallo: Building citizenship as an innovative service. European Journal of Urban and Regional Studies, 14(3), pp. 252-263.

Membretti, A. and Mudu, P. (2013). Where global meets local: Italian social centres and the alterglobalization movement. In: C. Flesher Fominaya and L. Cox, eds., Understanding European movements: New social movements, global justice struggles, anti-austerity protest. New York: Routledge, pp. 73-96.

Negri, T. (2012). Inventare il Comune. Roma: DeriveApprodi.

Novy, J. and Colomb, C. (2013). Struggling for the right to the (creative) city in Berlin and Hamburg: New urban social movements, new 'spaces of hope'? International Journal of Urban and Regional Research, 37(5), pp. 1816-1838.

Ostrom, E. (1990). Governing the commons: The evolution of institutions for collective action. Cambridge: Cambridge University Press.

Owens, L. (2009). Cracking under pressure: Narrating the decline of the Amsterdam Squatters' Movement. Amsterdam: Amsterdam University Press.

Pruijt, H. (2013). The logic of urban squatting. International Journal of Urban and Regional Research, 37(1), pp. 19-45.

Pruijt, H. (2017). Squatting in the Netherlands: The social and political institutionalization of a movement. In: F. Anders and A. Sedlmaier, eds., Public goods versus economic interests. London/New York: Routledge.

Raunig, G. (2007). Art and revolution: Transversal activism in the long twentieth century. Cambridge, MA: MIT Press.

Raunig, G. and Ray, G. (eds.) (2009). Art and contemporary critical practice: Reinventing institutional critique. London: MayFlyBooks.

Rebughini, P. (2000). Le culture giovanili. In: A. Melucci, ed., Parole chiave. Roma: Carocci, pp. 76-86.

Reed, T.V. (2005). The art of protest: Culture and activism from the civil rights movement to the streets of Seattle. Minneapolis: University of Minnesota Press.

Sassen, S. (1991). The global city. New York, London, Tokyo, and Princeton: Princeton University Press.

Satta, C. and Scandurra, G. (2014). Creatività e spazio urbano. Territorio, 68, pp. 39-45.

Sen, A. (2009). The idea of justice. London: Penguin.

Smith, O.F. (2005). Fluxus praxis: An exploration of connections, creativity, and community. In: A. Chandler and N. Neumark, eds., At a distance: Precursors to art and activism on the Internet. Cambridge, MA, and London: MIT Press, pp. 116-138.

Touraine, A. (2015). Nous, sujets humains. Paris: Seuil.

Valli, C. (2015). When cultural workers become an urban social movement: Political subjectification and alternative cultural production in the Macao movement, Milan. Environment and Planning A, 47(3), pp. 643-659. 
Vesudevan, A. (2015). Metropolitan preoccupations: The spatial politics of squatting in Berlin. Sussex: Wiley.

Weston, B. H. and Bollier D. (2013). Green governance: Ecological survival, human rights, and the law of the commons. New York: Cambridge University Press. 


\section{'I would rather choose \\ a mixed school'}

\section{Young people's secondary school choice in a low-income, multi-ethnic neighbourhood}

\section{Kirsten Visser}

\section{Introduction}

The assumption that the neighbourhood of residence has effects on the social outcomes of children and young people has influenced much social research as well as many urban policies. Growing up in a deprived neighbourhood has been shown to have a negative influence on several social outcomes, including educational attainment (Andersson and Subramanian, 2006; Kauppinen, 2007; Kintrea, St Clair and Houston, 2011; Nieuwenhuis and Hooimeijer, 2016). In this context the school can be an important pathway through which the neighbourhood context influences young people (Rumberger and Palardy, 2005; Sellström and Bremberg, 2006; Sykes and Musterd, 2011). Access to, and quality of, schools often differs between deprived and less deprived neighbourhoods. Moreover, the school is also a place where friendship ties and social networks are formed and maintained, and where norms and values are transmitted.

To understand how schools function as a pathway for the transmission of neighbourhood effects, it is crucial to understand how young people are selected into schools. The decisions that are taken after the end of primary school form an important transition in young people's lives which can potentially affect their future development and life chances. As noted by Hatcher (1998, pp. 6-7), the school choices that young people make 'are one element in the process of class differentiation in education.... These transition points are sites of social selectivity in terms of class, and often in terms of gender and ethnicity too'. Research into how young people select schools, however, has focused mainly on the perspectives of parents and has mostly focused on primary school choice (for exceptions, see Reay and Lucey, 2000, 2003; Yoon, 2016). This is an important shortcoming, as the children, not their parents, are the ones directly affected by the school choices that are made.

Moreover, traditional school choice literature is informed by rational choice theory, which suggests that school decision-making takes place based on calculations of the costs, benefits and probabilities of success of various options. More recent research, however, indicates that the context of school decision-making is far more complex than the result of weighting of rational costs and benefits of 
several educational options. School choice is part of a social process influenced by factors such as social class, ethnic background and norms, values and stories present in social networks (Ball and Vincent, 1998; Reay and Lucey, 2000; Bosetti, 2004). Bosetti (2004), for example, shows that when making decisions regarding their children's education, parents will rely on their personal values and subjective desired goals of education, as well as others within their social and professional networks to collect information. Similarly, Ball and Vincent (1998) illustrate how parents' school choice is often informed by subjective and incomplete 'grapevine' knowledge rather than the official information provided by schools.

In this chapter I will address these two issues by discussing the processes of secondary school decision-making of young people growing up in a low-income, multi-ethnic neighbourhood in Rotterdam, the Netherlands. Specific attention will be paid to the more subjective factors that influenced the choice for a neighbourhood school. The Netherlands presents an interesting setting to study school choice. It is a densely populated country: within a 10-kilometre radius a child can reach on average 10 relevant secondary schools (Koning and Van der Wiel, 2010). Moreover, the Netherlands has unrestricted free school choice, schools have negligible school fees and are easily accessible because of good public transport and bike infrastructure. Despite these factors, we see that in Feijenoord, the majority of the young people choose to attend a school in their neighbourhood - or at least in the relatively low-income, and multi-ethnic Rotterdam-South area. This can partly be explained by practical factors, such as the physical proximity of the school, but as I will explain in the remainder of this chapter, more subjective factors also play a role in this school choice.

\section{Neighbourhood deprivation and school quality}

Academic literature from particularly the United States and United Kingdom points to a relationship between neighbourhood deprivation and school quality: schools in deprived neighbourhoods are often of lower quality than schools in less deprived neighbourhoods (Jencks and Mayer, 1990; Putnam, 2016). Lupton (2004) shows that schools in deprived neighbourhoods in the United Kingdom have problems attracting good and experienced teachers, which can explain the differences in educational outcomes between these schools. Other studies show that teachers in deprived neighbourhoods expect less from their students and therefore stimulate them less to get good grades (Atkinson and Kintrea, 2004). Oberti (2007) found in the Paris metropolitan area that in low SES areas, there were less diversified and attractive school options, such as course and studyprogramme options, compared to high SES areas. Moreover, schools in deprived neighbourhoods are more likely to attract low SES children, often with minority backgrounds, whereas middle-class, often white, children select into better schools in less deprived neighbourhoods. This is problematic as it exemplifies the already existing inequalities in opportunities, and it limits children from different ethnic and SES backgrounds to come into contact with each other. In the 
Netherlands, the differences between schools in deprived and less deprived neighbourhoods are smaller than in the United States or United Kingdom. Nevertheless, the schools in deprived neighbourhoods often have a relatively large population of students from deprived and minority backgrounds. In the Dutch context, Sykes and Musterd (2011) find that children in deprived neighbourhoods often tend to go to lower-quality schools, which results in poorer educational outcomes.

\section{Young people's school choice}

The literature on neighbourhood and school segregation, however, pays limited attention to the agency young people have in choosing their schools. Studies on choice making in education focus on two lines of research. The first body of studies deals with parental decision-making, thereby placing parents at the centre of the choice debate. In these studies the reasons for school choice are generally reduced to three general domains: the quality of the education, the geographical distance of the school from home and the non-educational characteristics of the school, such as the (ethnic) characteristics of the school population. The second stream of studies focuses on the role that young people play as choice-makers. Increasingly, studies show that young people are involved in the choice process who are influenced by both the family context and the peer context. Reay and Lucey's (2000) research on the secondary school choice perspectives of 10- to 11-year-olds shows that the children played a central role in the school decision-making process and were often seen by their parents as the 'expert' on the local schools. The children also generated peer group discourses about secondary schools, in which certain schools were described as 'popular' and 'good' whereas others where described as less desirable. Similarly, Sykes (2011) shows that young people in her study in Amsterdam all recalled being central actors in their secondary school decisionmaking process, and many felt that they had had the final say in the decision.

In addition, some studies specifically focus on the school choice among young people with migrant backgrounds. A Swedish study of immigrant students that attended a local 'low-performing', 'high poverty' school, showed that they liked the school because it allowed them to maintain their local social network and because they felt a sense of cultural belonging and acceptance being among other immigrants. Moreover, they did not want to run the risk of being seen as different in a Swedish-majority school (Bunar, 2010). Studying young people from immigrant neighbourhoods who attended inner-city 'white' schools, Johansson and Hammarén (2011) found that the choice of attending these schools made both economic and social mobility possible but that the students also had to deal with being 'the other'.

\section{The Dutch school system}

In the Netherlands there is freedom of school choice, no catchment areas and a wide diversity of secondary schools. Moreover, almost all funding for schools 
comes from the Ministry of Education, which means that school fees are negligible and schools are independent of local taxes (van Welie, 2013). Around the age of 12, students are divided into three main tracks based on their abilities. The academic VWO prepares for university in six years, HAVO provides higher general education for five years giving access to higher professional education and VMBO is a vocational school, divided into different pathways lasting four years and giving access to apprenticeship. Students' suitability for the different tracks is assessed by a primary school leavers attainment test (CITO); parents may express preferences, but the secondary school board has the final decision. Schooling is compulsory until age 16 .

\section{Context and methods}

The research was carried out in Feijenoord, a district of Rotterdam. Feijenoord is located south of the river Meuse, an area that has traditionally been the poorer part of the city. Compared to the city average, the population of Feijenoord is characterised by relatively low-income and education levels and high unemployment levels. It is also one of the most diverse areas in the Netherlands. The largest non-Dutch groups are Turkish, Surinamese, Moroccan and Dutch Antillean. The area has to deal with social problems such as low levels of perceived safety, crime and drug use.

The focus of the research was on young people aged 13-19 years, who attended schools within the Feijenoord area. Respondents were recruited through community organisations and secondary and MBO (secondary vocational education and training) schools, by means of a non-random, convenience sampling strategy. In total, 47 interviews were conducted. The group of respondents consisted of boys and girls from diverse ethnic backgrounds (Dutch, Turkish, Moroccan, Surinamese, Eastern European, Dutch Antillean, Afghan and Pakistani). At the time of the interviews, the young people were attending or had attended six different secondary schools in the area. The schools include three public schools $(91 \%$, $92 \%$ and $94 \%$ non-Dutch students), two schools with a Christian denomination (one with $71 \%$ non-Dutch students, for the other data were not available), and one school with a Muslim denomination (no data on non-Dutch students were available). The schools range from vocational learning paths to pre-university learning paths.

The young people were asked retrospectively about which factors had influenced their secondary school choice. The interviews were transcribed in their entirety and coded and analysed using a standardised QDA program (NVivo). General patterns in the data that were identified in the first round of coding were further refined during the subsequent rounds. Text query and negative case analysis were used to determine the relative strength of the themes that emerged from the data. Each participant was assigned a pseudonym, and these pseudonyms are used throughout this chapter. 


\section{Results}

The narratives of the young people show that their school choices are the result of the complex interaction between perceptions, preferences, constraints and opportunities. As pointed out by Gewirtz, Ball and Bowe (1995, p. 76), the process of choice-making happens within a landscape of choice that is 'amorphous, processual, tentative and intuitive'. In this chapter I will discuss how young people learn about and navigate this 'landscape of school choice'.

\section{Learning about the landscape of choice: social networks, rumours and reputation}

The school choices young people make are largely influenced by their subjective perceptions of the schools that are available to them. Simon's (1990) work on bounded rationality is particularly relevant here. Individuals do not necessarily choose the best option; instead, they use 'experience to construct an expectation of how good a solution we might reasonably achieve and halting search as soon as a solution is reached that meets the expectation' (Simon, 1990, p. 9). In line with the idea of bounded rationality, we see that a young person selects schools based on their expectations of what is reasonable, rather than considering all schools in the city and necessarily choosing the best one. In other words, the young people have constructed a choice set of schools that are available to them and on which they have information. The narratives of the young people show that the perceptions of these different schools are formed based on information they achieve through both formal and informal sources.

The young people indicated that friends and family played an important role in influencing their school choices. These groups form sources of instrumental and social support, of values and expectations and of stories of success and failure. Family members and friends, for example, formed an important source of information about several issues, such as which schools were considered good and which ones to avoid, the type of children and culture at the school, the quality of teachers, the level of strictness and the amount of homework (see also Reay and Lucey, 2000). For the majority of respondents, as well as for their parents, the ideal school was one that family and/or friends already attended. As explained by Nick (19 years old, Dutch) about choosing school A: 'I just seemed like a good school to me, my oldest brother went there, and he got his diploma. So I thought it would be ok'.

Also the decision about which schools not to attend was made based on information from informal social networks. Young people learned about schools in the vicinity through story-telling, rumour and gossip. Jenna (17 years old, Moroccan), for example, explains:

First my sister wanted to send me and my cousin to school F, that's an Islamic school. I said: absolutely not! It's an Islamic school but they don't stick to 
the rules of the Islam there. I also heard - I am not sure if I am allowed to say this - that they have oral sex on the toilets. So I said: absolutely not!

Similarly, Soraya (14 years old, Moroccan) tells about how she learns about how something bad, like a fight, happens at a school in the neighbourhood through her informal network in the neighbourhood: 'For example, when there is a fight at school, the entire neighbourhood knows immediately about it. Within the hour everybody knows, whole Rotterdam knows'.

The information obtained through friends and family members was often seen as more reliable than 'official' sources of information, especially those provided by the schools themselves in brochures, on websites and through 'open days'. Quite some of the young people expressed scepticism about the information that schools gave during these 'open days', indicating that the school tries to make the school look nicer than it actually is. As noted by Soraya (14 years old, Moroccan):

I always feel that at an 'open day' they are telling lies, because they will never tell you: 'at this school you have to show your homework every day [. . .], be at school at 8 and if you are not there then this and that will happen'. They'll only say: 'this school is really fun, you will get help with your homework here and we will help you with getting you diploma, things like that'. They just want to advertise themselves.

Informal networks were thus considered more reliable than the official information provided by the schools. It has to be noted, however, that the young people were not influenced by one social network, but that their school choices were influenced by information from several networks at the same time. Different networks existed within the neighbourhood, and each provided access to different sources of knowledge. As the result of the different informal social networks, young people often produced contradictory accounts of the same schools. Younes (18 years old, Moroccan) and Aamina (18 years old, Dutch-Surinamese), for example, talk about the same school [E].

YOUNES: A lot has happened some years ago, stabbings and things like that. I thought: that's not the school for me.

AAMINA: For my secondary school I chose [school E] because all schools were already full. I didn't want to go to [school E] because I heard on the media that it was a bad school. . . . And then I went to my neighbours, because they attended this school and they convinced me. Until today I have never regretted my choice.

The citation of Aamina, furthermore, shows that the media played an important role in providing information about schools. While Koning and Van der Wiel (2013) already pointed to the role official newspapers play in disseminating school rankings, the young people's narratives add that official and unofficial (social) 
media can play an important role in informing the young people and parents about things that happen at a school. In this context, however, many of the young people also pointed out that the media only tend to cover the bad things that happen in the neighbourhood and at neighbourhood schools, realising that they also have to be critical about this information.

\section{Navigating the landscape of choice: physical and social proximity}

Young people thus constructed complex images of schools available to them based on a combination of official and unofficial information from different groups, such as family members and friends, as well as from individual experiences. After the young people learned about the characteristics of the schools available to them, they had to make the actual choice for a school.

Not surprisingly, the physical proximity of a school played an important role in choosing that school. A school in the neighbourhood was considered convenient in terms of less time spend on transportation. As noted by Zaynab (14 years old, Moroccan):

I rather go nearby than far away. Travelling takes a lot of time. I don't feel like doing that. If it's like 45 minutes from here [home] to my school, I have to wake up early. I rather go to a school in the neighbourhood, than I don't have to wake up early or have a long travel time.

More importantly, the local school was also seen as a source of physical safety that some of the young people and their parents valued more than getting access to - perhaps better - schools in other parts of the city. Even though the respondents acknowledged that the Feijenoord area had pockets of crime and a lack of safety, the area at the same time was linked to feelings of security, belonging and connection. Places that were far away were considered more dangerous because of unfamiliarity. Even if the young people were convinced schools outside the Feijenoord area would be more beneficial for future careers, some of them chose to stay because the costs in terms of lack of safety were deemed to be too high. As noted by Soraya (14 years old, Moroccan) about visiting school D's open day:

My mother though it was a bit scary over there. After exiting the train you had to walk for a while and that day we were followed by a man. So, she became scared: like 'You want to go to school here?' And she knew, close to my grandma's house there was also a school, so that's why I went there.

\section{Being with likeminded people}

For many of the young people, social proximity of the people at the school was even more important than physical proximity. The young people expressed a 
sense of satisfaction with, and belonging to, the local community, and for many of the young people, the neighbourhood formed an important part of their identity (Visser, Bolt and van Kempen, 2015). The majority of the young people had many friends in the neighbourhood; they indicated that they 'knew everybody' and felt accepted. These familiar and social networks could be continued in the school context. The feeling of being 'at home' at school and having friends, relatives and acquaintances there which could be a source of social support was considered an important factor for choosing a neighbourhood school. Xandra (17 years old, Surinamese) explains it as follows when asked why she chose school C:

My mother said: 'go to the same school as your sister'. It was also more convenient, because I knew a lot of my sister's friends. And she helped me a lot, and her class mates as well. And one boy who lives in this neighbourhood, a really kind guy, he helps with school things as well.

Particularly for young people with a migrant background, the choice for a neighbourhood school was based on the fact that they considered it a place where they could maintain a sense of acceptance and belonging, as the student body was ethnically diverse which resulted in cultural recognition. As explained by Driss (15 years old, Moroccan): 'I would rather choose a mixed school, because I learn more from children with diverse ethnic backgrounds and I also get along better with them'. The diversity of the neighbourhood school was thus seen as something positive, or at least something socially comfortable. This is line with the findings of Bottero (2004, p. 995), who states that 'our choices are governed both by contiguity and by the social comfort that comes from associating with "people like us"'. Interesting here is that the term 'mixed' was used by many of the respondents to indicate a mix of peers from different non-Dutch backgrounds. This is in contrast with how the term mixing is used in most literature and policy documents, where it usually entails a mix of 'black' and 'white' students.

\section{'Not my sort of place'}

While the local schools provided the young people in Feijenoord with a sense of belonging, the other side of the coin is that some young people felt that other schools - with a predominantly white student body or with a higher educational level - were 'not for them'. For them, choice-making seemed to be, in part, a process of self-exclusion. Some young people excluded themselves from higher levels of education, even though they had good scores on their primary school leavers attainment test (CITO), because they felt that they are not the type of person that 'likes long days at school' (Ali, 17 years old, Turkish) or 'likes reading the entire day' (Mitchell, 18 years old, Dutch/Surinamese). Moreover, some young people also believed that choosing another (white) school and doing it without any support from their neighbourhood social network would put a them in a situation in which they would feel 'out of place'. As noted by Farida (16 years 
old, Moroccan) about her preference for a mixed school: 'I like it better. I could also go to a school with only [white] Dutch people [. . .], but I think they would look differently at me'.

Furthermore, previous experiences of exclusion at a specific (type of) school, for example during open days or during primary education, influenced the choice for a different school. These experiences of exclusion, however, where not exclusive for white schools. The two examples that follow actually occurred at more diverse neighbourhood schools. Not surprisingly, these incidents were reason for the young people to choose a different school. As explained by Rafik (14 years old, Moroccan):

I was planning to go to [school C], but when I went to sign up, there was a janitor and he said 'you little Moroccan, you have to leave'. I think it was a janitor, he looked like a janitor, he was carrying cleaning equipment.

Another example was given by Irmak (18 years old, Turkish): 'I attended a Christian primary school, and I wasn't allowed to wear a headscarf there, and people would look at you in strange ways. So that's why [she chose Islamic school F]'.

In short, the interviews thus show that the young people in Feijenoord develop a sense of 'their sort of place'. This means choosing for a diverse secondary school in, or near, the neighbourhood of residence. One could argue that these sorting mechanisms are not very different from how white, middle-class children sort into schools, they also choose schools where they feel that they belong and where their friends are going. However, it is important to note here that the sense of a young person's place is formed in relation to the places that other individuals possess, in a web of unequal social positions (Katartzi, 2011). The diverse schools - often named 'black' schools in the Dutch media - where most of the young people ended up often had a worse reputation than the 'white' schools in other parts of the city. This might influence people's perceptions about the young people attending these schools as well as the chances the young people have later in life, such as getting access to higher education, internships or jobs.

\section{Conclusion}

The young people's narratives illustrated how school choices are influenced by a complex interaction of different forms of information, identifications and emotions. Young people based their school choices on incomplete knowledge from different informal social networks, and information from these social networks was often more influential than the information communicated through official channels, such as brochures, websites and 'open days'.

Moreover, both physical and social proximity played a role in young people's school choice. Choosing a neighbourhood school was convenient as there was limited travel time and because the familiar environment provided a sense of 
safety. Even though young people were aware of the risks of the Feijenoord area, attending a local school often felt safer than travelling to schools in other parts of the city. Even more importantly, young people in the Feijenoord area chose local schools because it provided them with a feeling of belonging and cultural recognition. The possibility of maintaining close relationships with their friends, and the concern of being reduced to outsiders in a 'white' school, played a role here. Moreover, young people distinguished between 'their kind of school' and 'not their kind of school' based on the ethnic diversity and educational level of the school. Based on the findings of this study, it can be concluded that we should not consider school choice as an individual matter. For the young people in this study, collective identifications mattered and shaped their school choices. Moreover, it is important to pay attention to the ways in which the young people perceive and understand their neighbourhood and school, and their position within this.

One could argue that issues like belonging are also important for the school choices of young people from white, middle-class backgrounds. However, the fact that 'black' schools and 'white' schools are unequal in terms of access to resources and reputation makes it problematic. Black schools are often stigmatised (Ispa-Landa and Conwell, 2015), and as such, young people might have unequal opportunities based on the school they attend. Moreover, a Swedish study (Johansson and Olofsson, 2011), has already shown that the conception of being 'the other' could have a strong influence on the life plans and the educational and occupation careers of young people.

In relation to policies aimed at mixing schools, this study shows that it is important to take the experiences and sense of belonging of young people into account. This research supports the recommendations of Agirdag (2011), who suggests that a policy that aims at forcibly moving non-Dutch students to white schools is likely not to be successful, as young people might not feel at home at these schools and this might result in lower self-esteem. Programmes that stimulate collective, voluntary enrolment of middle-class children in schools in low-income neighbourhoods are likely to be more effective. As noted by Agirdag and Van Houtte (2011), there are many open-minded, middle-class parents who would like to enrol their children in such schools but are afraid to do so because they believe that their children will be isolated. The collective nature of such programmes would make that the children would feel less isolated or 'out of place'. Moreover, high-SES students are likely to be less negatively affected by the composition of schools (Coleman et al., 1966).

\section{Bibliography}

Agirdag, O. (2011). De zwarte doos van schoolsegregatie geopend: Een mixed-method onderzoek naar de effecten van schoolcompositie op de onderwijsprestaties, het zelfbeeld en het schoolwelbevinden van de leerlingen in het lager onderwijs met bijzondere aandacht voor intermediaire processen. Doctoral Dissertation, Ghent University. 
Agirdag, O. and Van Houtte, M. (2011). A tale of two cities: Bridging families and schools. Educational Leadership, 68(8), pp. 42-46.

Andersson, E. and Subramanian, S.V. (2006). Explorations of neighbourhood and educational outcomes for young Swedes. Urban Studies, 43(11), pp. 2013-2025.

Atkinson, R. and Kintrea, K. (2004). Opportunities and despair, it's all in there' practitioner experiences and explanations of area effects and life chances. Sociology, 38(3), pp. 437-455.

Ball, S.J., and Vincent, C. (1998). 'I heard it on the grapevine': 'Hot' knowledge and school choice. British Journal of Sociology of Education, 19(3), pp. 377-400.

Bosetti, L. (2004). Determinants of school choice: Understanding how parents choose elementary schools in Alberta. Journal of Education Policy, 19(4), pp. 387-405.

Bottero, W. (2004). Class identities and the identity of class. Sociology, 38(5), pp. 985-1003.

Bunar, N. (2010). Choosing for quality or inequality: Current perspectives on the implementation of school choice policy in Sweden. Journal of Education Policy, 25(1), pp. 1-18.

Coleman, J.S., Campbell, E.Q., Hobson, C.J., James, M., Mood, A.M., Weinfeld, F.D., et al. (1966). Equality of Educational Opportunity. Washington, DC: US Dept. of Health Education and Welfare Office of Education.

Gewirtz, S., Ball, S.J. and Bowe, R. (1995). Markets, choke and equity in education. Buckingham: Open University Press.

Hatcher, R. (1998). Class differentiation in education: Rational choices? British Journal of Sociology of Education, 19(1), pp. 5-24.

Ispa-Landa, S. and Conwell, J. (2015). 'Once you go to a white school, you kind of adapt' black adolescents and the racial classification of schools. Sociology of Education, 88(1), pp. 1-19.

Jencks, C. and Mayer, S.E. (1990). The social consequences of growing up in a poor neighbourhood. In: National Research Council, Inner-city poverty in the United States. Washington, DC: The National Academies Press, pp. 111-186.

Johansson, T. and Hammarén, N. (2011). The art of choosing the right tram: Schooling, segregation and youth culture. Acta Sociologica, 54(1), pp. 45-59.

Johansson, T. and Olofsson, R. (2011). The art of becoming 'Swedish': Immigrant youth, school careers and life plans. Ethnicities, 11(2), pp. 184-201.

Katartzi, E. (2011). Narrating identities and educational choices: The case of migrant and Greek young people. Doctoral Thesis, University of Edinburgh.

Kauppinen, T.M. (2007). Neighborhood effects in a European city: Secondary education of young people in Helsinki. Social Science Research, 36(1), pp. 421-444.

Kintrea, K., St Clair, R. and Houston, M. (2011). The influence of parents, places and poverty on educational attitudes and aspirations. New York: Joseph Rowntree Foundation.

Koning, P. and van der Wiel, K. (2010). Kwaliteitsinformatie middelbare scholen maakt verschil. Economisch Statistische Berichten, 95(4585), pp. 294-297.

Koning, P. and van der Wiel, K. (2013). Ranking the schools: How school-quality information affects school choice in the Netherlands. Journal of the European Economic Association, 11(2), pp. 466-493.

Lupton, R. (2004). Schools in disadvantaged areas: Recognising context and raising performance. CASE paper 76. London: Centre for Analysis of Social Exclusion, London School of Economics and Political Science.

Nieuwenhuis, J. and Hooimeijer, P. (2016). The association between neighbourhoods and educational achievement, a systematic review and meta-analysis. Journal of Housing and the Built Environment, 31(2), pp. 321-347. 
Oberti, M. (2007). Social and school differentiation in urban space: Inequalities and local configurations. Environment and Planning A, 39(1), pp. 208-227.

Putnam, R.D. (2016). Our kids: The American dream in crisis. New York: Simon and Schuster.

Reay, D. and Lucey, H. (2000). Children, school choice and social differences. Educational Studies, 26(1), pp. 83-100.

Reay, D. and Lucey, H. (2003). The limits of choice' children and inner city schooling. Sociology, 37(1), pp. 121-142.

Rumberger, R.W. and Palardy, G.J. (2005). Does segregation still matter? The impact of student composition on academic achievement in high school. Teachers College Record, 107(9), pp. 1999-2045.

Sellström, E. and Bremberg, S. (2006). Is there a 'school effect' on pupil outcomes? A review of multilevel studies. Journal of Epidemiology \& Community Health, 60(2), pp. 149-155.

Simon, H.A. (1990). Alternative visions of rationality. In: P.K. Moser, ed., Rationality in action: Contemporary approaches. Cambridge: Cambridge University Press, pp. 189-204.

Sykes, B. (2011). One-sided geographies? The interplay among youth, neighbourhoods and schools, in spatial order and social position: neighbourhoods, Schools and Educational Inequality. Doctoral Thesis, University of Amsterdam, pp. 154-193.

Sykes, B. and Musterd, S. (2011). Examining neighbourhood and school effects simultaneously: What does the Dutch evidence show? Urban Studies, 48(7), pp. 1307-1331.

Visser, K., Bolt, G. and van Kempen, R. (2015). 'Come and live here and you'll experience it': Youths talk about their deprived neighbourhood. Journal of Youth Studies, 18(1), pp. 36-52.

Welie, van L. (2013). They will get there! Studies on educational performance of immigrant youth in the Netherlands. Doctoral Dissertation, University of Amsterdam.

Yoon, E.S. (2016). Young people's cartographies of school choice: The urban imaginary and moral panic. Children's Geographies, 14(1), pp. 101-114. 


\title{
Our Nation's Future \\ Youth visions of a post-Brexit Britain
}

\author{
Marco Antonsich, Panagiota Sotiropoulou, Leila \\ Wilmers, Cuomu Zhaxi and Sophie-Louise Hyde
}

\section{Introduction}

On 23 June 2016, the British electorate voted in favour of leaving the European Union in what has come to be known as the Brexit referendum. The counting returned $51.89 \%$ of the votes in favour of 'Leave' and $48.11 \%$ in favour of 'Remain'. Scholars and commentators have scrutinised this referendum through a variety of geographical and socio-demographic lenses. Geographically, the vote pointed to a clear fragmentation of the United Kingdom: England (53.38\%) and Wales $(52.53 \%)$ displayed higher support for 'Leave', whereas Scotland $(62.00 \%)$ and Northern Ireland (55.78\%) backed 'Remain'. While densely populated urban centres were more likely to support 'Remain', suburban communities, post-industrial towns, and coastal areas were more likely to vote 'Leave' (Jennings and Stoker, $2017)$. In terms of socio-demographics, a higher percentage (64\%) of workingclass voters supported 'Leave' than did upper- and middle-class voters (46\%) (Khalili, 2016) and, across these classes, people with conservative values and a desire for order were most likely to vote 'Leave', irrespective of education, income and political affiliation (Kaufmann, 2016). Immigration, measured in terms of its rate at the local level and demands for its control, has also been highlighted as a key predictor of the 'Leave' vote (Goodwin and Milazzo, 2017). This point brings forward the ethno-racial connotation of the Brexit vote. While 53\% of people describing themselves as white voted 'Leave', $67 \%$ of those describing themselves as Asian and $73 \%$ of those identifying as black voted 'Remain' (Lord Ashcroft, 2016). This explains why Brexit can also be read as a nostalgic call for a white, colonial Britain (Bhambra, 2017), imbued with feelings of discontent and anxiety over a present populated by racialized others perceived as undermining traditional understandings of Englishness/Britishness (Virdee and McGeever, 2017).

These studies help understand who voted for Brexit and why, but in this chapter, we are interested in a different question: what next? What are the perceptions, concerns and aspirations of the British people in relation to a post-Brexit Britain? We shall answer this question by focusing on young people, most of whom, due to their age, did not have the right to vote in 2016. In particular, we are interested 
in how young people close to adulthood perceive the future of the nation at this juncture. To this end, we will analyse visual and textual materials produced by various groups of young people living in Loughborough - an English market town located in the East Midlands. Their works formed the basis of Our Nation's Future: Loughborough Youth Creative Visions, a week-long exhibition held at Loughborough University as part of the 2017 ESRC Festival of Social Sciences. Before delving into the analysis of these materials, we shall first offer some background information about the relationship between youth, politics and nation and then explain how data were collected and analysed. The discussion section will highlight the major themes that we thought emerged from the artworks produced by the young people and, to conclude, we shall reflect on the ways in which these young people call the nation into existence when facing an uncertain future.

\section{Brexit, politics and youth}

Young people are often characterised as being disconnected from formal politics (Bastedo, 2015). They are said to be less likely to vote (Henn, Oldfield and Hart, 2017) or engage in party politics (O'Toole, 2015). These attitudes have been explained in relation to the so-called post-materialist turn which, since the 1970s, has characterised affluent Western societies (Inglehart, 1977). In these societies, younger cohorts and the better-off social strata tend to be driven by values of self-expression which are not always in tune with traditional forms of political representation. Political apathy towards formal politics was also found among British young people (Fox, 2015). This is seemingly motivated by the feeling that they have little say in governmental affairs (Sloam, 2011).

However, the Brexit referendum stands as an exception to this trend. Though still below the national turnout $(72 \%)$, a good percentage $(64 \%)$ of those aged 18-24 took part (Ipsos-Mori, 2016). Among them, 75\% voted 'Remain', signalling a generational divide which may be attributed to differences in values and cultural attitudes. Young British people are less hostile to the EU than older age groups (Fox, 2016) and have grown up 'in the slipstream of the anti-racist struggles of the 1970s and 1980s' (Virdee and McGeever, 2017). Consequently, multicultural education in schools, equality provisions at work and an anti-racist civic culture are an ordinary backdrop to their daily lives.

Young people also feel less strongly about national identity than the older generations. In his study on youth feelings towards being English or British, Fenton (2007) found a generalised sense of indifference (for a similar argument among Australian youth, see also Howard and Gill, 2001; Langer and Farrar, 2003). Instead of national identity, it is local communities, friends and families which emerge as more significant in defining the attachment, belonging and identification of young people (Scourfield et al., 2006, pp. 78-79; Fenton, 2007, p. 336).

Yet, one should be cautious about fully dismissing the relevance of the nation to young people. Indifference towards one's sense of national identity might actually confirm its 'banality' (Billig, 1995), i.e. its unreflexive working in the background 
of people's everyday lives. This is particularly true for ethnic majorities, whose national belonging goes uncontested. In their study on Irish Roman Catholic adolescents, Stevenson and Muldoon (2010) showed that, while those living in Northern Ireland proactively claimed their Irishness, those living in the Republic of Ireland were much less active in flagging their national identity, as this was, for them, a secure and uncontested 'banal' identity (see also Scourfield et al., 2006, p. 79, for the case of Wales). Similarly, children of migrants are more likely to show a reflexive attachment to the nation, as their national belonging does not carry the same certainty (Antonsich, 2016). In this sense, whether the nation matters or not has to be judged taking into consideration the national context and the ethno-racial background of those involved.

Many studies dismissing the nation's relevance for young people focus on inner-city areas where conviviality among a super-diverse population is the norm (Back, 1996). However, beyond these areas, racialized manifestations of the nation are still widely felt. For example, Nayak (2017) shows how racialized narratives of the nation remain central to white young people's assertions of identity in the deprived suburbs of the North East of England.

In addition, it is problematic to juxtapose the national to the local. As Cohen (1982) has rightly pointed out, the nation has an abstract quality that can only be apprehended locally and personally (Scourfield et al., 2006, p. 11). Local experience mediates national identity and, simultaneously, may also inform it (Jones and Desforges, 2003; Antonsich, 2018). For young people, the nation may be more often lived and practiced, forming part of the familiar background of their daily lives, than narrated or mobilised as an identity (Hopkins, 2013).

In this chapter, we aim to map the ways in which the nation is constructed in young people's visions for a post-Brexit Britain. When producing artworks which explicitly portrayed the future of Britain, many young people appeared to consider the nation closely. Yet, the question is, how? Here, we analyse which repertoires they used to give substance to their national visions. Before delving into the data, though, we describe the event (Our Nation's Future) which constituted the occasion for which the artworks were produced.

\section{Our Nation's Future - a visual participatory project}

As part of the annual ESRC Festival of Social Science in November 2017, the authors organised a week-long event titled Our Nation's Future: Loughborough Youth Creative Visions. Delivering on the festival's aim to bridge the gap between social scientists and the public, the authors sought to bring together academics from the Loughborough University Nationalism Network (LUNN), local policy makers, young people from youth groups and schools in and around Loughborough, and community members to engage with the topic of post-Brexit Britain.

The project's main objective was to give young people in Loughborough - a small university town located in the East Midlands of England, where around $54 \%$ of the eligible residents voted 'Leave' - the chance to creatively express 
their visions for the future of Britain. The resulting artworks formed the basis for a public exhibition and panel discussion with LUNN academics and the local MP.

We focused on a heterogeneous cohort of young people with mixed social status and ethnicity, aged between 14 and 19 and living in or around Loughborough. As most of this group was not eligible to vote during the referendum, our initiative worked as a platform which enabled them to voice their opinions, while also allowing us to map the ways they were managing the prospects of change and imagining the future of their nation as a direct result of the referendum.

Potential participants were approached through their instructors at secondary schools and youth groups during the summer of 2017. Participants were encouraged to use visual or performative art to express their views on post-Brexit Britain. This decision was made on the basis that, in the case of young people, visual and performative methods of participatory research offer more inclusive and richer registers of feelings compared to more traditional research methods (Kraftl, 2013).

Overall, 17 artworks were produced by groups and individuals: a theatrical performance, two short essays, 12 drawings, a photographic collage made on a wooden door and an animated video clip. ${ }^{1}$ For some artworks, we received a title and a short description.

We analysed data using a thematic approach adapted for multimedia data (Gleeson, 2011). Artworks and accompanying texts were coded in relation to the research aim. This process was initially conducted by the authors individually before the themes were discussed and rearticulated collectively.

\section{Portraying a post-Brexit Britain}

As a result of the open format of participants' contributions, the data collected revealed diverse forms and levels of reflection on the subject of post-Brexit Britain. Our initial categorisation distinguished between artworks which clearly revealed the personal feelings of the participants and those which offered a more dispassionate appraisal of Brexit. In the first case, feelings of distrust, despair, fear and abandonment dominated the artworks. In the second case, participants appeared to take the exercise in more didactic terms and prioritise factual information. Cutting across these broad categories were two themes: the personalisation and the localisation of Brexit. To make it meaningful and to be able to relate to it, young people rewrote this national event by mobilising aspects of their localised everyday life. This is an important point which challenges the scholarship on nation and young people discussed earlier in the chapter. Given their more limited mobility and social networks, young people's lives are more localised than those of adults. Their local environments are centred around home, school and neighbourhoods (Scourfield et al., 2006, p. 15; Harris, 2009, p. 192). However, we argue that these registers should not be read in opposition to the nation (Fenton, 2007), as evidence in this study reveals that local and personal repertoires mediate the ways young people make the nation present. In this section, we explore the participants' visions of the nation by grouping their artworks under different 
themes. We acknowledge that this is not the only possible categorisation, but our aim is to highlight the diversity of responses we received.

\section{A traumatic present}

Despite being asked to visualise the future of a post-Brexit Britain, the great majority of participants returned artworks which focused on the 'here and now': Brexit as a momentous present rather than an event which elicits visions for the future. This response resonates with what Leccardi (2006) calls the 'extended present'. The socio-economic transformation associated with contemporary risk societies (Beck, 1992) generates uncertainty and indeterminacy which, in turn, produces the loss of the idea of future among young generations. As control over their life plans is untenable, the new time of action becomes the 'extended present', 'that time span short enough not to escape the social and human domain but long enough to allow for some sort of projection further in time' (Leccardi, 2006, p. 41). With Brexit bringing additional uncertainty, it is not surprising that participants were more focused on the event itself rather than the future associated with it.

Among the most commonly recurring feelings was a sense of traumatic shock (Seidler, 2018). Figure 12.1 depicts Brexit as a painted European Union flag with a bleeding hole punched through the canvas, replacing one of the stars symbolising the Union. Interestingly, it is not a British flag that is bleeding. This suggests that

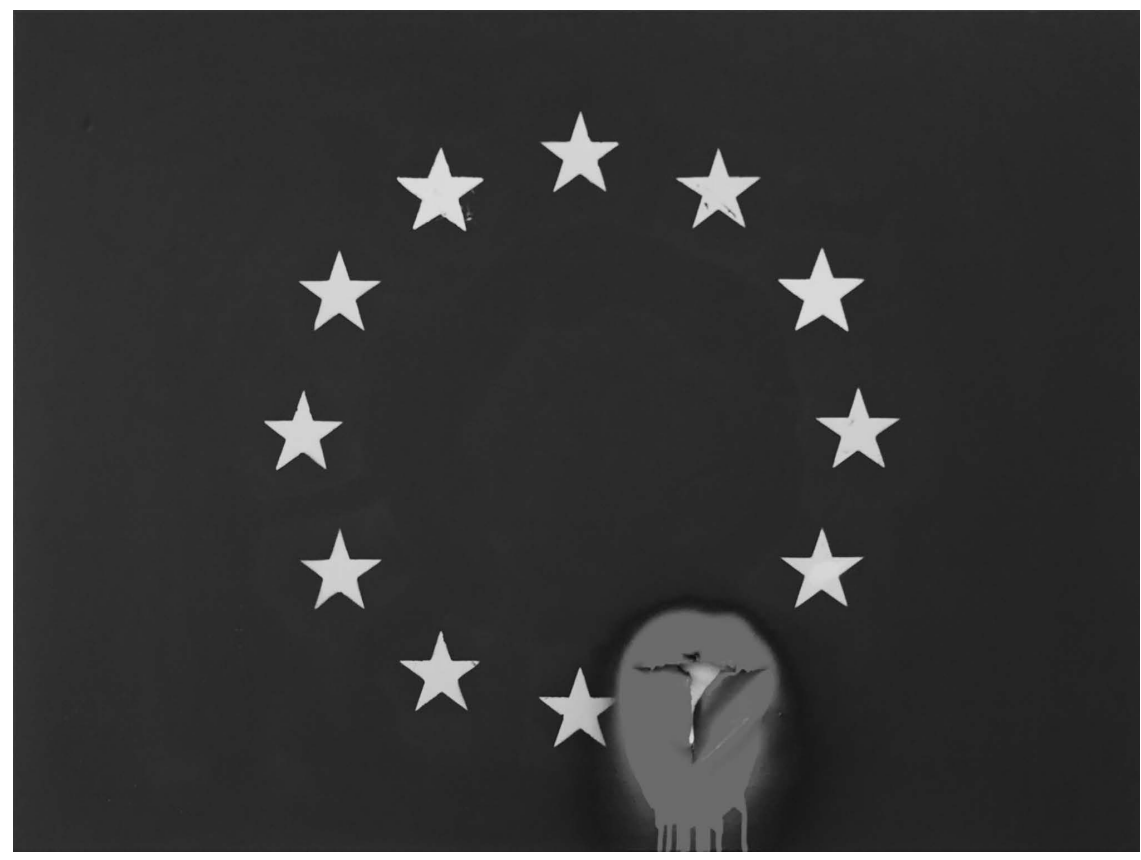

Figure 12.1 Bloodshot 
the participant wished to convey the impact of the traumatic event for the 'other side', too. The same distressing emotion emerges from another artwork - a collage depicting the European flag being licked by flames from a raging fire - which portrays the negative impact of Brexit on both sides. In the middle of the flag stands a broken United Kingdom; one cleavage separates England from both Scotland and part of Wales, while another separates Northern Ireland from the Republic of Ireland. Here, Brexit marks the departure of the United Kingdom from the EU and, simultaneously, marks the end of the United Kingdom itself: a drama unfolding in the present and anticipating a gloomy future. Brexit as a far-reaching, traumatic event is also apparent in the drawing of a globe with a missing piece. A chunk of Earth representing the United Kingdom lies on the floor, leaving behind a deep, dark hole. The violent extraction depicted in the image conveys a sense of Brexit as an event of epic traumatic proportions, which also returns in another drawing centred on a pair of scissors cutting the threads connecting the United Kingdom and Europe. In a seemingly ironic artwork titled 'Hang on in There', which portrays a bear-like figure hanging on barbed wire, the importance of a dramatic present is also palpable. Crafted in a graffiti style resonating with youth urban culture, this painting focuses on the difficulty of the 'here and now'. Endurance appears as a skill essential to survival in a condition of dangerous precariousness and, as the participant explains, is a sentiment that informs the British character: 'Britain has had one problem after another from the World Wars, the Great Depression and the recent economic downturn. But somehow we're still hanging on cause that's what we will carry on doing through thick and thin'. In this sense, Brexit exalts the enduring and resilient character of the nation, but it is not a nation cast against something (e.g. globalisation) or someone (e.g. immigrant) as voiced during the Brexit campaign.

\section{An uncertain future}

In artworks where the future emerges more clearly, a pervasive sense of uncertainty seems to dominate. Figure 12.2 portrays the same traumatic division as observed earlier, but it also tentatively depicts a new future. The painting shows a broken road that separates London from Paris. Feelings of desperation seem to characterise two men in suits - possibly businessmen - as they observe banknotes floating over the Channel amid sinking boats and sharks. Ripped national flags of European countries lie disorderly on the road as a way of symbolising the impact Brexit may have across the Channel. Yet, a sun surrounded by the European stars hangs over Europe and appears to signal a new future for nations proceeding in partnership. This ambivalence over the future of Europe surrounds the depiction of the United Kingdom, which is left in disarray.

Uncertainty also seems to dominate the artwork shown in Figure 12.3. Entitled 'Bus Stop', the drawing presents a faceless person dressed in the British flag getting off the 'Europe Express' bus. The present journey is over and the next one is unknown. The future destination is somewhere on the globe depicted on the bus shelter. However, a blurred timetable signifies that the destination and timescale of the next journey remain uncertain. The future is open as there is no answer to 


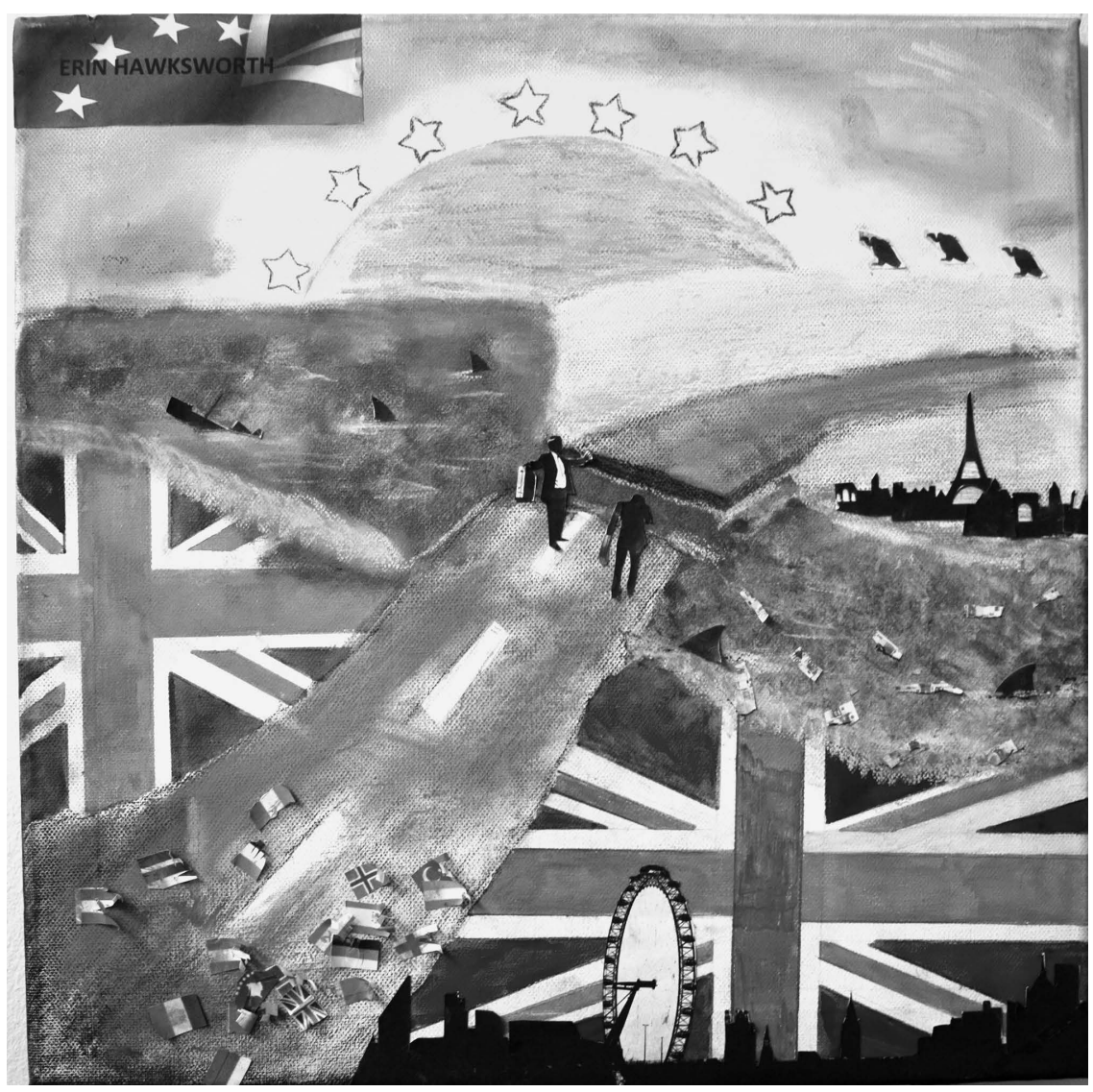

Figure 12.2 As we leave the EU

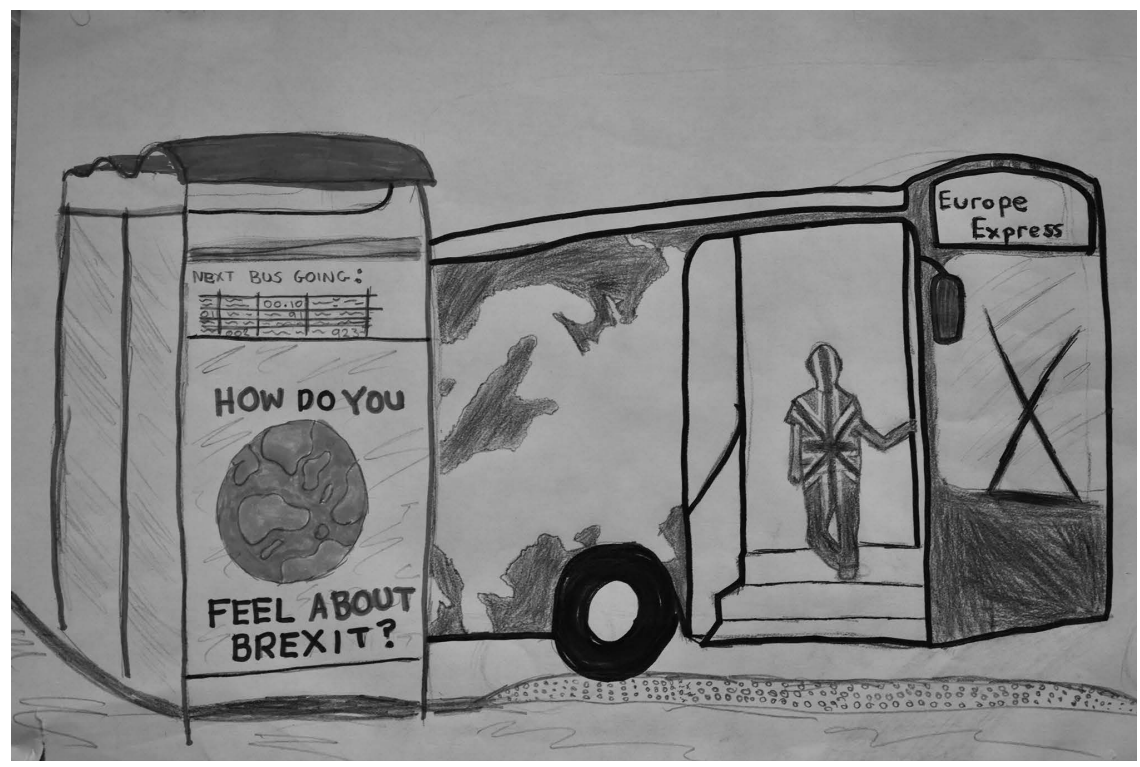

Figure /2.3 Bus stop 
the question: 'How do you feel about Brexit?' True, it is a less gloomy future than those portrayed in other artworks, as the author also confirms:

My thoughts on Brexit aren't major and I don't have an opinion on whether we are doing the right or wrong thing. I feel like even though the UK is leaving the EU, it doesn't mean we are going to ignore them or desert them. They're still as close to us as before.

Besides uncertainty, a sense of disorientation characterises another artwork which represents the future with a question mark that splits the EU and UK flags. There is no sense of direction and no anticipation of a positive or negative future. Disorientation and confusion are foregrounded, and these are symbolised by the serial repetition of ballot papers endlessly asking the question: 'Leave' or 'Stay'? The same confusion and concerns for the unknown are depicted in the theatrical play written and performed by 12 young children and adolescents from Frenzy Youth Theatre. Amid a cacophony of voices, the characters struggle to grasp what Brexit really means. After presenting a series of contrasting positions which, at times, escalate in tense exchanges, the play ends with an unanswered question: 'What happens now?'

\section{'Lots of hot air'}

Two other artworks convey, more clearly, the idea of Brexit as something which young people not only struggle to comprehend, but also perceive as happening above and beyond them. In a drawing titled 'Lots of Hot Air', empty talks heard during the referendum campaign are represented in the form of a hot air balloon suggesting feelings of distance towards a highly polarised political debate represented by a fracture across the balloon. Feelings of disenfranchisement and distrust are also apparent in another drawing which depicts Theresa May, the British Prime Minister, as a meek figure standing atop a large globe as she announces that she will throw the European flag into 'the bin'. Her promise 'to make Britain great again' is undermined by the postscript 'sike!!', a colloquial expression indicating irony which signals, once again, the distance young people put between themselves and formal politics (Mejias and Banaj, 2017).

\section{Clear visions}

Two artworks only conveyed a clear position about Brexit. Figure 12.4 represents a full-sized door split into two panels. The open panel showcases in bright colours the stories of non-British Europeans contributing to the Loughborough community, while the closed panel features a black-and-white collage of anti-immigration news headlines, images and slogans from the 'Leave' campaign. This open/closed, colour-coded visualisation highlights two contrasting ideas of nation: one centred on a lived and localised cosmopolitan conviviality, the other illustrated as a distant reality constructed by political and media discourse. 'Please Hold the Door' denotes a small act which could be interpreted as symbolic of the convivial weak 


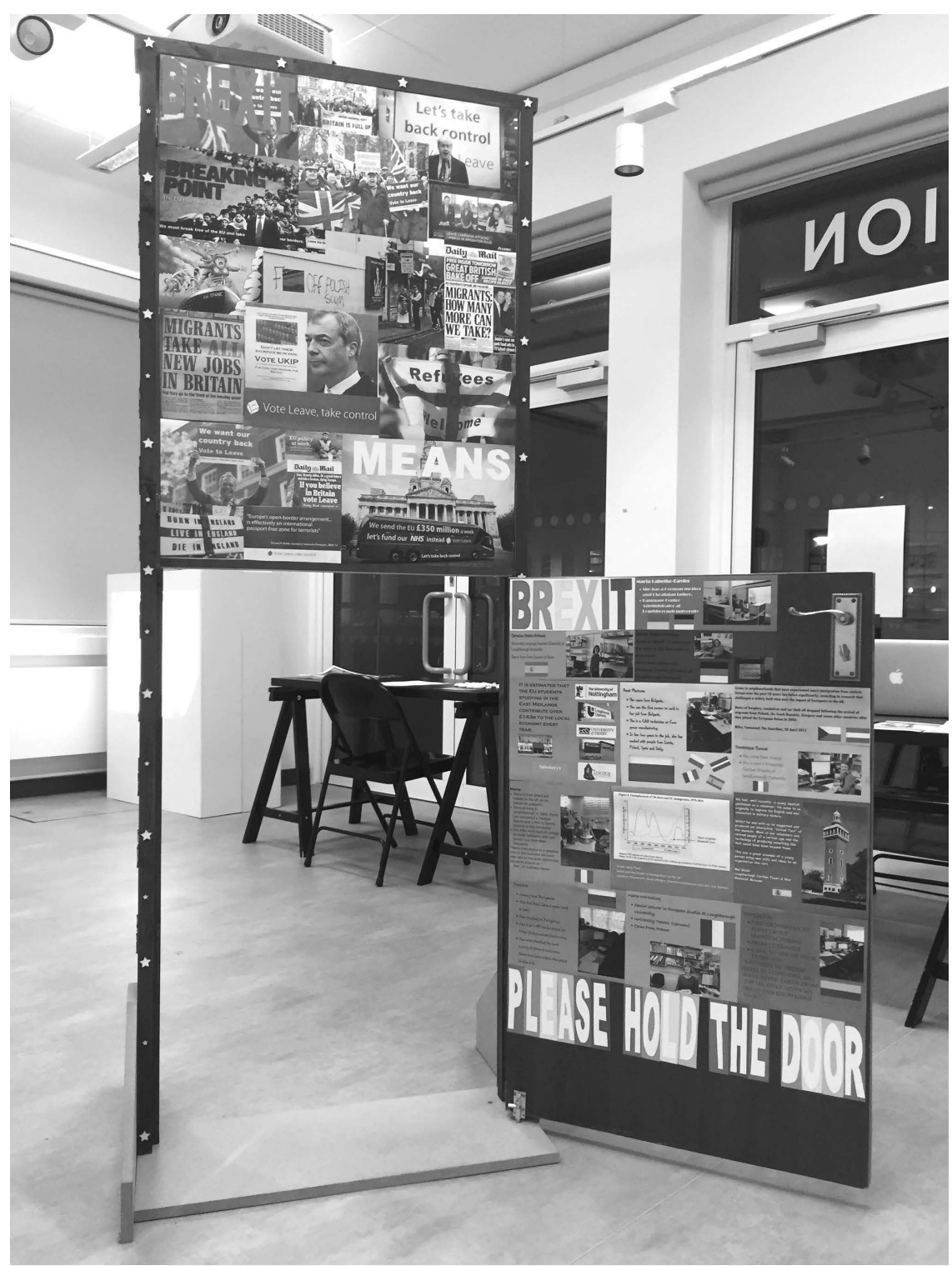

Figure 12.4 Please hold the door

ties between strangers in public spaces (Laurier and Philo, 2006). In their accompanying text, the participants recall how they were left 'in despair . . hang[ing] our heads in shame' while watching the anti-immigration slogans from the Leave campaign on TV. Furthermore, inspired by Martin Niemöller's poem, 'First they came ...', the participants wanted 'to speak out' in favour of 'a post-Brexit Britain 
that has a place for everyone irrespective of [their] background . . . Britain should hold the door open and welcome people into our country for their benefit as well as ours'.

A similarly unambiguous position emerges from Figure 12.5. The drawing symbolises the same traumatic experience and 'here and now' approach to Brexit

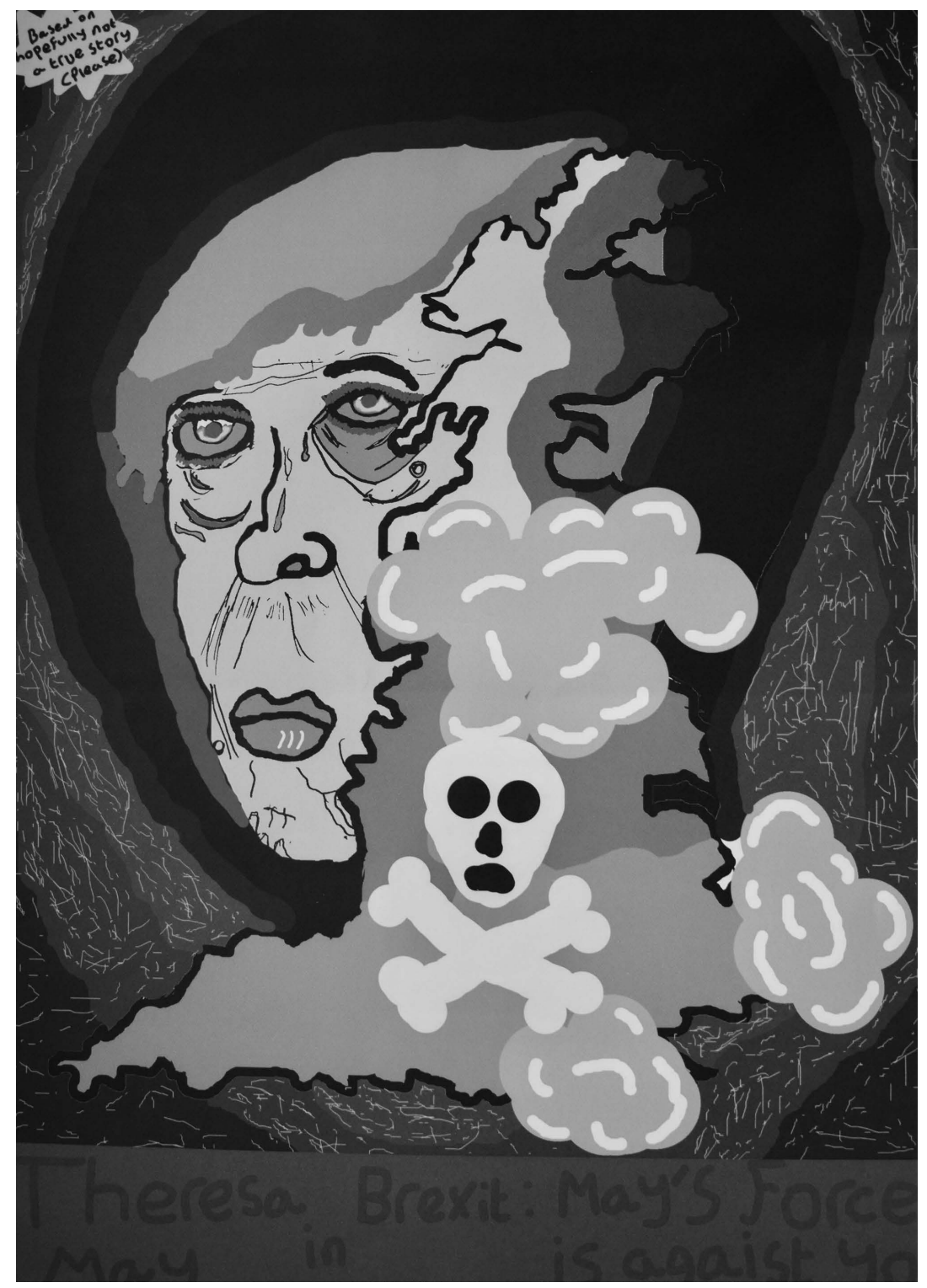

Figure I 2.5 May's force is against you 
as already seen in other artworks. Inspired by the movie Star Wars and humorously entitled 'May's Force Is Against You', the drawing depicts an apocalyptic scenario. A huge grey caricature of Theresa May looms over a solitary outline of a Britain spewing poisonous fumes. Scotland is already consumed and separated from England by a grey shadow, and neither Europe nor the world is represented. The focus is solely on the United Kingdom and its gloomy present with a small, hopeful caveat: 'Based hopefully not on a true story (please)'. In the accompanying words, May appears as a supreme leader who steers the country at her will in the absence of any voice from the people:

She wants to control the whole of the UK in the way she sees it in her image and no one else's and that means that the poor people, the people with different races and ethnic background, they will get left out and the rich get more, as always ... we'll never going to have our own voices about where Brexit is going.

In contrast to the previous artwork, no hope is expressed for a cosmopolitan, postBrexit Britain. Instead, the focus is on a grievance cast in populist tones which opposes the people to the governing elite.

\section{Localising the national}

While the artworks analysed thus far exhibit the emotions of their participants, other young people adopted a more detached approach to a post-Brexit Britain; presenting the results of their research as strict negatives and positives of Brexit. Among them were two long essays, one drawing and one video. The factual information collected varies in terms of quality and accuracy, but in all cases the interventions show no or little emotional investment. Here, Brexit is something to be researched. Interestingly, two of these interventions adopt a local lens to read the future of a post-Brexit Britain. One essay focuses on the impact of Brexit on universities and on Loughborough University specifically. It anticipates a loss of students, higher fees and fewer student exchanges. The video is a stop-motion animation featuring two participants drawing on a white board and illustrating what they believe the consequences of Brexit will be for Loughborough. The national is reduced to the local to make it meaningful, understandable and tangible in its impact. Two worried faces appear on the board at the beginning of the video, but this is the only instance when emotions are displayed. The remainder of the video comprises a list of negative consequences - loss of foreign population, rise of taxes, pressure on the NHS, and rise in house prices and university fees. Again, this presents a gloomy future framed in local terms.

The localisation of Brexit returns in one of the artworks previously discussed. 'Holding the Door' is centred on Loughborough as a site of cosmopolitan conviviality. This image is used to show the possibility of a different Britain; conflating the local and the national in a way that challenges the argument that young people move away from the nation and confine themselves in the local spaces of their 
everyday life. The local is certainly an important register for young people, but it is also used to make a statement about the kind of nation they want (Antonsich, 2018).

\section{Personalising the nation}

If the localisation of the nation is one modality through which young people depict the nation, then personalisation is another. In Figure 12.6, a human figure in a British flag stands alone and looks dejectedly to the ground. The figure is separated from a group of former friends, each one bearing the flag of a different European nation. A lonely chair is placed in a corner and the participant notes in the accompanying text that his intention was to convey a personal, relatable story: 'I was inspired to do this because I know that kids being left out of the conversation is a reality. I wanted to show something real, a picture that can be understood by myself and others who see it'. In the accompanying text of another artwork, another participant writes:

I am going to make a painting showing people wearing flags of their nation ... and we will have a sad face . . . I feel that this will show how we will be left out of the group of friends, and I am concerned how that will feel. I am worried we may become isolated. It is like being left out of a group of friends you have had for a while.

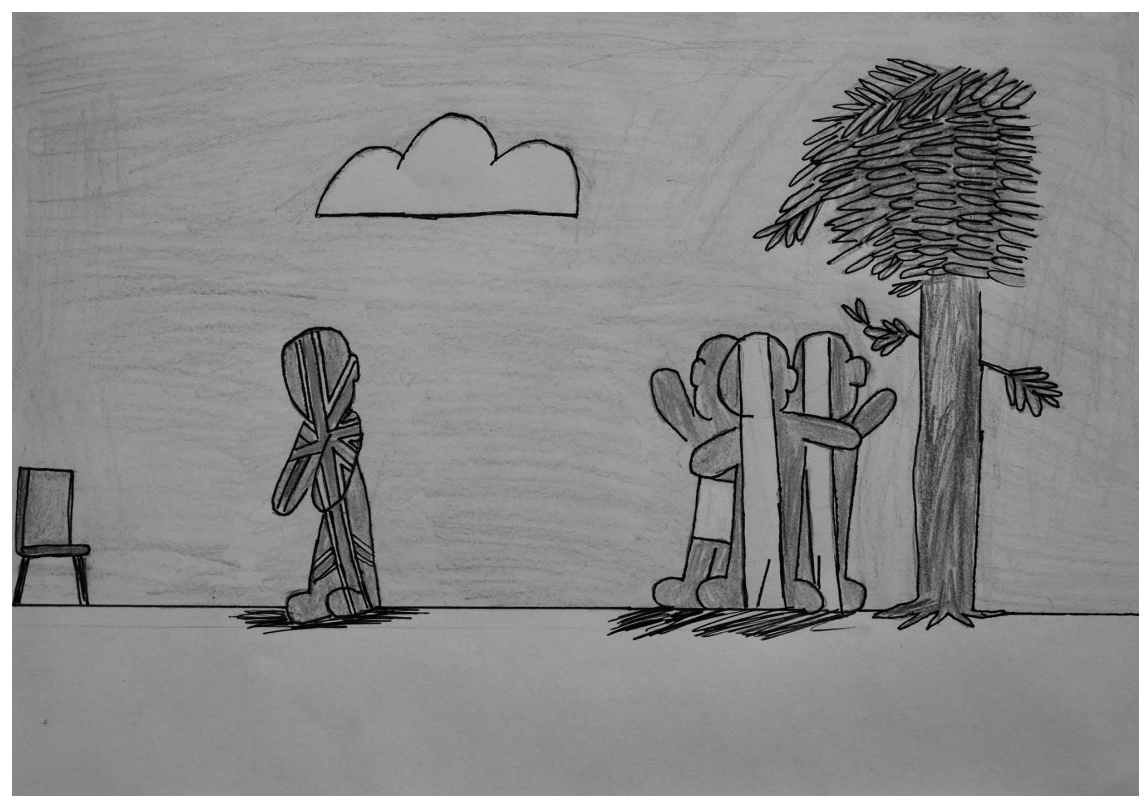

Figure 12.6 Conversation expectation 
In both cases, the nation is rewritten in personal terms so that Brexit can be understood in terms of lived experiences of social relationships. The reference to friendship serves to emotionally apprehend something which would otherwise remain distant. In other words, the register 'friends' is not alternative to the register 'nation' (Fenton, 2007), but it is mobilised to project a different image of nation from the one supported by the 'Leave' campaign. Here, as in other artworks, the nation is not narrated as a cocoon from which to protect 'us' against external 'threats' (immigration, Europe, global capital). The nation is portrayed as existing in relation to other nations like a person within a group of friends. This image calls for a 'relational nation' which clashes with the kind of Britain heralded in the 'Leave' campaign. It also provides an alternative meaning to being 'left out' in the context of Brexit. This term has been used to characterise those who voted 'Leave', feeling that globalisation does not work for them (Delanty, 2017). Yet, as much as Brexit has been the product of these 'left out' people, this artwork shows how the Brexit referendum has, in turn, produced a new kind of 'left out' - young people who cherish an interconnected world.

\section{Conclusion}

When the visions of a post-Brexit Britain offered by the young people in this study are analysed, four points of interest emerge. First, as also observed by Leccardi (2006), young people appear to be more focused on the 'here and now' than on projecting themselves in the future. Brexit is portrayed and experienced as a traumatic event absorbed in the present rather than projected into the future. In this sense, the participants in this study do not show clear evidence of how young people might act in 'a pioneering way' by anticipating the future for the wider society (Colombo and Rebughini, Introduction). They appear to be too overwhelmed by the present to anticipate 'our' future.

The participants did not rally around the nation in the same way as older strata of the population did. A great deal of this population voted for Brexit in nationalist terms; by heralding the nation as the supreme value to be defended and protected (Fenton, 2007, p. 322). The young people in this study instead presented an alternative image of nation - one which only exists in relation to other nations, like a friend within a group of friends. This idea of a 'relational nation' clearly goes against the present surge of nationalism, imbued with ideas of protectionism, sovereignty and xenophobia. Not surprisingly, immigration was barely present in the artworks and always treated either as a positive presence or as mere fact.

The reference to friendship used to construct the image of a 'relational nation' anticipates the third point. Contrary to some literature which suggests that young people are indifferent to the nation and their affective registers are oriented towards their local communities, friends and family (Fenton, 2007), our study highlights the intersections among these dimensions. In order to make sense of Brexit, participants mobilised their personal and local references, vesting the nation with human-like traits and narrating stories of broken relationships. The 
local place was the setting some participants used to materialise their idea of a post-Brexit Britain. In these instances, the nation coexists with alternative registers, and there are no clear signs to suggest that it does not matter for young people. There is no active flagging as in more nationalist visions aired during the Brexit campaign, but this seems to point more to the banality of the nation as a silent backdrop in participants' daily lives (Billig, 1995) than to their indifference to the national idea.

Finally, some of the artworks appear to confirm the distance some young people feel towards the formal political debate. Whether political apathy or indifference, this seems to prevent the emergence of clear political positions as most participants did not clearly express where they stood in relation to Brexit. They end up somewhere in the middle of the two distinct orientations to the nation that Fenton (2012) has identified for the ethnic majority in England: 'the resentful nationalist' and 'the liberal cosmopolitan'. Participants neither shared the resentment and anxiety towards change that translate into the mobilisation of the nation as a protective and exclusive shield (against someone or something) nor embraced, except in one case, the idea of a liberal, cosmopolitan nation. Context here matters: Loughborough is neither a metropolitan inner-city centre, where forms of multicultural conviviality are present, nor a suburb where an enraged white nationalism may thrive (Nayak, 2017). However, what many of the artworks convey is that participants felt a distinct lack of agency in relation to Brexit - an event imposed upon them by the older, voting population and political leaders.

If one is looking for new generational skills which can navigate the present world of uncertainties, this study does not seem to offer a clear answer. However, if one is to evaluate the role the nation plays in this present uncertain condition, it seems legitimate to anticipate a less nationalistic future. This does not imply the coming of age of a 'non-national generation' as Fenton (2007) maintains, but rather that of a generation which believes in what we might call a 'relational nation'. One that coexists peacefully with other nations and does not need to be actively flagged against someone or something, be this Europe, immigration or globalisation.

\section{Note}

1 Due to author's limited budget, only some selected artworks are published here. All artworks are available, in colour, at www.lboro.ac.uk/research/lunn/news-events/ youth-brexit-futures/gallery/.

\section{References}

Antonsich, M. (2016). The 'everyday' of banal nationalism - ordinary people's views on Italy and Italian. Political geography, 54, pp. 32-42.

Antonsich, M. (2018). Living in diversity: Going beyond the local/national divide. Political geography, 63, pp. 1-9. 
Back, L. (1996). New ethnicities and urban culture. London: UCL Press.

Bastedo, H. (2015). Not 'one of us': Understanding how non-engaged youth feel about politics and political leadership. Journal of Youth Studies, 18(5), pp. 649-665.

Beck, U. (1992). Risk society. London: Sage.

Bhambra, G.K. (2017). Brexit, Trump, and 'methodological whiteness': On the misrecognition of race and class. The British Journal of Sociology, 68(S1), pp. 214-232.

Billig, M. (1995). Banal nationalism. Thousand Oaks: Sage.

Cohen, A.P. (ed.) (1982). Belonging. Manchester: Manchester University Press.

Delanty, G. (2017). A divided nation in a divided Europe: Emerging cleavages and the crisis of European integration. In: W. Outhwaite, ed., Brexit: Sociological responses. London: Anthem Press.

Fenton, S. (2007). Indifference towards national identity: What young adults think about being English and British. Nations and nationalism, 13(2), pp. 321-339.

Fenton, S. (2012). Resentment, class and social sentiments about the nation: The ethnic majority in Engand. Ethnicities, 12(4), pp. 465-483.

Fox, S. (2015). Apathy, alienation and young people. PhD Thesis, University of Nottingham, Nottingham.

Fox, S. (2016). Young people and the EU referendum. Available at: http://blogs.cardiff. ac.uk/wiserd/2016/06/27/young-people-and-the-eu-referendum-5-key-lessons-frompolling-day/.

Gleeson, K. (2011). Polytextual thematic analysis for visual data - pinning down the analytic. In: P.E. Reavey, ed., Visual methods in psychology. New York: Taylor \& Francis.

Goodwin, M. and Milazzo, C. (2017). Taking back control? Investigating the role of immigration in the 2016 vote for Brexit. The British Journal of Politics and International Relations, 19(3), pp. 450-464.

Harris, A. (2009). Shifting the boundaries of cultural spaces: Young people and everyday multiculturalism. Social identities, 15(2), pp. 187-205.

Henn, M., Oldfield, B. and Hart, J. (2017). Postmaterialism and young people's political participation in a time of austerity. The British Journal of Sociology. Available at: https:// onlinelibrary.wiley.com/doi/pdf/10.1111/1468-4446.12309.

Hopkins, P.E. (2013). Young people, place and identity. London: Routledge.

Howard, S. and Gill, J. (2001). 'It's like we're a normal way and everyone else is different': Australian children's constructions of citizenship and national identity. Educational studies, 27(1), pp. 87-103.

Inglehart, R. (1977). The silent revolution. Princeton: Princeton University Press.

IPSOS-Mori (2016). How Britain voted in the 2016 EU referendum. IPSOS-Mori. Available at: https://www.ipsos.com/ipsos-mori/en-uk/how-britain-voted-2016-eu-referendum

Jennings, W. and Stoker, G. (2017). The tilting of Britain's political axis? Political insight, 8(3), pp. 4-7.

Jones, R. and Desforges, L. (2003). Localities and the reproduction of Welsh nationalism. Political geography, 22(3), pp. 271-292.

Kaufmann, E. (2016). Brexit voters. Available at: https://fabians.org.uk/brexit-votersnot-the-left-behind/.

Khalili, L. (2016). After Brexit: Reckoning with Britain's racism and xenophobia. In: Verso, ed., The Brexit crisis. A Verso report. London: Verso.

Kraftl, P. (2013). Beyond 'voice', beyond 'agency', beyond 'politics'? Hybrid childhoods and some critical reflections on children's emotional geographies. Emotion, space and society, 9, pp. 13-23. 
Langer, B. and Farrar, E. (2003). Becoming 'Australian' in the global cultural economy: Children, consumption, citizenship. Journal of Australian Studies, 27(79), pp. 117-126.

Laurier, E. and Philo, C. (2006). Cold shoulders and napkins handed: Gestures of responsibility. Transactions of the institute of British geographers, 31, pp. 193-207.

Leccardi, C. (2006). Redefining the future: Youthful biographical constructions in the $21 \mathrm{st}$ century. New directions for child and adolescent development, 113, pp. 37-48.

Lord Ashcroft (2016). How the United Kingdom voted on Thursday . . . and why. Lor Ashcroft Polls. Available at: https://lordashcroftpolls.com/2016/06/how-the-unitedkingdom-voted-and-why/

Mejias, S. and Banaj, S. (2017). UK youth perspectives and priorities for Brexit negotiations. London: London School of Economics.

Nayak, A. (2017). Purging the nation: Race, conviviality and embodied encounters in the lives of British Bangladeshi Muslim young women. Transactions of the institute of British geographers. Available at: https://rgs-ibg.onlinelibrary.wiley.com/doi/full/10.1111/ tran. 12168.

O'Toole, T. (2015). Beyond crisis narratives: Changing modes and repertoires of political participation among young people. In: K. Kallio, S. Mills and T. Skelton, eds., Politics, citizenship and rights. Berlin: Springer.

Scourfield, J., Dicks, B., Drakeford, M. and Davies, A. (2006). Children, place and identity. Abingdon: Routledge.

Seidler, V. (2018). Making sense of Brexit. Bristol: Policy Press at the University of Bristol. Sloam, J. (2011). Introduction: Youth, citizenship and politics. Parliamentary affairs, 65(1), pp. 4-12.

Stevenson, C. and Muldoon, O.T. (2010). Socio-political context and accounts of national identity in adolescence. British Journal of Social Psychology, 49(3), pp. 583-599.

Virdee, S. and McGeever, B. (2017). Racism, crisis, Brexit. Ethnic and racial studies, 41(10), pp. 1802-1819. 


\section{Index}

Note: Page numbers in italics indicate figures and page numbers in bold indicate tables.

Action movement 145

activists: middle-class youth as 22, 28-29; occupied spaces and 141, 143-147, 148; social autonomy and 144

agency 10-12, 20, 46; see also youth agency

Agirdag, O. 162

Altman, D. G. 103

ambivalence 26-28

Anthias, F. 59

anti-austerity mobilisation 89

Archer, M. 129

artists: collective mobilisations and 141 ; occupied spaces and 141-147, 148; post-Brexit visions of 168-178; Social Centres (Italy) 142-143

Athens (Greece) 32, 40

Baas, M. 50

Bäcklund, P. 5

Ball, S. J. 154, 157

Bauman, Z. 121

Baym, N. K. 34

Beck, U. 4, 20, 32, 46, 59, 90, 93

Belgium 61, 63, 67-68

Bellah, N. 45

Bey, H. 142

Blocchi proletari metropolitani 144

Bosetti, L. 154

bounded rationality 157

Bourdieu, P. 8, 10, 20, 21, 90

Bowe, R. 157

boyd, d. 34, 37

Brexit referendum: artistic portrayals of 165, 167-169, 169, 170, 171, $172-173,173,174,174,175-176,176$,
177-178; geographical voting results 165 ; localisation of $168,175-177$; personalisation of 168,177 ; socio-demographics of 165; uncertainty and $169-170$; youth opinions on $166,172-178$

Britain: Islam in 131, 133-135; Muslim women in $129,131-132,134,137-138$; national identity and $166-167$; political participation in 137-138; post-Brexit portrayals $165,167-170$; as relational nation 177; see also Loughborough (England); United Kingdom

British youth: national identity and 166-167, 177; opinions on Brexit 166, 172-178; political attitudes of 166,172 , 178; post-Brexit visions $168-170,171$, 172-173, 173, 174, 174, 175-176, 176, 177-178; relational nation views and 177

Butler, J. 12

Cairns, D. 49

Campbell, C. 33

Cartmel, F. 46

choice biography $35,46,51$

choice consumption 35

Coffey, J. 44

cohabitation 80

Cohen, A. P. 167

collective mobilisations $89,141,143$, 145-147

common goods 144

commons 147

complex connectivity 5

complexity $4-5,10$ 
complex precariousness 91

conspicuous consumption 35,39

consumption: conspicuous 35,39 ; construction of the self and 33, 41; economic crisis and 32, 35; flawed 37 , 41 ; identity formation and $32-33,36$; mobile phones and 37 ; social media and 33-41; structure of 35; unreality/semireality in 40; young people and 33-35

contradictory structures 29

counter school culture 22,28

creativity 77,85

Cresswell, T. 50

crisis 117

Croatia 115

cultural capital 20, 22

Cuzzocrea, V. 44

Deal, J. J. 103

de Certeau, M. 11

De Graaf, P. M. 62

de-institutionalised life spaces 90

Denmark 61, 63, 67, 71

deprived neighbourhoods $154-155$

digital economy 101-103

digital exclusion 117

digital nomads 103

digital technology 32-33, 116-117

disembeddedness 46

diversity 6-7

Du Bois-Reymond, M. 35

Dwyer, P. 46

economic autonomy $78,82-84$

economic crisis (2008-2009) see global

financial crisis (2008-2009)

economic vulnerability 60

education 20, 27-29; see also school

choice; school-to-work transitions

(STW)

educational attainment $63, \mathbf{6 4}, \mathbf{6 5}, \mathbf{6 6}, 67$

educational paradigm 23,28

Elliott, A. 46

employment: educational attainment and 63, 64, 65, 66, 67; flexi-lives and 44; junk contracts and 115; mobility and 49; part-time 66, 67; post-industrial era and 116; precariousness and 88 ; social exclusion and 88; see also labour market employment-centered regimes 61, 63, 72 England 165, 167; see also Britain epistemological fallacy 46
Esping-Andersen, G. 60

Estonia: cohabitation and 80; family support in 79,81 ; home ownership in 82 ; housing autonomy in $80-82,84-85$; parental homes and $80-81$; social protection in 79 ; unemployment risks in 78-79; youth strategies in 79

European Union: digital technology use in 117; junk contracts in 115; labour markets in 60; school-towork transitions (STW) in 59, 68; unemployment risks in 67-68, 114; workforce in 114; see also Brexit referendum

EU-SILC 62-63

EXCEPT project 76

extended present 169

Facebook 34

Farrugia, D. 44

Farthing, R. 47

Feijenoord (Rotterdam) 156-162

Fenton, S. 166, 178

Ferrarotti, F. 142

Finland 115

flawed consumers 37

flexibility 102

flexi-lives: concept of 44-45; as coping strategies 45 ; dynamism and 49 ; in Italy $47-52$; mobility and $48-52$

Font, J. 89

Foucault, M. 11, 12

France: immigrant youth employment in $68,70,72$; Islam in $131,134-135$; junk contracts in 115; Muslim women in $129,132,134-135,138$; political participation in 138; school-to-work transitions (STW) in 61, 63, 67; youth unemployment in 114

France, A. 47

Furlong, A. 46

Gallie, D. 60

Ganzeboom, H.B. 62

gender: ambivalence and 27-28; cultural capital and 20; labour market and 27, 60,63 ; migrant status and 59-60, 63; occupation status and 68 ; situational management of 28; violence and 133, 138; vulnerability and 60,72 ; wage differences 71 ; young Italians and 22; see also Muslim women; women 
generalised precariousness 91

generational constellations 4

generational location: intersectionality and 21; resistance and 22; situational management of 28; social change and 19; stratification and 20; uncertainty and $25-27$

Generation Y 22

Germany 143

Gewirtz, S. 157

Giddens, A. 90

global financial crisis (2008-2009): impact on young people 19, 32, 35-37, 59, 62; Italian discourse on 104, 111; junk contracts and 115; nature of consumption and 32,35

globalisation 5-6, 8, 143, 177-178

Greece: consumption in 32, 35-36; gender vulnerability in 72 ; junk contracts in 115; labour market in 67 ; migrant wage differences 71 ; sub-protective transition regime in $62-63,72$; unemployment risks in 67; vocational training in 62

Greek youth: consumption and 33-39; digital technology and 32-33; economic crisis and 36-37; as flawed consumers 37,41 ; identity formation and 32 , 36-37; labour market and 35; mobile phones and 37-38; performance of self $33-34$; as prosumers 35 ; selfrepresentation 33-41; social media and $37-41$

habitus 21, 29

Haddon, E. 47

Häkli, J. 5

Hammarén, N. 155

Harvey, D. 144

Hatcher, R. 153

heuristics 77

hijab 134-135, 138

Horizon 2020 programme 76

housing autonomy: cohabitation 80 ; home ownership 82; parental homes and $80-81,84$; transition to $78,80-81$; youth strategies for $80-82,84-85$

Iceland 115

identity: construction of 117; consumption and 32-33, 36; employment and 88; entrepreneurship of the self and 96; individualisation and 46; Mediterranean family and 88; middle-class youth and 28; Muslim youth and 135; national 166-167; nature of image in 37; neighbourhoods and 160; precariousness and 32, 88, 90, 92; social 28-29; social media and $32-34,36$; social reality and 117-118; uncertainty and 122

inactivity $\mathbf{6 5}, 67-68$

individualisation: agency and 52; choice biography and 46; coping strategies and 44; defining 45-46; disembeddedness and 46; mobility and 50; spatial reflexivity and 51; young people and $46-47$

individualism $44-47,52$

innovative practices 75

insecurity 89

Instagram 34, 40

InstaStories 35

institutional contexts: employmentcentered regimes $61,63,72$; liberal regimes $61,63,72$; post-socialist regimes 62-63; school-to-work transitions (STW) and 60-63; subprotective transition regimes 61-63, 72; unemployment and 78-79; universalistic regimes $60-61,63,71$; vulnerability and $60-62$

interconnectedness 5-7

International Socio-Economic Index (ISEI) 62

Internet 32, 103, 116-117

intersectionality 20-22, 29, 59

Ireland 115

Islam: in Britain 131, 133-134; cultural 135; in France 131, 134; individualised 136; prejudice and 133-135; radicalisation and 135; reclaiming of 134-135; see also Muslim women

ISTAT 22

Italian youth: ambivalence and 26-27; career aspirations of 106-107, 107, 108; cohabitation and 80 ; collective mobilisations and 141-147; cultural capital and 22; flexi-lives and 47-49; future expectations 24-26; gender and 22; generational location and 19, 21 , 25-27; individualism/individualisation in 47-48, 51-52; middle-class 22-23; mobility and 49-52; parental homes and 22, 80-81, 84; politics of the present 52; self-employment and 106; social 
locations of 23; spatial dilemmas 49; work attitudes of 101-102, 105-109, 109, 110

Italy: economic crisis in 104, 111; family support in 78, 81, 83; flexi-lives in 47-52; housing autonomy in $80-84$; housing in 142; junk contracts in 115; labour market in 104; occupied spaces in 143; self-employment in 104, 106; Social Centres 141-143; unemployment risks in $75,78,101$; youth strategies in 79; see also Milan (Italy); Rome (Italy)

Janta, B. 60, 71

Järvinen, K. M. 103

job insecurity $76-77,84,93$

Johansson, T. 155

junk contracts 115

Kallio, K.P. 5

Koning, P. 158

Korpi, W. 60

Koselleck, R. 117

labour market: education and 20, 27, 29; in the European Union 60; gap between school and 20, 27, 29; gender and 27, 60,63 ; in Greece 35, 67; in Italy 104; migrants and 61 ; migrant women in $60,63,67-68,71$; Polish youth and 113-114; precariousness in 20, 23, 25, 29, 89; social identity and 28; social protection and 78; uncertainty in $75-77$; women and 71 ; young people and 44; see also employment

Learning to Labour (Willis) 22

Le Blanc, G. 89

Leccardi, C. 45, 169, 177

Lefebvre, Henri 142, 144

Lemert, C. 46

liberal regimes $61,63,72$

Lincoln, S. 34

Lizardo, O. 3

Lorey, I. 93

Loughborough (England): post-Brexit visual art in 167-170, 171, 172-173, 173, 174, 174, 175-176, 176, 177; young people in 166-170, 178

Loughborough University Nationalism Network (LUNN) 167-168

Lucey, H. 155

Lupton, R. 154
Madsen, R. 45

Mannheim, K. 3

Martuccelli, D. 45

Marwick, A.E. 37

Massey, D. 50

May, Theresa 172, 175

Mediterranean family 88

Melucci, A. 7

Mendelson, A. 34

Metropoliz 144-145

middle-class youth: educational paradigm and 23,28 ; identity formation in 28 ; social locations of 23; sur-reflexivity and 29; young Italians 22-23

migrants: demographics of 63; de-skilling of 60; employment and 68; gender and 59-60; labour market and 61; national identity and 167; occupation status and 70; occupied spaces and 144-146; school-to-work transitions (STW) and 68 ; secondary school choice 155,160 ; second-generation 63 ; third-country 60,63 ; vulnerability and $60-62$; wage differences 70,71

migrant women: educational attainment and 67; inactivity and 67; labour market and $60,63,67-68,71$; occupation status and 70 ; unemployment risks of 67 ; vulnerability and 63 ; wage differences 70,71

Milan (Italy) 101, 104

millennials: assumptions about 101, 103; digital economy and 103; flexibility and 103; social imbalances and 22-23; uncertainty and 25-26, 28; work attitudes of 103-104, 110; young middle-class 20, 22-23; see also young people

misfortune 93-94

mobile phones 37-38, 144

mobility: digital economy and 103; employment and 49; flexi-lives and 48-52; individualisation and 50; modes of 50; reflexivity and 50; youth studies and 49

mobility capital 50

Montero, R. 89

Muldoon, O. T. 167

Museum of the Other and the Elsewhere (MAAM) 144-145

Muslim women: discrimination and 133-134; ethnic groups of 130-133; 
gender violence and 133, 138; hijab and 134-135, 138; Islam and 135-136; majority society and $130-131$, 133-134; patriarchal family models and 130-133; political participation of 129, 136-139; pursuit of goals by 132-133; rejection of cultural Islam 135; self-reflexivity of $130-131$, 139; socialisation of 129-130; subjectivation 130

Musterd, S. 155

national identity $166-167$

Nayak, A. 167

neighbourhoods: belonging and 160-162; deprived 153-155; identity and 160; impact on young people 153; informal networks in 158-159; school choice in $153-155,159-162$; school quality and 154-155

neoliberalism: marketing of artistic production and 146; opposition to 142, 146-147; private property and 144 ; social inequalities and 12, 143

Netherlands: migrant female inactivity in 67; occupied spaces in 143; school choice in 154-155; school funding in 155-156; school quality in 155 ; school tracks in 156; unemployment rates 114; universalistic regimes in 61, 63; see also Rotterdam (Netherlands)

networked publics 34

new skills 9-10

Niemöller, Martin 173

Northern Ireland 165, 167

occupation status $68,69,70$

occupied spaces: activists/artists in 141, 143-147, 148; as alternative spaces 142-143; collective mobilisations and 141, 143, 145-147; as landmarks 143; migrant housing and 144-146; political goals and 148, 148; as political practice 142

Ojala, S. 103

Oranje-Nassau, C. 60, 71

Ostrom, E. 141

Our Nation's Future: Loughborough Youth Creative Visions 166-167

Papacharissi, Z. 34

Papathanassopoulos, S. 34 part-time employment 66, 67

Paugam, S. 60

personal capacities 9-11, 13

photo tagging 34

place 49

Poland 80, 113-115, 117

Polish youth: digital technology and 117; labour migration of 113-114; migration for employment 113; self-confidence and 119-120; self-identification and 119-122; uncertainty and 118-122 political action 89

politics of the present $4,11-14,52$

Portugal 115

post-Brexit visual art $168-170,171$, 172-173, 173, 174, 174, 175-176, 176, $177-178$

post-socialist regimes $62-63$

practical sense 77

precariousness: alleviating 94; defining 89-91, 93-94; de-institutionalised life spaces and 90; discourse on 89-90; generalised/complex 91; identity formation and 32, 88; insecurity and 89; labour market and 20, 23, 25, 29, 89; metaphors of 94-95; misfortune and 93-94; physical implications of 95; political dimension of 89; simple 91; social capital and 89; social life and 91; weak employment and 88 ; young people and 44, 91-97

presentification 8-9, 14

Prince, D. 51

proximity $5-6$

Pyöriä, P. 103

Rabinovich, L. 60, 71

radical uncertainty 92

rationality $76-77,157$

Reay, D. 155

reflexivity $50-51$

Rendall, M. S. 60, 71

risk society $32-33$

Robards, B. 34

Rogelberg, S. G. 103

Rome (Italy) 141, 144-147

Rotterdam (Netherlands) 154, 156; see also Feijenoord (Rotterdam)

Rubin, J. 60, 71

Saari, T. 103

savings 82 
school choice 153-155; see also secondary school choice

school quality $154-155$

school-to-work transitions (STW): counselling and 61, 71; cross-national differences in duration 62; European Union 59; institutional contexts and 60-63; migrants and 68; part-time employment and 67; reproduction of inequality in 71 ; vulnerability and $60-62,68,71$; women and 68

Scotland 165

secondary school choice: belonging and 160-162; immigrant students and 155,160 ; peer group discourses on 155 ; physical proximity in 159 ; selfexclusion and 160-161; social media and 159; social networks and 157-159; social proximity in 159-160; subjective factors in 157-162; young people and 154-162; see also school choice second-generation migrants 63 self $33-35,39$ self-realization 93

self-reflexivity 130-131, 139

self-representation 33-41

Sheller, M. 49

Simon, H. A. 157

simple precariousness 91

simple rules 77

situational management 28-29

Slovak Republic 62-63, 71

Slovenia 115

smartphones 117

social autonomy 144

social capital 76, 89

Social Centres (Italy) 141-143

social change 1-4, 19-21

social exclusion 9-10, 13, 88, 160-161

social generation $2-3$

social identity $28-29$

social inclusion 10

social innovation 77,108

social life 8, 49, 91-92, 144, 147

social locations $4,13,20,22-23,28,59$

social media: consumption and 33-40;

Facebook 34; identity formation and 32-34, 36; Instagram 34, 40; manipulation of 39-40; networked publics and 34; performance of self $33-35,39-41$; unreality/semi-reality in $39-40$ social networking sites (SNS) 32

social protection $78-79$

social realism 6,129

social stratification 10,113

social vulnerability 60

Spain: junk contracts in 115; precariousness in 88; school-to-work transitions (STW) in 72; sub-protective transition regimes in 62-63

Spanish youth: family support and 94, 97; job insecurity and 93, 96; precariousness and 91-97; public subsidies and 94, 97; self-realization and 93, 96; transition to adult life 95-97; uncertainty and 93-94, 97; unemployment and 96

spatial dilemmas 49

spatial reflexivity 51

Spin Time 145-146

squatting 141, 143, 145; see also occupied spaces

Stevenson, C. 167

Strand, M. 3

structural reproduction 22

subjectivation 130

subjectivity 77

sub-protective transition regimes 61-63, 68,72

Sullivan, W. H. 45

super-diversity 6

sur-reflexivity 20, 29

Sweden 61, 80

Swider, A. 45

Sykes, B. 155

Teatro Valle (Rome) 141-142, 146-147

Temporary Autonomous Zones (TAZ) 142

third country migrants 63

Third Wave, The (Toffler) 116

Threadgold, S. 44

Tiidenberg, K. 34

Tipton, S. M. 45

Toffler, A. 116

Torcal, M. 89

Touraine, A. 90, 129-130

transition to adult life: economic autonomy and $82-83$; housing autonomy and $80-82$; job insecurity and $76-77,84$; see also school-to-work transitions (STW)

Treiman, D. J. 62

Tsang, F. 60, 71 
uncertainty: future planning and 25-26; job insecurity and 84 ; labour market and 75-77; new skills and 10; perception of 8; post-industrial era and 115-116; radical 92; self-identification and 119-122; strategies for $119,121-122$; young people and $4-5,7-9,93-94,97$, $118-122$

unemployment: educational attainment and 63, 64, 67; Estonia 78-79; European Union 77-78, 114; France 72; global financial crisis and 59; Greece 36; Italy $19,75,78,101,104,110$; migrants and 67-68; migrant women and 67-68; Netherlands 156; Poland 114; return to parental home and 80-81; Spain 96; women and 67-68; youth 19, 36, 49, $59,72,75,101,104,110,114$

United Kingdom: Brexit referendum 165-170, 172; cohabitation in 80; liberal regime in $61,63,72$; migrants in 63 ; migrant wage differences 71 ; school quality in 154-155; schoolto-work transitions (STW) and 68; unemployment risks in 67,72 ; see also Britain

universalistic regimes $60-61,63,71$

Urry, J. 50

Van der Wiel, K. 158

Van Houtte, M. 162

van Zoonen, L. 34

Vincent, C. 154

Vinge, V. 121

vocational education and training (VET) system $61-62,71-72$

vulnerability: defining 59-60; economic 60 ; educational attainment and 67 ; gender and 60,72 ; institutional contexts and 60-61; migrant status and 60, 63,
72; migrant women and 63; part-time employment and 67; personal autonomy and 12; school-to-work transitions (STW) and 59-63, 68, 71; social 60; youth perceptions of 8,10

wage differences 70,71

Wales 165,167

Walther, A. 60

Willis, P. 20, 22-23, 28

women: employment and 68; labour market and 71; migrant 60, 63, 67; occupation status and 68 ; precariousness and 115; unemployment and 67; see also gender; Muslim women

Woodman, D. 46

work culture 101-103

working-class youth 22, 28

Wyn, J. 46

young people: choice biography 35 ; complexity and 4-5; diversity of contexts and 6-7; innovative practices and 75; interconnectedness of 5-7; opportunities for 75-76; personal capacities of 9-11, 13; politics of the present and 4, 11-14; presentification and $8-9$; proximity and $5-6$; risk society and 32 ; social change and $1-3$; uncertainty and $4-5,7-9$; unemployment rates 114; see also British youth; Greek youth; Italian youth; millennials; Polish youth; Spanish youth

youth agency: future planning and 23-26; gender and 27; intersectionality and 20-21; opportunities for 10-11; social structure and 29; structural reproduction and 22; studies of 46; see also agency youth studies 2-3, 44, 46, 49 
